\section{Abaisser bas}

I. Abaisser à une faible hauteur, en direction du sol

Pronominal

1455 Et veritablement, je cuiday de prime face que ce fussent gouttes de cire et y mis la main pour les touchier et puis me abaissay bas pour veoir contre le jour et me sembla que c'estoient gouttes d'eaue engelées. C'est une chose que plusieurs gens ont vue (Bertrandon de la Broquière, Le Voyage d'outremer)

1949 Les yeux s'ouvrent sous la mousse Et les pieds écrasent parfois les paupières Alors les rideaux s'abaissent encore plus bas

La tête tourne et se cache dans le creux des bras

Et les souvenirs s'émeuvent

La nuit qui s'en va

(Pierre Reverdy, Main-d'œuvre)

Transitif

1848 Il en coûterait d'abaisser les regards si bas après les avoir élevés si haut (François de Chateaubriand, Mémoires d'outre-tombe)

II. Dévaloriser, humilier profondément, mettre dans une position très inférieure Pronominal

1637 Daphnis est fort aimable, et si Florame l'aime

Est-ce à dire pourtant qu'il soit aimé de même?

Florame avec raison adore tant d'appas, Et Daphnis sans raison s'abaisserait trop bas,

Ce feu, si juste en l'un, en l'autre inexcusable,

Rendrait l'un glorieux et l'autre méprisable.

Simple, l'amour peut-il écouter la raison ? (Pierre Corneille, La Suivante)

1849 S'il faut que mes yeux soient tentés, que mes pieds trébuchent, que ma croyance défaille, ah ! que je sois plutôt comme les aveugles qui tâtonnent les murs, comme les paralytiques qui se traînent sur le ventre, et comme les pauvres idiots qui n'ont pas le sens de manger. Je m'humilierai de toutes mes forces, je mabaisserai plus bas que la boue, plus bas que les fourmis et que les vers de terre. Toi seul es haut ! Je ne cherche pas à te trouver, mais à t’aimer ! (Gustave Flaubert, La Tentation de saint Antoine)

Transitif

1766 Si le corps humain est, comme on l'enseigne au peuple, d'une nature au-dessus de celle des brutes, parce qu'il est la coque ou l'enveloppe qui renferme une âme immortelle, laquelle abandonne le corps à la mort, ce corps abandonné n’a donc plus rien en soi qui nous porte à le respecter davantage que celui d'un bœuf, d'un mouton, d'un cochon, dont nous mangeons tous les jours : au contraire, si l'homme est en tout semblable aux brutes, pourquoi avoir d'autres sentiments, d'autres égards pour son cadavre que pour celui de ces dernières ? Nous sommes bien orgueilleux de nous élever si haut, ou bien injustes de les abaisser si bas. Le respect que l'on a pour un corps mort, et qui empêche de le manger, est donc ridicule et mal fondé (Henri-Joseph Dulaurens, Le Compère Mathieu)

\section{CORPUS WEB :}

Je mabaisse bas vers le sol, inclinant ma tête en révérence [https://www.fanfiction.net/s/ 1289699/3/Szajha] (24.4.2016)

Non sérieusement arrête tu fais pitié tu t'abaisse bas la sérieux [https://fr-fr.facebook. com/pages/Chez-Micha\%C3\%ABl/134272629 983326] (24.4.2016)

Une table articulée, qui monte et descend, position fauteuil etc. Une vraie révolution qui permettra à bon nombre de personnes en situation de handicap de pouvoir enfin être auscultées chez leur médecin ; de pouvoir s'installer comme il faut vu que la table s'abaisse bas et minimisant les manipulations grâce aux diverses articulations [http://dd44.blogs.apf. asso.fr/archive/2014/10/23/billet-d-humeur-demmanuelle-betty.html] (24.4.2016)

REMARQues : Bas est un adjectif-adverbe de lieu qui peut indiquer la direction, partant d'un ni- 
veau supérieur vers un niveau inférieur, au sens concret ainsi qu'au sens figuré. En tant que circonstant de lieu, il souligne l'action de faire descendre une chose à un niveau inférieur, plus bas (I). Du point de vue moral ou social (II), il s'emploie pour désigner l'état de soumission d'une personne, le fait de se plier aux exigences ou à la volonté d'une tierce personne, s'avilir. Dans le contexte amoureux, il souligne le fait de se dévouer entièrement à l'autre, l'idée de sacrifice. Outre le fait de désigner le sens d'un mouvement, bas a très souvent une connotation négative et traduit l'idée de médiocrité, d'infériorité et peut aussi souligner un sentiment de gêne ou de honte. Il reste invariable (ex. de 1637 et le troisième exemple du $\mathrm{CW}$ ) et est modifié par si, trop, plus. Il s'oppose à élever haut (ex. de 1848). VoIR AUSSI : descendre bas, élever haut

\section{Abandonner net \\ Abandonner ou cesser brusquement et complètement \\ Transitif \\ 1758 vous vous croyez en droit d'abandonner net un pauvre Suisse (Voltaire, [Lettre] / Pièces inédites)}

1876 Quoique ce ne fût qu'un vieux numéro, fort endommagé par de laborieux services, Jane y prit subitement intérêt. Elle abandonna net ses derniers apprêts et se mit à chercher dans la feuille froissée... quoi donc? (Claire de Chandeneux, Les Deux Femmes du major)

1982 En règle générale, lorsque le sportif de haute compétition se " reconvertit ", comme l'on dit, il abandonne net son activité physique antérieure (Le Débat)

\section{Abattre menu}

Anéantir, réduire, écraser en petits morceaux Transitif

1552 Les Andouilles soudain apperceurent ce nouveau renfort, et se mirent en fuite le grand gallot, comme s'elles eussent veu tous les diables. Frere Jean à coups de bedaines les abbatoit menu comme mousches : ses soubdars ne se y espargnoient mie (François Rabelais, Le Quart Livre)
REMARQUES : Suite au préfixe $a$-, abattre crée une sémantique résultative où menu désigne l'état final de l'objet de l'action. Abattre menu se dit ainsi d'une action violente, voire cruelle, où le sujet fait tomber à l'aide d'une arme un être animé. Menu reste invariable. Abattre menu est devenu un archaïsme. VoIR AUSSI : hacher menu

\section{Abattre mort}

Tuer, mettre à mort

Transitif

1100 L'escut li freint e l'osberc li desclot, Trenchet le piz, si li briset les os, Tute l'eschine li desevret del dos, Od sun espiet l'anme li getet fors, Enpeint le ben, fait li brandir le cors, Pleine sa hanste del cheval l'abat mort, En dous meitiez li ad briset le col (Chanson de Roland, 1204)

-1200 Ou cors li mit la lance, qui qu'an plort ne qui rie ;

Tant soué l'abait mor qu'i ne brait ne ne crie (Floovant [fin XII ${ }^{\mathrm{e}}$, 286)

$\sim 1460 \mathrm{ilz}$ se mirent a une fenestre. Sy n'y eurent guieres esté, quant Patroclus le bon archier descocha sa saiette sus la dame si droit qu'il lui en percha la gorge et morte l'abaty au prez de Jason, et puis il s'en issy de son embuche moult joyeux. Trop fu troublé Jason quant il vey sa dame ainsy trebuchier morte. Il la cuida relever, mais l'ame lui party du cors (Raoul Lefèvre, L'Histoire de Jason, p. 238, 15)

1515 Toutesfois à quelque peine le bouterent sur une charette pour l'emmener au Wassieulx, et quant se vint au descendre à la vallée du Wassieulx, de peure que ledit cheval ne tomba, le corche cheval mist la main darier affin qu'il ne versaist, mais par coup de fortune la corde, qui ne valloit guiere, de quoy estoient liez les piedz dudit cheval rompit, et ad cause qu'il estoit enflez, comme dit est, ses jambes ce estandirent et se remisrent en leur propre lieu, aussi ad cause du hochement de la charette, et tellement regecta ledit cheval qu'il donna proprement ung sy grant coup du fer du pied de darier contre la tente de 
la teste du corche cheval qu'i l'abatist tout royd mort. Et cecy fut vray, car plus de cent personne le veirent; et ainsi donques le cheval mort tua ung homme, dont chascun en estoit esbahis (Philippe de Vigneulles, Les Cent Nouvelles nouvelles, p. 233, 112)

1824 Le sire de Rieux, maréchal de Bretagne, arriva à la tête de sept cents lances. Les Anglais furent vivement assaillis, et le sire Tanneguy-Duchâtel abattit mort, d'un coup de sa puissante hache d'armes, le comte de Beaumont, leur capitaine. Cet avantage ne servit en rien à l'entreprise du comte de la Marche (Prosper de Barante, Histoire des ducs de Bourgogne de la maison de Valois)

1923 Merville et Phénor retrouvent enfin Néala, juste au moment où un brutal l'abat morte à ses pieds. Phénor expire ; l'affreux trépas de Néala a été pour lui le coup de grâce, et pour nous un soulagement (Servais Étienne, Les Sources de «Bug-Jargal»)

1966 Le lendemain, pendant la cérémonie, Helyanor trouve devant l'église quatre chevaliers qui, par jeu, joutent et le provoquent ; il abat morts les deux premiers, les autres se retirent ; il part ensuite s'embusquer dans les bois (Roger Lathuillère, Guiron le courtois)

Pronominal

2000 Justiciable,

pour

pesanteur

d'

offense,

elle

s'abat morte

et

vive

contre

terre (Jacqueline Frédéric Frié, Transparences)

\section{CORPus WeB :}

Tandis que l'on célèbre le Jubilé de la Reine Victoria à coups de feu d'artifices dans les rues de Toronto, Amos Robinson, boxeur ayant refusé au cours d'un match décisif, est abattu mort par balle dans sa chambre d'hôtel [http://theavengers.fr/index.php/hors-serie/ annees-2000/les-enquetes-de-murdoch-2008/ les-enquetes-de-murdoch-saison-1] (24.2.2016)

Et lorsqu'il la retira, le monstre s'abattit, mort, tel la Tour de garde Impératrice que les Vartallensis détruisirent lors de la Bataille des Chemins de givre [https://www.fictionpress. com/s/2303950/9/Darven] (24.2.2016)

Le premier réflexe du jeune homme fut de tirer une salve de trois rayons sur sa cible qui s'abattit mort sur le sol [http://board.fr.ogame. gameforge.com/board98-les-archives-du-forum/ board423-les-archives-la-vie-des-univers/ board404-archives-hall-of-fame/901134-martymacfly-elites-vs-booba74-k-o-cdr-78m] (24.2.2016)

Sans réponses tu m'as laissée abattue morte dans mon être [http://creapoemes.com/ index.php?threads/ma-pri\%C3\%A8re.97024] (24.2.2016)

REMARques : Avec le verbe abattre, mort devient un adjectif-adverbe résultatif. L'accord est la règle. On pourrait donc classer les exemples comme prédication seconde, mais dans le troisième exemple du CW il reste invarié malgré le sujet grammatical féminin. Il semble qu'abattre mort ait acquis, du moins partiellement, un statut de verbe complexe qui intègre l'adjectifadverbe. Dans l'exemple de 1515, mort est modifié par tout raide. Raide mort est devenu une collocation lexicalisée toujours en usage. Raide y occupe une fonction de modifieur de l'adjectif mort. On observe donc la combinaison de trois adjectifs où les premiers modifient les suivants. Dans l'exemple de -1200, l'adjectif-adverbe soué (soef) est antéposé à la construction résultative abattre mort, ce qui confirme la lexicalisation de celui-ci comme verbe complexe. Notons l'emploi de décocher droit et trébucher mort (ex. de -1460).

\section{Abattre plat}

Étaler quelqu'un, le faire tomber à terre de tout son long

Transitif

+1250 Quant Ysengrin vit l'uis overt, Et li vilein felun cuvert

A cuinnies et a macues Vienent corant parmi les rues, Entre la porte et le vilein 
Fet Ysengrin nn [sic] saut a plein.

Si fort le horte qu'il l'abat

En une fange trestot plat (Le Roman de

Renart [ $2^{\mathrm{e}}$ moitié XIII $\left.{ }^{\mathrm{e}}\right]$, Ib, 2588)

1403 C'est d'aventure, se monter

On les voit hault, car pou on prise

Sagece et grant science apprise,

Et verité, qui nul ne flate,

Que tricherie abat jus plate.

Toutefoiz, pouons nous veoir

De ceulx, que Dieu souffri seoir

Hault en ce siecle, qu'ilz estoient

Gouvernez par ceulx qui savoient

Et ou sapience manoit (Christine de Pisan,

Le Livre de la mutacion de fortune, II, 5088)

REMARQUES : Avec le verbe abattre, plat devient un adjectif-adverbe résultatif qui désigne ici l'état final de la cible. Dans l'exemple de 1403, l'adjectif-adverbe est accordé avec l'objet direct féminin antéposé (vérité). Plat est modifié par trestot, dans l'exemple de +1250 .

\section{Abattre seri}

Faire tomber sans faire de bruit

$\pi$ abattre soef

\section{Abattre soef}

Faire tomber en douceur, délicatement, avec soin Transitif

+1150 Puis m'en eistrai en sus demie liue large,

Si me verrez lancier, se vos en prenez guarde,

Tres qu'al piet de la tor, et l'un denier abatre

Si soëf et serit, ja nes movrat li altre

(Pèlerinage ou Voyage de Charlemagne à

Jérusalem et à Constantinople [2 $2^{\mathrm{e}}$ moitié $\left.\left.\mathrm{XII}{ }^{\mathrm{e}}\right], 611\right)$

REMARQues : Soef est un adjectif-adverbe de manière qui caractérise ici l'action de provoquer la chute d'un être animé ou inanimé, tout en montrant un certain égard envers l'objet qui subit l'action. Il est coordonné avec l'adjectif-adverbe seri 'sans faire de bruit' qui vient compléter et renforcer le sémantisme de soef.

\author{
Aboyer aigu \\ Émettre un cri de haute fréquence (en parlant \\ du chien) \\ $\pi$ aboyer grave
}

\author{
Aboyer enroué \\ Aboyer en émettant un son rauque (en parlant \\ du chien) \\ $\lambda$ aboyer grave
}

\section{Aboyer grave}

Émettre un cri de basse fréquence (en parlant du chien)

Intransitif

1946 c'était bibi tenant en laisse une cinquantaine de chiens de toutes races, de tous poils, de toutes tailles, et qui sautaient, et qui jappaient autour de moi et aboyaient à qui mieux mieux, en majeur et en mineur, grave, enroué et aigu (Blaise Cendrars, L'Homme foudroyé. La Main coupée)

CORPus Web :

Voyou se mit à aboyer grave, un aboiement de joie [http://alzheimer-maman-et-moi.overblog.com/article-18665348.html] (24.4.2016)

En revanche, ma chienne de 2 ans devient complètement hystérique, saute sur la boite aux lettres et aboie grave et agressivement quand la voiture arrive [http://nosamisleschiens.fr/lefacteur-et-le-chien] (24.4.2016)

Tous les caniches ke j'ai connus aboyaient grave !!! [http://bebes.aufeminin.com/forum/ les-bibous-de-mai-2001-sont-pas-au-top-de-leurforme-fd133569-p5] (24.4.2016)

REMARQUES : Aboyer s'insère ainsi dans le groupe des verbes du type parler, chanter, etc. qui admettent une série ouverte de modifieurs indiquant une propriété de la voix. Grave est un adjectif-adverbe de manière qui se dit d'un glapissement, hurlement, dont les tons sont bas et graves. Dans l'exemple de 1946, grave apparaît coordonné avec deux autres adjectif-adverbes : enroué, et aigu, qui intensifient ou précisent l'action. Les trois adjectifs-adverbes restent invariables (ex. de 1946 et le troisième exemple du $\mathrm{CW}$ ). Dans le $\mathrm{CW}$, grave est employé comme intensifieur au sens de 'fortement', comme dans l'emploi en vogue grave belle. Notons la coordination avec agressivement dans le second exemple du CW. 


\section{Absorber entier}

Absorber complètement

入 absorber net

\section{Absorber net}

Faire disparaître d'une manière brutale, tout d'un coup

Transitif

1853 GEORGE. Alors, la loi française, Qui souffre un mauvais acte, est une loi mauvaise. (Il se lève)

LE NOTAIRE. Vous pouvez accepter, monsieur ; mais l'héritier

Se charge, en acceptant, du passif tout entier ;

Et six cent mille francs, payés pour votre père,

Absorberont, tout net, la dot de votre mère. Vous serez, d'un seul coup, un homme ruiné. - Cela vaut examen

(François Ponsard, L'Honneur et l'argent)

CORPUS WEB :

Le champ protecteur éclata et absorba net, pile au bon moment, le sortilège de désarmement [https://www.fanfiction.net/s/9644889/17/ Sigma] (24.4.2016)

Je ne lui laissai pas le temps de protester ; mon anus dilaté absorba net son érection renaissante [http://www.gai-eros.org/w/index.php/ La_mante_religieuse] (24.4.2016)

Elle nu pas le temps de penser à autre chose car une lumière aveuglante l'absorba net et elle se sentit dans une extase puis plus rien [http:// hakanahane.skyrock.com/2445782293-Chapitre-1Tome-1.html] (24.4.2016)

Ses jambes la propulsent dans la première salle de l'exposition. Très vite le choc est là : face à elle chaque écran l'absorbe nette et entière, chaque vitrine aspire son œil, par quoi commencer? Ses pieds l'emportent dans un dédale de pas ryhtmés par les battements de cils de ses yeux dilatés [http://www.clothetome.com/Variationssur-le-fil-de-la-mode_a136.html] (13.11.2013)

REMARQues : Dans l'exemple de 1853, absorber net désigne l'action de dévorer, engloutir, épuiser une certaine somme d'argent. L'action se fait de façon brutale et sans détour, de manière crue. Tout net apparaît détaché du verbe, sans doute par souci stylistique, voire de correction linguistique, la langue parlée n'employant pas de pauses, normalement. Les trois premiers exemples du CW mettent en évidence la grande variété de ce qui peut être absorbé. L'adjectif-adverbe net a une valeur intensive qui peut être renforcée par le modifieur tout, et lorsqu'il est renforcé par tout, prenant le sens de catégoriquement. Il est invariable dans la plupart des cas, mais le dernier exemple du CW montre une variante d'interprétation comme prédicat second accordé. Celui-ci est coordonné avec entière, où le féminin est marqué phonétiquement. On ne saurait donc attribuer l'écriture absorber nette à un simple effet phonétique sur la graphie qui serait dû à la prononciation audible du - $t$ au masculin net.

\section{Accélérer fort}

Appuyer à fond sur l'accélérateur

$\pi$ emmener droit

\section{Accélérer lent}

Accélérer lentement

入 tirer fort

\section{Accepter ferme}

Accepter quelque chose d'une manière définitive, en s'en tenant aux conditions fixées $\lambda$ acheter / prendre / vendre ferme

\section{Accoler étroit}

Serrer (quelqu'un) étroitement dans ses bras Transitif

1160 Li enfant doucement dormoient, estroit acolé se tenoient ; [variante : estroit entracole s estoient, p. 114] bouce à bouce ert cascuns dormans (Flore et Blancheflor, 2626)

-1200 Mont fut granz li eschac que Frans ont conquesté.

Floovanz s’an repaire à Loon la cité. Sa mere vai ancontre, estroit l'ai escolé, Doucemant lou baisai, puis aprés lou barné (Floovant [fin XII ${ }^{\mathrm{e}}$, 2520)

+1200 Il se descharge de la somme,

Si la presente a la bourjoise ;

Et cele, a cui gaires n'en poise, 
L'acole et baise mout estroit

(Le Sacristain [XIII $], 240)$

1275 Lors le deit estreit acoler

Et baisier, pour meauz afoler (Jehan de

Meun, Roman de la rose [1269-1278], 13693)

1285 Mout volontiers le gant baisast, Ce sachiez, se baisier l'osast ; Mais bien savoit c'on li torroit, Se devant la gent le baisoit. Souz sa chemise l'ot bouté, Estroit le tenoit acolé ; Perdre nel vorroit a nul fuer, Pour ce l'ot mis contre son cuer (Adenet le Roi, Cleomadés, 6048)

Pronominal

-1300 Helissanz de Coloigne tint Berart par le doit,

Sor le jon et sor l'erbe s'assïent por le froit, Doucement s'antrebaisent et acolent estroit (Jehan Bodel, La Chanson des Saisnes [fin $\left.\mathrm{XIII}^{\mathrm{e}}\right]$, 2618)

1450 Et souvent s'entre respondoient et s'entre disoient de telles gracieuses parolles. Et tousjours s'entre acolloient estroit de plus fort en plus fort (Roman de Troilus et Cressida, p. 182)

REMARques : Accoler étroit désigne l'action de prendre quelqu'un dans ses bras en posant les mains autour du cou ou sur les épaules et en appuyant les joues l'une contre l'autre. L'adjectif étroit, employé ici adverbialement, renforce l'idée d'intimité et peut avoir un caractère érotique. Étroit reste invariable (ex. de -1200) et peut être librement antéposé ou postposé au verbe. Il est modifié avec moult. Dans l'exemple de 1450, accoler étroit est intensifié par de plus en plus fort. Vieilli aujourd'hui. Notons l'emploi de baiser étroit et s'entrebaiser étroit.

\section{Accompagner épais}

Protéger une personne d'une manière dense et rapprochée

Transitif

1573 HIPPOLYTE. Il ne se couvre point le chef ambicieux

D'un bastiment doré qui menace les cieux Il n'a mille valets, qui d'une pompe fiere
L'accompagnent espois et devant et derriere (Robert Garnier, Hippolyte)

REMARQUES : L'adjectif-adverbe de manière espois désigne ici l'action de protéger une personne de façon dense et compacte, ici pour montrer la richesse et la magnificence du maître. Vieilli aujourd'hui, il traduit la densité, le nombre élevé de personnes entourant un être animé, souligne aussi un aspect massif, voire étouffant. Espois traduit également la proximité entre le maître et les valets et met ainsi en valeur l'intention, la démarche protectrice de l'accompagnateur. Les deux adverbes de lieu qui accompagnent épais viennent souligner et renforcer l'aspect de densité et insistent sur le rapprochement entre les êtres, le côté serré et fermé.

\section{Accourir droit}

Venir en hâte, directement vers quelqu'un/

quelque chose

Intransitif

1160 Tarcons, uns Troïens,

Les voit, cele part vet poignant tot droit.

[variante : acorant droit, II, p. 186]

Il lor comança a huchier :

Ou fuiez vos, malvés guerrier?

(Eneas, 7062)

+1350 Quant a la porte vint, s’a veü .iij. serjans, Qui estoient monté sur .iij. chevaus courans ;

Quant li uns des .iij. fu le cheval percevans, Qui tout droit au chastel s'en estoit acourans,

Au devant est venus comme foudre volans (Brun de la Montaigne [2 moitié $\mathrm{XIV}^{\mathrm{e}}$, 3343)

1532 Ainsi, dist Panurge [...] : Ha pauvres pulces, ha, pauvres souris, vous aurez mauvais hyver, le feu est vostre paillier, sortirent plus de six, voire plus de treize cens et unze chiens, gros et menus tous ensemble, de la ville, fuyant le feu. De premiere venue accoururent droit à moy, sentant l'odeur de ma paillarde chair demy routie, et m'eussent devoré à l'heure, si mon bon ange ne m'eust bien inspiré, me enseignant un remede bien oportun contre le mal des dens (François Rabelais, Pantagruel) 
1863 Enfin accourut droit à moi un ancien aide de camp du duc d'Orléans qui se trouvait alors tout naturellement aide de camp du roi sans le moindre effort (Alfred de Vigny, Mémoires inédits)

1895 Ma Myrto, représente-toi ce qu'eût été ta vie si, au lieu de poser sur tous les hommes d'Arles, puis sur les deux cœurs qui te trompèrent également, elle était accourue droit à lui depuis son matin! Il parlait et Myrto l'entendait merveilleusement (Charles Maurras, Le Chemin de Paradis)

1925 Ah ! Je te connaissais bien ! Que l'on te dise : «va-t'en », c'était assez pour que tu reviennes; et que ce soit ta femme qui te le dise, assez pour que tu accoures, tout droit, sans rien voir, fou perdu. Et te voilà, et moi aussi... ah ! Bon dieu, ça y est tout de même ! Il était à présent à deux pas de Raboliot (Maurice Genevoix, Raboliot)

CORpus Web :

S'exclama bruyamment une serveuse afro-américaine avant de sauter par-dessus le bar et accourut droit vers Damon [https://www. fanfiction.net/s/11178136/11/Monster-in-theDark] (24.4.2016)

Clarke reprit rapidement ses esprits et $a c$ courut droit sur moi en attrapant mes mains pour m'inspecter sous toutes les coutures [https:// www.fanfiction.net/s/11275739/2/Love-is-weak ness] (24.4.2016)

Mais Sakura n'eut pas vraiment le temps d’y réfléchir, car un kunaï allé s’abattre sur elle, celle-ci eu juste le temps de l'esquiver, pour s'accourir droit vers Sakira, qui à son tours était visée par la lame meurtrière [https://www.fanfic-fr. net/fanfics/imprimer/animes-mangas//Naruto/ Une-mission-sans-retour/20588/102015.html] (24.4.2016)

REMARQues : Accourir droit désigne l'action de venir le plus directement, en courant, à toute hâte vers un lieu exerçant une attirance sur le sujet. Droit est un adjectif-adverbe de manière-direction qui traduit ici la précision de l'action et renforce l'idée de finalité. Il reste invariable (ex. de 1895 et le dernier exemple du CW) et est modifié par tout. Jusqu'au $\mathrm{xx}^{\mathrm{e}}$ siècle, accourir droit est ré- gulièrement complété par la préposition à , suivie d'une destination ou d'une personne. Cette tendance de s'associer à une préposition directionnelle devient encore plus pertinente à partir du $\mathrm{xx}^{\mathrm{e}}$ siècle, notamment avec sur et vers, au point de faire partie du groupe prépositionnel comme modifieur de la préposition (droit à, droit sur, droit vers). Notons l'emploi de fou perdu 'follement perdu' dans l'exemple de 1925.

\section{Accroître haut}

Rendre beaucoup plus grand, plus important Transitif

+1400 Qui trop se fie es grans biens de Fortune, En verité, il en est deceü ;

Car inconstant elle est plus que la lune. Maint des plus grans s'en sont aperceü, De ceulz meismes qu'elle a hault acreü, Trebusche tost, et ce voit on souvent Que ses joyes ne sont fors que droit vent (Christine de Pisan, Cent balades / Euvres poétiques [début $\mathrm{XV}^{\mathrm{e}}$ ], I, p. 13, 5)

CORPUS WEB :

Les plans de ZPower incluent un puits prouvé, accroissent haut l'itinéraire pour l'déploiement rapide de la technologie dans le monde entier [http://www.zpower.com/fr/ aboutus_company.htm] (25.4.2016)

le montant du paiement divisé augmenté à un rythme croissant, ce qui montre qu'il ya eu une augmentation de la rentabilité de l'entreprise et cela est dû à des efforts accrus haut externaliser le travail pas cher dans d'autres parties $\mathrm{du}$ monde [http://freefrencharticles. com/education/limpact-de-lexternalisation-surhoneywell-performance-de-lentreprise] (7.5.2014)

Le phare 190PS Land Rover Freelander SD4 accélère de repos à 60 mph en 8,7 secondes avec une vitesse accrue haut de $118 \mathrm{mph}$ [http://landrover-france.blogspot.co.at/2011/03/2011-landrover-freelander-2.html] (7.5.2014)

REMARQUES : Haut (hault) est un adjectif-adverbe de lieu qui a un sens spatial et désigne un point élevé. Au sens figuré, il réfère à l'action de rendre beaucoup plus grand, plus important, plus fort, ou d'élever le statut d'une personne. Haut reste invariable. 


\section{Accueillir bel}

Recevoir (une personne) de manière agréable, plaisante

Transitif

1175 Or li cuide cil bien merir

La mort son frere dont se deut

Et qu'en sa cort si bel l'aqeut

(Gautier d'Arras, Ille et Galeron, 961)

1275 Quant Bel Acueil fet vous avra

Si beau semblant come il savra,

Car mout set bel [variante : bien] genz acuillir,

Lors devez la rose cuillir (Jehan de Meun, Roman de la rose [1269-1278], 7677)

REMARQUES : L'adjectif-adverbe de manière adopte ici la forme neutre bel, marque de la fonction adverbiale. Accueillir bel désigne l'action de réserver à une personne un bel accueil, la recevoir agréablement se comporter devant elle d'une manière plaisante et, éventuellement, lui offrir l'hospitalité. Bel est modifié par si.

\section{Accuser bas}

accuser tout bas : porter un jugement, reprocher en secret, intérieurement

Transitif

1654 Et bien qu'à chaque membre on égale sa playe,

On épargne son Ame autant comme on l'effraye,

Lartifice cruel de ces Courages bas

Fait languir son supplice, et vivre son trépas ;

Sa Langue est arrachée, et parmy la poussiere

Acheve en palpitant une plainte grossiere, Elle accuse tout bas ces cruels traittemens, Qui deffendent les cris à de si grands tourmens,

L'oreille suit la langue, et le nez suit l'oreille,

Ses mains souffrent en suite une rigueur pareille,

Et ses Yeux tout remplis de ces coups inhumains

Ont la mesme disgrace et vont chercher ses mains

(Georges de Brébeuf, La Pharsale de Lucain)
1788 MME DE ROSELLE. Je voudrois pourtant lui ressembler.

$$
\text { (à part) }
$$

Allons, nous voilà seuls. Il est temps de parler.

(Haut)

Vous accusez tout bas Madame de Mirbelle, Monsieur: votre bonheur est retardé par elle (Collin d'Harleville, L'Optimiste)

1833 Viens ! Le jour va s'éteindre... il s'efface, et je pleure.

N'as-tu pas entendu ma voix ? écoute l'heure ;

C'est ma voix qui te nomme et t'accuse tout bas ;

C'est l'amour qui t'appelle, et tu ne l'entends pas! (Marceline Desbordes-Valmore, Euvres poétiques)

1876 Les uns prétendaient savoir que les Mouradzyys l'avaient commandé, les autres accusaient tout bas le vieil Osman d'être le meurtrier et d'avoir payé l'assassinat magique à un docteur juif (Arthur de Gobineau, Nouvelles asiatiques)

1968 Ses panégyristes vantaient sa piété, son savoir, la chasteté qui lui avait fait préférer aux secondes noces les mélancoliques austérités du veuvage ; ses détracteurs l'accusaient tout bas d'aimer les femmes, tout en convenant que ce goût est moins scandaleux chez une noble dame que pour les hommes le penchant contraire, car il est plus beau, déclaraient-ils, pour la femme d'assumer la condition virile que pour un homme d'imiter la femme (Marguerite Yourcenar, L'Euvre au noir)

\section{CORPuS WeB :}

Il aurait ainsi permis de découvrir si le commanditaire est celui qu'on accuse tout bas [http:// news.acotonou.com/h/13814.html] (28.4.2016)

A saint-Robin, petite ville de province, tous les notables reçoivent des lettres anonymes calomnieuses signées « Le Corbeau ». La plus insoutenable suspicion se propage partout, chacun s'accusant tout bas d'être le corbeau [http://www. classiquesducinema.com/page/8] (28.4.2016) 
Cette fédération est accusée tout bas d'être « voleuse de talent » chez Canada Alpin [http:// vivezvancouver.radio-canada.ca/vivezvancouver /Ski_alpin/2010/01/29/002-guay-vendredi.shtml] (28.4.2016)

REMARQUES : Bas est un adjectif-adverbe de lieu qui, avec une interprétation de manière, relève au figuré du caractère discret de l'action, du fait de ne pas le dire publiquement, à haute voix. Le verbe accuser référant à l'idée de reproche, l'objet est alors présenté comme coupable (d'une faute, d'un défaut, d'une action blâmable et répréhensible), sans pour autant que le sujet l'en informe, par peur ou manque de courage. Bas reste invariable (ex. de 1788) et est toujours modifié par l'adverbe tout qui lui donne une valeur intensive signifiant 'très bas'.

\section{Accuser faux}

Dénoncer à tort, charger sans justification

Emploi absolu

1863 Par rapport aux « faits » dont l'anonyme charge les Pères du concile d'Embrun, $\mathrm{M}$. de Sisteron montre qu'il accuse faux dans les démarches qu'il leur impute (Encyclopédie théologique)

1707 afin, (s'ils accusent faux) qu'ils soient punis comme des traitres et des espions (La Clef du cabinet des princes de l'Europe)

2014 - Non... non... j'ai tout mon esprit, et je rétracte ma première déposition... je l'annule... Je me suis trompé... j'ai accusé faux (Léon Sazie, Zigomar. Livre premier : Le Maître invisible)

\section{Accuser juste}

Signaler à juste titre

Emploi absolu

1660 MASCARILLE. Ah ! Je m'inscris en faux contre vos paroles. La renommée accuse juste en contant ce que vous valez; et vous allez faire pic, repic et capot tout ce qu'il y a de galant dans Paris (Molière, Les Précieuses ridicules)

1740 Ma petite cousine avoit accusé juste, en disant qu'elle ne nous tiendroit pas longtemps compagnie (Jacques de Varenne, Mémoires du chevalier de Ravanne)
Transitif

1822 D'après le trouble qui accompagne les discours des amants, il ne serait pas sage de tirer des conséquences trop pressées d'un détail isolé de la conversation. Ils n'accusent juste leurs sentiments que dans les mots imprévus ; alors c'est le cri du cœur (Stendhal, De l'amour)

\section{Acesmer beau (bel)}

I. Être orné, paré d'une belle manière

Transitif

+1225 Quant la pucele fu montee

Si bien et si biel acesmee,

S'est la plus biele creature

$\mathrm{U}$ ains jor se penast nature,

Ke son sens n'i ot celé (Le Chevalier as deus

espees [ $2^{\mathrm{e}}$ quart XIII'] ${ }^{\mathrm{e}}$, 1152)

II. Avoir un bon équipement pour la guerre, pour un tournoi

Transitif

1276 Armé se sont, lors est chascuns montés, N'i ot nul d'aus qui ne fust arreés Bien et a droit et tres bel acesmés (Adenet le Roi, Les Enfances Ogier, 3728)

1325 Mais quant il est biaus acesmez

Et avec ce hardiz esmez

Pour .i. fort fait d'armes outrer,

Adont se fait à droit moustrer ;

Veschi bel et bonté ensemble

Qui tournoi commence et assemble ;

Diex, comme il fait terre trembler !

(Watriquet de Couvin, Dits, p. 121, 101)

REMARQUES : Dans le premier exemple, acesmer bel se dit d'une femme portant de beaux ornements (coiffe, guimpe, atours, chaînes, anneaux, etc.). Dans le contexte de la guerre, il désigne un équipement de soldat très complet, comprenant les armes, les armures, les blasons, etc. L'adjectif-adverbe de manière tend à adopter la forme neutre bel, mais son emploi comme prédicat second accordé au cas sujet s'observe dans le dernier exemple. L'accord renforce la perspective résultative (beau comme état acquis). L'adjectif-adverbe est modifié par si. Le verbe acesmer figure dans sa forme du participe passé semi-adjectivisé et désigne le résultat du verbe transitif. 


\section{Acheminer droit}

I. Se rendre de manière directe en un lieu Pronominal

1190 Li dus Richart s'en part quant les voit ainz meslés,

A Deu a nos barons em plorant conmandés,

Parmi l'ost des paiens s'est droit acheminés.

Or le conduie Dex par ses seintes bontés (Fierabras (L), 4174)

-1200 Et quant il furent la, si l'ont tout aor[n]é, Quant ont fait lor offrande, si sont tout retorné,

Tout droit vers douche Franche se sont acheminé (Elie de Saint Gille [fin $\mathrm{XII}^{\mathrm{e}}$ ], 2739)

1275 Atant depart de la roïnne, Droit vers la porte s'achemine, Tot à pié, l'espee el poing destre Et l'escu tient à la senestre (Floriant et Florete, 1436)

1276 Quant Carahués fu de ses gens sevrés Et chascuns d'aus fu arrier retornés, Fors que li quatre qui o lui sont remés, Aprés ce n'est gaires la arrestés, Droit devers Sustre s'en est acheminés (Adenet le Roi, Les Enfances Ogier, 4430)

1610 Mais pour revenir à notre discours, apres qu'Attila eut pris Aquilée, et ruiné le pais d'alentour, il s'achemina droit à Rome, et ne faut point douter qu'il ne l'eust prise et saccagée, si Valentinian perdu de courage, ne se fust rendu son tributaire, et ne luy eust accordé sa sœur Honorique pour femme (Honoré d'Urfé, L’Astrée)

1629 Mais parce que cela n’appartient point à mon discours, je le passeray sous silence, pour vous dire seulement en continuant le cours de mon Histoire, que de Bider nous nous acheminasmes droit à Visapore, où nous estions asseurez de trouver la Cour du Roy de Decan ; et comme nous arrivions dans cette grande Cité, nous ouïmes plusieurs trompettes qui sonnerent des fanfares à trois diverses reprises dans la grande place où est assis le Palais du Roy, et vismes en suitte un grand homme vestu d'une riche cotte d'armes, accompagné de quatre Herauts (François de Boisrobert, Histoire indienne d'Alexandre et d'Orazie)

1787 Du gros de la troupe se détacha tout à coup un grand diable de palefrenier qui, s'acheminant tout droit vers la remise, commença par poser sa chandelle sur le marchepied du carrosse, où je restais dans une horrible transe (Jean-Baptiste Louvet de Couvray, Une année dans la vie du chevalier de Faublas)

1942 Enfin il se leva, les renvoya avec douceur, l'oiseau vers les arbres sombres et le chien vers la maison. Puis il s'achemina droit vers nous, à pas tranquilles, en balançant un peu les bras. Aucune hésitation, aucune gêne. Lui aussi, je le pense, avait compté les jours et les heures : il savait que c'était le dernier soir de notre séjour près de lui (Maurice Genevoix, Le Lac fou)

II. Envoyer, diriger directement vers un lieu déterminé

Transitif

-1200 Li quens Guillames a sa voie hastee, Droit vers Orenge a s'ost acheminee (Aliscans [fin XII $]$, 3969)

1532 Auquel tous furent obeissans, excepté ceux qui estoient dedans Larigno, lesquelz soy confians en la force naturelle du lieu refuserent à la contribution. Pour les chastier de ce refus, l'empereur fit droit au lieu acheminer son armée (François Rabelais, Pantagruel)

CORPUS WEB :

L’affaire des enseignants contractuels, entrés en grève de la faim depuis le 14 juillet dernier, s'achemine-t-elle droit vers une fin tragique ? [http://chlef.centerblog.net/197.html] (30.4.2016)

Chaque jour, les fruits et légumes arrivent de Rungis et sont acheminés tout droit vers le centre de stockage de La belle vie situé dans le 1er arrondissement de la Capitale [http://vivre. paris/10e-offerts-sur-votre-premiere-commandela-belle-vie-6290] (30.4.2016)

quand on est arrivé en chantant « la patrouille de la panthère, s'achemine droite et fière, la truffe en avant, la queue dans le vent, elle 
avance agilement (bis) etc..... » tout le monde se marrait on a eu notre petit effet !! [http://www. fraternite.net/forum/voirtopic.php?topic $=1506 \&$ forum=3\&start=137] (12.11.2013)

Mabrouk, Epau 2003, c'est un récit magnifique et impeccable, veut dire sans incidents, voilà une bonne préparation nous achemine droite vers la réussite de notre entrevue, on aura un répit, du début de l'année, et après ça sera le relancement dans la fin du mois,,donc,,il faut profiter du temps qui nous est donné pour intensifier notre préparation,, bonne matinée pour tous,, [http://www.forum.immigrer.com/ topic/91532-vous-attendez-lentretien/page-1643] (12.11.2013)

REMARques : Droit est un adjectif-adverbe de manière-direction qui caractérise le trajet parcouru par un objet ou une personne. Acheminer droit, sous sa forme pronominale, s'utilise en général dans le contexte de la guerre, désignant une armée qui avance vers un but sans faire de détours. Dans un contexte plus neutre, il désigne simplement l'action de s'avancer en direction d'un lieu ou d'une personne. Dans son emploi transitif, il signifie le fait d'envoyer une armée en la faisant avancer vers un lieu déterminé. Droit reste invariable (v. aussi les deux premiers exemples du CW) et est modifié par tout. Acheminer droit est généralement suivi (ou précédé) d'une préposition de lieu indiquant la direction (à, vers). Droit a ainsi tendance à s'associer avec ces prépositions au point de faire partie du groupe prépositionnel comme modifieur de la préposition. Le troisième exemple du CW montre l'emploi de droit comme prédicat second fléchi qui désigne une qualité du sujet, mais il pourrait s'agir également d'un reflet de la prononciation québécoise du - $t$ final. À la différence de cet emploi pleinement accepté, dans le dernier exemple l'accord est réalisé pour la fonction adverbiale de manière-direction. Il s'agit donc d'un adverbe accordé qui se heurte au dogme de l'invariabilité de l'adverbe. On ne saurait pas attribuer l'accord à un effet de phonétique, à l'instar de droit à, puisque l'accord n'est pas audible dans droit vers. La syntaxe met en évidence que le dernier exemple est écrit très spontanément.

\section{Acheter appétissant}

Acheter des choses appétissantes

$\pi$ acheter frais

\section{Acheter beau}

Acheter de belles choses

Emploi absolu

1952 Quand elle achetait, elle achetait beau (Exemple entendu, 27 mai 1952 / Grundt : 236)

1989 Achetez beau. Achetez réfléchi. Achetez Braun (Publicité / Noailly 1997a)

\section{CORPuS WeB :}

A trois enfants, on ne se pose même plus la question et on profite de toutes les combines possibles pour acheter beau et pas cher [http://www. lepetitmondedelvira.com/article-la-cavernede-lala-acheter-malin-et-d-occasion-pour-vosenfants-122171857.html] (30.4.2016)

savez vous ou je peux acheter $B E A U$ :-) un carnet de plongee ? car les standards je ne les trouve pas tres jolis :-) [http://www.plongeur.com/ forums/showthread.php?t=11351] (30.4.2016)

Ils voulaient juste dire, me semble t-il, qu'une plante comme celle là est achetée belle, mais qu'elle ne le reste pas longtemps parce qu'on peut difficilement leur donner les conditions adéquates pour un développement harmonieux [https://www.cactuspro.com/forum/read. php?1,271994,272056,quote=1] (30.4.2016)

REMARques : Beau est un adjectif-adverbe de manière qui appartient au langage familier $\mathrm{du}$ commerce et du marketing. Acheter beau caractérise l'acquisition d'objets dont l'achat fait naître un sentiment d'admiration, souvent mêlé de plaisir, assurant un effet d'appréciation esthétique positive. Beau reste invariable et peut complémenter un verbe transitif dans son emploi absolu. Dans ce cas-là, il modifie un objet sous-entendu, non-spécifié. Le troisième exemple du CW illustre son emploi en tant que prédicat second accordé. Notons la collocation acheter beau et pas cher ainsi que l'emploi de acheter réfléchi. 


\section{Acheter bon}

Se procurer un objet de bonne qualité Transitif

1562 JOSSE. Et voyla pourquoy davantage

Je me suis mis en mon devoir

De chercher moyen de l'avoir,

N'ayant grand esgard au doire,

Affin de plustost me complaire :

Voyla pourquoy, quoyque ce soit.

MARION. "Qui bon l'achette, bon le boit» (Jacques Grévin, Les Esbahis)

1793 BON. On dit familièrement en parlant de vin, Tirer du bon, donner du bon : Et proverbialement, Qui bon l'achète, bon le boit. Et cela ne se dit pas seulement du vin, mais figurément de toute autre marchandise, pour dire, qu'il n'y faut pas plaindre l'argent : Et que Quand on l'achète bonne, on s'en trouve bien (Nouveau dictionnaire françois)

\section{CORPUS WEB :}

Bruno achète bon et cher pour satisfaire la clientèle prête à payer le prix quand elle est bien au-dessus de son assiette [http://www.sudouest. fr/2010/05/15/du-bon-a-pessac-92431-2780.php] (30.4.2016)

et la pignorerie en plastoc me fait peur, trop de mauvais souvenir sur des machines du bricogasin du coin ou aux bout de qlq semaines le disque a meuler ne tourne plus rond. j'suis plutôt du genre, j'achète «bon » et je m'en sert de suite [http://www.metabricoleur.com/t3601-j-aime-laferraille] (30.4.2016)

La choucroute est achetée bonne et cuite, par fainéantise et parce qu'en Alsace, elle est bonne même déjà cuite [http://aumenuamidi.blogspot. co.at/2016/03/aie-confiance.html] (30.4.2016)

REMARQUES : Acheter bon caractérise l'acquisition d'objets de bonne qualité. Le proverbe Qui bon achète, bon le boit réfère, en parlant d'une boisson et par extension de denrées qu'on achète, au fait qu'en dépensant la somme nécessaire, on peut espérer une marchandise de bonne qualité, transmettant ainsi une morale selon laquelle il vaut mieux acheter une bonne marchandise chèrement qu'une mauvaise à bon marché. Notons la collocation bon et cher. L'objet interne qui est modifié par boire bon en emploi absolu peut devenir un complément d'objet explicite accordé en prédication seconde (dernier exemple du CW). Mentionnons l'emploi de boire bon.

\section{Acheter cher}

I. Acheter à un prix élevé

Transitif

1160 Voz armes sont chier achatees, Se doivent bien estre gardees ; Se vostre escuz estoit perciez, Vos serïez trop domagiez ; Tant com l'avroiz sain et antier, Ne donroiz an altre denier (Eneas, 6729)

-1200 Mais se vous port i volez prandre, L'an lou vouz voudra molt chier vandre, Molt l'estovra achater chier, Qu'an la nef vandra reverchier Premiers li sire et puis la dame (Guillaume d'Angleterre [fin $\mathrm{XII}^{\mathrm{e}}$ ], 2345)

1403 Helas ! Si est il plain de joye Qui la peine de ce degré Peut un peu de temps prendre en gré. On n'a pas grant bien pour neant, Et, cil, qui se va pourvoyant Sagement, doit chier acheter Ce dont peut en grant pris monter (Christine de Pisan, Le Livre de la mutacion de fortune, I, 3295)

+1489 De chiens, en envoyoit querir partout : en Espaigne des allans, en Bretaigne des petites levrètes, levriers, espaigneulx, et les achaptoit chier; en Valence, de petiz chiens veluz qu'il faisoit achapter plus cher que les gens ne les vouloyent vendre (Philippe de Commynes, Mémoires [1489-1498], VI)

1615 Nous aurions, des nostres mesmes, ce que nous achetons si cher des estrangers : soyes, cottons, baumes, liqueurs, gommes, bois médicinaux et aromatiques, gaïac, salsepareille, sassafras (nommé à la Floride " Pavagne », et en Virginie « Winank »), costus doux, costus amer, sandal blanc, sandal citrin, sandal jaune, bois d'esquine, casse fistule, cassia ligna, poivre long, et plusieurs espiceries (Antoine de Montchrestien, Traicté de l'économie politique) 
1668 Le pauvre Carpillon lui fit en sa manière : Que ferez-vous de moi ? je ne saurais fournir

Au plus qu'une demi-bouchée.

Laissez-moi Carpe devenir :

Je serai par vous repêchée.

Quelque gros Partisan m'achètera bien cher (Jean de La Fontaine, Le Petit Poisson et le pêcheur / Fables)

1735 LA BARONNE. Autre méprise, monsieur. Je l'ai acheté, assez cher même, d'une revendeuse à la toilette.

LE MARQUIS. Cela vient de lui, madame. Il a des revendeuses à sa disposition et, à ce qu'on dit même, dans sa famille

(Alain-René Lesage, Turcaret)

1756 Cette loi seule doit rendre sa mémoire chére à tous les peuples ; ainsi que ses efforts pour soutenir la liberté de l'Italie doivent rendre son nom précieux aux Italiens. C'est en vertu de cette loi que longtems après, le roi Louis Hutin dans ses chartes déclara que tous les serfs qui restaient encor en France, devaient être affranchis, parce que c'est, dit-il, le royaume des francs. Il faisait à la vérité payer cette liberté ; mais pouvait-on l'acheter trop cher ? Cependant les hommes ne rentrèrent que par degrés et très-difficilement dans leur droit naturel (Voltaire, Essay sur l'histoire générale et sur les mours et sur l'esprit des nations)

1830 C'est d'Angleterre que nous est venue la chimère politique de représenter le peuple par des hommes qui se rient de ses misères, et dont les intentions secrètes sont bien exprimées dans ces deux phrases ; l'une du ministre Walpole, disant : «J'ai dans mon portefeuille le tarif de toutes les probités du parlement ; » l'autre d'un député anglais, disant à ses commettans : « Je vous ai achetés cher, il faut que je vous vende cher. » Sans doute il y a des exceptions à cette perversité ; on voit des représentans [sic] très intègres ; mais qu'importe? (Charles Fourier, Le Nouveau monde industriel ou l'Agriculture combinée)
1842 Tenez, monsieur, ajouta-t-elle avec colère et en jetant trois pièces de cent sous sur la table du greffe, payez-vous. Aussi bien n'est-ce pas acheter trop cher le plaisir de ne plus vous voir. Le greffier ne répondit rien, retint sa somme, et rendit le reste : probablement il était habitué à de pareilles scènes (Louis Reybaud, Jérôme Paturot à la recherche d'une position sociale)

1873 Ceci étonna un peu Passepartout, qui savait tout ce que son maître devait au dévouement du guide. Le parsi avait, en effet, risqué volontairement sa vie dans l'affaire de Pillaji, et si, plus tard, les indous l'apprenaient, il échapperait difficilement à leur vengeance. Restait aussi la question de Kiouni. Que ferait-on d'un éléphant acheté si cher? Mais Phileas Fogg avait déjà pris une résolution à cet égard (Jules Verne, Le Tour du monde en quatrevingts jours)

1935 Les Allemands avaient besoin de peaux de lapins. Les poils filés leur servaient de textile. Ils achetaient donc très cher les fourrures de lapin, et délivraient, à ceux qui voulaient faire pour eux la récolte par les rues, des cartes qui servaient de laissez-passer (Maxence Van der Meersch, Invasion 14)

1959 MADAME. De plus en plus ! Des glaïeuls horribles, d'un rose débilitant, et du mimosa ! Ces folles doivent courir les halles avant le jour pour les acheter moins cher. Tant de sollicitude, ma chère Solange, pour une maitresse indigne, et tant de roses pour elle quand Monsieur est traité comme un criminel ! (Jean Genet, Les Bonnes)

1994 Nous espérions seulement qu'elle s’améliorerait avec le temps... Depuis, les situations se sont modifiées, mais, hélas, les règles qui président aux échanges internationaux restent les mêmes dans leurs grandes lignes : acheter le moins cher possible les matières premières, et revendre le plus cher possible les produits manufacturés (Amadou Hampâté Bâ, Oui Mon Commandant!) 
Emploi absolu

1580 POLYNICE. C'est tousjours bon marché, quelque prix qu'on y mette.

Nul n'achette trop cher qui un Royaume achette (Robert Garnier, Antigone)

1669 LA FLÈCHE. Je vous vois, Monsieur, ne vous en déplaise, dans le grand chemin justement que tenoit Panurge pour se ruiner, prenant argent d'avance, achetant cher, vendant à bon marché, et mangeant son blé en herbe.

CLÉANTE. Que veux-tu que j'y fasse ? Voilà où les jeunes gens sont réduits par la maudite avarice des pères ; et on s'étonne après cela que les fils souhaitent qu'ils meurent (Molière, L'Avare)

1770 LE MARQUIS. On peut le savoir, le calculer. On ne le peut ni ne le doit. Qui est-ce qui peut calculer et savoir quel déchet, quelle perte je puis avoir fait. Je puis avoir acheté cher. C'est à moi, si j'ai été dupé, à m'en tirer le mieux que je pourrai ; mais personne n'a droit de s'en mêler (Ferdinando Galiani, Dialogues sur le commerce des bleds)

1947 Ajoutez à ça mes frais généraux, mes frais d'encadrement, mon bénéfice et calculez. $\mathrm{Si}$ je vous achète trop cher, je suis obligé de faire un prix exorbitant, parfaitement prohibitif (Marcel Aymé, Le Vin de Paris)

1987 La nouvelle répartition de la garde-robe témoigne tout autant de l'envolée des valeurs hédonistes et psy propres à nos sociétés. Pour un nombre croissant de personnes, on préfère acheter souvent qu'acheter cher, on préfère acheter des petites pièces que des " gros vêtements ", c'est là une expression vestimentaire typique du nouvel âge de l'individualisme (Gilles Lipovetsky, L’Empire de l'éphémère)

Pronominal

1691 On a ici un grand nombre d'esclaves qui s'achètent et se vendent fort cher. Ce sont des maures et des turcs. Il y en a qui valent jusqu'à quatre et cinq cents écus (Marie-Catherine d'Aulnoy, Relation $d u$ voyage d'Espagne)
II. Subir les conséquences fâcheuses de

quelque chose

Transitif

+1265 Car se tu bois sur ma deffense

Chier accateras la despense

(Richars li Biaus [3 $3^{\mathrm{e}}$ tiers XIII ${ }^{\mathrm{e}}$, 956)

1275 Mains en noia le jour dedens cele riviere

Et mains en gist sanglens parmi la sablonniere

Qui par santé n'aront ja mais autre litiere ; La jouste Limbanor ont achetee chiere (Adenet le Roi, Buevon de Conmarchis, 2903)

1623 Mais helas il n'est point de plaisir sans tristesse,

Tousjours apres le bien, le mal se fait sentir,

Nous eusmes bon marché de ces douces carresses,

Mais nous en achetons bien cher le repentir. Nous en avons porté la robbe de Mercure, À peine en nostre bouche est resté une dent,

Si tost n'eusmes passé le destroit de nature Que nous vismes Suri Baviere et

Claquedent

(Jean Auvray, Le Banquet des muses ou Les Divers Satires)

1794 Je trouve tant de folie au voyage d'Amérique, qu'il me semble que c'est acheter même trop cher le plaisir certain de me décider à ce dernier acte si désirable dans ma situation. Avant tout, il faut que j'aille en Angleterre (Germaine de Staël, Lettres inédites à Louis de Narbonne)

1848 Annibal. Certes, je ne suis pas pour te le disputer.

Ton hymen a de quoi tous deux nous contenter,

Car à toi, s'il assure une belle retraite

Et le droit de jouer à la Madame... honnête, Il me met à l'abri, moi qui veux mourir gras,

Des caprices du sort à l'heure des repas ; Mais je l'achète cher, car jusqu'ici mon rôle Est fatigant ! (Émile Augier, L’Aventurière) 
1968 Mais le crime de bigamie n'était pas de ceux qu'on commet d'un cœur léger. « Si vous m'en croyez, fit-il, vous laisserez en paix votre serviteur et n'achèterez pas si cher deux sous de repentir... Vous plaît-il tant que cela de voir l'argent de Martin passer à des réfections d'église ?» (Marguerite Yourcenar, L'Euvre au noir)

III. Obtenir quelque chose au prix de grands sacrifices, de grands efforts

Transitif

1276 Merci requier, ne sai s'ele iert trouvee, Mais, par celui qui fist ciel et rousee, Se je ne l'ai, chier ara achetee Charles ma terre, ainz qu'il l'ait conquestee (Adenet le Roi, Les Enfances Ogier, 167)

+1400 Ayez pitié de moy, ma dame chiere : Chiere vous ay plus que dame du monde, Monde d'orgueil, ne me faites vo chiere Chiere achater par reffus, blanche et blonde ;

L'onde de plour m'ostez si que revoye Voye d'avoir soulas qui me ravoye (Christine de Pisan, Le Livre du duc des vrais amans / Euvres poétiques [début $\left.\mathrm{XV}^{\mathrm{e}}\right]$, III, p. 131, 2312)

+1415 L'AMANT. Se je vous dy bonne nouvelle, Mon cueur, que voulez vous donner? LE CUEUR. Elle pourroit bien estre telle Que moult chier la vueil acheter (Charles d'Orléans, Poésies [ 1415-1440], I, Ballade XXXIII, p. 52)

1541 Qui me contrainct

Qu'autant de temps qu'en amour juste et sainct

Je l'ay porté dedans mon cueur empraint Par amour forte, Autant de temps pour meschant je le porte. Impossible est que jamais il en sorte.

Sa lascheté

Donnera foeille à ma grant fermeté. Ô que l'honneur sera cher acheté De ne partir hors de l'amour dont le voy departir!

Où est l'esprit comme le mien martyr ?

Il n'en est point

(Marguerite d'Angoulême, La Coche)
1596 Ou comme un jeune lys, de la pluye aggravé, Laisse pendre son chef, qui fut si relevé. Victoire Cadmeane, et trop chere achetée, D’un ny d'autre party tu n'as esté chantée ! (Philippe Desportes, Euvres)

1634 DORImant. Pourriez-vous approuver que je prisse avantage

Pour immoler ce traître à mon peu de courage?

J'achèterois trop cher la mort du suborneur,

Si pour avoir sa vie il m'en coûtoit l'honneur,

Et montrerois une âme et trop basse et trop noire

De ménager mon sang aux dépens de ma gloire

(Pierre Corneille, La Galerie du Palais)

1668 Il y mourut en traînant son lien.

Sage s’il eût remis une légère offense.

Quel que soit le plaisir que cause

la vengeance,

C'est l'acheter trop cher, que l'acheter d'un bien

Sans qui les autres ne sont rien

(Jean de La Fontaine, Le Cheval s'étant voulu venger du cerf / Fables)

1836a ô hommes libres! Quand alors vous remercierez Dieu d'être nés pour cette récolte, pensez à nous qui n'y serons plus ; ditesvous que nous avons acheté bien cher le repos dont vous jouirez; plaignez-nous plus que tous vos pères! (Alfred de Musset, Confessions d'un enfant du siècle)

1836b Je n’ai reçu qu'indirectement des nouvelles de Denys Benoist depuis son départ pour Alais. Je désire que son entreprise réussisse. Les bénéfices qu'elle peut donner me paraissent achetés bien cher par les soins, la fatigue, et l'ennui d'une manutention de ce genre (Félicité de Lamennais, Lettres inédites ... à la baronne Cottu)

1863 Madeleine, je n'ai plus besoin de vous, je ne veux plus de secours, je ne veux plus rien... Je ne veux pas d'une assistance achetée si cher et d'une amitié que j'ai 
rendue trop lourde et qui vous tuerait. Que je souffre ou non, cela me regarde (Eugène Fromentin, Dominique)

1890 La plus grande des religions a vu son berceau signalé par les faits du plus pur enthousiasme et par des farces de convulsionnaires telles qu'on en voit à peine chez les sectaires les plus exaltés. Il faut donc s'y résigner : les belles choses naissent dans les larmes ; ce n'est pas acheter trop cher la beauté que de l'acheter au prix de la douleur (Ernest Renan, L'Avenir de la science)

1921 Règne rose, bonds légers, tirer des herbes parfumées de ce qui m'entoure, règne rose plaine rose règne. J'achète très cher l'invisible richesse. La lumière s'est levée avec le rideau (Paul Éluard, Les Nécessités de la vie)

1927 Je voudrais que la leçon, du moins, vous servît. Il ne vous en aura coûté qu'une petite course inutile. Ce n'est pas acheter trop cher le conseil d'être désormais moins bavard, moins empressé de prendre, et plus poli... Êtes-vous vraiment si essoufflé ? (Georges Bernanos, L'Imposture)

Pronominal

1853 Ce à quoi je me heurte, c'est à des situations communes et un dialogue trivial. Bien écrire le médiocre et faire qu'il garde en même temps son aspect, sa coupe, ses mots même, cela est vraiment diabolique, et je vois se défiler maintenant devant moi de ces gentillesses en perspective pendant trente pages au moins. Ça s'achète cher, le style ! Je recommence ce que j'ai fait l'autre semaine (Gustave Flaubert, Correspondance)

1884 Il lui avait pris les mains, il les serra paternellement, avec une émotion triste.

- Oui, si vous êtes heureuse... allez, le malheur s'achète aussi bien cher quelquefois.

Naturellement, dans l'ardeur de cette bataille qu'il livrait à la mer, Lazare avait abandonné la musique (Émile Zola, La Joie de vivre)
1893 l'action est cette méthode de précision, cette épreuve de laboratoire, où, sans jamais comprendre le détail des opérations, je reçois la réponse certaine à laquelle aucun artifice de dialectique ne supplée. Là est la compétence : peu importe si elle s'achète cher. Mais encore n’y a-t-il pas équivoque et inconséquence dans ce règlement de vie ? S'il faut toujours opter entre plusieurs partis, pourquoi sacrifier ceci à cela (Maurice Blondel, L'Action : essai d'une critique de la vie et d'une science de la pratique)

1897 L'erreur de ma vie fut dès lors de ne continuer longtemps aucune étude, pour n'avoir su prendre mon parti de renoncer à beaucoup d'autres. N'importe quoi s'achetait trop cher à ce prix-là, et les raisonnements ne pouvaient venir à bout de ma détresse (André Gide, Les Nourritures terrestres)

\section{Acheter à un prix élevé (par extension)}

Transitif

1748 - En vérité, lui répliqua la seconde, il faut avoir de bonnes raisons de ménager les gens, pour acheter si cher leur discrétion.

- Je n'en ai pas de meilleures qu'une autre, repartit Céphise ; cependant je ne m'en dédis pas (Denis Diderot, Les Bijoux indiscrets)

1800 LA DUCHESSE. (à part) Que devenir ? À quelle honte mes périls et mon ambition me condamnent !

LOPEz. Cessez d'être inexorable, et je vous paie mon bonheur d'un service que vous n'achèterez jamais trop cher. La destinée de votre époux est dans mes mains. LA DUCHESSE. Au nom du ciel... parlez (Népomucène Lemercier, Pinto ou La Journée d'une conspiration)

1822 GERVAL. Eh bien je t'en donne, deux mille... trois mille !

MARGUERITE. Ah diable... J'achèterais les vignes à Claudin.

GERVAL. Répondras-tu ? Est-ce acheter assez cher la mort ? Parlez donc !... 
MARGUERITE. Les vignes à Claudin !... Qu'est-ce que cela peut faire, il n'est pas du pays.

GERVAL. Eh bien...

(Honoré de Balzac, Le Nègre)

1848 Clorinde. Tous les jours ce sont des coups nouveaux...

Hélas! vous m'achetez plus cher que je ne vaux !

Croyez-moi, mon ami, cédez devant l'orage Et quittez un amour qui veut trop de courage (Émile Augier, L’Aventurière)

Pronominal

1942 Mais, de cette promenade d'aujourd'hui, je ne devais pas revenir non plus. Elle me donne un peu plus le droit de m'asseoir à leur table, et de me taire avec eux. Ce droit-là s'achète très cher. Mais il vaut très cher : c'est le droit d'être. C'est pourquoi, ce bouquin, je l'ai signé sans gêne... il ne gâchait rien (Antoine de Saint-Exupéry, Pilote de guerre)

V. Obtenir la complicité de quelqu'un, le corrompre contre une grosse somme d'argent Transitif

1902 Je l'apprends ; je le devance chez le gouverneur russe de la place, à qui je montre les documents de nos loges : et le comte d'Artois ne peut entrer dans la ville que sans cortège, à la condition de s'enfermer en son hôtel, sous un nom d'emprunt, de n'y recevoir âme du monde, et de n'en bouger pas... Il fallut que l'abbé de Montesquiou achetât très cher Talleyrand et les sénateurs de l'empire, pour qu'Alexandre se laissât tromper et consentît au retour des bourbons (Paul Adam, L'Enfant d'Austerlitz)

1995 Quel stratège n’a pas intérêt à connaître les plans de l'ennemi ? La Baronne avait les moyens d'acheter cher les juges ; la Comtesse n'avait les moyens que d'acheter bien les témoins. Il fallait profiter de l'aubaine (Françoise Chandernagor, L'Enfant des Lumières)

CORPUS WEB :

Dernière difficulté: dans une louable démarche vertueuse, les pouvoirs publics de- mandent aux méthaniseurs d'optimiser la consommation de la chaleur produite dans les cogénérateurs (lire ci-contre) : plus la chaleur est utilisée, plus l'électricité est achetée cher [http://www.lanouvellerepublique.fr/Vienne/ Actualite/Economie-social/n/Contenus/ Articles/2015/03/15/Pres-de-vingt-projets-dansla-Vienne-2257435] (30.4.2016)

Alors, je me demandais... je sais que c'est la première guitare américaine du groupe et que Harrison en était très fier, et qu'il l'a achetée d'occasion. Alors voilà : est-ce qu'il l'a achetée chère ? [http://www.yellow-sub.fr/forum/viewtopic. php?f=8\&t=2842] (30.4.2016)

REMARQUES : Cher peut être analysé comme un adverbe de manière, qui est l'interprétation dominante, ou comme adjectif en prédication seconde indiquant le prix élevé de ce qui est vendu (I). Dans le second cas, il peut être accordé, mais l'emploi invarié est plus usuel, surtout en français moderne. L’idée d'un coût élevé est pris au figuré pour renvoyer aux conséquences d'un comportement (II), pour mesurer un effort entrepris (III), pour décrire le prix moral de quelque chose (IV) ou dans le domaine de la corruption pour payer les faveurs de quelqu'un (V). L'emploi familier documenté dans le CW s'avère plus libéral par rapport à l'accord, qui est fonctionnellement justifié, mais moins accepté dans l'usage établi, à la différence des autres langues romanes (par exemple en espagnol Comprar cara la casa 'acheter chère la maison'). Cher est modifié par assez, bien, fort, jamais, même, (le) moins, plus, si, très, trop. Notons l'emploi de mourir gras, valoir cher, vendre cher. VOIR AUSSI : vendre cher

\section{Acheter ferme}

Acheter quelque chose sans sursis et d'une manière définitive, en s'en tenant au prix et aux conditions fixées

Emploi absolu

1853 En achetant ferme payable fin courant, l'on devenait porteur des inscriptions de rente, sans avoir déboursé autre chose que la commission due à l'agent de change (Nicolas Boyard, La Bourse et ses spéculations) 
1856 PEPONET. Je...

OCTAVE. Vous achetez ferme?...

PEPONET. Permettez...

OCTAVE. Non ?... à prime alors

(Théodore Barrière et Ernest Capendu, Les

Faux Bonshommes)

Transitif

1909 Mr. W. N. Balcombe représentait à Londres la marque Hartmann. Il achetait ferme chaque année trois cent mille bouteilles et les revendait par l'intermédiaire de sousagents dans toutes les parties du monde (Pierre Hamp, Vin de Champagne)

1935 Tout cela risquait de pourrir. A Anvers, quatre péniches de mille tonnes de blés américains, achetées "ferme », s'échauffaient et germaient. Un bateau avait pris feu. Quelques jours encore, et tout serait à jeter à la mer (Maxence Van der Meersch, Invasion 14)

1939a Office et dépôt. Les livres nouveaux ne sauraient, dans la plupart des cas, être achetés ferme par le libraire car les risques seraient trop grands (La Civilisation écrite)

1939b Les camelots. Pour les journaux de midi et du soir, les camelots sont approvisionnés par des voitures à des points fixes dans Paris ou au service central de vente des journaux du soir, rue du Croissant. Ils paient comptant et achètent ferme sans reprise d'invendus le nombre d'exemplaires qu'ils croient pouvoir vendre ( $\mathrm{La}$ Civilisation écrite)

\section{CORPUS WEB :}

En aéroport, les maisons de luxe délèguent souvent l'exploitation à un partenaire spécialisé, qui emploie ses propres vendeurs et lui achète ferme la marchandise [http://www.lefigaro.fr/ societes/2013/04/11/20005-20130411ARTFIG 00380-les-boutiques-d-aeroports-nouveleldorado-des-griffes-de-luxe.php] (4.5.2016)

Le Distributeur achète ferme les Produits au Fournisseur en vue de leur revente dans le Territoire [http://www.droit.co/mod\%C3\%A8le-decontrat-de-distribution.html] (4.5.2016)
Vous levez vos titres. C'est à dire, vous achetez ferme vos actions comme dans une opération au comptant.

Vous reportez vos titres. C'est à dire, vous ne voulez ou ne pouvez acheter ferme vos titres. Cela arrive quand le montant de vos engagements est supérieur au montant de vos liquidités [http://www.abcbourse.com/apprendre/1_le_ fonctionnement_du_srd2.html] (4.5.2016)

Pour avoir des avocats toujours mûrs, je les achète fermes et les conserve 2 ou 3 jours dans une feuille de papier journal à température ambiente [http://www.trucmania.com/Cuisine/Desavocats-a-point.html] (25.10.2013)

REMARQUES : Acheter ferme désigne le caractère définitif et conclu de l'acquisition d'un objet par l'achat. Achetant ferme, on ne revient pas dessus, les prix et les conditions étant définis par le vendeur et/ou l'acquéreur. Dans cet emploi, il reste invariable (ex. de 1909) et peut soit figurer comme modifieur d'un verbe transitif, soit comme seul complément du verbe dans son emploi absolu. Acheter ferme appartient au langage du marketing et du commerce (exemple de 1935). Le dernier exemple du CW montre l'emploi accordé en fonction de prédicat second ; ferme a ici le sens de 'consistant, assez dur, qui a la chair ferme'. Nous citons acheter ferme comme représentant d'une série de verbes : accepter / parier / ponter / prendre / vendre ferme. Notons l'emploi de payer comptant.

\section{Acheter frais}

Acheter des produits de date récente

Transitif

1911 Il avait déjà fallu changer quatre fois le bouquet du vase. Levé tôt le matin, il courait l'acheter tout frais. Chaque fois, il prenait la botte plus grosse, et le surplus mis de côté, un jour qu'elle en respirait le parfum, il fut bien forcé de le lui donner (Charles-Ferdinand Ramuz, Aimé Pache, peintre vaudois)

Emploi absolu

1955 J'achète frais, j'achète appétissant, j'achète sain parce que j'achète sous cellophane (Paris Match [publicité] / Grundt : 258) 


\section{CORPUS WEB :}

Cueillir le cassis bien mûrs au mois de juillet ou l'acheter frais sur son marché [http:// cuisinedelali.canalblog.com/archives/2005/08/ 15/725986.html] (4.5.2016)

Tout au long du week-end, le hareng sera roi et le public pourra l'acheter frais ou grillé le long des quais [http://www.paris-normandie.fr/ detail_article/articles/PN-1103242/poisson-fraispoisson-grille-1103242\#.Vynqe01f2Uk] (4.5.2016)

Le mieux pour qu'un café reste frais c'est déjà... de l'acheter frais ! [https://javry.com/ posts/comment-conserver-son-cafe-en-grains] (4.5.2016)

j'adore la choucroute, et je l'achète fraîche, c'est bien meilleurs que toutes ses boîtes à la noix [http://lechaudrondetaka.canalblog.com/ archives/2011/09/13/22024180.html] (25.10.2013)

REMARQUES : Frais peut être analysé, d'une part, comme un adverbe de manière qui s'emploie dans le domaine de l'alimentaire ou de la botanique et réfère à l'acquisition de produits nouvellement récoltés, qui n'ont subi aucune altération et destinés à être consommés ou servis en l'état. Frais est alors le modifieur d'un objet interne ('ce que l'on achète est frais') ou, sur un plan plus abstrait, un type de comportement, qui se rapproche d'une lecture comme façon d'acheter. Dans cet emploi, frais reste invariable et peut complémenter un verbe transitif (ex. de 1955). D'autre part, il se prête également à une analyse en tant que prédicat second orienté vers l'objet (exemple de 1911). Dans cet emploi, il s'accorde en genre et nombre avec l'objet (v. aussi les exemples du CW). Il est modifié par tout. Notons que l'exemple de 1955 contient aussi les groupes acheter appétissant ('acheter des produits appétissants, qui donnent envie de manger') et acheter sain.

\section{Acheter intelligent}

Acheter (des produits) judicieusement, bien mesurer leur utilité réelle en faisant preuve d'une conscience écologique $\lambda$ acheter juste, bronzer idiot

\section{Acheter juste}

Acheter de manière fondée et pertinente Emploi absolu

1951 Achetez juste et intelligent [c'est-à-dire des melons dans la saison des melons] (Elle, 30 septembre 1951 / Grundt : 362)

\section{CORPUS WEB :}

Commerce équitable : juste acheter ou acheter juste ? [http://www.ac-grenoble.fr/armorin. crest/beespip3/spip.php?article193] (4.5.2016)

Acheter juste et en toute sécurité [http:// www.lemoniteur.fr/articles/acheter-juste-et-entoute-securite-28145743] (4.5.2016)

Je suis maudite des ballerines en ce moment je crois ! J'ai pris la fâcheuse habitude de les acheter juste juste à ma taille car je déteste les perdre quand le cuir se détend... sauf que le cuir ne se détend pas toujours [http://fashion. world.free.fr/archives/tag/repetto/index-7.html] (5.5.2016)

chaussures en plastique pour rivière ou plage neuves t23 (ne chaussent pas grand), marque tribord, jamais servi car achetées justes, petit crans en dessous pour éviter de glisser, semelle assez épaisse en plastique à l'intérieur qui peut s'enlever [https://www.leboncoin.fr/ chaussures/809930100.htm] (5.5.2016)

Remarques : Dans l'exemple de 1951, acheter juste réfère à l'acquisition judicieuse de produits corrects. Il s'agit d'un slogan publicitaire qui contient également acheter intelligent. Plus récemment (premier exemple du $\mathrm{CW}$ ), il inclut un certain intérêt pour l'écologie ou le commerce équitable. Cet exemple joue avec la polysémie de juste, qui signifie 'seulement, ne faire autre que' en antéposition (juste acheter). Il reste invariable et peut modifier un verbe dans son emploi absolu. Dans le troisième et le quatrième exemple $\mathrm{du} \mathrm{CW}$, juste réfère à des chaussures trop serrées et fonctionne ainsi en tant que prédicat second orienté vers l'objet. Juste est alors accordé avec l'objet au pluriel (dernier exemple). Notons aussi l'emploi de chausser grand dans le domaine de l'habillement. 


\section{Acheter malin}

Faire un achat réfléchi, en comparant les prix et en tenant compte des promotions

入 bronzer idiot

\section{Acheter prudent}

Acheter avec précaution, avec prudence

Emploi absolu

2020 Offres de sécurité : achetez prudent. Dans le contexte de menaces actuel, il est plus important que jamais d'investir dans les bons outils et technologies de sécurité (Le Monde informatique, consulté en ligne le 20.10.2020)

REMARQUES : Achetez prudent est ici une traduction de l'anglais buy smart (généralement plutôt traduit par acheter malin)

\section{Acheter réfléchi}

Acheter après réflexion, en connaissance de cause

$\lambda$ acheter beau

\section{Acheter responsable}

Acheter des produits qui respectent

l'environnement

入 bronzer idiot

\section{Acheter sain}

Acheter des produits sains, bons pour la santé Emploi absolu

\section{Corpus Web :}

J'ai une vie saine et équilibrée, je cuisine beaucoup et surtout des légumes, j'achète sains et rien d'industriel [http://bebe.doctissimo.fr/ blog/4361-Ca-se-passe-tres-bien-chez-McDonalds.html] (25.10.2013)

REMARQUES : Accord curieux de sain, peut-être motivé par « légumes ». Voir également une occurrence d'acheter sain sous acheter frais.

\section{Acheter sérieux}

Acheter quelque chose de sérieux, de valable Emploi absolu

1981 Achetez sérieux. Flaine. La vraie propriété (Le Figaro magazine)

\section{Acheter solidaire}

Acheter en pensant au bénéfice des autres, notamment des défavorisés

Emploi absolu

2013 Achetez solidaire ! Achetons solidaire! En cette fin d'année, choisissez Frère des Hommes pour acheter vos cartes postales (http://fdh.org/Achetez-solidaire.html / Corpus Coiffet 2018 : s.v.)

\section{Acheter utile}

Acheter le strict nécessaire

Emploi absolu

2013 Non, non ! Tu achètes utile, et c'est tout ! Avec le budget qu'on a, pas de gadgets qui servent à rien et tout ! C'est toujours le même problème chez IKEA ! (Exemple entendu / Corpus Coiffet 2018 : s.v.)

\section{Acheter vil}

Acheter quelque chose à bon marché, à bas prix Emploi absolu

+1249 Dou bleif ameiz la grant vendue, Et chier vendre de ci au tans Seur lettre ou seur plege ou seur nans, Vil acheteir et vendre chier Et uzereir et gent trichier Et faire d'un deable deus Por ce que enfers est trop seux (Rutebeuf, Poèmes [pièces datables de 1249 à 1272], I, p. 507, 299)

REMARQUES : Dans l'ancienne langue, acheter vil caractérise l'acquisition d'objets à bon marché (v. l'expression à vil prix). Notons l'emploi de vendre cher. VOIR AUSSI : vendre petit

\section{Achever seul}

Achever, compléter une chose sans assistance externe

Emploi absolu

1634 Après achève seul, je ne puis sans supplice Forcer ici mes bras à te faire service, Et mon reste d'amour en cet enlèvement Ne peut contribuer que mon consentement (Pierre Corneille, La Place royale)

1663 ARNOLPHE. Vous achèverez seule; et, pas à pas, tantôt Je vous expliquerai ces choses comme il faut. 
Je me suis souvenu d'une petite affaire : Je n'ai qu'un mot à dire, et ne tarderai guère (Molière, L'École des femmes)

1664 LA PRINCESSE. Achevez seules, si vous voulez. Je ne saurois demeurer en repos ; et quelque douceur qu'aient vos chants, ils ne font que redoubler mon inquiétude (Molière, La Princesse d'Élide)

1836 Tous les beaux discours qu'ils me pourraient débiter n'y feraient rien. Je sais d'avance ce qu'ils vont dire, et j'achèverais toute seule. Je les ai vus étudier leurs rôles et les repasser avant d'entrer en scène ; je connais leurs principales tirades à effet et les endroits sur lesquels ils comptent (Théophile Gautier, Mademoiselle de Maupin)

Transitif

1704a Bien plus, après avoir commencé les choses que nous savons par cœur, nous voyons que notre langue les achève toute seule longtemps après que la réflexion que nous y faisions est éteinte tout à fait ; au contraire la réflexion, quand elle revient, ne fait que nous interrompre et nous ne récitons plus si sûrement (Jacques-Bénigne Bossuet, De la connaissance de Dieu et de soi-même)

1842a La vie me pesait; je regrettais parfois que la maladie m'eût épargné. Malvina cherchait bien à me distraire, mais la mélancolie était la plus forte. Notre jeune docteur devait seul achever ma guérison. Il faut vous dire que nous nous étions étroitement liés (Louis Reybaud, Jérôme Paturot à la recherche d'une position sociale)

1842b Puisque la seule enfant qui pouvait sur la terre

Étreindre ma pensée et toutes ses splendeurs

A refusé sa lèvre au fruit qui désaltère

Et comme un vieux haillon rejeté mes grandeurs,

J'achèverai tout seul ma course solitaire,

Et nul ne connaîtra mes sourdes profondeurs

(Théodore de Banville, Les Cariatides)
1843 Après avoir parlé ainsi avec une remarquable volubilité, le docteur remit son masque, salua profondément Consuelo, et se retira, la laissant achever son souper toute seule si bon lui semblait : elle n'était guère disposée à le faire (George Sand, $L a$ Comtesse de Rudolstadt)

1845 - Vous le voyez, reprit Rodin d'une voix si épuisée qu'elle devint bientôt presque inintelligible, la punition commence déjà... un... des Rennepont est mort... et... songez-y bien... cet acte de décès... ajouta le jésuite en montrant le papier que le père d'Aigrigny tenait à la main, vaudra un jour quarante millions à la compagnie de Jésus... et cela... parce que... je vous... ai... Les lèvres de Rodin achevèrent seules sa phrase (Eugène Sue, Le Juif errant)

1848 16. Bataille de Waterloo. Le 18 juin 1815, vers midi, je sortis de Gand par la porte de Bruxelles ; j’allai seul achever ma promenade sur la grande route. J'avais emporté les commentaires de César et je cheminais lentement, plongé dans ma lecture (François de Chateaubriand, Mémoires d'outre-tombe)

1851 - Ils sont tous amoureux de ma maîtresse, et je crois bien que le vicomte en est fou. Amaury tourna le dos brusquement, et laissa Julie achever seule ses commentaires (George Sand, Le Compagnon $d u$ Tour de France)

1872 M. Michelin achevait tout seul, à l'autre bout de la pièce, une terrine de foie gras dont il avait réussi à s'emparer (Émile Zola, La Curée)

1885 Mais quelle mort ! La chair, misérable martyre,

Retourne par son poids où la cendre

l'attire,

Vos corps sont revenus demander des linceuls :

Vous les avez jetés, dernier lest, à la terre, Et, laissant retomber le voile du mystère, Vous avez achevé l'ascension tout seuls ! (Jules Lemaître, Les Contemporains) 
1921 Avec Mme de Stermaria, cette après-midi, que j'allais achever seul, me paraissait bien vide et bien mélancolique (Marcel Proust, Du côté de Guermantes 2)

1929 LE JAPONAIS. Seigneur Rodrigue, vos paroles m'empêchent de dessiner. J'ai compris ce que vous vouliez. J'ai établi vos repères. La chose ne vous appartient plus et si vous permettez, je l'achèverai tout seul.

DON RODRIGUE. Tâche du moins de ne pas me rater ça, comme tu avais fait du saint Georges. Tu n'y avais rien compris, mon pauvre vieux

(Paul Claudel, Le Soulier de satin)

Pronominal

1704b Et il en arriveroit à peu près de même que dans la respiration, que nous pouvons suspendre par la volonté quand nous veillons ; mais qui s'achève pour ainsi dire toute seule par la simple disposition du corps, quand l'ame le laisse agir naturellement, par exemple dans le sommeil (Jacques-Bénigne Bossuet, De la connaissance de Dieu et de soi-même)

\section{CORPuS WeB :}

Concrètement, je pense qu'il ne sert à rien que quelqu'un se désigne comme responsable d'un projet qui ne lui tient pas à cœur, ou dont il sait pertinemment bien au départ qu'il ne pourrait pas techniquement l'achever seul (« seul » voulant dire ici sans qu'il n'ait lui-même la garantie que quelqu'un d'autre qui lui est proche l'aidera) [http://linux-bruxelles.bxlug.narkive.com/ TqG49TRE/postes-a-responsabilite] (5.5.2016)

Par exemple en laissant filer Jonathan Duhail, pour profiter d'une poursuite menée à trois. Et achevée seul dans la grande montée menant à Saint-Sernin-du-Bois. «J'ai recollé au ravitaillement, vers le 12e kilomètre » [http:// www.lejsl.com/sport-local/2015/03/09/un-bou quet-a-la-verrerie] (5.5.2016)

À seize ans, elle se fait modèle puis danseuse espagnole pour échapper à la monotonie de la maison meublée tenue par sa mère et elle achève seule son instruction par la lecture [http:// www.secondemain.ca/acatalog/Secondemain Nin_Ana_s_7460.html] (5.5.2016)
REMARQUES : Seul peut être analysé comme un adjectif-adverbe de manière qui désigne le fait de mener à terme une entreprise, une action, un plan, ou un repas, le sujet pouvant être un objet ou une personne qui, sans aide quelconque, sans compagnie, parvient à venir à bout du processus en cours. Dans son emploi pronominal, il désigne la manière spontanée, presque naturelle dans l'action. Il se prête également à une analyse en tant que prédicat second orienté vers le sujet. Il ne s'agit néanmoins pas d'un simple prédicat second, puisqu'il exprime plutôt une manière d'effectuer une action 'sans aide' ou, si l'on veut, une circonstance. L'accord avec le sujet du verbe est systématique. C'est un des cas où l'usage et la correction linguistique admettent l'accord. L'accord aide à différencier « Les lèvres de Rodin achevèrent seules sa phrase " de "Les lèvres de Rodin achevèrent seule sa phrase ». Seul est souvent renforcé par tout.

\section{Aconter petit}

Accorder peu d'importance à quelque chose Transitif

1365 Pas ne doit avoir honte créature vivant De faire son pourfit, en loyauté régnant Et j'aconte petit aussi, au remanant, S'on me moque de chou que requier le marquant (Li Romans de Bauduin de Sebourc, Chant II, 836)

REMARQUES : L'ancien français emploie petit comme quantifieur, remplacé par peu dans l'usage moderne, exprimant une petite quantité. Au figuré, il désigne le fait d'accorder peu d'importance ou de valeur à quelque chose ou à quelqu'un, le sujet montrant peu d'estime ou affichant peu de considération.

\section{Acostumer bel}

Habiller d'une manière raffinée, élégante Transitif

-1100 Tant i plurat e le pedra e la medra E la pulcela que tuz s'en alasserent. En tant dementres le saint cors conreierent Tuit cil seinur e bel l'acustumerent : Com felix cels ki par feit l'enorerent ! (Vie de saint Alexis [fin $\mathrm{xI}^{\mathrm{e}}$ ], BFM, 499) 
REMARQUES : En ancien français, acostumer bel est l'équivalent du tour moderne habiller beau. L'adjectif-adverbe de manière adopte la forme neutre bel. Sa fonction adverbiale ne fait donc pas de doute.

Acoudre fort

入 coudre fort

\section{Adestrer ferme}

Conduire, accompagner quelqu'un contre son gré, avec force

Transitif

1250 LI PREECIERES. Puis prisent et l'image et lui,

Mout ferm l'adestrerent et tinrent, Tant que il devant le roy vinrent, Qui mout fu liés de le victoire (Jehan Bodel, Jeu de saint Nicolas, 25 [prologue])

REMARQUES : Dans l'ancienne langue, adestrer ferme caractérise l'action de marcher fermement à côté d'une personne, et par extension, de la guider, l'amener vers un lieu ou une personne, avec fermeté. Il est invariable et est modifié par moult.

\section{Adorer fort}

Vénérer, aimer profondément

$\lambda$ adorer haut

\section{Adorer haut}

Vénérer, aimer profondément, d'un amour

supérieur, pur

Pronominal (réciproque)

1868 Je veux que nous nous adorions plus loin et plus haut, au-dessus des amours vulgaires et convenues de la foule, dans une tendresse absolue qui n'ait point le souci des misères et des hontes d'ici-bas (Émile Zola, Madeleine Férat)

Transitif

1891 L'argent, l'argent roi, l'argent dieu, au-dessus du sang, au-dessus des larmes, adoré plus haut que les vains scrupules humains, dans l'infini de sa puissance ! (Émile Zola, L’Argent)

\section{CORPUS WEB :}

Il n'y a pas d'aussi grand amour que celui que l'on donne. S'aimer oui, mais s'adorer haut et fermement ; ca tue la beauté de l'amour ; ca tue l'amour de la beauté [http://pasc-a-parle. blogspot.co.at] (5.5.2016)

Donc la saison commence. Bonheur incomparable pour la multitude, même les marioles de la politique qui détestent ça, ne peuvent pas faire autrement que d'adorer haut et fort et partout où ils peuvent le proclamer [http://www.richard3. com/2007/08] (5.5.2016)

Grosse surprise avec The Streets que j'avais découvert sur Skyrock quand j'avais 13 ans. Autant dire que je ne savais pas à quoi m'attendre. Je peux aujourd'hui les adorer haut et fort après le set tout simplement énorme qu'ils nous ont offert [http://www.aparté.com/2011/10/festivalfestival-internacional-de-benicassim-2011] (5.5.2016)

Tout mimi ses cupcakes, Emilie les adore hauts en couleurs, et vous les personnalise selon vos désirs ! Mais attention uniquement sur commande [http://boopsleblog.wordpress.com/ 2012/11/12/les-cupcakes-et-nous] (12.11.2013)

REMARQUES : Haut est un adjectif-adverbe de lieu qui a un sens spatial et désigne un point élevé. Avec une interprétation de degré, il réfère au fait d'aimer une personne d'une manière supérieure et pure, voire divine ou au fait de vénérer, de vouer un culte à une chose, telle l'argent dans l'exemple de 1891. Il reste invariable (ex. de 1868) et est modifié par plus. La collocation plus loin et plus haut met en évidence la vitalité métaphorique des concepts locaux associés à loin et haut. Notons également la collocation haut et fort. L'accord est possible quand haut devient un prédicat second orienté vers l'objet direct (dernier exemple du CW). VoIR AUSSI : adorer bas, aimer profond

\section{Adresser droit}

I. Se diriger directement, en ligne droite (vers quelque chose / quelqu'un)

Intransitif

1175 D'iloec les voient assanler, La tere bondir et tranler Öent d'iluec benignement, Et voient tot apertement 
Ces chevaliers droit adrecier,

Et ces escus fraindre et percier,

Ces haubers rompre et desconfire

Chevaliers navrer et ochire

(Gautier d'Arras, Ille et Galeron, 5805)

II. Se dresser, s'élever

Pronominal

1285 Moult doucement au commencier

Se conmença a adrecier

Tout droit encoste la grant tour

(Adenet le Roi, Cleomadés, 5181)

1628 MESSAGER. Droit à luy s'adressa la route que tenoit

Un royal Galion, qui de Sidon venoit, Dans lequel un Seigneur, qu'ils appellent Balorte,

Est chargé d'ambassade et de preuve tres-forte

Pour du fait de Leonte esclaircir nostre Roy (Jean de Schélandre, Tyr et Sidon)

III. Diriger son regard exactement, précisément Transitif

1526 Ung grant courcier sur lequel proprement Estoit ung Roy, armé triumphamment, Lequel avoit

La main en l'aer, dont le peuple disoit Que celluy Roy Venise menassoit

Et qu'ainsi soit, son regard adressoit

Droit comme picque

Vers les climatz de mer Adriatique,

En demonstrant que celle main bellique

Corrigeroit l'arrogance publique

Venitienne

(Jean Marot, Le Voyage de Venise)

IV. Expédier une chose directement

Transitif

1675a Il y a trois semaines que je vous écrivis et vous envoyai trois ou quatre lettres de recommandation pour l'affaire de M. Levasseur. J'adressai le paquet droit chez vous, et comme je n'en ai point eu de réponse, j'en suis en peine et meurs de peur qu'il n’ait été perdu (Mme de Sévigné, Correspondance)

1675b Il m'a fait mille compliments par Bandol ; je lui en ai rendu par la même voie et j'ai adressé la lettre droit à Aix. En voilà une de votre évêque, vous y verrez toujours les mêmes précautions ; il ne veut pas être pris par le bec. Nous verrons un peu sa manière de peindre (Mme de Sévigné, Correspondance)

V. Se tourner vers quelqu'un directement, pour lui parler et obtenir de lui quelque chose

Pronominal

1845 Dans cette perplexité, l'idée m'est venue de m'adresser tout droit à votre Grandeur, parce qu'on m’a dit que sa bonté égalait sa puissance, qu'elle avait l'esprit élevé et le cœur vraiment apostolique. J'ai eu foi en elle et j'ai osé (George Sand, Correspondance)

CORPUS WEB :

Halte aux magouilleurs, gameleurs, enfumeurs, frondeurs... Il faut s'adresser droit dans les yeux au peuple et non aux socialistes pas très à l'aise, en ce moment, dans leurs fauteuils de sénateurs et de députés [http://www.pcf.fr/58320] (7.5.2016)

Les thèmes et les rythmiques réussissent systématiquement à trouver une accroche efficace pour s'adresser droit au corps et au cour, quand bien même on ne saurait trop conseiller à ceux qui n'ont jamais écouté Zita Swoon d'entamer ailleurs leur pèlerinage [https:// www.playlistsociety.fr/2011/05/zita-swoongroup-dancing-with-the-sound-hobbyist/14979] (7.5.2016)

Elle dit toujours ce qu'elle pense en regardant la personne a qui elle s'adresse droit dans les yeux [http://blog.tvmag.lefigaro.fr/secretstory/2009/09/-et-cest-parti-pour.html] (7.5.2016)

Remarques : Droit est un adjectif-adverbe de manière-direction. Il est modifié par tout. Droit a tendance à s'associer avec des prépositions qu'il précède (à, dans, encoste, vers) au point de faire partie du groupe prépositionnel comme modifieur de la préposition, notamment dans la locution droit dans les yeux. Droit reste invariable (ex. de 1845, où le sujet correspond à l'auteure, George Sand).

\section{Affirmer clair}

Affirmer clairement

$\lambda$ affirmer haut 
Affirmer fort

Affirmer fortement

$\lambda$ affirmer haut

Affirmer haut

I. Affirmer sans ambages

Transitif

1912 Ils affirment bien haut qu'ils ne veulent admettre dans la pensée que des idées claires et distinctes ; - c'est en fait une règle insuffisante pour l'action, car nous n'exécutons rien de grand sans l'intervention d'images colorées et nettement dessinées, qui absorbent toute notre attention ; - or peut-on trouver quelque chose de plus satisfaisant que la grève générale à leur point de vue ? (Georges Sorel, Réflexions sur la violence)

1989 Je l'affirme haut et fort : qui ne s'est jamais retrouvé à poil devant son éditeur, sous l'œil de feu Vittorio de Sica, pendant qu'un ex-ministre de l'Intérieur pousse des petits cris autour de lui, ignore tout de la honte (Daniel Pennac, La Petite Marchande en prose)

1996 Néanmoins, ses yeux de myope nous scrutaient. Plus que ceux de Lupin, au lycée. Qui, un jour, malgré tout, en pleine classe : «Vous, Schreiber, vous seul ici, auriez une chance d'intégrer à Normale Supérieure. » Il l'affirmait haut et clair ; pourtant Boris et moi l'irritions maintes fois. Boris et moi, prince régnant. Au visage d'ange, selon Parrault (Boris Schreiber, Un silence d'environ une demi-heure)

II. Affirmer à voix haute, de manière distincte Transitif

1921 Infirmité plus morale peut-être qu'intellectuelle : au fond, et comme nous l'avons déjà montré plusieurs fois, il a peur de la lumière. Quand l'incertitude le prend, il affirme un peu plus haut, comme d'autres chantent pour se donner du courage (Henri Bremond, Histoire littéraire du sentiment religieux en France)

1935 Un mieux ! Voir un peu, sortir du néant ! Il en éprouvait un choc dans la poitrine, de penser à ces choses. Il s'arrêta, affirma tout haut, dans son abstraction :

- Il me faut ces douze séances... Une espèce d'écho nasillard lui avait répondu (Maxence Van der Meersch, Invasion 14)

1956 Le 20, le colonel de Chevigné le répétait à Maccloy. Le 23, Philip et Tixier l'affirmaient très haut à Roosevelt. Le 16 novembre, j'avais été voir MM. Churchill et Eden, qui m'avaient prié à un entretien dès qu'était parvenue à Londres la proclamation de Darlan annonçant qu'il gardait le pouvoir au nom du maréchal et avec l'accord des alliés (Charles de Gaulle, Mémoires de guerre)

\section{CORPUS WEB :}

Face à la \#rumeur : "L'affirmer haut et fort va-t-il suffire à convaincre et surtout à rassurer les patients ? » [https://twitter.com/paulinerichoux/ status/705502887296765954] (7.5.2016)

" Offrir une parole et un espace pour affirmer haut et fort la présence légitime des Juifs en France » [http://www.crif.org/fr/actualites/ $\% \mathrm{C} 2 \% \mathrm{AB}$-offrir-une-parole-et-un-espace-pouraffirmer-haut-et-fort-la-pr\%C3\%A9sence-1\%C3\% A9gitime-des-juifs-en-france- $\%$ C2\%BB/55321] (7.5.2016)

L'auteur, qui emmène le lecteur au cœur des débats politico-culturels ayant façonné l'identité irlandaise depuis l'indépendance, explore la voie culturelle irlandaise unique qui se dégage des traditions intellectuelles européennes qui ont été imposées à ce pays mais ne l'ont pas éloigné d'un certain culturalisme exclusif consistant à affirmer haut et fort la spécificité de sa culture à l'heure d'une mondialisation uniformisante [https://www.unicaen.fr/puc/html/articlea639. html?id_article=800] (7.5.2016)

»Il allait ainsi, inverser la tendance et $a f$ firmer haute et fort l'émancipation de la femme [http://www.babnet.net/festivaldetail-9772.asp] (7.5.2016)

REMARQUES : Haut est un adjectif-adverbe de lieu qui a un sens spatial et désigne un point élevé. $\mathrm{Au}$ figuré, avec une interprétation de manière, il désigne l'affirmation précise d'une conviction, manifestée à voix haute, voire, d'une voix forte, de manière distincte et perceptible, voire 
de parler sans ambages. Il reste généralement invariable (ex. de 1936, et les deuxième et troisième exemples du CW, mais il porte l'accord avec l'objet dans le dernier exemple du CW) et est modifié par bien, tout, très, un peu plus. Affirmer haut peut prendre un complément nominal (exemple de 1936) ou un complément phrastique introduit par que (exemple de 1978). Notons l'occurrence des collocations haut et clair, ainsi que de haut et fort.

\section{Affonder bas}

Sombrer profondément Intransitif

+1400 Peine esmonder, Joye abonder, Tout marchander, Et dueil seder, Bas affonder, Et reffonder, Bel regarder, Voir recorder, Sanz point bourder, Pais accorder, Non descorder, Droit recorder Pour amender, En sens fonder Et perfonder (Christine de Pisan, Lays / Euvres poétiques [début Xve], I, p. 128, 80)

Remarques : Bas s'emploie comme un adjectif-adverbe de lieu qui indique la direction, partant d'un niveau supérieur vers un niveau inférieur, au sens concret et aussi au sens figuré. Il réfère ici à l'effondrement physique ou moral du sujet, celui-ci, par dépit, en raison d'une tristesse profonde, perdant toute énergie de lutter, cessant de lutter. La citation contient une série de constructions parallèles : bel regarder, voir 'vrai' recorder, droit 'correctement' recorder.

\section{Agir global}

Agir au niveau de la planète $\lambda$ penser global

\section{Agir local}

Agir au niveau local

$\lambda$ penser global

\section{Agir net}

Agir sans hésitation

Intransitif

1933 Cela vint comme un tourbillon et passa aussi vite, parce qu'Augustin vit un urgent devoir d'en arracher sa pensée. Il fallait voir clair, agir net, dans toute la partie du traitement où il était possible d'agir. Toutes ces réflexions n'avaient pas grand sens (Joseph Malègue, Augustin ou Le Maître est là)

REMARques : Net est un adjectif-adverbe de manière qui s'emploie dans une situation où le sujet passe à l'action ou prend une mesure, une décision d'une manière claire et catégorique. Il traduit une certaine détermination dans la prise de décision ou dans l'action. Notons l'emploi en série avec voir clair.

\section{Agir vrai}

Agir avec sincérité

入 penservrai

\section{Agiter bas}

I. Tourmenter, troubler, inquiéter en secret Transitif

1560 Voilà désja la foy opprimée et esteinte. Car vaguer, varier, estre agité haut et bas, douter, vaciller, estre tenu en suspens, finalement désespérer, n'est pas avoir fiance (Jean Calvin, Institution de la religion chrestienne)

1794 Écoute, jeune ami de ma première enfance, Je te connais. Malgré ton aimable silence, Je connais la beauté qui t'a contraint d'aimer,

Qui t'agite tout bas, que tu n'oses nommer (André Chénier, Élégies)

1900 Nos sens, nos sens divins sont de beaux enfants nus

Jouant aux vagues d'or des vieilles mers païennes,

Innocents, radieux, ivres, les deux mains pleines

Des fruits juteux cueillis aux jardins ingénus.

Pensive et poursuivant ses antiques chimères 
Lâme assise non loin surveille leurs ébats ; Parfois son doigt se lève et commande et, tout bas,

Elle agite en son cœur l'espérance des mères (Albert Samain, Le Chariot d'or)

\section{Remuer dans tous les sens}

Transitif

1653 Mais comme il vous souvient, cette heureuse bonace,

Changée en un moment aux tempestes fit place.

Aprez le premier choc qui la flotte écarta, Les vaisseaux que le vent vers Damiette porta,

Haut et bas agitez, souffrirent sans naufrage,

Tout ce que peut l'esprit qui regne dans l'orage (Pierre Le Moyne, Saint-Louys)

III. Être débattu, discuté

Pronominal

1850 Non, le drame ici n'est pas restreint à la vie privée, il s'agite ou plus haut ou plus bas. Ne vous attendez pas à de la passion, le vrai ne sera que trop dramatique (Honoré de Balzac, Les Paysans)

REMARQUES : Bas est un adjectif-adverbe de lieu qui exprime la direction, partant d'un niveau supérieur vers un niveau inférieur. Au sens figuré, il peut aussi être interprété comme un adjectif-adverbe de manière qui réfère à l'état secret, non-communiqué d'un fait ou d'un sentiment. Ici, il s'utilise dans les contextes suivants : En (I), il se dit d'un sentiment qui trouble, excite le sujet mais qui est dissimulé, non communiqué. En (II), dans la collocation haut et bas, il désigne le fait de branler, secouer dans tous les sens (ici : un navire). Dans son emploi pronominal (III), il réfère à une chose (ici : un drame) mise en discussion dans un groupe et qui, parfois, peut faire sujet de débat, voire de dispute. Bas est souvent coordonné avec l'adjectif-adverbe haut avec lequel il constitue une opposition sémantique désignant les points extrêmes d'un mouvement. Haut et bas sont invariables (ex. de 1653, 1900) et ils peuvent être modifiés par plus, tout.

\section{Agiter haut}

Bouleverser

$\pi$ agiter bas

\section{Aimer bas}

I. Aimer quelqu'un qui se trouve dans une situation sociale ou hiérarchique inférieure Emploi absolu

1275 Adonc li respon Blanchandine : Dame, si comme Amors destine Covient amer, soit haut ou bas Ele ne s'i regarde pas

(Floriant et Florete, 3823)

1560 Ou quand on aime bas, jamais on n'est épris (Pour estre seule à seul) de crainte d'estre pris ;

Ou bien s'on est surpris, ce n'est que moquerie Qui n'apporte jamais querelle ny furie (Pierre de Ronsard, Élégies, p. 282)

1596 Et à l'autre un beau teint donne mortelle atteinte ;

L'un transira de froid, l'autre mourra de chaud ;

L'un compare aux rochers celle qui le tourmente,

Lautre fait de sa dame une lune inconstante ;

L'un se plaint d'aimer bas, l'autre d'aimer trop haut (Philippe Desportes, Euvres)

1913 « Ne sais-tu pas qu’un poète français a dit que, pour avoir ses ébats, on devait aimer bas ? » Et voilà comme je respecte et protège celle que j'aime. Ah ! Seule, une réparation publique, éclatante ! (Valéry Larbaud, A.O. Barnabooth)

II. Aimer discrètement, secrètement Transitif

1857 Les moralistes indigènes se plaignent de tous les excès commis dans la campagne, comme un père déplore les fredaines de son fils. On le gronde tout haut, on l'aime tout bas ; on serait bien fâché qu'il ressemblât au fils du voisin, qui n'a jamais fait parler de lui (Edmond About, Le Roi des montagnes) 


\section{CORpus Web :}

En fait je prefere optique que laser puisque la sensibilité je l'aime basse, et parce que j'ai tendance à soulever ma souris (d'après le topic apprivoiser une souris, c'est important de faire gaffe) [http://www.jeuxvideo.com/forums/1-611155919-2-0-1-0-sc2-steelseries-kana-ou-razerimperator.htm] (11.11.2013)

c'est une modification qui peut se faire dans le sens inverse en + donc pour ma part celui qui l'aime basse et bien c'est son affaire et si un jour il la vend, le prochian pourra la réhausser sans rien abimer [http://e12e28.forumperso.com/ t250p120-ma-mesrine-mobil] (11.11.2013)

REMARQUES : Bas est un adjectif-adverbe de lieu qui exprime la direction, partant d'un niveau supérieur vers un niveau inférieur. En tant que modifieur d'aimer, il se prête à une interprétation de manière au sens figuré qui réfère aux sentiments qu'une personne éprouve pour quelqu'un d'autre, et à la façon de les exprimer. En (I), il désigne la situation sociale inférieure de la personne aimée. En (II), il traduit une certaine réserve dans la façon de montrer ses sentiments ou de les transmettre, c'est-à-dire de façon discrète, sans trop les dévoiler, voire les garder secrets.

Il reste invariable et est modifié par tout. Aimer bas apparaît combiné avec haut, ce qui souligne l'intensité ou le degré de la démonstration des sentiments. L'emploi comme prédicat second est possible (v. les exemples du CW dans lesquels le sens est 'de faible intensité'), et dans cet emploi, il s'accorde avec l'objet antéposé au verbe. En fait, les groupes lexicalisés aimer bas et aimer haut appartenaient à la langue ancienne où ils désignaient un comportement culturellement typé. Aujourd'hui, il ne reste plus que l'emploi en tant que prédicat second ou, éventuellement, le fait d'aimer secrètement (aimer tout bas). Notons l'emploi de gronder haut.

\section{Aimer bref}

Aimer sur une courte durée Transitif

+1400 Se vous me donnez congié

Par conseil de mesdisans,

Dame que servie j'é

Par l'espace de dix ans,
$\mathrm{Au}$ lit me mettrez gisans ;

N'oncques ne m'amastes brief,

Se vous me faites tel grief

(Christine de Pisan, Cent balades / Euvres

poétiques [début XVe], I, p. 84, 6)

CORPUS Web :

Je n'ai rien contre les scènes hot, mais je les aime brèves et suggestives [http://lesromantiques. yuku.com/topic/6652/201209-Nous-nousaimerons-demain\#.UoEFoPPkSUk] (11.11.2013)

REMARques : Bref est un adjectif-adverbe de temps qui traduit l'expression de sentiments sur une courte durée, surtout dans la langue ancienne. Bref s'utilise également en tant que prédicat second, et dans cet emploi, il s'accorde avec le sujet antéposé au verbe (CW).

\section{Aimer cher}

I. Aimer mieux

Transitif

+1200 Or me dites foit deuez

La riens q[ue] uos pl[us] ch[ier] amez

Et q[ue] die[us] ioie uos ameint

Ou la pl[us] bele dame meint

De soissons, la pl[us] bele oire

(Le Foteor, manuscrit D, 30)

1450 SIMON CRENËUS. Ha ! messeigneurs, pardonnez moy :

Pour riens jamais ne le feroye,

Car tant reprouchié en seroye

Que jamais jour n'aroye honneur.

Vous sçavez le grant deshonneur

Que c'est huy de la croix porter :

Certes, j'aymeroye plus chier

Mourir que faire tel office (Arnoul Gréban,

Le Mystère de la Passion, 24369)

1544 Mon œil feit ternir,

Mon ame finir,

Mon corps trebucher.

Mais mon maistre cher

N'a permis secher

Mon los, bruit et fame,

Car jadis plus cher

M'ayma chevaucher

Que fille ne femme

(Clément Marot, Épitaphes) 
1580 CREON. Les voici, les serpens, Les pestes, que j'aimois plus cher que mes enfans.

Avez-vous consenti à cette sepulture ?

ISMENE. Ce fut moy qui en eut la principale cure (Robert Garnier, Antigone)

II. Éprouver, par affinité naturelle ou élective, une forte attirance pour quelqu'un ou quelque chose ; accorder beaucoup d'importance, préférer de loin

Transitif

1344 LA Royne. Mon chier seigneur, s'a fait celui

Jehan que vous si chier amez, Qui vous et moy a diffamez

Si laidement.

LE Roy. Je m'en vengeray bien briément, Par Dieu qui fist et ciel et terre (Miracle de saint Jehan Crisothomes, 566)

1547 Car sache que, s'on ayme bien, On craint courroucer sa partie Aussi cher qu'on ayme sa vie (Le Conseil au nouveau marié / Ancien Théâtre françois)

CORPUS WEB :

- 14 ans : Plomb (on fait passer le message de ne pas aller voir ailleurs) -15 ans : Cristal (les goûts de merde continuent) - 16 ans : Saphir (on commence à s'aimer cher) Ah... la bourgeoisie !: 20 ans : Porcelaine (avec les goûts, les couleurs aussi sont à chier) [http://journal.gayattitude. com/2012/08/21] (14.5.2016)

ba nan avan ct pas bein komen el fezé mé mnt el a son pelo et ils s'aiment cher dc moi jrespecte ! [http://ced69lasseu.skyrock.com/profil/ wall] (14.5.2016)

Moi, mes dentifrices, je les aime chers et dégueulasses. Ouais bébé [https://twitter.com/ chamoi/status/66919385478070272] (11.11.2013)

ReMARques : Cher est un adjectif-adverbe de manière qui caractérise la valeur accordée à une personne ou une chose. Il est parfois affaibli sémantiquement (I), se rapprochant de préférer de loin. Il reste invariable, dans la plupart des cas. Il est modifié par aussi, si, plus. D’après les données de Frantext, il s'agirait d'un archaïsme de l'ancienne langue, mais le CW montre qu'aimer cher est toujours en usage. Il s'emploie également en tant que prédicat second. Dans cet emploi, il peut s’accorder avec l'objet antéposé au verbe (dernier exemple en CW)

\section{Aimer double}

Aimer deux fois plus

Transitif

1863 - Oui, cher frère, répondit Isabelle, vous la possédez, et ce m'est un bien grand bonheur que de pouvoir vous le dire. Vous avez en moi une sœur dévouée qui vous aimera double pour le temps perdu, surtout si, comme vous l'avez promis, vous modérez ces fougues dont s'alarme notre père, et ne laissez paraître que ce qu'il y a d'excellent en vous (Théophile Gautier, $L e$ Capitaine Fracasse)

1954 Quand un enfant est anormal il faut justement l'aimer double (Exemple entendu, 23 novembre 1954 / Grundt : 389)

REMARQues : Double est un adjectif-adverbe de degré qui réfère à la quantité, l'accent étant mis sur la quantité d'amour apportée à une personne, 'multipliée par deux'.

\section{Aimer ferme}

Aimer beaucoup et avec constance

Transitif

1450 JHESUS. Or te dy que jadis estoient Deux debteurs qui foison devoient De finance a ung usurier.

Les debtes de l'un qui restoient, Bien a cinq cens deniers montoient ; L'autre a cinquante en nombre entier. Or n'ont de quoy paier tous deulx Si leur quicte que riens n'y clame. Si te demande lequel de eulx Plus ferme son crediteur ame (Arnoul Gréban, Le Mystère de la Passion, 13940)

CORPuS Web :

Faire cuire les pâtes (pour ça je pense que tout le monde sait faire - personnellement je les aime ferme " al denté ») [http://www.savaou. com/pates-a-la-carbonara-pour-6-personnes] (11.11.2013)

pour les meringues

-blancs d'œufs montés en neige... pas besoin qu'ils soient super fermes, 
-50 à $60 \mathrm{~g}$ de sucre par blanc d'œuf et remélanger au batteur.

-fariner la plaque sinon ça colle et impossible à enlever

-faire des petits tas à la cuillère

four thermostat 2 ou $150^{\circ}$ pendant minimum $1 \mathrm{~h}$ si on les aime collantes ou $2 \mathrm{~h}$ si on les aime fermes [http://www.maximomes.org/forum/ printview.php?t=33994\&start $=0 \&$ sid $=61 \mathrm{fe} 45153 \mathrm{a}$ b35a419cca2717e7229166] (11.11.2013)

REMARQUES : Aimer ferme réfère à la quantité et à l'intensité dans la démonstration de sentiments, d'amour envers quelqu'un, sujet et objet étant animés. Il désigne le caractère constant de l'action. Il peut également référer à la consistance de quelque chose (ici de la nourriture). Dans ce cas-là il adopte une fonction de prédicat second, qui devrait être accordé avec l'objet direct, selon la norme, mais le premier exemple du CW reste invarié.

\section{Aimer figuratif}

Aimer, dans l'art, le genre figuratif

Emploi absolu

1960 M. Chu, chinois, peint abstrait mais aime figuratif (France-Soir, 9 avril 1960 / Grundt : 230)

REMARQUES : Figuratif réfère au goût prononcé pour un art qui s'attache à reproduire exactement l'apparence des objets représentés. L'interprétation est inférentielle puisque l'adjectif réfère à l'objet de l'amour et non pas à la façon d'aimer. Notons l'emploi de peindre abstrait.

\section{Aimer gavé}

Aimer beaucoup

Transitif

CORPus Web :

el franchemen je l'aime gavé sé ma sœur el tro belle je te fai dé gro bisous ma cheri [https: //marseillaisdu33320bogoss.skyrock.com] (4.1.2019)

elle é TJR la pr mwa elle voit dir'ect ke jvé pa bien ou si jvé bien !!! et moi je seré tjr la pr elle pask je l'aime gavé et el é belle gentil... laché dé... [https://miniprincess13.skyrock.com/2. $\mathrm{html}]$ (4.1.2019)

hoooo ma chiri calors ste mef je l'aime gavé elle me tro delire est elle est toujours la kan ta besoin d'elle de toute façon je ne vais po ecrire un roman je l'aime tout simplement [https://mllelolita.skyrock.com] (4.1.2019)

REMARQUeS : Gavé est un quantifieur en usage régional, ici du Sud-Ouest. VoIR AUSSI : gagner gavé

\section{Aimer haut}

I. Manifester un sentiment élevé et pur, différent de l'amour bas, éventuellement au sens d'un amour très fort

Emploi absolu

$\sim 1280$ En fame de tel vice esprise Ne soit ja ton entente mise : Nul ne doit tenir en chierté Fame esprise de tel fierté. D'amer haut ne t'esbahiz mie, Quer Ovide nous certefie (Vivien de Nogent, La Clef d'amour, 273)

1578 Las ! pour avoir aymé trop haut, Et n'avoir servi comme il faut, Amour ce tourment nous accorde De nous battre le sein de coups, Et vous crier à deux genoux Mercy, pardon, misericorde (Pierre de Ronsard, Mascarades, p. 190)

1629 CARDENIO. Pardon, chaste deesse, à mes voux innocens :

Si vous estes divine, il vous faut des encens,

Et si j'aime trop haut, accusez la nature Du pouvoir de vos yeux et du mal que j'endure.

Je ne pouvois, ma sainte, ensemble à vostre aspect Avoir l'ame sensible et garder le respect (Pichou, Les Folies de Cardenio)

1648 Aussi bien de vostre œil vous pourrez captiver

Les dieux les plus puissants et plus remplis de gloire,

Mais sans aimer trop haut, je desire trouver Mes lauriers asseurez en petite victoire (Nicolas Vauquelin des Yveteaux, Euvres poétiques)

1724 Pour moi, depuis que je ne sais plus aimer, il me semble que mon âme n'est plus qu'un 
faible reste de ce qu'elle était autrefois. Cependant je ne me plains point de l'amour, car, s'il m'avait laissé un cœur sensible, il m'aurait peut-être fait aimer si haut, qu'il m'aurait fallu mourir plutôt que d'avouer mon secret (Montesquieu, Correspondance)

II. aimer tout haut : aimer publiquement, ouvertement, au grand jour

Transitif

1879 Quel bonheur que j'aie été blessé et que je sois couché dans ce lit ! Je n’aurais jamais su qu'il m'aimait. Ah ! je crois qu'on eût mieux fait de m'aimer tout haut ! Il me semble qu'il me restera toujours, de ma vie d'enfant, des trous de mélancolie et des plaies sensibles dans le cœur! (Jules Vallès, Jacques Vingtras : L'Enfant)

\section{CORPUS WEB :}

Nous avions envie de sortir et de nous promener main dans la main, de flâner en amoureux dans les endroits publics, de nous aimer haut et fort à toute heure du jour [http://www.ellequebec. com/societe/psycho/j-etais-amoureuse-dun-homme-de-20-ans-mon-aine/a/25369/2 (15.5.2016)

je tends mon verre pour une goutte champagne.. le temps de trinquer pour tous ceux qui s'aiment haut et fort !!! [https://nelhia777. wordpress.com/2010/12/30/poesie-pour-lesamoureux] (15.5.2016)

Le romantique n'a t-il pas la trique quand il aime la femme par les mots ? Mais est ce qu'il l'aime haut comme ses mots ? [http://answers. yahoo.com/question/index?qid=20111221055419 AAnXMGO] (11.11.2013)

Certains l'aime haute, d'autres basse, les classique blanche et bleu, et les plus fun en rose, menthe à l'eau ou léopard, la converse est une institution, à la base destiné aux collégiens mais vite adopté par les fashionnistas la trentaine bien rempli ! [http://bigdollsboudoir.blogspot. co.at/2013/06/du-cas-de-la-converse.html] (11.11.2013)

REMARQUES : Haut est un adjectif-adverbe de lieu qui exprime la direction, partant d'un niveau inférieur vers un niveau supérieur. En tant que modifieur d'aimer, il se prête à une interpréta- tion de manière au sens figuré qui réfère (I) à des sentiments d'amour supérieurs, souvent secrets, opposés au désir de les exprimer, voire de les réaliser charnellement (amour bas). L'amour haut cristallise ainsi un idéal culturel lié à une époque. Dans l'exemple sous (II), cet idéal est réduit au fait de manifester ouvertement son amour. Cette acception est marquée par la collocation tout haut. En tant qu'adverbe, il reste invariable et est modifié par si, tout, trop. Les deux premiers exemples du CW expriment l'intensité de l'amour, notamment par la collocation haut et fort et l'emploi pronominal du verbe. Aimer haut apparaît parfois combiné avec bas (v. aimer bas). Le troisième exemple du $\mathrm{CW}$ renoue avec la valeur morale qu'avait aimer haut au Moyen Âge, mais l'emploi de trique 'pénis en érection' crée tout de même un contexte ambigu. L'emploi comme prédicat second fléchi est possible, comme dans le quatrième exemple du CW, où il réfère à une marque de chaussure en vogue (la Converse).

\section{Aimer moyen}

Aimer moyennement, plus ou moins

Transitif

2000 Les sous-chefs se mettent à prendre la parole à tour de rôle pour donner leurs commentaires : « j'aime moyen », «j'adhère plutôt », «je suis pas hyper-convaincu même si je saisis bien l'idée ", "c'est une piste à investiguer » (Frédéric Beigbeder, 99 francs)

2012 J'aime moyen coucher avec les garçons (corpus de films français / Bedijs 2012 : 251)

VOIR AUSSI : apprécier moyen

\section{Aimer petit}

Aimer peu

Transitif

-1200 Voit le li cuens, si le contrala : Par dieu, vasal, molt petit vos ama, Ki a Guillame joster vos envoia, Celui d'Orenge, ki ja repos n'avra (Aliscans [fin $\mathrm{XII}^{\mathrm{e}}$ ], 2188)

+1200 Quant li rois ot oi toute sa naissance et son estre, il dist a Merlin : «Merlins, tu amas 
moult mon pere et moult li fus loiaus, et il ne t'amoit mie petit. Tu sés de mon afaire plus que tout cil dou monde" (Merlin [1 $1^{\text {er }}$ quart XIII'], p. 162)

+1216 Par Mahomet qui tot fist et forma, Saces de voir que moult petit t'ama Qui ce vert elme en ton cief te laça ; S'adont te vit ja mais ne te verra, Et s'il te voit grans pités l'en prendra (Huon de Bordeaux, 5537)

\section{CoRpus Web :}

On a un pâton pas beau qu'on aplatit avec les mains, plus ou moins selon qu'on l'aime petit ou qu'on l'aime gros [http://fasgianu.eklablog. com/mco-236-le-fly-et-autres-bonnes-petiteschoses-a119389192] (15.5.2016)

Perso, la courgette je l'aime petite et crue, avec son croquant, ses vitamines, sa légère âpreté... cuite, je la trouve sans grand intérêt gustatif... [http://paladar-lepet.blogspot. co.at/2011_08_01_archive.html] (15.5.2016)

REMARQUeS : L'ancien français employait petit comme quantifieur au sens de 'peu'. Aimer petit réfère donc à un amour de faible intensité. Petit est modifié par moult ou la négation mie. Historiquement, moult (< lat. multum / multō) est aussi un adjectif-adverbe. Aujourd'hui, seul l'emploi comme prédicat second semble possible ; petit adopte alors son sens concret 'contraire de grand' et s'accorde avec l'objet antéposé au verbe (CW).

\section{Aimer plein}

aimer tout plein : aimer beaucoup, énormément Transitif

1546 Cor Dieu je le croy. Ce sera d'un beau petit enfantelet qu'elle sera grosse. Je l'ayme desja tout plein, et ja en suis tout assoty (François Rabelais, Tiers Livre)

1594 Ce sont bons Princes et bons Catholiques, et qui vous ayment tout plein (Satyre Ménippée)

1863 - Oh ! Je l'aime déjà tout plein. J'en suis féru ; il me la faut et je l'aurai, dussé-je pour y parvenir user des inventions les plus subtiles, vider mes coffres et pourfendre cent rivaux (Théophile Gautier, Le Capitaine Fracasse)
1882 - Vingt francs, vous savez bien ce que c'est que vingt francs, ne faites pas la bête, reprit Berthe. Donnez-nous vingt francs, et nous vous aimerons, oh! Nous vous aimerons tout plein ! (Émile Zola, Pot-Bouille)

1906 J'attends pour bientôt une lettre de vous, mon cher Monsieur l'Abbé, une lettre de réconciliation, et je vous promets d'y répondre dans les six jours. Ergo... croyez que je vous aime tout plein. Georges (Georges Bernanos, Lettres inédites)

\section{Corpus Web :}

hé, il est sympa ce Psyclon! très yelworC, mais la petite dimension cybergremlin ultravénèr ridicule décomplexé par-dessus est assez sympax, un petit côté happy hardcore d'épouvante, je commence à l'aimer tout plein, je sais pas si ça va durer... [http://www.gutsofdarkness. com $/$ god $/$ forum.php? page $=5 \&$ sujet $=14035$ ] (15.5.2016)

Virtuellement on peut aimer tout plein tout plein. Aucun risque de contamination vénérienne de rienne [http://www.auberge-espagnole. org/sources/voir_debat.php?no_debat=7464] (15.5.2016)

J'espère qu'elles vont vite trouver une bonne famille pour les aimer tout plein [http://www. clicanimaux.com/collecte-3100-sos-transport5-chiennes-a-sauver-avant-vendredi-soir-] (15.5.2016)

\section{Son envie m'électrise}

Mes bas frottent le haut de mes cuisses

Il les aime pleines

Et, à chaque marche, son désir, je le devine [http://www.lespoemes.com/forum/poeme-ero tique-f20/les-escaliers-t37325.html] (11.11.2013)

Remarques : Plein est un adjectif-adverbe de manière qui caractérise un sentiment qu'on éprouve pour une autre personne de manière entière et profonde. Plein exprime ainsi une intensité forte. Notons l'emploi absolu dans le deuxième exemple du CW. Toujours modifié par l'adverbe d'intensité tout, il reste invariable. Plein s'utilise également en tant que prédicat second accordé avec le sens 'rondes, charnues' (dernier exemple du CW). 


\section{Aimer profond}

Aimer profondément, beaucoup

Transitif

1285 Maintenant, se Dieus me consaut, Ai nonmee une qui mout vaut ; Dont me couvient l'autre nonmer. A ! Dieus, tant par font a amer ! (Adenet le Roi, Cleomadés, 18566)

1976 Par exemple, l'idée que nous communiquons essentiellement par les mots : les femmes que j'ai aimées profond ou désirées vif, les sculptures, tableaux, objets, musique qui m’ont touché, les chats qui ont daigné vivre près de moi, m'ont persuadé du contraire. Qui peut traduire en clair, déchiffrer dans toutes ses significations le message d'une koré du $\mathrm{VI}^{\mathrm{e}}$ siècle ? (Claude Roy, Somme toute)

\section{CORPUS WEB :}

Et elle n'a pas compris pourquoi je n'avais pas fait de gâteau au chocolat à son frère alors même qu'elle m'avait dit qu'elle m'aimait profond du cœur [http://la-tribu-de-juju.net/2016/01/ tablette-clempad-5-0-chat] (15.5.2016)

Toujours aussi créatifs ses « délires » et son « Deep » ne déroge pas à la règle, alors je l'aime profond !!! son nouveau titre « obsessionnel » [http://www.zikpot.fr/artiste-G.ENJOY] (15.5.2016)

moi j'ai un ptit de 4ans qui m'a dit qu'il m'aimait profond ds son cœur jusqu'au ciel ! [http:// www.notrefamille.com/forum/Thematiques/ Papotages-(autres-sujets])/J-en-ai-de-lachance-t1010626.aspx (15.5.2016)

Et le Kréol dit « Amen », je l'aime profonde et sans vaseline [http://www.zinfos974.com/ Carburant-Les-arretes-interministeriels-signespar-trois-ministres_a67805.html] (15.5.2016)

Pour les canards c'est juste que je les aime profonds et n'ayant que des planches à faible volume, j'ai peur d'être dérangé, même dans $1 \mathrm{~m}$ ça peu parfois bien secouer sur un canard planté sans suffisamment de conviction :D et pas trop fan de reculer de 2 mètres à chaque mousse $: P$ [http://www.shaperoom.net/forum/viewtopic. php?f=10\&t=6739\&hilit=demandais\&start=30] (11.11.2013)
REMARQues : Métaphore à base conceptuelle locale, profond (parfont) est un adjectif-adverbe de manière qui caractérise un sentiment éprouvé par son intensité et sa durée. Profond s'utilise également au sens concret en tant que prédicat second accordé (deux derniers exemples du CW). Notons l'emploi de désirer vif.

\section{Aimer vrai (voir) \\ Aimer sincèrement \\ Transitif \\ 1200 B[ie]n sai me fe[m]me n'est pas fole \\ Mais voist souuent a la carole \\ A tout iours mais voir l'amerai \\ A nul iour mais nel mesq[ue]rrai \\ (Auberee, 739)}

\section{CORPUS WEB :}

Aimer vrai, aimer sans vouloir " posséder ». Aimer sans attacher mais au contraire en laissant l'autre libre d'exister en dehors de soi [https:// fr-fr.facebook.com/retouralasourcelnd/photos/a. 275583005933542.1073741830.275254235966419/5 84715301686976/?type=3\&theater] (16.5.2016)

Alors je crois que j'ai pas fini de vous aimer les copines et les amies et que je vais commencer à bien vous aimer, à vous aimer vrai [http://forum. psychologies.com/psychologiescom/rencontreset-seduction/aimer-vrai-sujet_4425_1.htm] (16.5.2016)

C'est d'ailleurs, le plus bel héritage que nous pouvons léguer à nos enfants, de les aimer "vrai » tel qu'ils sont, tel que nous sommes [http://coachingpnlfamilial.ca/article-disp. asp?i=7] (16.5.2016)

ohh ! j'adore..la 1 et la 3 c'est la simplicité de la vie que j'aime vraie sans sophistication.. s'asseoir et contempler en cessant les idées.à deux bien sûr c'est mieux [http://c-est-pas-lui.overblog.com/article-divagations-109550265.html] (11.11.2013)

REMARQues : Vrai est un adjectif-adverbe de manière qui caractérise la façon dont quelqu'un montre ou exprime ses sentiments : de façon conforme à la réalité, sans rien dissimuler, sans chercher à mentir et d'une manière incontestable, authentique. Vrai s'utilise également en tant que prédicat second (deux derniers exemples du CW). Dans l'avant-dernier exemple du CW, il réfère à 
l'authenticité du sentiment, au fait d'aimer quelqu'un tel qu'il est. Aimer vrai y est employé comme verbe complexe invarié, comme une sorte de formule. Par contre, l'accord est fait dans le dernier exemple du CW.

\section{Ajourner clair}

Assigner quelqu'un en justice, le citer officiellement, publiquement à comparaître à un jour déterminé devant un juge, un tribunal Transitif

+1100 Ainz que seit jurz mult lur est tart ;

A grant greine, a voiz truble,

Dïent que avrat peine duble.

Respunt l'abés : « Ne avrat turment

Plus que ad oüd par jugement. »

Et puis qu'il fud cler ajurnét,

Od tut Judas s'en sunt turnt

(Benedeit, Voyage de saint Brendan

[1 ${ }^{\mathrm{er}}$ quart XII $\left.\left.{ }^{\mathrm{e}}\right], 1491\right)$

\section{Ajouter bas}

Ajouter à voix basse

Transitif

1656 Et il [= le père Filiutius] y donne encore [...] un autre moyen plus sûr d'éviter le mensonge. C'est qu'après avoir dit tout haut, « Je jure que je n'ai pas fait cela », on ajoute tout bas : « aujourd'hui », ou qu'après avoir dit tout haut, "Je jure », on dise tout bas, " que je dis »; et que l'on continue ensuite tout haut, " que je n'ai point fait cela ». Vous voyez bien que c'est dire la vérité (Blaise Pascal, Les Provinciales)

1743 L'envie de plaire est l'aurore qui annonce l'arrivée de l'amour dans le cour d'une jeune personne ; aussi se faisoit-il déja sentir dans celui de cette aimable demoiselle. La premiere parole qu'elle dit au fils d'Effendi, fut qu'elle étoit charmée de le voir. Elle ajouta tout bas, que c'étoit son absence qui l'avoit mise dans l'état où il la voyoit (Claude Godard d'Aucour, Mémoires turcs)

1784 Et en-effet, nous avons-su par-après que c'était deux hommes de $\mathrm{V}$ qui passaient, dont l'un avait-demandé à l'autre, si son fils reviendrait bientôt de l'armée ? Ce- lui-ci avait-répondu avec force (car il avait-appris la mort de son fils la veille) Jamais ! ajoutant plus bas : Il est mort (Nicolas Rétif de la Bretonne, La Paysanne pervertie ou Les dangers de la ville)

1805 - Hélas ! répliqua-t-il, hier encore, j’aurois envié de si vifs témoignages d'affection, mais aujourd'hui, je n'ai de place dans mon ame que pour un seul désir : voir Mathilde un moment, lui dire un mot...

- Dites-le-moi, interrompit la reine, je vous assure qu'il ne sera pas perdu pour elle.

- Non, madame, répondit Malek Adhel, elle seule doit l'entendre.

Bérengère ayant regardé si son époux ne l'observoit pas, fit un geste de la main, pour désigner le rideau qui les séparoit de l'alcôve de l'oratoire, en ajoutant très-bas et très-vite :

- Eh bien ! Je vais me reculer, et elle seule vous entendra (Sophie Cottin, Mathilde)

1848 - Quoi?

- Mon piano, qui joue tout seul, ut, la mi ré do, la si sol ré. Gredin de ré, va ! Il sera toujours faux.

- Mais ce n'est pas chez vous, sans doute, lui dit Rodolphe, qui ajouta bas à l'oreille de Colline sur qui il appuya lourdement, il est gris

(Henri Murger, Scènes de la vie de bohème)

1877 L’abbé s'élança au-devant de Lucie en lui disant à voix basse :

- Au nom du ciel, ne faites pas ce scandale...

Et il ajouta encore plus bas :

- Si les malédictions que votre mariage attire sur ma tête excitent en vous quelque compassion...

(George Sand, Mademoiselle La Quintinie)

1884 Voici comment j'en ai parlé, le 30 avril 1877, devant l'Académie des sciences : « Dans un mémoire remarquable, le docteur Koch a constaté que les petits corps filiformes découverts par M. Davaine peuvent passer à l'état de corpuscules brillants après s'être reproduits par scission, puis se ré- 
sorber... » et plus bas, j'ajoutais : "On doit penser que ces corpuscules peuvent survivre d'une année à l'autre sans périr, prêts à propager le mal » (Louis Pasteur, Correspondance)

1904 - Qu'est-ce que tu apportes là ?

- Du lait, Rose.

Elle ajoutait tout bas : «Quatre sous de lait pour eux cinq, il n'y en aura pas assez pour les faire dormir ; quatre sous d'absinthe, y en aura assez... Dodo, l'enfant do... » (Léon Frapié, La Maternelle)

1924 - Une femme, vois-tu, doit recommencer de séduire son mari tous les jours. Il faut supporter d'être la maîtresse ou qu'il y ait une maîtresse à côté de soi.

Maman Lecœur ajoute presque bas :

- Pincengrain est un homme supérieur. Il avait sans doute droit à autre plaisir. Mais la Gerboise est vraiment moins que rien (Marcel Jouhandeau, Les Pincengrain)

1926 Pour la première fois je prends la main que j'aime, je l'embrasse. Voyez comme mon geste est sûr, comme ma main est forte, comme elle vous tient pour toujours...

Tout bas elle ajoutait :

- Vous me briseriez, si vous vouliez!

Puis, tout haut :

- Je ne sais pourquoi les autres vous aiment. Je ne sais pourquoi l'on aime (Jean Giraudoux, Simon le Pathétique)

1936 Elle songeait à la fin solitaire de Jérôme. Ses yeux s'emplirent de larmes. Elle fit une courte pause et ajouta, bas, comme pour elle-même : "Seule, avec l'Esprit » (Roger Martin du Gard, Les Thibault. L'Été 1914)

1948 Sylvaine s'écroula dans les bras de son amie en disant :

- Ma pauvre chérie! Toujours si bonne, si dévouée. Et plus bas elle ajouta :

- Tiens-toi, hein ? Je t'en supplie!

Lulu faisait attention à ne pas mettre les pieds dans les flaques d'eau (Maurice Druon, Les Grandes Familles)

1962 Il regarda de nouveau vers la femme qui s'était mise à marcher lentement sans sortir de la clarté du lampadaire ; il soupira et, très bas, il ajouta :

- Les putains ne sont pas toujours sur les trottoirs. Et puis, une putain, est-ce qu'on sait jamais pourquoi elle est putain ? (Bernard Clavel, La Maison des autres)

1997 - Y s'croit invulnérable, mon capitaine, dit le cuirassier Brunel en sautant à cheval. - Assez de sornettes ! grogna SaintDidier, qui ajouta plus bas à l'intention de Lejeune : Je ne peux pas leur en vouloir, la mort de notre général les a secoués...

Fayolle ferma sa cuirasse et Lejeune le regardait (Patrick Rambaud, La Bataille)

\section{CORPuS Web :}

On ne peut donc que se réjouir d'entendre notre Premier ministre nous promettre haut et fort « la réforme fiscale ». Et se désoler qu'il doive ajouter tout bas qu'elle prendrait dix ans [http://www.lettreducadre.fr/7738/vive-limpot] (16.5.2016)

Ce qui fait dire à nos économistes en vue : " nous avons été naïfs... », et d'ajouter tout bas : « ... et nous le resterons ! » [http://huma niterouge.alloforum.com/message.php?cate gorie $=625 \& \mathrm{msg}=3828](16.5 .2016)$

Ces derniers mots furent ajoutés tout bas, comme s'il craignait que sa remarque ne fût entendue par son meilleur ami [https://www. fanfiction.net/s/4830734/4/Lemon-Incest] (16.5.2016)

REMARQues : Bas est un adjectif-adverbe de lieu qui, dans l'emploi figuré, devient un adverbe de manière qui désigne le volume d'une voix faible. Ajouter bas se dit de l'ajout de paroles caractérisé par un abaissement de la voix par pudeur ou pour ne pas être entendu de personnes non concernées. Il reste invariable et est modifié par encore plus bas, plus, presque, tout, très. Il s'oppose à dire tout haut / dire tout bas (exemple de 1656) et à promettre haut et fort (premier exemple $\mathrm{du}$ CW). VoIR AUSSI : dire / parler haut

\section{Ajouter haut}

Ajouter à voix haute

Transitif

1667 Lorsqu'il y fut arrivé, il lui dit en présence de toute la cour : 
- Pourquoi pensez-vous que je vous ai envoyé querir?

- Je n’ai garde, Sire, de le savoir, lui répondit-il.

- Ce n'est, dit le Roi, que pour vous entretenir ; et ajouta tout haut : Je veux bien que tout le monde sache que voilà l'un des hommes de mon royaume que j'estime le plus (Robert Arnauld d'Andilly, Mémoires)

1751 Je parierois ma vie, a-t-elle ajouté assez haut pour me le faire entendre, qu'il est entré autant d'humeur que de mal de tête dans le refus qu'on a fait de voir un homme si respectable. Mon dieu! Que de gens qui se plaignent d'autrui, dont le bonheur dépend d'eux-mêmes ! (abbé Prévost, Lettres angloises [trad.])

1832 - Ma foi, je ne sais pas. Ce que j’ai de mieux à faire, continua-t-il à demi-voix et se parlant à lui-même, c'est, je crois, d'aller au fond de la rivière ou de me faire sauter la cervelle.

- Vous êtes d'heureux coquins, vous autres, ajouta-t-il haut, vous êtes à l'abri de ce qui me tue aujourd'hui

(Alphonse Karr, Sous les tilleuls)

1859 La somnambule hésita longtemps.

- Oui... oui... dit-elle tout à coup... je vois un homme grand... brun.

- Armand, pensa Baccarat. - Et elle ajouta tout haut :

- Pense-t-il à moi ?

- Non

(Pierre-Alexis Ponson du Terrail, Rocambole)

1876 Il ajouta plus haut :

- Enfin, on a besoin de tout le monde, venez vite. M. de Lamberthon s'était précipité vers la salle des séances (Émile Zola, Son Excellence Eugène Rougon)

$1881-$ Tu es donc devenu fou ? me dit tout bas Alexandrine, qui vient de rentrer et me tire par les basques de ma redingote, - et tout haut elle ajoute : " Tenez, monsieur Vingtras, voilà ce qu'on en fait, de ceux qui veulent délivrer leurs frères! » (Jules Vallès, Jacques Vingtras : Le Bachelier)
1885 - N'empêche, ajouta très haut Chaval d'un air de défi, que si ce cochon de Dansært me parle sur le ton de l'autre jour, je lui colle une brique dans le ventre... je ne l'empêche pas, moi, de se payer les blondes qui ont la peau fine (Émile Zola, Germinal)

1928 Geneviève lutte contre une seule idée : il ne sait pas... et le regarde avec étonnement. Elle ajoute tout haut :

- Je suis venue...

et passe sa main sur son front. Les vitres blanchissent, versent dans la pièce une lumière d'aquarium. « La lampe se fane », pense Geneviève

(Antoine de Saint-Exupéry, Courrier Sud)

1947 Et les petits vautours, au réfectoire, après avoir envoyé au pain sec contre le mur une cloche qui faisait du bruit avec ses sabots, ajoutaient très haut :

- Ça se laisse taper dans la lune, et ça fait du boucan. Cette outrecuidance magnifique empêchait sourires et révoltes (Jean Genet, Miracle de la rose)

1950 - Oui, reprit-il avec gaucherie, tu as raison : nous croyons les mêmes choses. Je te remercie d'avoir dit cela.

- Bonsoir, Joseph, fit David.

Il ajouta un peu plus haut, comme Joseph traversait la rue :

- Pense à la réponse que tu dois me donner (Julien Green, Mö̈ra)

1951 - On n'en parlera plus : je m'arrangerai ! conclut enfin le fermier qui ajoute, très haut : « Allons, ouste ! Rentrons. Le serein va tomber.»

Simon se penche, démonte la petite fourche qui calait sa gaule, arrache vivement sa ligne (Hervé Bazin, Le Bureau des mariages)

1958 - Non, ajouta-t-il un peu penaud, il n’y avait pas de papiers.

- Et le chargement?

- Des livrets matricules, ça doit être, mon yeutenant, fit-il d'un air gêné. Des pleines caisses de livrets matricules.

Il ajouta entre haut et bas :

- Il y en a sûrement pour toute une division (Julien Gracq, Un balcon en forêt) 
CORPUS WEB :

$\mathrm{Vu}$ comment elle était habillée, elle n'était même pas apte à se rendre à la réserve toute seule. "Franchement... une robe blanche..." J'ajoute, tout haut, parce que je trouve ça... dingue ! Dans dix minutes, elle allait être marron clair sa robe ! [http://givingforafrica.forumactif. org/t442-la-boite-a-rps-lily-euphemia-can-youhelp-me] (16.5.2016)

- Elle « Je vais voir»

- Moi, dans ma tête " ben ouais ce serait cool de ta part, vu qu'on s'apprête à cramer la $\mathrm{CB}$ » et j'ajoute tout haut « et des bas pour essayer sivouplé » trop tard, elle est déjà repartie [http://blogs. lexpress.fr/styles/paris-by-light/2012/03/17/ louboutin-comme-des-chiens] (16.5.2016)

Tu comptes sur tes doigts dix fois puis tu dis tout haut " dix ». Et tu continues une nouvelle dizaine. Tu ajoutes tout haut « vingt» ! Etc. [http:// pouvoirdespierres.forumpro.fr/t9813p325-la-loide-l-attraction-2eme-partie] (16.5.2016)

REMARQUeS : Haut est un adjectif-adverbe de lieu qui a un sens spatial et désigne un point élevé. Dans l'emploi figuré, il devient un adverbe de manière qui désigne le volume d'une voix. Ajouter haut se dit de l'ajout de paroles caractérisé par un haussement de la voix de manière à être entendu. Haut reste invariable et est modifié par assez, plus, tout, très, un peu plus. Notons la collocation ajouter entre haut et bas.

\section{Alever droit}

Lever, élever selon une ligne droite, verticale Transitif

1365 Se ie ne sentoie de mi humblement. mais ai mon arme outre que droit alleueit ; Ensicom cilz qui est de sa meire seureiz. ensi soit li retribution et li paiement de mon arme (Psautier lorrain, p. 134)

REMARQUES : Droit est un adjectif-adverbe de direction-manière qui indique la façon d'avancer, de pointer dans une direction.

\section{Aller aigu \\ Monter dans les aigus (la voix) \\ $\pi$ aller bas}

\section{Aller aise}

Se déplacer facilement, avec agilité, aisance Intransitif

1170 Qui mellor quiert, ne set qu'il viaut. Qui le chevauche, ne se diaut, Ainz va plus eise et plus soef Que s'il estoit an une nef (Chrestien de Troyes, Erec et Enide, 1401)

REMARQues : Aise est un adjectif-adverbe de manière qui caractérise le mouvement d'une personne se déplaçant sans difficultés, comme un navire glissant sur l'eau. L'adjectif-adverbe soef ajoute l'idée de tranquillité à l'action. L'emploi adverbial de aise et soef appartient à l'ancien français.

\section{Aller bas}

I. Tomber, au sens figuré, jusqu'au point de non-retour

Intransitif

1403 Encor y a un autre point, Qui trop vient a ceulx mal a point, Car tout ce qu'ilz auront cuidé, Qui au monter leur ait aidié, Cherra sur eulx au devaler, Qui si bas les fera aler Que jamais n'en releveront (Christine de Pisan, Le Livre de la mutacion de fortune, I, 3094)

1624 Mais Dieu veut qu'Angoulesme soit la fatale retraicte des affligez, et tout bien consideré, ce n'est pas aller fort bas que de tomber sur une montagne. Aussi certes, s'il y a quelque chose à redire en l'administration des Finances, on ne peut pas le blasmer d'avoir fait le mal (Jean-Louis Guez de Balzac, Les Premières Lettres)

1937 On est bien, au fond de l'abîme. Il est doux de penser qu'on ne peut aller plus bas. Quel repos dans la profondeur! Quelle paix dans le parfait désespoir ! (Georges Duhamel, Le Désert de Bièvres)

1995 Depuis deux ans il avait dégringolé par paliers : une suite de marches, puis chaque fois une plate-forme qui lui donnait l'illusion qu'il n'irait pas plus bas ; mais la plate-forme était trop courte, l'élan trop 
grand - la chute continuait. Le nouveau ministre ne fit plate-forme qu'un mois (Françoise Chandernagor, L'Enfant des Lumières)

II. la bannière va bas en cent ans : la destinée peut basculer irréversiblement à tout moment Intransitif

-1465 Chacun dira Mal

Contre luy, jurera, mesdira, Maulgrera Dieu qui luy contredira ; Parjuremens, blasphemes redira ;

C'est la maniere

Comme va bas en cent ans la baniere Et le paisant tenant vertu planiere Boit o les roys d'Anjou et de Trosniere Et aultres vins (Jean Meschinot, Lunettes des princes, p. 83, 1759)

III. s'en aller bas : disparaître, tomber dans l'oubli

Pronominal

1550 Qu'ainsi soit, je vous prie, s'il ne plaist aux hommes de croire à Dieu, fauldra-il que sa verité s'en aille bas? Mais plustost, comme dit sainct Paul, que l'homme demeure menteur tel qu'il est, et que ceux ausquels il plaist à Dieu se reveler le tienent pour veritable (Jean Calvin, Des scandales)

1953 Le lièvre court pour mettre un point Au regard fixe de la chouette L'araignée ne fait qu'une toile Utile ou inutile un grenier une ruine Je me sens m'en aller très bas Très haut très près très loin très flou Et net immense et plus petit Que le ciel amassé pour moi J'imite le plus machinal Des gestes d'un lieu dit la terre (Paul Éluard, Poésie ininterrompue)

IV. Tomber, se placer à un niveau inférieur, dans une échelle hiérarchique

Intransitif

1610 C'est pourquoy il ne faut pas aller trop haut par des parolles enflees, superbes et distraictes de la facilité : car cela est trop obscur, fardé, broüillé et pedant : comme aussi il ne faut point affecter la simple façon du langage plus commun, de peur qu'en le recherchant on ne se treuve d'aller trop bas, et de ramper sur la terre comme les animaux plus infirmes (Pierre de Deimier, L'Académie de l'art poétique)

1636 Dernier precepte de la conversation des esgaux.

À ces trois maximes j’ajouste pour dernier et general precepte, que jamais il n'entreprenne d'entretenir personne pour luy plaire, qu'il n'ait premierement bien consideré son humeur, ses inclinations, et de quelle trempe il a l'esprit : afin de n'aller point plus bas, ny plus haut qu'il ne faut, mais de l'accompagner de si près, que tous ses discours s'ajustent à sa portée (Nicolas Faret, L'Honneste Homme)

1891 Par chacun de ces mots on m'évoque, on m'adjure,

Et tantôt c'est louange, et tantôt c'est injure.

Je suis l'esprit Milieu ; l'être neutre qui $v a$ Bas sans trouver Iblis, haut sans voir Jéhovah ;

Dans le nombre, je suis Multitude ; dans l'être,

Borne. Je m'oppose, homme, à l'excès de connaître (Victor Hugo, Dieu)

1926 Toutes ces circonstances extérieures qui nous empêchent de nous rencontrer sont bien étranges. D'ailleurs avec le diable on peut aller très bas, mais jamais très loin (Paul Claudel et André Gide, Correspondance)

1943 L'énergie libérée par la disparition d'objets qui constituaient des mobiles tend toujours à aller plus bas. Les sentiments bas (envie, ressentiment) sont de l'énergie dégradée. Toute forme de récompense constitue une dégradation d'énergie (Simone Weil, La Pesanteur et la grâce)

V. Considérer des choses inférieures du point de vue social, moral, intellectuel, spirituel Intransitif

1844 Un garçon intelligent et sobre, qui aurait commencé l'escompte avec un très petit capital, comme Mlle Thuillier, achète alors un quart de charge d'agent de change. 
Allons plus bas ! Un petit clerc est notaire, un chiffonnier a mille écus de rentes, les plus malheureux ouvriers ont pu devenir fabricants (Honoré de Balzac, Les Employés)

CORPuS Web :

Marché : On peut aller plus haut avant d'aller plus bas.... [https://leblogalupus.com/2015/08/27/ marche-on-peut-aller-plus-haut-avant-dallerplus-bas] (18.5.2016)

Elle allait bas, très bas et les deux autres concurrents avaient renoncé à sa poursuite [https://www.wattpad.com/158718389-harrypotter-nouvelle-g\%C3\%A9n\%C3\%A9ration-4james-sirius/page/3] (18.5.2016)

Elle a une grande tessiture, elle va bas ET haut, je maintiens qu'elle va bien aigu [= la voix] [http://www.beaute-test.com/forums/index. php?topic=259525\&start=165] (18.5.2016)

Avoir la capacité de tracer des points élevés et à la fin d'acquérir des informations sur la tendance du marché, si elle va basse ou haute [http://www.investplus.org/strategies-debu tants-a03626677.htm] (11.11.2013)

REMARQUES : Bas est un adjectif-adverbe de lieu qui indique la direction, partant d'un niveau supérieur vers un niveau inférieur. Au sens figuré, il peut aussi être interprété comme un adjectifadverbe de manière qui réfère à l'état d'âme ou à la situation sociale d'une personne. (I), généralement utilisé dans une négation, décrit la chute du sujet, au sens figuré, caractérisée par un point de non-retour (au plus bas). (II), expression imagée certainement inspirée du proverbe Cent ans bannière, cent ans civière dans lequel bannière représenterait la destinée qui, comme dans une guerre, peut s'écrouler rapidement et inexorablement. (III) exprime métaphoriquement le fait de partir au-delà, donc ne plus exister sur Terre, de disparaître. (IV) s'emploie pour décrire un déclin, une chute vers le bas, dans une échelle hiérarchique, dont le résultat est généralement négatif. (V), dans une suite d'énonciations, exprime une descente pour le sujet qui les considère comme inférieures. Bas reste invariable et est modifié par fort, plus, si, très, trop. Le troisième exemple du $\mathrm{CW}$, qui réfère à la voix humaine, contient aussi les adjectifs-adverbes aigu et haut, ce dernier constituant le contraire de bas, ce qui en renforce le sémantisme par l'opposition. Dans le dernier exemple du CW, le verbe aller s'emploie comme copule; bas et haut s'accordent alors avec le sujet.

\section{Aller beau (bel)}

I. Se déplacer, avancer avec distinction, avec élégance

Intransitif

$\sim 1209 \mathrm{Si}$ lor prie et mande par nons Que, se Dex les deffent d'anui, Qu'il soient tuit encontre lui A Sainteron sanz nule faille Et que chascuns plus bel i aille Et miex acesmez qu'il porra (Jean Renart, Roman de Guillaume de Dole, 1948)

+1250 Puis conmande que l'en atort Bel e cortoisement la cort. Quant il out tot ce conmande, Si est tot meintenant monte Et avocques li de sa gent Tant qu'il s'en va et bel e gent (Le Roman de Renart [2 $2^{\mathrm{e}}$ moitié XIII $]$, XIII, 672)

II. Aller bien, seoir, convenir parfaitement Intransitif

-1377 Et pour ce que n'estoie mie Toudis en un point, m'estudie Mis en faire chansons et lais, Balades, rondiaus, virelais Et chans, selonc mon sentement, Amoureus et non autrement ; Car qui de sentement ne fait, Son ouevre et son chant contrefait. Ne moustrer aussi ne pooie Les maus d'amours que je sentoie A ma dame qui en chantant Me va si bel comme enchantant (Guillaume de Machaut, Remède de Fortune, 412)

III. Aller, courir avec agilité Intransitif

1389 Et aussi les chienz n'en peuent mie si bien assentir comme font par mi les fortz ne ne se peuent si bien tenir es routes, quar, quant les chienz chascent par mi les fortz, ilz vont touz jours la menee par ou le cerf va. Et, quant ilz sont ou cler pays, ilz se balancent sa et la, pour ce qu'ilz ont bel 
aler, et aucune foiz acuillent le change ou aucune foiz par le cler pays et par leur resdour trespassent routes (Gaston Phébus, Livre de chasse, p. 203, 152)

\section{IV. bien et beau s'en va carême : jouir à} nouveau des plaisirs défendus au temps de carême Intransitif

+1415 Et puis, pour jouer a tintin, Avecques moy tost se leva ; A ce jour de saint Valentin, Bien et beau Karesme s'en va (Charles d'Orléans, Poésies [ 1415-1440], II, Rondel CCXLVII, p. 432)

1552 Gens de bien, dieu vous salue et guard. Je ne vous peulx veoir. Attendez que je chausse mes lunettes. Ha, ha. Bien et beau s'en va quaresme, je vous voy (François Rabelais, Le Quart Livre, prologue)

1650 Ils n'avoient soucy d'autre affaire Que de dormir, faire grand chere, Rire, danser les mattassins, Et de joüer des mannequins, Se veautrans, allans sur l'herbette A quatre pattes, à courbette, A petits sauts, à petits bonds, Comme gentils petits Moutons, Joüans à la mouche, à la bresme, A bien et beau s'en va Caresme, A croquignolle, à coquimber, A je n'y tiens ny bois ny fer, A pille-nade, joque fore, Et mille autres beaux jeux encore (Charles d'Assoucy, L'Ovide en belle humeur)

V. aller tout beau : aller doucement, prudemment

Intransitif

1573 FLEURIE. Vaille que vaille, Je rompray l'huis.

PAQUETE. Vous n'estes sage. Ne croyez pas vostre courage ; Dissimulez, allez tout beau (Jean-Antoine de Baïf, Le Brave)
VI. s'en aller tout beau : partir, quitter un lieu doucement, sans faire de bruit, sans plus Pronominal

1610 Bien-Venu. Vos histoires m'ont fait souvenir de trois dames qui devisoient de leurs marys, et de tout ce qui estoit en eux. L'une d'entr'elles dit : "Je ne sçay que vous trouvez tant à redire en vos marys ; quant à moy, je me contente fort du mien. Il est vray qu'il y a je ne sçay quoy de petit, c'est qu'il a la c... noire » Le mary les oyoit conferer, et tout beau s'en alla en la maison (Béroalde de Verville, Le Moyen de parvenir)

\section{CORPUS WEB :}

Quel genre de chemin veut-on emprunter ou créer ? Dans quel sorte de paysage ? Seul ou en compagnie? Aller loin, ou aller vite, ou aller profond, ou aller haut, ou aller beau, etc ... ? Définir précisément ce qui, à chaque carrefour de vie, nous fera choisir telle voie plutôt que telle autre [http://www.noetique.eu/ articles/philosophies/lart-de-vivre-sa-vie/view] (18.5.2016)

dj jean jean ils vont beau les sièges du tsd 6 cet automne ils vont passer du noir au gris [http:// www.remontees-mecaniques.net/forums/index. php?showtopic=1365] (18.5.2016)

Merci pour vos réponses, elles vont belles, mais je veux du concret (); [http://www.raphaelharoche.net/forum/index.php?action=profile;ar ea=showposts; $\mathrm{u}=12178]$ (11.11.2013)

les essaies robes de mes filles, faut imaginier qu'elles ont les couronnes de fleurs, bien coiffés, elles vont belles mes poupettes [http:// www.i-services.com/membres/forum/messages. php? page $=25 \&$ uid $=6778 \&$ sid $=1809 \&$ idsujet $]$ $=976660 \& p g i=106(11.11 .2013)$

Un « jeune » en scooter... oui, oui, on voit parfaitement! toujours les même !! et même pas capable de se battre, ça va chercher un flingue. ils vont beaux les caïds! [http://m.leparisien.fr/ plus/commentaires/ajax/3103833] (11.11.2013)

Remarques : Beau est un adjectif-adverbe de manière qui caractérise la façon qu'a une personne de se déplacer, ou, au sens figuré, le fait que quelque chose convienne à quelqu'un. Jusqu'au XIV ${ }^{e}$ siècle, cet adjectif-adverbe de 
manière adopte la forme neutre bel. (I) décrit le déplacement de quelqu'un habillé avec élégance et raffinement. (II), seoir, convenir à quelqu'un. (III), ici, en parlant de chiens, décrit leur course agile et fluide. Dans l'exemple de 1389, bel aler peut être lu comme nominalisation. (IV) réfère à la fin du carême, où les excès sont à nouveaux permis, décrit la volupté, le plaisir de la chair. (V), se déplacer ou agir prudemment. Beau est modifié par plus, si, tout. La coordination syntaxique avec bien dans les exemples sous (V) souligne sa nature adverbiale. Dans cet emploi, il reste invariable (v. les deux premiers exemples $\mathrm{du}$ CW). Dans les trois derniers exemples du CW, le verbe aller se rapproche de sa fonction comme copule, vont se rapprochant de sont, suivie d'un adjectif prédicatif, mais beau permet également parfois une lecture plus adverbiale 'bien' (dernier exemple). Dans ce dernier exemple, beau adopte le sens ironique de 'ça va bien pour eux'. La langue standard n'accepte d'ailleurs guère les exemples 3 e $4 \mathrm{du}$ CW, au point qu'on peut y voir une faute de frappe (vont belles pour sont belles), mais le fait que nous pouvons citer trois emplois d'aller comme verbe copule allié au fait que la construction est usuelle dans les autres langues romanes suggère tout de même que les exemples reflètent un usage sous-standard. La continuité de l'usage ancien documenté dans le CW est plus forte qu'il n'apparaît dans les exemples de Frantext. Notons les groupes aller gent, aller profond et aller haut.

\section{Aller digne}

Marcher, se déplacer dignement, fièrement Intransitif

1385 Pour ce mendre, petite et grande Doit garder son ranc a l'offrande Et ailleurs, selon ce qu'elle est ; Et se a aucune en desplest Qui d'aler digne n'est devant (Laquel chose advient bien souvant), N'en doit chaloir a la plus digne : Tousjours soit rebouté l'indigne Contre cellui qui mieulx vaudra (Eustache Deschamps, Le Miroir de mariage, 9287)

1862 Alors, repassèrent en foule dans ses souvenirs les aimées d'autrefois, avec leurs attitudes préférées, leurs regards doux ou fiers : blondes, brunes, elles allaient lentes ou rapides, dignes ou cyniques. Mais pas une n'obtint un sourire. Elles ne parlaient plus ni à son imagination ni à son cœur. Anna était devenue tout son horizon (Paul Reider, Mademoiselle Vallantin)

\section{Corpus Web :}

Trop tard Nik c'est irratrapable, inutile de me donner l'illusion d'une quelconque convivialité ou entente dans ce forum, je préfére m'en aller digne! [http://www.lamainverte.org/ forums/viewtopic.php?f=30\&t=14035\&start=45] (22.5.2016)

Kriss écoute cet infirmier touareg raconter comment il $v a$, digne et déterminé, sans médicament, à pied, à dos d'âne ou de chameau, soigner ses frères nomades dans des régions aussi démunies qu'isolées [http://www.lemonde. $\mathrm{fr} /$ voyage/article/2009/11/20/bon-voyage-lakriss_1339735_3546.html] (22.5.2016)

Eh bien figurez-vous qu'ils y allèrent, dignes, fiers, et... seuls [https://www.justfocus.fr/ musique/critique-musique/pierre-et-georges-auconcert-des-chk-chk-chk.html] (22.5.2016)

REMARQues : Digne désigne l'attitude empreinte d'une certaine fierté, d'un respect de soi-même que montre quelqu'un. Il a donc sémantiquement une grande affinité avec la prédication seconde. Dans l'exemple de 1862, la flexion marque tous les attributs comme étant des prédicats seconds, même si leurs significations sont plus (lentes ou rapides) ou moins (dignes ou cyniques) affines à la modification du verbe. L'exemple met en évidence la force qu'acquiert la prédication seconde dans les romans du XIx ${ }^{\text {e }}$ siècle, créant un contraste avec l'ancien et le moyen français où l'emploi invariable passe plus facilement. S'y ajoute la tendance moderne du style littéraire à préférer l'emploi détaché du prédicat second (CW).

\section{Aller direct}

Aller directement

Intransitif

1972 Si vous êtes un paumé, un cradingue, un total orphelin, de préférence avec les flics au cul, alors laissez-vous faire, pas besoin de plan Taride, même en rasant les murs 
vous y allez direct. Vous trouverez facilement, c'est au bout du chemin, quand vous en avez marre, quand vous en pouvez plus (Bertrand Blier, Les Valseuses)

1987 Julius le Chien, lui, va direct inspecter sa gamelle (Pennac, La Fée Carabine)

1990 Après des paroles aussi encourageantes j'ai pas voulu tâter le terrain plus longtemps. Je suis allée direct au vif du sujet (Fanny Seguin, L'Arme à gauche)

\section{CORPUS WEB :}

Oui bien sûr et ces courriers iront directs à la poubelle. Les Députés et Sénateurs ne demanderont jamais une telle chose[twitter.com/upr asselineau/satus] (22.10.2020)

Certes le cadre pourrait être un peu plus bucolique mais c'est encore cela l'Espagne : des égouts qui vont directs à la mer et des poissons enivrés par le liquide[gobages.com/news-peche/ poissons] (11.08.2014)

Inutile de louer un local commercial au faubourg, rue de la democratie, c'est vos economies qui vont directes a ces vereux de proprietaires [https://www.tripadvisor.fr/ShowTopic-g187152i1725-k5126051-Local_commercial_collioureCollioure_Pyrenees_Orientales_Occitanie.html] (22.10.2020)

REMARQUES : Aller direct tend à remplacer aller droit dans le français plus récent. On peut le considérer comme variante économique remplaçant aller directement dans des registres familiers, surtout oraux. En effet, l'ensemble des exemples dans Frantext mettent en évidence son usage récent dans ce type de registre. L'adjectif-adverbe direct y est très apprécié. Bedijs (2012: 250-251) cite « tu prends les reflexes direct », « tu lui as dit stop direct », " tu uses direct la violence ».Direct, dont l'accord ne serait pas audible à l'oral, reste invarié dans les exemples littéraires cités, mais le CW y ajoute trois exemples qui ont été sélectionnés parmi un grand nombre de cas disponibles sur Internet. L'accord ne change ni le sens ni la fonction par rapport à l'emploi invarié. Ajoutons que l'accord de son homologue espagnol directo est très fréquent et audible à l'oral (Hummel 2015).

\section{Aller doux}

I. Se déplacer doucement, tranquillement Intransitif

1573 TAILLEBRAS. J’y vas.

SANNOM. Et tant vous allez doux !

Il s'est jetté dans les filets

Tant des maistres que des valets

Qui luy avoyent dressé l'enceinte.

Le vieillard l'attend à l'atteinte

Pour surprendre cet adultere

(Jean-Antoine de Baïf, Le Brave)

1606 une taverne que nous passasmes au village de La Ferriere sans oser boire de peur de la pleuresie toute certaine, desjà que trop en danger de prendre mal sans cela, car il est impossible de mediocrement s'echauffer ny d'aller doux parce que le corps esbranlé contrebas emporte de son poids les jambes et les pieds qui vont plus qu'ils ne voudroient et se peuvent à peine retenir (Voyage d'Italie)

1619 Saint François voyant une brebis toute seule emmi un troupeau de boucz : « Regardes, » dit il a son compaignon, « comme cette pauvre petite brebis est douce parmi ces chevres ; Nostre Seigneur alloit ainsy doux et humble entre les Pharisiens. »Et voyant une autre fois un petit aignelet mangé par un porceau : Hé, petit aignelet, dit il tout en pleurant, que tu representes vivement la mort de mon Sauveur (Saint François de Sales, Introduction à la vie dévote)

II. Fonctionner doucement, gentiment Intransitif

1601 Mais voyci la difference; le sage se reigle et se range à ce qui est selon nature et raison, regarde au debvoir, tient pour apocryphe et suspect ce qui est de l'opinion, condamne tout à faict ce qui est de la passion, et pour ce vit-il en paix, chemine tout doucement en toutes choses, n'est poinct subject à se repentir, se desdire, changer ; car quoy qu'il advienne, il ne pouvoit mieux faire ny choisir ; et puis il ne s'eschauffe poinct, car la raison va tout doux (Pierre Charron, De la sagesse) 
III. Agir tranquillement, calmement, sans faire de bruit

Intransitif

1653 Dieux ! Comme ils gagnent la guerite Et tournent le dos à vos coups : Mais c'est assez, allez tout doux, Ils pourroient rentrer en courroux, Et puis casser teste et maschoire, Suffit de les avoir soûmis, On a perdu mainte victoire Pour trop presser ses ennemis (Charles d'Assoucy, Le Ravissement de Proserpine)

1665 Réglez votre temps sur le nôtre ; Aujourd'hui l'une, et demain l'autre : Tout avec ordre ; et, croyez-nous, On en va mieux quand on va doux (Jean de La Fontaine, Les Cordeliers de Catalogne)

IV. s'en aller doux : partir doucement, lentement, tranquillement

Pronominal

1848 La mâture criait, l'air sifflait dans les poulies. À la proue, le nez dans la brise, un mousse chantait ; nous n'entendions pas les paroles, mais c'était un air lent, tranquille et monotone qui se répétait toujours, ni plus haut, ni plus bas, et qui se prolongeait en mourant, avec des modulations traînantes. Cela s'en allait doux et triste sur la mer, comme dans une âme un souvenir confus qui passe. Le cheval se tenait debout, du mieux qu'il pouvait, sur ses quatre pieds et mordillait sa botte de foin (Gustave Flaubert, Par les champs et par les grèves)

1928 ANDOCHE. « Son pouls, i' n'va guère vite ", disait el' médecin à la bientôt veuve. « Ah », dit-elle, « si seul'ment eç' pouls-là, il était monté sur un' bounn' bête ! mais s'en va tout doux, tout doux, pa'ç' qu'il est sur un bourri ! Ah, ah, ah... » (Roger Martin du Gard, La Gonfle)

1945 Des bombes à retardement sur la voie, vous ferez quelques kilomètres à pied, et vous reprendrez le train de l'autre côté du danger. Le train s'en va tout doux, tout doucement, tâtant le terrain avec les roues. Le crépuscule descend ses voiles sur le paysage : c'est une ville ou ce qui reste d'une ville (Elsa Triolet, Le Premier Accroc coûte deux cents francs)

\section{CORPUS WEB :}

Je vais m'atteler à tout ça de manière pacifique ! on pose les truelles et le plâtre, ici on y $v a$ tout doux ! On caresse notre peau dans le sens du poil et on lui dit qu'on l'aime ! [https://oakmoon. fr/astuces-anti-boutons] (22.5.2016)

Arrivée tardive pour la livraison de la semaine... petite semaine de vacances oblige, on y va tout doux ;) Cela n'enlève rien à l'utilité du contenu je l'espère, bonne pioche ! [http://alternatives.blog.lemonde.fr/2014/10/25/ la-selection-alternatives-de-la-semaine-8] (22.5.2016)

Non c’est ma maman de cœur qui est tombée gravement malade durant les fêtes d'où ma pause de presque un mois, elle va tout doux et s'affaiblit beaucoup [http://crisitane.canalblog.com/ archives/2016/01/29/33287764.html] (22.5.2016)

Dans un soyeux bruissement d'ailes, un ange blanc s'est envolé, vers ce pays plein de soleil où vont les chiens martyrisés. Va, toute douce, toi si petite, et si fragile qu'une caresse t'aurait brisee, sans te connaitre, on t’a aimée [http://www. levriersansfrontiere.com/article-petite-fanny-ma-fait-un-signe-elle-s-est-envolee-123571758.html] (22.5.2016)

RemARques : Doux est un adjectif-adverbe de manière qui caractérise la façon dont quelqu'un se déplace, ou dans un sens figuré, la façon dont quelqu'un exécute une action. Aller doux est particulièrement ouvert au jeu des interprétations métaphoriques qu'offrent l'adjectif doux et le verbe aller, qui se rapproche aussi parfois de sa fonction de copule. Doux est modifié par ainsi, tout. Il reste invariable dans la majorité des exemples ci-dessus (mais voir le dernier exemple du CW où il s'accorde avec le sujet féminin). La tendance à l'invariabilité distingue aller doux d'autres combinaisons avec le verbe aller où l'attribut en prédication seconde est systématiquement fléchi : (s'en) aller content, humble, triste, cynique, digne, etc. 


\section{Aller droit}

I. Aller en suivant une ligne droite

Intransitif

1119 E cancer signefie,

Ne larrai nel vus die,

Ki ne pot dreit aler

Par terre ne par mer (Philippe de Thaon,

Comput [1119 ou 1113], 1609)

1285 Dist Crompars : Sire, n'en doutés

Que ja mais ne se verseroit

Cis chevaus, ains va tous jors droit.

Teus est li chevaus, sans mentir

(Adenet le Roi, Cleomadés, 2442)

1544 PROU. Ouy mieux les aulx, que l'encens. PEU. Qu'il contrefait bien le gentil !

MOINS. Tournons delà.

PEU. Non, allons droit. S’il vient à nous, laissons le courre.

PROU. Il fault sçavoir par quel endroit

Se tire gresse de la bourre (Marguerite

d’Angoulême, Trop, prou, peu, moins)

1693a Mère Écrevisse un jour à sa Fille disait :

Comme tu vas, bon Dieu ! ne peux-tu marcher droit?

Et comme vous allez vous-même ! dit la Fille.

Puis-je autrement marcher que ne fait ma famille?

Veut-on que j'aille droit quand on y $v a$ tortu? (Jean de La Fontaine, L'Écrevisse et sa fille / Fables)

1719 La philosophe essuya les murmures

Du sot peuple, et les têtes dures

Firent gloire d'aller toûjours à reculon.

Pour les vieilles erreurs point de respect bizare ;

Examinons aussi la nouveauté.

Par les deux excès on s'égare ;

Mais la raison va droit ; marchons de son côté (Antoine Houdar de La Motte, Fables)

1824 Les Français sont les hommes du monde les plus propres à devenir fous, sans perdre la tête. Ils ne se trompent guère que méthodiquement, tant ils sont peu faits pour la méthode. Leur raison va toujours plus droit et plus vite que leur raisonnement (Joseph Joubert, Pensées, essais, maximes et correspondance)
1835 Il ne tournait plus en cercle autour de sa proie avec des regards fins et une marche cauteleuse ; mais il allait droit et ferme, en long et en large, brusquement, frappant du pied et faisant sonner ses talons éperonnés. La chambre tressaillit (Alfred de Vigny, Servitude et grandeur militaires)

1914 Les étoiles, une à une, se lèvent vers l'horizon oriental, tandis qu'à l'autre bord, la lune s'enveloppe dans les brumes du couchant. Ils vont tout droit, dans le vent froid, dont le frissonnement s'est levé en même temps que les ténèbres totales descendaient sur la terre (Ernest Psichari, Le Voyage du centurion)

1919 Il ne connaissait pas ces boyaux sinueux taillés dans la boue. Mais de loin en loin, des agents de liaison, ou des brancardiers lui disaient : "Suis tout droit » et il allait tout droit sans vouloir se reposer.

Il aperçut enfin une planchette : " poste de secours » et descendit dans le gourbi (Roland Dorgelès, Les Croix de bois)

II. Aller directement (+ préposition), en ligne droite, sans détour Intransitif

1170 Por tel forfet haïr te doi ;

Car trop feïs grant mesprison.

Fiancier t'an estuet prison,

Et sanz nul respit or androit

Iras a ma dame tot droit ;

Car sanz faille la troveras

A Caradigan, se la vas

(Chrestien de Troyes, Erec et Enide, 1030)

1175 Il parole a le fille au roi,

Mais mout li quiert mains de desroi,

Que la pucele ne vaudroit.

Andoi en vont au roi tot droit,

Mais Ganors prise mout petit

Tot canqu'il ont parlé et dit

(Gautier d'Arras, Ille et Galeron, 3389)

+1200 Kant chele entent k'ensi le mainterroit, $A u$ cordoan l'en veut aler tot droit

(Vie de saint Alexis [XIII'], p. 292, 439)

+1365 S’un petit alons detriant,

Tant nous est le deduit plus lons, Mès je sçai bien que nous alons 
Droit au buisson sans nul fourvoi (Jean Froissart, Poésies [3 $3^{\mathrm{e}}$ tiers XIVe])

+1415 Va tost, mon amoureux desir, Sur quanque me veulx obeir, Tout droit vers le manoir de Joye ; Et pour plus abregier ta voye, Prens ta guide Doulx Souvenir (Charles d'Orléans, Poésies [ 1415-1440], I, Chanson XLV, p. 231)

+1489 Ledit conte alla droit aux ennemys (Philippe de Commynes, Mémoires [14891498], VIII)

1601 Tout ce jour se passa en partie à l'oraison, car à ce mal il n’y avoit aucun remède humein ; nous estions logés à confort près l'église des Jacobins, nous alasmes droit à Dieu, le vray consolateur des désolés (René de Lucinge, Les Occurrences de la paix de Lyon)

1654 Le grand docteur qu'estoit cét homme en la science de gouverner ! Jamais la face des affaires ne le trompa. Jamais il ne fut politique à faux, ni ne s'esgara, pour paroistre beau parleur, dans les vastes espaces de la vray-semblance : il alloit tousjours tout droit à la verité ; et voyoit si nettement la suite des choses en leur premiere disposition, que les succez les plus irreguliers ne démentoient gueres les conjectures qu'il en avoit faites (Jean-Louis Guez de Balzac, Dissertations politiques)

1675 Ce discours est donc ce qui s'appelle des paroles vaines, qui n'ont autre but que de vous faire voir, ma bonne, que l'état où je suis sur votre sujet serait parfaitement heureux si Dieu ne permettait point qu'il fût traversé par le déplaisir de ne vous avoir plus, et pour vous persuader aussi que tout ce qui me vient de vous ou par vous, me va droit et uniquement au cœur (Mme de Sévigné, Correspondance)

1745 Que de douceurs contenues dans ce que je vous dis là, madame ! L'amour peut en avoir de plus folles ; peut-être n'en a-t-il point de plus touchantes, ni qui aillent si droit et si nettement au cœur, ni dont ce cœur jouisse avec moins de distraction, avec tant de connaissance et de lumières (Pierre de Marivaux, La Vie de Marianne)

1836 La preuve irréfragable se trouve chez les animaux, même chez ceux qui ont le moins de raisonnement. Ils vont tout droit aux corps qui donnent les sensations de l'odorat, du bruit, de la vue, sans faire aucune espèce de raisonnement ; parce qu'ils sont guidés vers ces corps par la vue ou le tact, et l'habitude établit bientôt l'association des corps avec l'impression produite par la lumière, par les vibrations sonores, par les émanations odorantes (François-JosephVictor Broussais, Cours de phrénologie)

1840 Mais alors leur consommation ne sera plus égale à leur production, le salaire ne payera pas le service productif, le travailleur ne pourra pas racheter son produit, et nous retomberons dans toutes les misères de la propriété. Je ne parle pas de l'injustice faite au travailleur dépouillé, des rivalités, des ambitions excitées, des haines allumées : toutes ces considérations peuvent avoir leur importance, mais ne vont pas droit au fait (Pierre-Joseph Proudhon, Qu'est-ce que la propriété ?)

1845 Le lendemain Sauviat partit pour Paris et fut absent pendant une semaine environ. Pierre Graslin était, vous l'imaginez, peu causeur, il allait droit et promptement au fait. Chose résolue, chose exécutée. En février 1822, éclata comme un coup de foudre dans Limoges une singulière nouvelle (Honoré de Balzac, Le Curé de village)

1867 On le prend pour éviter un détour, pour gagner quelques minutes. Il est traversé par un public de gens affairés dont l'unique souci est d'aller vite et droit devant eux. On y voit des apprentis en tablier de travail, des ouvrières reportant leur ouvrage, des hommes et des femmes tenant des paquets sous leur bras (Émile Zola, Thérèse Raquin)

1879 Est-ce que tu sais leurs noms, berger?

- Mais oui, maîtresse... Tenez ! juste au-dessus de nous, voilà le Chemin de saint 
Jacques (la voie lactée). Il $v a$ de France droit sur l'Espagne. C'est saint Jacques de Galice qui l'a tracé pour montrer sa route au brave Charlemagne lorsqu'il faisait la guerre aux Sarrasins (Alphonse Daudet, Lettres de mon moulin)

1902a - Satan est votre hôte, madame la marquise ! Il rampe et s'agite immodérément de l'autre côté de cette cloison !...

Ninon le croit devenu fou : elle va tout droit à la porte de la salle d'étude, veut l'ouvrir, l'ébranle, mais en vain : un verrou, de l'intérieur, a été poussé ; mais une autre porte communique avec l'antichambre ; elle y court : même obstacle !... (René Boylesve, La Leçon d'amour dans un parc)

1903 Notre cerveau français, s’il est fatigué, encombré, perd ses qualités de finesse. Notre vue va moins droit au centre de son objet. Nous cessons d'être des faiseurs de clarté. Notre génialité, je veux dire notre logique inventive, s'émousse (Maurice Barrès, Mes cahiers)

1905 Elle s'excusa humblement. Elle ne pouvait se faire illusion sur l'insuccès de ses innocentes avances : elles allaient droit contre leur but, elles éloignaient Christophe. Il ne prenait plus la peine de cacher sa mauvaise humeur ; il n'écoutait même plus quand elle parlait (Romain Rolland, Jean-Christophe. L’Adolescent)

1922a Parmi tous ces feux, bien distribués maintenant, aucun ne bouge. Je me mets à enjamber les voies. Je suis la seule direction que je connaisse. Je prends garde surtout aux fils de signaux, qui luisent moins que les rails et qui, tendus plus haut, trompent davantage le pas. Je vais droit sur ce grand lampadaire, auquel je me suis accrochée, le soir où j'ai fait ma première traversée de la ligne (Jules Romains, Lucienne)

1948 Cette «pratique de deux mille ans » qui n’a guère changé depuis Quintilien, nul doute qu'elle ne lui parût bavarde, ratiocinante et rabâcheuse. Lui, il était allé tout droit et tout seul au grain des choses et avait laissé la paille des mots (Jean Guéhenno, JeanJacques : En marge des Confessions)
1967 Avant de prendre l'autobus du retour, la jeune fille acheta des boucles d'oreilles bon marché, mais clinquantes, des lunettes de soleil en forme de cœur, des chaussures, des corsages, des jupes, des soutiens-gorge, un bustier, un maillot deux pièces, elle allait vite et droit à l'objet désiré, car elle l'avait choisi, après réflexion, sur les catalogues les plus récents (Jean-Pierre Chabrol, Je t'aimerai sans vergogne)

III. s'en aller droit : se rendre directement

(en un lieu, vers quelqu'un)

Intransitif

+1313 Son messaige li dist et conte, Cieus s'apareille et si monte

S'ot le messaige a compaingnon

Et s'en uont droit viers le doignon

De celi qui mande l'auoit

(Jean de Condé, Poèmes [1313-1337], 1456)

+1370 mais sitos que li contes Henris de Lancastre fu venus, qui grandement honnoura messire Jehan de Hainnau et les Hainnuiers dou grant et biau service que il faisoient à la roine d'Engleterre et à son fil et au pais, il eurent avis et consel que il s'en iroient tout droit viers Bristo, là ou li rois d'Engleterre et chils Hues li Espensiers et ses pères et li contes d'Arondiel se tenoient (Jean Froissart, Chroniques (A))

1389 Donc di je que, puis que veneur n'est oyseus, il ne peut avoir males ymaginations, et, s'il n'a males ymaginations, il ne peut fere males euvres, quar l'imagination va devant, et, s'il ne fet males euvres, il faut qu'il s'en aille tout droit en paradis (Gaston Phébus, Livre de chasse, p. 54, 34)

1538 Finablement, de ma chambre s'en $v a$ Droict à l'estable, où deux chevaulx trouva ;

Laisse le pire, et sur le meilleur monte, Pique et s'en va. Pour abréger le compte (Clément Marot, Épitres)

1584 Dès ledit jour, il fist couper sa barbe, qu'il avoit toujours nourrie longue depuis qu'il estoit prisonnier, paia les sept cents ecus pour les deux amandes, et le lendemain s'en alla droit à Fontainebleau, où la Cour 
estoit, pour tascher à obtenir son rappel de ban ; mais il n'y trouva point d'amis, et lui fut tout à plat denié (Pierre de L’Estoile, Registre-journal du regne de Henri III)

1610 Mais elle luy portoit tant de haine, qu'elle ne le peust croire mort avant que l'avoir veu. Elle sort donc de son logis, s'en va droit au pallais, et voyant le corps sans teste, se lave les mains de son sang, et receut un si grand contentement de sa mort (Honoré d’Urfé, L’Astrée)

1623 je voy que les hommes apostoliques heritiers de leur esprit, s'en vont tout droit aux princes estrangers, au roy du grand Mogo et à celuy de la Chine, qu'ils disputent contre les philosophes, et les plus apparens de la gentilité, d'autant qu'ils se fient en la bonté de leur cause, pour laquelle ils sont prests d'espancher leur sang et endurer la mort, et au contraire je voy que tous les heretiques, craintifs et desfians de leur cause, ont tasché de se couvrir et cacher dans les tenebres, d'autant que l'oracle de verité qui ne mentit jamais, dit nommément, que tout homme qui fait mal, hayt la lumiere, et ne s'advance point en public, afin que ses œuvres ne soient point descouvertes (François Garasse, La Doctrine curieuse des beaux-esprits de ce temps)

1755 Déja du jour la belle avant-courière de l'orient entrouvrait la barriére. Or vous savez que cet instant préfix changeait Madame en Monsieur Conculix. Alors brulant d'une flamme nouvelle il s'en $v a$ droit au lit de la pucelle, les rideaux tire, et lui fourant au sein les doigts velus d'une gluante main, il a déjà l'héroïne empestée d'un gros baiser de sa bouche infectée : plus il s'agite, et plus il devient laid (Voltaire, La Pucelle d'Orléans)

1810 Mon dessein est d'y rester, tant que l'eau coulera et que les arbres verdiront,

c'est-à-dire jusqu'aux grandes chaleurs, car alors tout sera sec, verdure et ruisseaux, et alors je partirai, et m'en irai droit à Paris si je ne m’arrête en Suisse, comme je fis l'an passé pour fuir la rage de la canicule ; ainsi faites état de me voir arriver au départ des hirondelles (Paul-Louis Courier, Lettres écrites de France et d'Italie)

1859 Il était assez proprement vêtu, et comme il avait rasé ses favoris et sa barbe et coupé ses cheveux, il espérait que Rocambole, si le hasard le jetait sur sa route, ne le reconnaîtrait pas au premier coup d'œil. Venture s'en alla tout droit rue de la pépinière, à l'hôtel Artoff (Pierre-Alexis Ponson du Terrail, Rocambole)

1874 Mlle Aurélie était d'une jolie force ; elle poussait un cri d'hirondelle à chaque coup de raquette, riant comme une folle quand le volant s'en allait droit sur le nez du jeune abbé ; puis, elle se ramassait dans ses jupes pour l'attendre ou reculait par petits sauts, avec un bruit terrible d'étoffe froissée

(Émile Zola, La Conquête de Plassans)

1882 La nuit, mon cœur se serre un peu dans cet isolement de Robinson. - Quand le vent siffle au dehors, quand la mer fait entendre dans l'obscurité sa grande voix sinistre, alors j'éprouve comme une sorte d'angoisse de la solitude, là, à la pointe la plus australe et la plus perdue de cette île lointaine, - devant cette immensité du Pacifique, - immensité des immensités de la terre, qui s'en va tout droit jusqu'aux rives mystérieuses du continent polaire (Pierre Loti, Le Mariage de Loti)

1896 Grâce à toi je me vois de dos Et bien plus vraisemblable : Dans ton croquis, à pas lourdauds, Je m'en vais droit au diable. Moi qui, pour la postérité. Sur une aile céleste Croyais m'envoler, révolté, Fatal et tout le reste ! (Paul Verlaine, Euvres poétiques complètes)

1922b Ses mains bouffies se croisent d'une façon rapide, coutumière : tous ses gestes ont ici quelque chose d'aisé, de secret, de so- 
litaire. Il lève sa face inerte ; son regard, filtrant sous les cils, s'en $v a$ droit vers le crucifix. Il offre à Dieu sa déception, cette épreuve nouvelle (Roger Martin du Gard, Les Thibault. Le Cahier gris)

1950 «Encore un peu de gniôle, voulez-vous ? J'ai besoin d'un coup de fouet. » J'avale une longue gorgée d'eau-de-vie rude, et je m'en vais, tout droit vers les 75 qui donnent de la gueule, avec ensemble, dans le bois. J'arrive au milieu d'artilleurs littéralement soulevés de joie (Maurice Genevoix, de 14)

IV. Aller directement (+ infinitif)

Intransitif

1559 Et, entrant en la chambre, veid sa femme lisant le livre, qu'il faignit ne veoir poinct, mais alla tout droict parler aux dames qui estoient d'un autre cousté (Marguerite d'Angoulême, Heptaméron, p. 148, 138)

1693b La rareté du fait donnait prix à la chose.

L'Oiseau, par le Chasseur humblement présenté,

Si ce conte n'est apocryphe,

Va tout droit imprimer sa griffe

Sur le nez de Sa Majesté.

Quoi ! sur le nez du Roi ? Du Roi même en personne.

Il n'avait donc alors ni sceptre ni couronne? (Jean de La Fontaine, Le Milan, le roi et le chasseur / Fables)

1805 Le long péronier péronéo-tarsien s'engage sous l'os cuboïde, et traverse la plante du pied pour s'insérer à l'os métatarsien du pouce, et au premier cunéiforme. Le court péronéi-sus-métatarsien $v a$ droit s'insérer à la base externe de l'os métatarsien du petit doigt (Georges Cuvier, Leçons d'anatomie comparée)

\section{Se comporter convenablement}

Intransitif

1567 L'un va tout droit, l'autre va de travers, Et toutesfois l'advis d'un homme sage Tout seul par art conduit tout ce mesnage (Pierre de Ronsard, Le Bocage Royal, p. 363)

1608 L'AMIRAL. Il faut servir le Roy, fust-ce contre raison.
BALORTE. Quand l'ennemy fait perte, usons de la poursuite.

LES ARCHERS. On ne peut aller droit sous meschante conduite.

THAMYs. Sauver un innocent ce n'est point trahison (Jean de Schélandre, Tyr et Sidon)

1734 Pour ce qui est de moi, je n'y entends point finesse ; je ne saurais gagner ma vie à gouverner les filles, je ne suis pas si aisé, et je la gagne à faire le tracas des maisons ; que chacun dans son métier aille aussi droit que moi. Il m'est avis que le vôtre est encore plus casuel que le mien, et je ne suis pas aussi friand de ma condition que vous l'êtes de la vôtre (Pierre de Marivaux, Le Paysan parvenu)

1785 Figaro. Et si je vaux mieux qu'elle ? Y a-t-il beaucoup de Seigneurs qui puissent en dire Autant?

LE Comte. Cent fois je t’ai vu marcher à la fortune, et jamais aller droit

(Pierre-Augustin de Beaumarchais, Le Mariage de Figaro)

1848 On est étonné tout d'abord de voir un homme aussi habituellement doux, soumis et, ce semble, timide, que l'était M. de Tillemont, - ce même homme qui se tenait toujours à genoux devant le père Lami, comme lui disait Bossuet, - parler si franc et si ferme quand il a affaire au rude abbé. Mais il n'est rien tel que ces doux et ces humbles pour aller droit et haut, quand ils sont une fois émus dans la défense de ce qu'ils jugent l'équité et la vérité (Charles Sainte-Beuve, Port-Royal)

VI. aller droit son chemin : agir selon sa propre volonté

Transitif

1844 Ma peine pour le consoler de ce qu'il s'est fait souffrir à propos de moi, ne sera-t-elle pas perdue ? Je n'en irais pas moins droit mon chemin, advienne que pourra ! Il n'est bruit ici que des libelles de Pyat à Janin, et de Janin à Pyat (George Sand, Correspondance)

1923 - Mademoiselle, prenez garde. Vos yeux voient trop clair. Ce n'est pas l'affaire des jeunes filles. 
- Oh ! les jeunes filles, aujourd'hui, vont droit leur chemin, même si ce n'est pas le droit chemin

(Henry Bordeaux, La Vie est un sport)

VII. aller droit devant soi : progresser en ligne droite, sans se détourner de sa route

Intransitif

1846 Nos enfants de France surtout, qui sont si vifs et si parleurs, avec un bon sens très-précoce, nous ramènent sans cesse aux réalités. Ces innocents critiques ne laissent pas d'être embarrassants pour le sage. Leurs naïves questions lui présentent trop souvent l'insoluble nœud des choses. Ils n'ont pas appris, comme nous, à tourner les difficultés, à éviter tels problèmes, qu'il semble convenu, entre sages, de n'approfondir jamais. Leur hardie petite logique va toujours droit devant elle (Jules Michelet, Le Peuple)

VIII. s'en aller droit : partir en se tenant droit Pronominal

1883 Elle, serrée dans un corset qu'elle ne laçait qu'une fois par semaine, s'en allait droite, la taille étranglée, les épaules larges, les hanches saillantes, en se dandinant un peu (Guy de Maupassant, Contes et nouvelles)

1893 Je ne veux pas que des ennemis restent près de moi ! Je ne veux pas qu'on reste près de moi, à me rendre fou ! Elle s’était levée, très pâle. Elle s'en alla toute droite, sans se retourner, en emportant son ouvrage. Pendant le mois qui suivit, Pascal essaya de se réfugier dans un travail acharné de toutes les heures (Émile Zola, Le Docteur Pascal)

IX. s'en aller droit (en parlant d'un chemin) : s'étendre en longueur de manière linéaire Pronominal

1886 De grand cœur, je vous assure, comme on se venge ! Ils se turent un instant. La route large de Saint-Ouen s'en allait toute droite, à l'infini ; et, au milieu de la campagne rase, le petit convoi filait, pitoyable, perdu, le long de cette chaussée, où coulait un fleuve de boue (Émile Zola, L'Euvre)
1912 Après l'étouffement des voûtes d'arbres, après la forêt pleine d'embûches, on a déjà une impression de sécurité et de « chez soi » à rentrer dans l'immense enclos du temple où les broussailles n'ont guère plus que la taille humaine et où l'avenue dallée s'en va droite et sûre vers un semblant de village (Pierre Loti, Un pèlerin d'Angkor)

$X$. Marcher en se tenant dans une position droite, verticale (prédication seconde)

Intransitif

1897 Paillot reconnut dans la foule M. le premier président Cassignol. Le vieillard faisait sa promenade quotidienne. La foule agitée, qui l'avait surpris dans son itinéraire, inquiétait sa marche petite et sa vue affaiblie. Il allait, encore droit et ferme, portant haut sa tête desséchée et blanche (Anatole France, L'Orme du mail)

1927 Une sonnette tinte trois petits coups et se baissent toutes les têtes. Alors on ne verra point cette femme qui va droite entre les rangs des chaises, et dont nul ne pourrait d'ailleurs empêcher l'ascension, car la force qui la mène déjà n'est plus de terre. Elle étend les bras (René Crevel, Babylone)

XI. s'en aller droit : partir sans faire de détours Pronominal

1902b Il se rappelait les vieux à barbe blanche, avec de gros sacs qui les tirent en arrière, qui montent pourtant la rue et s'en vont tout droit. Il se rappelait les grands gaillards qui font de grands pas et auraient bien la force de travailler et qui, bien entendu, s'arrêtent boire la goutte "Au Petit Salé » (Charles-Louis Philippe, Le Père Perdrix)

1916 - Il est venu un peu d'eau sur la glace, dit-il, et la neige a fondu ; mais nous devons être bons pour traverser pareil. Marche, Charles-Eugène !

Le cheval flaira la nappe blanche avant de s'y aventurer, puis s'en alla tout droit (Louis Hémon, Maria Chapdelaine)

XII. Bien aller, convenir parfaitement Intransitif

1915 Quand il n’y a pas de rime, il faut, ma foi, s'en passer. 
Si mon vers ne va pas tout droit, ce n'est pas qu'il y manque des pieds,

Précédant de peu ma pensée, comme l'aveugle qui tâte avec son bâton

(Paul Claudel, Corona benignitatis anni Dei)

1925 - Je suis Bonnenfant, si tu veux savoir. C'est mon nom de naissance, mais il m'allait si dret qu'on ne m'a point donné d'autre sornette (Maurice Genevoix, Raboliot)

\section{CORpus Web :}

Arudy : un passage piéton qui va... droit dans le mur ! [http://www.larepubliquedespyrenees. fr/2016/03/03/arudy-un-passage-pieton-qui-vadroit-dans-le-mur,2007268.php] (25.5.2016)

Quand la musique va droit au cœur [http:// www.lalsace.fr/haut-rhin/2016/01/11/quand-lamusique-va-droit-au-coeur] (25.5.2016)

Voila une photo que je qualifie de parfaite : quelle netteté, aucun flou, une petite merveille, merci elle s'en va droit dans mes favori [http:// www.fond-ecran-image.com/galerie-membre, riviere,courant-continujpg.php] (25.5.2016)

Les deux petites gamines attirent leur père vers la chambre mortuaire, et la Marianne, elle s'en va, droite et digne [http://alainlecomte.blog. lemonde.fr/2007/12/15] (25.5.2016)

REMARques : Droit est un adjectif-adverbe de manière-direction. Au sens figuré, il devient un adverbe de manière qui indique une action qui s'adresse directement à quelqu'un/quelque chose, ou à un comportement droit. Dans ces cas-là, droit est invariable. Droit peut s'analyser comme un prédicat second, quand il indique une position verticale ou une attitude droite, et dans cet emploi il s'accorde avec le sujet (v. aussi le dernier exemple du CW). Il s'emploie dans les contextes suivants : (I), non suivi d'une préposition, décrit le fait de se déplacer en suivant une ligne droite, sans s'arrêter ni faire de détours. (II), se rendre de manière directe en un lieu (ou vers une personne) ; il est généralement précédé d'une préposition (à, contre, jusqu'à, dans, vers). Aller droit s'emploie au sens propre ou au figuré (aller à la vérité). (III), idem que (II), y ajoutant l'idée d'un éloignement. (IV), décrit l'immédiateté de l'action, l'infinitif exprimant le but. (V), se dit d'une personne adoptant un comporte- ment convenable et invitant à l'exemple. (VI), contrairement à (VII), cette expression traduit une sécurité, une volonté d'agir chez le sujet. (VII), expression dont le sens est proche de la définition (I) mais qui, dans certains contextes, peut signifier que le sujet avance sans réfléchir, sans but précis. Peut également traduire l'idée de volonté chez le sujet. (VIII), idem que (X) avec une nuance d'éloignement de la personne. (IX), généralement accordé avec le sujet, s'en aller droit réfère ici à une route, une avenue qui s'étend de toute sa longueur à perte de vue. (X), relatif à une personne qui se déplace en tenant son dos et ses épaules bien droites (prédicat second). (XI), proche de la définition (I), mais exprimant en plus une nuance d'éloignement. (XII), se dit de quelque chose qui convient parfaitement au locuteur. Droit est modifié par aussi, moins, plus, si, tout. Notons la collocation aller droit et ferme. Mentionnons également l'emploi de marcher droit, nourrir long, parler franc, parler ferme, priser petit, voir clair. VOIR AUSSI : acheminer droit

\section{Aller dru}

Aller vivement, rapidement, avec vigueur ; de façon compacte (quand il s'agit d'un groupe) Intransitif

1594 Allons tous, dru et espais, Pour luy demander la paix : Nous irons jusqu’à sa table, Tant il est Prince accostable ! (Satyre Ménippée)

1609 Mais retournons à table, où l'esclanche en cervelle

Des dents et du chalan separoit la querelle, Et sur la nappe allant de quartier en quartier,

Plus dru qu'une navette au travers d'un mestier,

Glissoit de main en main, où sans perdre avantage,

ebrechant le cousteau, tesmoignoit son courage (Mathurin Régnier, Les Satires)

1624 Il pleure quand il faut faire de la depense ; S'il mange, c'est du pain, encore bien petit, 
Et n'est selon son goust sausse que d'appetit ;

Mais ses dens vont bien dru quand quelcun le convie ;

Ses valeureuses mains imitent la furie

D’Achilles combattant, lors qu'elles vont au plat,

Ou d'un diable affamé qui déjeune au Sabat ;

Un autre prez de luy ne fait pas ses affaires,

C'est la peur et l'effroy des tables estrangeres

(Jacques Du Lorens, Premières satires)

1734 DORIMÈNE. Votre belle : voilà une épithète bien placée!

FRONTIN. Je défie qu'on la place mieux ; si vous entendiez là-bas comme il se démene, comme les déclarations vont dru, comme il entasse les soupirs, j'en ai déjà compté plus de trente de la dernière conséquence, sans parler des génuflexions, des exclamations (Pierre de Marivaux, Le Petit-Maître corrigé)

1739 FRONTIN. Eh ! mais, mais ... mon oncle un peu de patience ; comme vous allez dru sur les questions! Vous m'essoufflez

(Antoine de Fériol, comte de Pont de Vesle, Le Somnambule)

1930 Une note douloureuse (le sapin est sonore) retentit et se prolonge sous bois. N'importe, le bûcheron y va dru ; son souffle haletant scande les coups (Marie Dutoit, Mon Jura ... et le monde)

CORPUS WEB :

Cette association de jeunes entrepreneurs qui entend « se mobiliser sur le made in France » et « faire travailler plus d'ateliers, d'usines et de salariés français ", voulait y aller dru. Avec leur enquête qui autopsie les boutiques de huit partis politiques, et celle aussi de l'Assemblée nationale, ils tentent en effet de les inciter autant que possible à s'approvisionner en matériel tricolore [http://www.marianne.net/leurs-gadgetsles-partis-politiques-aiment-peu-made-infrance-100235483.html] (25.5.2016)
Pour répondre au désormais célèbre " l'important c'est que ça glisse », je dirais qu'en escalade faut y aller dru dans le pentu ... À part ça, si vous êtes cons et arrogants ne venez pas, sinon vous pouvez venir c'est sympa (surtout si vous êtes jeunes et belles...) [http:// associationsportive.insa-toulouse.fr/fr/shn international/shn2/interviews_shn/pierre_eric_ goudal_martin_bonnet.html] (25.5.2016)

Pour s'en convaincre, il faut prendre le dur jusqu'à Lisieux puis se perdre dans ce pays d'Auge peuplé de vergers de pommiers haute tige, appelés ainsi parce que leurs troncs vont dru et droit sous les couronnes des branches [http:// next.liberation.fr/food/2016/01/01/calvados-dedrouin-divin_1423863] (25.5.2016)

Le fiacre des pauvres s'est offert cette nuit une audience de prose

Fréquences lapidées aux engeances gémellaires

Elles vont drues, les promesses aux serments oubliés

Glisser d'une vague excuse les fragments dévoués

Et c'est fête en mon âme aux flagrances des rosiers [http://laqutedekakan.blogspot. co.at/2012/03/elles-sont-venues.html] (11.11.2013)

REMARQUES : Aller dru caractérise la force d'un déplacement, d'une action, souvent par rapport à l'action compacte d'un ensemble (v. la collocation avec épais dans l'exemple de 1594) : ainsi que l'herbe drue dont les pousses sont serrées et touffues, aller dru et épais réfère à des personnes se déplaçant de manière groupée, voire serrée. À la différence d'autres collocations avec le verbe aller, où le modifieur est systématiquement fléchi (v. (s'en) aller content, triste, cynique, digne, etc.), dru reste invariable dans la plupart des cas. Ceci souligne son affinité adverbiale. L'emploi poétique peut chercher la force expressive de la flexion (v. le dernier exemple du CW). Dru est modifié par bien, plus. Notons la collocation $d r u$ et droit dans le CW.

\section{Aller épais}

Se déplacer de manière groupé, en serrant les rangs

入 aller dru 


\section{Aller facile}

Évoluer sans difficulté, sans problème, sans

effort

Intransitif

1909 Il pouvait tout : appréhender les gens, les interroger, les déshabiller, après la question réglementaire :

- Vous n'avez rien à déclarer ?

Le travail allait bien, facile; les caisses de champagne, toutes pareilles, se posent sans recherche

(Pierre Hamp, Vin de Champagne)

1960 Ça cuit vite - ça va facile

(Radiodiffusion-Télévision Française, 18 janvier 1960 / Grundt : 219)

\section{CORPUS WEB :}

Mais où s'arrêtera t'il ? Petite déception pour moi avec Voltigeur de Myrt. Il semblait aller facile dans le dernier tournant et, tout à coup à mi ligne droite, il s'est arrêté [http://www.equidia.fr/ live/796006-2] (29.5.2016)

Dans les tribunes, on voyait que cheval et jockey " allaient facile » et que sans incident, ils iraient jusqu'au bout..... et après la dernière haie BOURGUEIL a mis un bon coup de rein pour gagner de 2 longueurs [http://www. etienneleenders.fr/entraineur-chevaux-decourses-galop-plat.html?annee=2016] (29.5.2016)

" Les préparations vont facile », explique Luc Missante, de AutoTechnica [http://fr.after salesmagazine.be/nl/blog/item/Autotechnica pour_75_pour_cent_lou/109] (29.5.2016)

car moi je dis « il n'y a pas de chevaux tarés ou vraiment unmontables ou autres », il y a des gens qui pensent savoir et qui font tout de travers, qui bousillent le cheval. bizarre tout de même j'en ai débourrer des centaines (oui çà défilait à un moment de ma vie et j'ai fait çà 30a) et bizarrement tous allaient faciles après... alors coup de chance ? non savoir attendre le bon moment, SENTIR quand il faut faire quoi surtout [http:// www.chevalannonce.com/forums-9738935-votreavis-sur-ce-cheval-achat-hongre-4-ans? $p=9$ ] (29.5.2016)

REMARques : Facile est un adjectif-adverbe de manière qui se dit de quelque chose qui fonctionne facilement et donc, qui présente des avantages dans son utilisation, indépendam- ment de la volonté du sujet. Il reste invariable, mais la flexion apparaît dans l'écriture spontanée du dernier exemple dans le CW. Il s'agit d'un des adjectifs-adverbes qui, contrairement à la tendance générale, pourraient avoir succédé à l'adverbe long facilement, non pas forcément par apocope, mais par remplacement, à partir du $\mathrm{xx}^{\mathrm{e}}$ siècle. Notons son emploi usuel dans le monde des courses hippiques.

\section{Aller ferme}

I. Aller, agir avec assurance, volonté, détermination

Intransitif

1727 Lisidor. Nous allons emmener et ma nièce et ma sœur, Pour vous laisser tous deux.

LÉANDRE. (à part) Allons ferme, mon cœur.

Notre ennemi paroît ; tâchons de nous défendre (Philippe Destouches, Les Philosophes amoureux)

1835 Il ne tournait plus en cercle autour de sa proie avec des regards fins et une marche cauteleuse ; mais il allait droit et ferme, en long et en large, brusquement, frappant du pied et faisant sonner ses talons éperonnés. La chambre tressaillit (Alfred de Vigny, Servitude et grandeur militaires)

1842 Le dernier tableau est atroce : la passion augmente ; la mort, épaules courbées, contractée, attire, accroche et griffe, devant et derrière, un évêque qui le sent bien et qui va... il va, ferme et mélancolique; sous la griffe même, il ne craint que Dieu. Partis de Strasbourg à quatre heures. La flèche nous suit presque jusqu'à Offenbourg. Temps gris et bas (Jules Michelet, Journal).

1844 Mais, avec une rage que vous devez concevoir, je me mis à travailler les cadavres qui me séparaient de la couche de terre sans doute jetée sur nous, je dis nous, comme s'il y eût eu des vivants! J'y allais ferme, monsieur, car me voici! Mais je ne sais pas aujourd'hui comment j'ai pu parvenir à percer la couverture de chair qui mettait une barrière entre la vie et moi (Honoré de Balzac, Le Colonel Chabert) 
1897 Paillot reconnut dans la foule M. le premier président Cassignol. Le vieillard faisait sa promenade quotidienne. La foule agitée, qui l'avait surpris dans son itinéraire, inquiétait sa marche petite et sa vue affaiblie. Il allait, encore droit et ferme, portant haut sa tête desséchée et blanche (Anatole France, L'Orme du mail)

1900 Oh ! Ce rêve tragique en moi toujours vivace,

Que l'amour et la mort, vieux couple fraternel,

Sur mon corps disputé, quelque soir solennel,

Comme deux carnassiers, s'abordent face à face !...

Qu'importe j'irai ferme au destin qui m'attend.

Sous les lustres en feu, dans la salle écarlate,

Que mon parfum s'allume, et que mon rire éclate,

Et que mes yeux tout nus s'offrent !... des soirs, pourtant

(Albert Samain, Le Chariot d'or)

II. aller ferme devant soi : agir, poursuivre son but avec assurance, détermination Intransitif

1767 Je la perdis. Je ne me le pardonnerai jamais. Celui qui fait dépendre sa conduite de l'opinion, n'est jamais sûr de lui-même. Et où en serions-nous, si, pour être honnêtes gens, il falloit attendre un siécle impartial et un prince infaillible ? Allez donc ferme devant vous (Jean-François Marmontel, Bélisaire)

III. s'en aller ferme : partir avec assurance, volonté, détermination, fermeté

Pronominal

1908 Ce moment de faiblesse ne dura qu'un instant. D'un air posé, il reconnut :

- Eh bien ! Oui, c'est moi. Et puis après ? Une négresse : c'est pas une affaire!

Il s'en alla, toujours ferme et digne, rempart vivant de l'ordre et de la morale (Pierre Mille, Barnavaux et quelques femmes)

\section{CORPUS WEB :}

Une fois positionnée, l'arme doit s'enfoncer dans la chair et il faut y aller ferme pour la ressortir et la re rentrer [http://www.zombiesworld. com/la-scie-le-crash-test] (29.5.2016)

Le premier spectacle découvert à la rentrée, la première représentation annonciatrice des joyeusetés théâtrales de l'automne, sera donc cette formidable performance d'acteurs, cette truculente galerie d'Irlandais paumés et autres cyniques créatures hollywoodiennes incarnés avec gourmandise par Christian Pereira et Eric Métayer. Ils y vont ferme ! [http://www. ddo.fr/labruyere/dcplp/presse_telerama.htm] (29.5.2016)

Néanmoins et tout d'abord, saluons l'exploit. Du moins si l'on s'en tient à ce qu'on nous dit, à ce que nous...racontent les medias habituels, aux ordres ou pas, et qui, pour une fois ou plutôt une fois de plus, y vont ferme dans le mélo et la quasi sanctification d'une malheureuse qui n'en demandait pas tant et surtout pas d'être passée par le calvaire qui lui vaut, aujourd'hui, une notoriété planétaire [http://journal-info. blogspirit.com/archives/category/actualites/ index-10.html] (29.5.2016)

REMARQues : Aller ferme traduit l'idée d'assurance, éventuellement de courage du sujet, au moment d'agir (I, II), au sens propre (se déplacer) comme au figuré (agir), aussi avec s'en aller (III). Même si les exemples avec le sujet au singulier ne le mettent pas en évidence, ferme admet souvent une interprétation comme prédicat second. Il partage son ambiguïté avec droit. Ainsi la collocation droit et ferme donne lieu à deux interprétations 'directement et fermement' et 'debout et avec fermeté'. Le CW met en évidence la tendance à l'emploi adverbial invariable dans le langage informel de nos jours. Notons l'emploi de porter haut.

\section{Aller fort}

I. Aller avec force, entrain Intransitif

1543 Les fiers chevaulx piquer donne toy garde, Ains par la resne à force les retarde. De leur gré vont, voyre si roide et fort, 
Qu'à les tenir fault merveilleux effort (Clément Marot, Livre second de la métamorphose)

1627 Il passa pardevant une fosse d'où Cyane sortit à demie nuë, et avec de longs cheveux espars comme si elle fust venu de se baigner, mais la charrette alla si fort qu'elle ne put faire à Pluton la reprimende qu'elle avoit premeditee (Charles Sorel, $L e$ Berger extravagant)

1783 la bête est à bas ; mais je reste en selle ; je la presse à coups redoublés... va, mon ami... va... foutre !... ah !... ah !... va fort... ah !... bougre !... ah !... que tu fais bien ça ! (Honoré de Mirabeau, Le Libertin de qualité)

1857 Je me levai, décidé à l'expulser de vive force. Un mouchoir était mon arme, mais je m'en servais sans doute assez maladroitement ; je l'étourdis, je l'effrayai ; il tourbillonnait de vertige, et de moins en moins songeait à sortir. Mon impatience croissait ; j'y allai plus fort, et trop fort sans doute... il tomba sur l'appui de la fenêtre, et ne se releva plus (Jules Michelet, L'Insecte)

1993 Vous pouvez être à Rome dans trois jours ? - Naturellement.

- Disons mercredi soir pour jeudi matin très tôt. Vous voyez ?

- Je vois.

Je vois surtout qu'il faut aller vite et fort. Après tout, je me suis peut-être trompé, et le message indirect de Gleb pouvait comporter un désir de négociation inédite ? Sur l'Affaire elle-même? (Philippe Sollers, Le Secret)

II. Aller vite

Intransitif

1573 MAXIME. N'attendez point là que Cinthien retourne, car il est entré secrettement par l'huis de derriere en la maison. Et qui voudra entendre du Negromant, s'y courre apres, mais qu'il se despeche, car il va si fort qu'il semble que le diable l'emporte (Jean de La Taille, Le Négromant)
1627 Faites nous donc conduire bien dextrement, repartit Amarylle, car à ce que dit Claudian en parlant du char de Triptoleme, les routes de l'air ne sont pas moins dangereuses que celles des eaux. Le carrosse alloit bien fort tandis qu'ils parloient de la sorte, et ils furent en peu de temps au chasteau du magicien. Amarylle eut de la peine à se persuader qu'elle fust encore Lysis (Charles Sorel, Le Berger extravagant)

1882 Il semblait rouler depuis des heures sur un pont, lorsque Trublot, sortant le premier de sa rêverie, risqua cette remarque judicieuse :

- Cette voiture ne va pas fort. Mais rien ne put hâter le trot du cheval, il était onze heures, lorsqu'on arriva rue d'Assas (Émile Zola, Pot-Bouille)

1883 Pépé, toujours pendu à sa main, allongeait ses courtes jambes pour la suivre. Elle l'oubliait. Il finit par dire :

- Tu vas trop fort, petite mère. Alors, elle s'assit sur un banc : et, comme il était las, l'enfant s'endormit en travers de ses genoux (Émile Zola, Au bonheur des dames)

1995 Comme si les chiens d'ici étaient contrebandiers! Ailleurs, oui, je ne dis pas... Mais ici ils ne pourraient pas passer la rivière, le courant va trop fort. Allez, Maman, il faut décaniller, prendre l'escampette... Tirer nos chausses, quoi ! Vite ! (Françoise Chandernagor, L'Enfant des Lumières)

III. Exagérer, aller souvent

Intransitif

1675 Je vous cache, et au monde, et à moimême, la moitié de la tendresse et de la naturelle inclination que j'ai pour vous. On $v a$ fort à l'opéra ; on trouve pourtant que l'autre était plus agréable. Baptiste croyait l'avoir surpassé ; le plus juste s'abuse (Mme de Sévigné, Correspondance)

1839 Cependant une invincible curiosité me poussait à le chercher, comme si mon sort eût dépendu de cette découverte. Je me mis à l'œuvre. Oh ! Que de grimoire passa sous mes yeux! Quelle ardeur à l'étude ! 
Si mon oncle m'eût vu, ou seulement mon professeur ! - studieux jeune homme, ménagez-vous, m'eût-il dit ; vous y allez trop fort (Rodolphe Toepffer, Nouvelles genevoises)

1945 et quand, allant à la fontaine, elle rencontre une femme, elle s'arrête et hurle : "putain! » de temps en temps, elle s'administre elle-même une douche, peut-être trouve-t-elle qu'elle va trop fort ? Avanthier, je l'ai vue toute trempée, avec l'eau qui commençait à geler sur elle, et elle n’a même pas attrapé un rhume (Elsa Triolet, Le Premier Accroc coûte deux cents francs)

1947 Personne n’y croyait plus beaucoup à leurs histoires de front élastique et de replis stratégiques. Et les Anglais y allaient un peu fort avec leurs bombes et leurs messages personnels incompréhensibles. Lorsqu'on entendait : « Les bulles de savon mourront au petit jour ", il se trouvait toujours un rigolo pour souligner la présence de Pierre Dac à Londres (René Fallet, Banlieue sudest)

1986 La mort en ce tabac. Chaque jour apporte son petit nécrologe. Il verse un petit rhum dans son café :

- C'était le plus grand, c'est sûr.

- Tu crois pas que tu vas fort? Un grand acteur, je veux bien. J'ai vu tous ses films, c'est pour dire. Mais le plus grand, là, t'es sûr de sec tu dis ?

(François Caradec, La Compagnie des zincs)

IV. Se répandre rapidement

Intransitif

1740 « Songe seulement, s'il n'y auroit pas moyen d'y remédier. Tu sais que j'ai le malheur de ne pouvoir tenir contre l'ennui. » « Je le sais, Monseigneur, » répondit l'Abbé ; « mais ce malheur vous arrive si souvent, et le mal $v a$ si fort en augmentant, que faute de remèdes je crains à la fin d'être obligé de vous laisser mourir » (Jacques de Varenne, Mémoires du chevalier de Ravanne)
1936 C'était son évêque à Libourne qui réclamait l'internement...

Y avait la foule, sous nos arcades... Ils se régalaient, ils perdaient rien de la belle séance... Et les commentaires allaient fort... Ça ruminait énormément... Ils apercevaient les fafiots qu'étaient répandus dans la case... Mais moi aussi j'avais bien biglé... (Louis-Ferdinand Céline, Mort à crédit)

\section{Convenir, bien fonctionner}

Intransitif

1842 Hier, j’ai lancé une épigramme qui a dû atteindre maître Hénarez au vif, il n’a rien répondu, il avait fini sa leçon, il a pris son chapeau, et m'a saluée en me jetant un regard qui me fait croire qu'il ne reviendra plus. Cela me va très fort : il y aurait quelque chose de sinistre à recommencer La Nouvelle Héloïse de Jean-Jacques Rousseau, que je viens de lire, et qui m’a fait prendre l'amour en haine (Honoré de Balzac, Mémoires de deux jeunes mariées)

1850 Si je n'avais en France ma mère dont l'affection me rappelle, je vous assure que j'irais bien jusqu'en Chine par terre ; la vie à cheval me va fort. Nous couchons sous les arbres. Nous buvons aux fontaines. Il est vrai que la nuit les puces m'empêchent de dormir. Je regarde la lune, ça m'occupe (Gustave Flaubert, Correspondance. Supplément)

1872 Et il y avait, à côté, le trou d'un poêle, où se trouvait un bout de tuyau. L'émotion prenait l'ancien ouvrier. - J'y ai passé cinq ans, murmura-t-il. Ça n'allait pas fort dans ce temps-là, mais, c'est égal, j'étais jeune... vous voyez bien l'armoire ; c'est là que j'ai économisé trois cents francs, sou à sou (Émile Zola, La Curée)

1933 Depuis que tu es là, on a des frais, c'est forcé.

- Je vous paie largement...

- Il n'est pas question de payer. Mais on a des frais. Le travail va moins fort, les habitudes sont changées, on est obligé de manger autrement : tout coûte. Il faut 
regarder aussi qu'on t’a élevée... sans que ça paraisse, les choses vont vite (Marcel Aymé, La Jument verte)

1976 Chaque fois que je suis un peu malade : la purée. Jamais de surprise. Ce soir, quand Franck est arrivé, Maman est partie. Ça prouve quand même bien que ça ne va pas fort fort entre eux. Je lui ai raconté pour Jeanine, mais il savait déjà et on a pas mal ri, à la fin, il m’a regardé (Patrick Cauvin, Monsieur Papa)

\section{CORPUS WEB :}

Elle griffe son pere et mon fils de 13 ans. Elle y va tres fort, et plus c'est fort plus elle est contente. Ils saignent mais c'est mieux le lendemain elle griffe au meme endroit pour enlever la croute et est tres fiere de sa reussite. j'ai beau dire que ca doit s'arreter elle n'y prete pas attention. Et recommence de plus belle. Ca laisse des cicatrice tellement elle $v a$ fort [http://forum. doctissimo.fr/psychologie/parents/sos-griffesang-sujet_146252_1.htm] (30.5.2016)

Elle dérange, Juliette Bouchet, dans ses partis pris, dans les enchaînements, dans le dénouement, dans le regard qu'elle pose sur cette jeune femme paumée et violente. Elle va loin, elle $v a$ fort, elle y va tout droit ! [https://avherter. com/2015/05/27/le-double-des-corps-de-juliettebouchet-editions-robert-laffont] (30.5.2016)

Elle alla, forte de cette conclusion, à son ancien palais [https://www.fanfiction.net/s/ 11863548/1/Le-Besoin] (30.5.2016)

Elle alla, forte de sa science des étoiles lointaines, déjoua la menace d'un chemineau nocturne, réprimanda une meute de loups qui s'en voulaient faire festin ; elle se fia à sa bonne étoile qui brillait pour elle seule dans son firmament et balisait son chemin vers le « pont » [http://atelier plume901.blogspot.co.at/2013/03/ecrire-unconte-mardi-8-janvier-2012-en.html] (30.5.2016)

REMARQUES : Fort est un adjectif-adverbe d'intensité. Aller fort réfère donc à l'intensité d'une action. L'exemple de 1543 implique encore une qualité appartenant au sujet animé, qui est fort, mais la plupart des exemples n'impliquent plus la force comme qualité d'un être animé. Notons la tendance à l'emploi impersonnel dans cela / ça va fort. Fort reste invariable dans son emploi adverbial et est modifié par bien, si, très, trop, un peu. Aller fort (I) désigne le fait d'aller, par extension de faire quelque chose, avec force, vigueur, aussi combiné avec vite. Par extension, (II) désigne le fait de se déplacer à grande vitesse, fréquemment utilisé pour qualifier la vitesse des chevaux. (III) désigne le fait d'exagérer que ce soit par des paroles ou par des faits. (IV) associe la force d'un processus à celui de la rapidité de son expansion. Généralement employé à la forme négative, $(\mathrm{V})$ désigne l'état mental ou de santé de quelqu'un ou le bon fonctionnement d'une affaire ou d'une relation. Les deux derniers exemples du CW illustrent un emploi usuel où l'adjectif détaché fort retrouve son emploi par rapport à une qualité humaine : fort de est suivi de ce qui a donné une force supplémentaire au sujet. Notons l'emploi de aller raide, aller droit et la réduplication fort fort.

\section{Aller gai}

I. Aller gaiement, joyeusement, sans se préoccuper

Intransitif

1698 LE CHEVALIER. (à Valère) Fussiez-vous descendu du lugubre Héraclite

De père en fils, parbleu, vous rirez de ce trait.

Vous faites le Caton ; riez donc tout-à-fait, Mon oncle ; allons gai, gai ; vous avez l'air sauvage

(Jean-François Regnard, Le Distrait)

1709 SAINT-GERMAIN. Et montrez-vous

joyeuse,

Famille amoureuse :

De la perte d'un amant

On se console aisément ;

Et dans ce siècle nôtre

Un clou chasse l'autre.

Allons gai, monsieur le procureur, Contre fortune bon cœur (Marc-Antoine Legrand, La Famille extravagante)

1867 Tantôt, il s'asseyait sur les montagnes qui bordent le lac, où l'air est si pur et l'horizon si lumineux. La troupe fidèle allait ainsi, gaie et vagabonde, recueillant les inspirations du maître dans leur première fleur. Un doute naïf s'élevait parfois, une 
question doucement septique (Ernest Renan, Vie de Jésus)

1870 Il allait, il marchait, la tête relevée de dessus cette épaule, où elle penche fatiguée. Il allait gai, avec toutes sortes d'aimables enfantillages, qui me disaient tendrement : « Voyons, es-tu content ? Je vais mieux, je suis en train, je ne suis pas encore si bête ! » (Edmond et Jules de Goncourt, Journal)

1896 N'est-ce pas ? En dépit des sots et des méchants

Qui ne manqueront pas d'envier notre joie, Nous serons fiers parfois et toujours indulgents.

N'est-ce pas ? Nous irons, gais et lents, dans la voie

Modeste que nous montre en souriant l'Espoir,

Peu soucieux qu'on nous ignore ou qu'on nous voie

(Paul Verlaine, Euvres poétiques com plètes)

II. s'en aller gai : partir gaiement, joyeusement Pronominal

1760 [ils] reçoivent cent coups d'étrivières, se relèvent, remettent leurs culottes, remercient le bon Père, le saluent très-humblement en baisant le bout de sa manche, et s'en vont contents et gais, s’ils le peuvent. Mais voilà un orage terrible, mêlé de pluie, de grêle et de neige ; et, au milieu de cet orage, une colonie qui nous vient de Sussy (Denis Diderot, Lettres à Sophie Volland)

1843 - Je revenais plus triste que je n'étais partie... et je renfonçais mes larmes pour ne pas être battue ! Tenez... au marché... ce qui me faisait envie, oh ! bien envie, c'était de voir des petites ouvrières bien proprettes, qui s'en allaient toutes gaies, avec un beau pot de fleurs dans leurs bras. - Je suis sûr que si vous aviez eu seulement quelques fleurs sur votre fenêtre, cela vous aurait tenu compagnie? (Eugène Sue, Les Mystères de Paris)

\section{CORpus Web :}

Alors très talentueux, le sympathique Barthelemy s'en allait gai en chantant et en dansant « à gauche quand YAYI BONI dit à gauche, à droite quand YAYI BONI dit à droite ", son tamtam dont le son produisait de l'électricité et de l'eau en abondance partout dans le pays, en bandoulière... [http://24haubenin.info/?MILLIARDSHOLLANDAIS-EVAPORES] (30.5.2016)

Sharon lui saute dans les bras et lui donne un gros baiser et s'en $v a$, gaie comme un pinson [http://www.lesfeuxdelamour.org/article18453304.html] (30.5.2016)

Mais déjà, malgré le temps maussade, il faut constituer les groupes, se munir du matériel adéquat, gilet fluo, gants, sans oublier la panoplie de sacs de toutes les couleurs. Et chaque petite troupe s'en va, gaie et motivée, qui vers la Semois, le Brugeland, la Saboterie, qui vers la Haute Rive, le Bochet, la Rochette, le Charmois, les inévitables Routheux, sans oublier, au retour, les Croisettes, les Marronniers, les Paquis, la Culée, tous ces noms si familiers à notre quotidien [http://www.moyen.be/?p=280] (30.5.2016)

REMARQUES : Aller gai est un groupe figé où gai s'emploie comme interjection, donc sans flexion, notamment dans les deux premiers exemples. À partir de la fin du XVII ${ }^{\mathrm{e}}$ siècle, l'emploi comme prédicat second accordé avec le sujet du verbe commence à prédominer. Avec s'en aller, gai est toujours un prédicat second. Notons que le sens du verbe aller est plus concret dans s'en aller gai 'partir' que dans aller gai, qui peut référer à un comportement ou une attitude parfois proches de la copule soyons gais. Allons gai, notamment avec réduplication (aller gai gai), semble plus oral et informel que la prédication seconde.

\section{Aller gent}

Partir doucement, gracieusement Pronominal

+1250 Puis conmande que l'en atort Bel e cortoisement la cort. Quant il out tot ce conmande, Si est tot meintenant monte Et avocques li de sa gent Tant qu'il s'en va et bel e gent (Le Roman de Renart [2 $2^{\mathrm{e}}$ moitié XIII ${ }^{\mathrm{e}}$, XIII, 672) 
REMARQues : Gent est un adjectif-adverbe de manière vieux qui réfère aux qualités physiques et/ou morales, ou la manière douce de la personne qui se déplace ; il souligne la grâce dans l'action. La coordination de gent avec le neutre bel souligne sa fonction adverbiale. Malgré ces caractéristiques formelles, la signification de gent le relie avec le sujet du verbe.

\section{Aller haut}

S'élever, atteindre un niveau supérieur Intransitif

1119 Que il unkes ne fait, Ainz est dit par figure E par divine cure ; Quant halt ne pot aler, Ne plus bas avaler Que en capricornum, Dunc est solsticium (Philippe de Thaon, Comput [1119 ou 1113], 3267)

+1250 Et dist Renars « ce fu bien fet. Mielz chantez que ne solieez. Encore se vos voliees, Irieez plus haut une jointe» (Le Roman de Renart [2 moitié XIII'], II, 933)

1637 LYZANTE. Mes vrais supplices sont ma constance, et ma foy,

Qui me forcent, rendant mes peines eternelles,

De mourir en moy mesme, et de revivre en elles :

Quelques traits que Clytie employe à ma langueur,

J'ay plus de fermeté qu'elle n'a de rigueur, Le desir de souffrir s'augmente par ma peine,

Ma gloire va plus haut, plus elle est inhumaine (André Mareschal, Le Railleur)

1680 Car, il faut dire le vrai, cela est fort commode, mais aussi c'est bien tout ce que nous pourrons faire que d'aller par ce chemin-là jusqu'en paradis ; assurément nous n'irons pas plus haut (Mme de Sévigné, Correspondance)

1774 Enfin, mon ami, j'en suis si contente, que je voudrois que vous l'eussiez fait ; et ce- pendant je suis certaine que vous feriez mieux encore : vous iriez plus haut, et vous n'auriez pas ses défauts. Mais prononcez vite : ai-je trop d'enthousiasme? (Julie de Lespinasse, Lettres à M. de Guibert)

1805 Peu à peu le prince s'est placé si près d'elle, que, même en ne le regardant pas, elle ne perd aucun de ses mouvemens, aucune de ses émotions : cette vue a quelque chose de contagieux qui augmente son trouble ; distraite, préoccupée, penchant sa tête sur sa poitrine oppressée, hélas ! Ce n'est plus à son Dieu qu'elle pense, son imagination ne va ni si haut, ni si loin. Sans doute le prince l'a devinée, car il ose prendre sa main entre les siennes et la presser contre ses lèvres (Sophie Cottin, Mathilde)

1823 On a le droit de croire que les offres de ce plénipotentiaire envers le souverain revenu allèrent bien plus haut et bien plus loin encore ; mais que Napoléon indigné les repoussa pour ne pas trop dégrader sa politique, a-t-il dit (Emmanuel de Las Cases, Le Mémorial de Sainte-Hélène)

1839 Ainsi, quelle que soit sa condamnation, elle ne sera jamais assez forte. D'ailleurs la question va plus haut. Évidemment, en ceci les classes lettrées n'ont jamais obtenu la protection accordée aux modeleurs de pendules et aux fabricants d'indiennes qui inventent un dessin (Honoré de Balzac, Correspondance)

1848a On est étonné tout d'abord de voir un homme aussi habituellement doux, soumis et, ce semble, timide, que l'était M. de Tillemont, - ce même homme qui se tenait toujours à genoux devant le père Lami, comme lui disait Bossuet, - parler si franc et si ferme quand il a affaire au rude abbé. Mais il n'est rien tel que ces doux et ces humbles pour aller droit et haut, quand ils sont une fois émus dans la défense de ce qu'ils jugent l'équité et la vérité (Charles Sainte-Beuve, Port-Royal)

$1848 \mathrm{~b}$ Votre fin et votre principe ne diffèrent pas : c'est Dieu qui est votre père, et c'est lui qui est votre but. Il est l'alpha et l'oméga de 
votre destinée ; vous ne pouvez regarder plus bas sans vous perdre, aller moins haut sans périr. En vain, si vous êtes ingrats, en appellerez-vous à la bonté contre la justice (Henri-Dominique Lacordaire, Conférences de Notre-Dame)

1849 Je ne connaissais pas la Ciguë. C'est charmant, mais quel progrès depuis ! Allez toujours, et vous irez bien haut. Voulez-vous remercier pour moi M. Arsène Houssaye de m’avoir envoyé une loge (George Sand, Correspondance)

1859 Mon ramier, sois béni ! Sauve-toi sans retour!

Va demander pardon pour les faiseurs de chaînes ;

En fuyant les bourreaux, laisse tomber les haines.

Va plus haut que la mort, emporté dans l'amour ;

Sois clément comme lui... sauve-toi sans retour !

(Marceline Desbordes-Valmore, Élégies)

1901 Mais si nous nous en contentions, si nous ne regardions plus rien par de là, si nous en induisions que toute pensée qui va trop loin ou trop haut a nécessairement tort et que la vérité se trouve toujours dans le détail matériel, si nous ne cherchions pas, n'importe où, dans des incertitudes souvent plus étendues que celles que la petite explication nous a forcé d'abandonner, par exemple dans l'étrange mystère de la fécondation croisée, dans la perpétuité de l'espèce et de la vie, dans le plan de la nature, si nous n'y cherchions pas une suite à cette explication, un prolongement de beauté et de grandeur dans l'inconnu, j'ose presque assurer que nous passerions notre existence à une plus grande distance de la vérité que ceux-là mêmes qui s'obstinent aveuglément dans l'interprétation poétique et tout imaginaire de ces noces merveilleuses (Maurice Maeterlinck, La Vie des abeilles)

1909 le combat gigantesque de la science contre la nature ; - plus bas, troupe silencieuse, les hommes et les femmes de bonne volonté, les cœurs braves et humbles, qui, au prix de mille peines, ont atteint à micôte, et ne peuvent aller plus haut, rivés à une vie médiocre, se brûlant en secret dans d'obscurs dévouements (Romain Rolland, Jean-Christophe. Dans la maison)

1912 Aucun d'entre les Polynésiens, dans tous les cas, n'est allé aussi haut. S'il y a, entre tous les Océaniens et les vieux habitants de l'île de Pâques une filiation préhistorique, c'est chez les Maoris qu'il faut voir leurs héritiers les plus légitimes (Élie Faure, Histoire de l'art : l'art médiéval)

1953 L'air de Didon : Chers tyriens, tant de nobles travaux..., au premier acte, est solennel comme il convient, mais quelque peu froid, conventionnel ; au contraire, l'expression du désespoir de la reine, au dernier acte, atteint le sublime, et jamais l'art de Berlioz n'est allé plus haut (René Dumesnil, Histoire illustrée du théâtre lyrique)

1960 Le niveau des connaissances acquises au cours de la première étape ne $v a$ pas très haut : à la fin de cette scolarité, l'enfant bien doué sait lire et écrire une phrase simple, a retenu quelques passages poétiques, appris les chiffres et les nombres bien plus que les opérations élémentaires, a été initié aux poids et mesures (Encyclopédie pratique de l'éducation en France)

\section{CORPUS WEB :}

Quel genre de chemin veut-on emprunter ou créer ? Dans quel sorte de paysage ? Seul ou en compagnie? Aller loin, ou aller vite, ou aller profond, ou aller haut, ou aller beau, etc ... ? Définir précisément ce qui, à chaque carrefour de vie, nous fera choisir telle voie plutôt que telle autre [http://www.noetique.eu/articles/philo sophies/lart-de-vivre-sa-vie/view] (18.5.2016)

Marché: On peut aller plus haut avant d'aller plus bas.... [https://leblogalupus.com/2015/08/27/ marche-on-peut-aller-plus-haut-avant-dallerplus-bas] (18.5.2016)

Lorsque vous négociez avec la moyenne mobile, l'opérateur peut regarder la courbe de 
moyenne mobile (qui est tiré a coïncidé avec la courbe de prix en monnaie principale) et voir si elle va haute ou basse pour déterminer la tendance [http://pistecapitaine.blogspot. co.at/2012/08/forex-trading-indicateurstechniques.html] (8.11.2013)

Bonjour j'ai un mustang 95 avec un 3.8L manuel et j'ai un gros probleme au decollage l'acceleration est tres lente jusqu'a $2500 \mathrm{tr} / \mathrm{min}$ passer sa il va numero 1 et au ralenti il vire mal mais si je lui donne un coups de gaz il le prend parfaitement et la temperature du moteur monte tres vite elle va haute [http://www.montrealmustang. org/forum/index.php?/topic/20806-problememoteur] (8.11.2013)

REMARQUES : Haut est un adjectif-adverbe de lieu qui a un sens spatial et désigne un point élevé, au sens concret et aussi au sens figuré. Aller haut se dit de quelqu'un ou quelque chose atteignant un degré élevé d'intelligence, de noblesse, de talent, de spiritualité, de dévotion, de félicité, d'audace, aller devant être compris comme "atteindre ". Dans l'exemple de 1119, haut aller s'oppose à bas avaler. Haut reste invariable et est modifié par aussi, bien, bien plus, moins, plus, si, trop. Notons la collocation avec l'adjectif-adverbe droit, insistant sur le caractère droit, convenable et propre à l'élévation, ainsi qu'avec l'adverbe loin. Dans l'écriture spontanée du CW, la flexion semble possible. L'accord insiste sur la qualité d'une courbe située haut(e) ou bas(se), ou de celle de la température qui est haute. Mentionnons l'emploi de parler franc, parler ferme, aller profond, aller beau.

\section{Aller impec}

Seoir, convenir parfaitement

Intransitif

1987 Avec l'argent de Gisèle, je peux enfin m'acheter le nouveau jean de toile estampillé, couleur sable foncé, que je guignais depuis un bail à la SGGG. Il me $v a$ impec, et Gisèle de mes rêves de viol me le fait savoir gentiment au cours de dessin (Bruno Bayon, Le Lycéen)

REMARQUES : Aller impec signifie 'convenir parfaitement'. Impec est une réduction familière de l'adjectif-adverbe impeccable ou de l'adverbe im- peccablement. La combinaison « verbe + impec(cable) » constitue une série ouverte dont nous ne citons que quelques variantes.

\section{Aller isnel}

I. s'en aller isnel: partir rapidement, aussitôt

Pronominal

+1100 Quant je vi le pastorel

Qui se partoit de celi

Vers li m'en vois mout isnel,

De mon cheval descendi

(Romances et pastourelles françaises des XII ${ }^{e}$ et XIII ${ }^{e}$ siècles, p. 283)

-1300 Or s'an va li messages isnel com une aronde,

Et Murgafiers remaint sor Rune la

parfonde ;

La gent de France voit de qoi li prez abonde,

Bien li samble q'anqi soient tuit cil do monde (Jehan Bodel, La Chanson des Saisnes [fin XIII'], 4466)

1375 Dieu veult que t'en voises isnel,

La derriéres, en un prael

Ouquel il a une fontaine,

Tout seul, ame avec toy ne maine

(Miracle de Robert le Dyable, 1647)

II. Aller rapidement

Intransitif

+1350 Si apela celui que trenchoit du coutel

Et li a dit : «Amis, ales tost et isnel

A la porte savoir qu'il i a de nouvel. »

Li varles, qui tenoit un hanap a clavel,

Dist : «Sire, voulentiers, puis qu'il vos

vient a bel » (Brun de la Montaigne

[2e moitié XIV $], 1884)$

1381 CLOTILDE. Non, sire ? Donques me tairay

Pour maintenant, vaille que vaille.

Han! certes, il fault que m'en aille

De ci en ma chambre, chier sire.

Par les reins sanz tant de martire

Que trop. Faites tost, Ysabel ;

Or en alons ensemble isnel :

Ne puis plus ci (Miracle de Clovis, 1298)

REMARQues : En ancien français, isnel est un adjectif-adverbe de manière qui caractérise un déplacement rapide ; employé aussi au sens tem- 
porel de 'aussitôt', notamment en combinaison avec tost (tôt). D'origine germanique, isnel était courant jusqu'en moyen français avec la même signification que schnell 'rapide', son correspondant en allemand moderne. Le fait qu'on ait utilisé ce mot emprunté comme adjectif-adverbe montre que l'emploi adverbial de l'adjectif était un procédé productif. Isnel reste invariable et est modifié par ensemble, moult. VoIR AUSSI : venir isnel

\section{Aller juste}

Bien fonctionner, fonctionner avec précision Intransitif

1724 CLARINE. Il ne trouvoit pas plus de honte pour un honnête homme à avoir une femme infidelle qu'une montre qui n'iroit pas juste (Marc-Antoine Legrand, Le Philanthrope)

1919 Or, précisément parce que M. Baslèvre contemplait à ce moment la pendule du père Gros, il s'avisa d'y lire l'heure.

- Quoi ! dit-il, n'avance-t-elle pas ?

Et se levant d'un bond, il boutonna son pardessus. Le hasard semblait avoir décidé.

- Non, dit Gustave, elle va juste. Tu es pressé?

- Ma signature...

- Je comprends... raison de plus pour apprécier ta visite inespérée

(Édouard Estaunié, L’Ascension de $M$. Baslèvre)

\section{CoRpus WeB :}

J'ai reçu les petites chaussons de mer... Ils vont justes, peut-être s'étirent-t-ils un peu en les mettant !!! [https://fr-fr.facebook.com/Brindilles. fr/posts/122882391081070] (08.11.2013)

Remarques : Aller juste s'emploie dans le domaine de l'horlogerie, référant à tout appareil ou dispositif qui permet de mesurer le temps et d'indiquer l'heure, fonctionnant avec exactitude. Juste s'emploie aussi quand des chaussures ou vêtements sont trop étroits ou serrés (CW). L'exemple du CW montre que l'accord adverbial n’a pas disparu de l'écriture spontanée.

\section{Aller léger}

I. Aller avec légèreté, aisance, agilité et/ou insouciance

Intransitif

1894 Elle avait deux lettres ce jour-là. La première qu'elle lut exhalait une gaie odeur d'amour ; Jacques ne s'était jamais montré plus riant, plus simple, plus heureux, plus charmant. Depuis qu'il l'aimait, disait-il, il allait si léger et soulevé d'une telle allégresse que ses pieds ne touchaient plus la terre (Anatole France, Le Lys rouge)

1947 Une voix du cœur prononça : « L'intérieur se désole. » Enfin la peur se levant en eux, comme un léger vent sur la mer, la peur les gonfla. Ils allèrent plus loin, plus légers, entre des roches, des falaises vertigineuses, parfois très rapprochées, où ne volait aucun aigle. Ces parois se resserrèrent encore (Jean Genet, Miracle de la rose)

II. Partir, disparaître avec légèreté, agilité Intransitif

1922 Tandis qu'ils se glissaient à travers l'ombre des longs corridors, la jeune femme, en guise d'adieu à leurs plaisirs qu'elle sacrifiait à l'amour, lui récita les vers du poète : « La tulipe fleurit promptement et s'en va légère et rapide, mais le rubis qui se forme avec lenteur ne craint rien du vent ni de la pluie et traverse toutes les saisons " (Maurice Barrès, Un jardin sur l'Oronte)

1959 Quand un buisson lui semble propice, elle $\mathrm{y}$ entre franchement, froisse les branches, se couche pesamment, imprime sur les feuilles mortes la rondeur de ses flancs, de sa croupe, et puis s'en va, légère, ombre roussâtre qui se confond avec les palmes rousses des fougères, les feuilles sèches des chênes de taillis (Maurice Genevoix, Routes de l'aventure)

\section{CORPus Web :}

C'est bien pour ça qu'ils vont léger sur les corrections, s'ils peuvent éviter, ils le font ! [http:// www.jeuxvideo.com/forums/1-50-38086150-2-01-0-mettre-des-lunettes-conseil.htm] (8.11.2013) 
Elle allait léger, et même cette poitrine à peine suggérée (bien que malicieusement soulignée par le procédé ingénieux de la ceinture haute, il en convenait) se fondait dans la silhouette gracile [http://theordanworld.forumgra tuit.org/t221-la-ou-le-soleil-brille] (8.11.2013)

REMARQUES : Dans le premier exemple, aller léger caractérise la façon dont quelqu'un se déplace, tout en reflétant son état d'âme insouciant, libre. Aller se rapproche donc de sa fonction de copule. Les autres exemples (sauf CW) appartiennent au domaine de la prédication seconde, léger s'accordant avec le sujet du verbe aller. Léger est modifié par plus, si. Il s'emploie surtout dans un registre soutenu, littéraire. Dans l'écriture spontanée du CW, la signification adverbiale 'à la légère' (premier exemple) n’a pas disparu. Léger tend alors à l'invariabilité.

\section{Aller lent}

Aller lentement, avec lenteur

Intransitif

$\sim 1177$ Li chevaus qui ne va pas lant S'efforce, quant an l'esperone (Chrestien de Troyes, Yvain ou Le Chevalier au lion)

1275 La ou Sarrazin poignent contre la nostre gent,

Gerars et Guielins vinrent premierement ; Chascuns ot bon destrier qui ne va mie lent (Adenet le Roi, Buevon de Conmarchis, 259)

$\sim 1275$ Lors ont des esperons feruz Leurs chevaux qui pas ne vont lent Ainz courent plus isnelement Qu'arondele ne puet voler (Floriant et Florete, 1015)

1365 Quant il oï le noise et le demainement, Sus son cheval monta, qui ne va mie lent (Li Romans de Bauduin de Sebourc, Chant VII, 788)

1535 Ces flots jumeaus de lait bien époissi Vont et revont par leur blanche valée, Comme à son bord la marine salée, Qui lente va, lente revient aussi (Pierre de Ronsard, Les Amours)
1862 Alors, repassèrent en foule dans ses souvenirs les aimées d'autrefois, avec leurs attitudes préférées, leurs regards doux ou fiers : blondes, brunes, elles allaient lentes ou rapides, dignes ou cyniques (Paul Reider, Mademoiselle Vallantin)

1934 Laure avait, de nouveau, pris l'habitude de cette calme existence où le temps semble aller plus lent (Daniel-Rops, Mort, où est ta victoire?)

Pronominal (s'en aller lent)

1833 la femme qu'on appelait Lélia et qui s'en allait lente et blême, enveloppée dans son manteau de velours noir, traînant à sa suite un cortège à qui elle ne daignait pas jeter un regard... (George Sand, Lélia)

CORPUS Web :

Ouais, on avait joué à SOM et comme ma connection n'est pas fait pour les jeux en réseau sa allait lent [www.jeuxvideo.com/forums] (9.8.2020)

Le cortège allait lent...sous la pluie de septembre[m.facebook.com/permalink/Le cercueil flambant] (9.8.2020)

REMARques : Aller lent renvoie au fait de se déplacer avec lenteur. L'ancienne langue l'emploie surtout à la forme négative comme équivalent de viste(ment) et isnel(ement), sans doute quand la rime le demande. Dans la langue moderne, c'est la fonction de prédicat second accordé qui domine, et qui souligne la lenteur du sujet. Il peut être modifié par plus.

\section{Aller long}

I. Aller loin

Intransitif

1280 Pour si dous iex doit on bien lonc aler Et mout $i$ a pressïeus saintuaire, Mais on n'i laist baisier ni adeser Ne on ne doit penser si haut salaire (Adam de la Halle, Chansons, VIII, 33)

$\sim 1300$ Mais tuit si home sont mort a grant hascie ; Ains que euisent lonc ale une arcie, Tout piece a piece lor car fu dehecie (Aliscans [R], 482) 
II. Produire des selles importantes, qui 'vont loin'

Intransitif

1534 Lesdictz bergiers les requirent courtoisement leur en bailler pour leur argent, au prix du marché. Car notez que c'est viande celeste, manger à desjuner raisins avec fouace fraiche, mesmement des pineaulx, des fiers, des muscadeaulx, de la bicane, et des foyrars pour ceulx qui sont constipez du ventre, car ilz les font aller long comme un vouge, et souvent, cuidans peter ilz se conchient, dont sont nommez les cuideurs de vendanges

(François Rabelais, Gargantua)

\section{CORPUS WEB :}

Ben avec des colosses qui ont disparus, elle va longue... très longue cette quête :/

Quelqu'un a vu un colosse quelque part ? [http://forum.eredan.com/viewtopic. php?pid=747227] (7.11.2013)

Qu'est ce qu'elle va longue cette fin de saison ! Longue, mais longue... On n'éprouve plus aucune émotion avec cette équipe, c'est quand même le comble pour le PSG [http:// onlyoneparis.blogs.francefootball.com/ archive/2010/03/20/kombouare-a-l-image-de-lasaison.html] (8.11.2013)

On m'a dit que si on utilise le baby born dans le bain, elle va long à sécher et il paraît qu'il ne faut pas lui donner la bouille parce que le nettoyage pas terrible [http://m.bebe.ch/drupal/ node/83221?device=mobile] $(8.11 .2013)$

REMARQUES : Long est un adjectif-adverbe de quantité qui désigne une extension, une distance ou une durée parcourue. Usité en ancien français, (I) signifie parcourir une longue distance. Dans (II), Rabelais décrit la capacité laxative des raisins (cuides, foyrars), qui permet au sujet d'expulser des selles longues " comme un vouge ». Long reste invariable. Dans l'écriture spontanée du CW, l'accord non orthographique « qui ont disparus » prouve les difficultés orthographiques de l'auteur du premier exemple, mais la terminaison au féminin de longue est audible dans la langue parlée, donc probablement authentique. Si l'on regarde aussi le second exemple du CW, la flexion se confirme comme variante de la langue parlée informelle. Dans les trois exemples du CW, la lecture figurée temporelle prédomine. Aller se rapproche alors d'une fonction de copule.

\section{Aller menu}

I. Voler, tomber rapidement, en grande quantité Intransitif

1190 Dont oïssiez buissinez, cors et grailles sonner,

Et Turs et camelleuz et glattir et usler.

Plus menu vont saietes que noif qu'on voit gresler ;

Dont veïssiez perrieres ces grans pieres geter,

Et ces aspis d'achier et ferir et hoer

(Fierabras (L), 3928)

1598 Et apres, fut le Docteur Fauste remis à l'air et en l'instant y eut force coups de fouldre et esclairs - tellement que cela alloit si menu que le Docteur Fauste se tint coy sans sonner mot, ayant grande frayeur et tout tremblant (Pierre-Victor Cayet, L'Histoire prodigieuse du Docteur Fauste)

II. aller menu et souvent : aller avec fréquence, continuellement

Intransitif

1370 Aprés ces paroles il vendirent leur nef, et puis se mistrent a voye et errerent tant qu'il vindrent a Romme et prindrent hostel dehors les murs de la cité de Romme. Or vous dy que Silirans n'avoit mie mis en oubly le carrel par ou il entroit en la tour l'empereur, ains y ala menu et souvent, tant qu'il sceut que bon fu, et prist tant $\mathrm{du}$ tresor et apporta par pluseurs foiz a Berinus et aux autres tant qu'il en eurent a grant plenté et firent un riche manoir au dehors de Romme (Roman de Berinus, I, p. 228)

REMARques : Menu est un adjectif-adverbe de manière dont les significations se dégagent à partir de son sens de base 'petite quantité', notamment dans le domaine temporel : fréquemment, souvent en peu de temps. Par extension, il signifie 'rapide'. Usité au Moyen Âge, (II) désigne un animé allant à un endroit avec fréquence et rapidité. Aller menu (I) réfère à des flèches ou à des éclairs tombant plus rapidement et en plus 
grand nombre que des flocons de neige. Menu reste invariable et est modifié par plus, si. Notons la collocation usuelle menu et souvent et l'emploi de tenir coi.

\section{Aller moche}

Se porter mal

Intransitif

1959 - Comment ça va?

- Ça va moche

(Exemple entendu / Grundt : 219)

\section{CORPUS WEB :}

AMEL, tu as bien de la chance d'avoir du soleil. Chez moi, il va moche !!! déprimant. mais bon [http://www.yabiladi.com/forum/etes-vousessayettes-67-3575697-page=16.html] (7.11.2013)

REMARQUES : Moche est un adjectif-adverbe qualificatif qui rentre dans une réponse familière équivalente à Ça va mal. Opposé à l'adjectif standard laid, l'emploi de moche met en évidence le caractère informel de l'exemple. Dans l'exemple du CW, il va moche réfère au temps ; il équivaut donc à il fait mauvais du registre standard.

\section{Aller modeste}

y aller modeste : ne pas dépenser beaucoup d'argent, avoir un train de vie modeste Intransitif

1947 Depuis trois ans, je ne m’occupe plus de rien. Les affaires en or, je les regarde passer et je vis sur mon capital. Mes économies, elles ne sont pas lourdes, mais j’y vais modeste.

Médé se moquait de moi. Je voyais son unique petit œil briller de malice pendant qu'il me racontait ces foutaises (Marcel Aymé, Le Vin de Paris)

\section{CORPUS WEB :}

La féria mélée à la fête foraine est plutôt craignos, grand défilé de piches, beauf', cagoles, gitans et niktameres : la bagarre n'est jamais loin et le pickpocket vous frôle de près. Ceux qui ont la gueule de la terreur y font leur défilé de frime, les autres y vont modestes pour eviter les embrouilles. Un endroit plus fréquentable en hiver qu'en été.Feu d'artifice du 14 juillet de bonne qualité [http://www.faitbonvivre.com/ avis-riverains.php?idville=13774] (9.01.2014)
Tu as raison : mais les objectifs de base pour la Bravo étaient très modestes et, de fait, fait pour être dépassés. Ils y vont modestes. ça c’est bien ! [http://www.forum-auto.com/marques/fiat/ sujet6850-13720.htm] (9.012014)

REMARQUES : Dans la collocation y aller modeste, le modifieur se comporte comme un adjectifadverbe de manière équivalent à modestement, même si son affinité sémantique avec la prédication seconde est sans doute également présente. Dans le contexte financier, elle réfère à une retenue du sujet concernant ses dépenses, signifiant par extension qu'il est de condition modeste, humble. Sur l'ensemble des occurrences de modeste, la prédication seconde orientée vers le sujet du verbe prédomine clairement. Nous avons donc affaire à une locution figée dont l'interprétation oscille entre lecture adverbiale et lecture prédicative. Dans le premier exemple du $\mathrm{CW}$, seule la lecture comme prédication seconde est possible.

\section{Aller mollo}

Ralentir le rythme

Intransitif

1951 Il me prête sa canadienne et je m'embarque au volant sur des routes à peine catholiques. Il m'a recommandé d'aller mollo jusqu'au fond de la vallée, mais j'y vais encore plus mollo que ça : les virages au nord sont comme des patinoires (Jean Giono, Les Grands Chemins)

2012 - Bah, tu devrais lui expliquer d'y aller mollo sur la dope. Putain, je te jure, il fait peur à voir. L'autre jour, avec Farid, on a dû le calmer. Il voulait nous en acheter pour un régiment (Stéphane Osmont, Éléments incontrôlés)

REMARQUES : Aller mollo porte le même sens que aller mou, 'y aller doucement', mais il s'agit d'une troncation suffixée de l'adverbe mollement. C'est donc un des rares cas où l'on peut morphologiquement prouver que l'adverbe court est dérivé de l'adverbe en-ment. En sens inverse, aller mou ne saurait être expliqué comme troncation de l'adverbe en -ment. 


\section{Aller mou \\ y aller mou : agir doucement, délicatement, sans violence \\ Intransitif}

1946 Pézenas, qui s'en foutait tout autant que lui, mais qui avait du moins la prudence de s'en cacher, lui disait qu'il travaillait à la mords-moi-le-nœud. Vas-y mou, lui glissait-il, quand Monsieur Hermès bousculait un peu trop brutalement la vaisselle sous le nez d'un client. C'est plus de la carte, c'est du pancrace ! (Raymond Guérin, L'Apprenti)

1951 J'ai cru moi-même à la fracture du crâne.. - C'est très gentil, mais pourquoi avezvous choisi ma porte pour jouer au bélier? Entre parenthèses, vous n'y êtes pas allé mou, elle est toute gondolée !

- Parce que j'allais chez vous, pardi !

- Je comprends... C'est Léon qui vous envoie... (René Fallet, Le Triporteur)

1969 J'ai pris un second bifton et je l'ai traité moins rudement. Cette fois, je n'ai pas percé le papier. Alors, à la plume fine, j’ai fait un 8 d'un 2 et un 7 d'un 1. J'y allais mou. Ça m’a demandé une bonne heure, mais quand j'ai tendu le billet ainsi retouché à bout de bras, pour juger de l'effet, je n’ai pas regretté ma peine (Léo Malet, Sueur aux tripes)

\section{CORPUS WEB :}

Enfin, il dit que vous devriez toujours remplacer vos têtes de brosse au moins une fois tous les 3 mois. C'est parce qu'ils vont mou et ne peut plus maintenir la force nécessaire pour pousser le lâche plaque et les débris attaché à vos dents [http://www.neosante.org/traitementparodontale-a05085945.htm] (7.11.2013)

REMARQUes : Mou est un adjectif-adverbe de manière qui exprime l'atténuation de la façon dont quelqu'un exécute une action. Y aller mou est une locution familière qui se dit de quelqu'un adoptant un comportement plus doux, adapté à la situation, voire trop réticent, pour d'éviter un embarras, un accident, etc. Dans les exemples cités ci-dessus, mou reste invariable. Dans l'exemple du $\mathrm{CW}$, aller mou réfère à un processus par lequel la tête des brosses à dents devient molle. Il s'agit donc d'un emploi prédicatif avec aller en fonction de copule dynamique et télique.

\section{Aller net}

I. s'en aller net : partir, disparaître

immédiatement, complètement

Pronominal

1671 Mais je vous veux premièrement, Prouver par bon raisonnement,

Que ce mal dont la peur vous mine et vous consume,

N'est mal qu'en votre idée, et non point dans l'effet.

En mettez-vous votre bonnet

Moins aisément que de coutume?

Cela s'en va-t-il pas tout net?

Voyez-vous qu'il en reste une seule apparence :

Une tache qui nuise à vos plaisirs secrets ?

(Jean de La Fontaine, La Coupe enchantée)

II. cela va net : le travail se fait sans entrave Intransitif

1757 Maintenant, à chaque article, nous verrons revenir ce refrain des lois constitutives. Cela va net à l'assemblée des États généraux du royaume, et même cette réunion des parlements avec la jonction des princes et des pairs, où ceci les mène, a plus de poids et d'effet encore que les États généraux : voilà un gouvernement national tout formé, avec un avantage de plus, savoir que le clergé ne s'y trouve pas (René-Louis d'Argenson, Journal et Mémoires)

REMARQUES : Aller net (I) se dit de quelque chose qui disparaît d'un coup et totalement. (II) renvoie au fait de procéder sans faire de détours. Net est modifié par tout. VoIR AUSSI : absorber net

\section{Aller petit}

I. s'en aller petit : partir, quitter un lieu craintivement, sans gloire

Pronominal

+1150 Del moustier saint Denis le maistre confanon

Et la senescaudie de tout uostre roion, 
Et petit s'en ira que par mi ne parton

(Aiol et Mirabel [ $2^{\mathrm{e}}$ moitié XII $]$, 8095)

II. Parcourir peu de distance ; prendre peu de temps

Intransitif

1170 Isnelemant passent le pont, Mes mout orent alé petit

Quant de la tor amont les vit

Cil qui de la tor estoit sire

(Chrestien de Troyes, Erec et Enide, 3675)

+1225 Petit eurent alé en tel manière quant il virent terre. Et il demandèrent as maronniers quele terre chou estoit. Et li maronnier respondirent que che estoit terre de Sarrazins (La Comtesse de Ponthieu [2 $2^{\mathrm{e}}$ quart XIII ${ }^{\mathrm{e}}$, p. 198)

1250 Des mors et des navrez devant li tant versa Petit i peut aler qui sus mort ne monta (Doon de Mayence, p. 263)

RemARQUes : En ancien français, aller petit exprime le fait d'avancer peu. Dans l'exemple (I), la personne à laquelle réfère le sujet s'éloigne en évitant de se faire remarquer. Petit reste invariable et est modifié par plus, tout.

\section{Aller plein}

s'en aller plein : sans ralentir son allure

Pronominal

+1250 Brichemer n’i entent nul mal.

Vers la vile par mi un val

S'en vont le droit chemin tot plein.

Atant estes vos un vilein

Qui avoit avoc lui trois chens

(Le Roman de Renart [2 $2^{\mathrm{e}}$ moitié XIII'], X, 1079)

1857 Les Scythes vagabonds aux flèches meurtrières

Les Gélons demi-nus, les Sarmates lointains...

C'était plaisir alors! Des légions entières

Franchissaient le Danube, au pays des Germains!»

Et tandis que sa voix s'en allait large et pleine,

Melaenis le brûlait du feu de son haleine (Louis Bouilhet, Melænis)
CORPUS Web :

Au moins ils vont quitter le camp et à onze heures deux cars " Pous ", de Decazeville, qui étaient venus les chercher s'en vont pleins, vers la liberté [http://espana36.voila.net/r_arto/pll15. html] (13.11.2013)

Remarques : Plein est un adjectif-adverbe de manière qui caractérise la poursuite d'un chemin, indiquant sa pleine possession. Dans l'exemple de l'ancien français, il est modifié par l'adverbe d'intensité (tout) qui le précède. L'exemple rappelle la locution toute sa pleine voie 'sans ralentir son allure'. Plein s'utilise aussi comme prédicat second (avec large) accordé avec le sens 'sa voix était large et pleine' (1857) et '(les cars) étaient pleins' (CW).

\section{Aller profond}

I. Aller profondément

Intransitif

1275 Combien que dou fleuve s'aproochent ;

Un petitet, senz plus, en beivent,

$\mathrm{E}$, quant la douceur aperceivent,

Volentiers si parfont iraient

Que tuit dedenz se plongeraient (Jehan de Meun, Roman de la rose [1269-1278], 6013)

1839 Soudain apparaît

La seconde armée

De lances semée,

Comme une forêt.

Elle va profonde,

Et mugit et gronde

D'un souffle infernal

(Ernest Buschmann, Rameaux)

1937 Elle est allée seulement plus profond, si profond que la chair elle-même y répond par une souffrance inconnue, qui rayonne du centre de la vie dans le pauvre petit corps douloureux (Georges Bernanos, Nouvelle Histoire de Mouchette)

1972 Pour la voûte crevée, ils aggravèrent le trou jusqu'à ce qu'ils rencontrent de la maçonnerie saine. À vrai dire, ils n'allèrent pas bien profond, car le travail avait été bien fait, dans les siècles d'obscurantisme (Henri Vincenot, Le Pape des escargots) 
II. Aller en profondeur, pénétrer

(intellectuellement, sentimentalement, historiquement)

Intransitif

1910 Par son impotence même de mal, de cruauté Corneille va plus profond que Racine. Car la cruauté n'est point, tant s'en faut, ce qu'il y a de plus profond. Elle n'est point le profond du cœur, elle n'est point le profond de l'homme (Charles Péguy, Victor-Marie, comte Hugo)

1936 Et s'il y en a qui plus tard, en se souvenant de leur capitaine, disent : « quand même, c'était 'un bon bougre', j’aurai été bien payé. » Ayant lu cela, Costals avait relevé la tête ; cela allait très profond en lui, et il songeait : « je suis un type dans le genre d'Hurluret. Naturellement, il y a en moi autre chose. Mais je suis aussi Hurluret » (Henry de Montherlant, Pitié pour les femmes)

1938 - Tu m'aimeras plus quand je serai plus là, elle gueulait. Oh ma nine, oh ma belle quique ! elle faisait Madeleine Dietrich en pleurant aque des yeux qu'ils allaient profond dans le cœur. Tandis que toi, elle disait, tu seras toujours beau petit et $\mathrm{tu}$ viendras jamais vieux (Albert Cohen, Mangeclous)

1974 Pons Sabatier, Randon de Chateauneuf, Joachim Amargier ; d'autres portaient les noms des villages et des hameaux du canton précédés d'une particule.

- Nos racines vont profond, Olivier ! (Robert Sabatier, Les Noisettes sauvages)

1991 Passe le récit, aveuglement compris, quand la philosophie répète et piétine. Mais elle seule peut aller assez profond pour démontrer que la littérature va encore plus profondément qu'elle

(Michel Serres, Le Tiers-Instruit)

\section{CORPus Web :}

Quel genre de chemin veut-on emprunter ou créer ? Dans quel sorte de paysage ? Seul ou en compagnie? Aller loin, ou aller vite, ou aller profond, ou aller haut, ou aller beau, etc ... ? Définir précisément ce qui, à chaque carrefour de vie, nous fera choisir telle voie plutôt que telle autre [http://www.noetique.eu/ articles/philosophies/lart-de-vivre-sa-vie/view] (18.5.2016)

la largable, ascenseur, hippopotame, bouteille de périer et tout le tointoin ne sont pas la pour aller plus profond... mais pour descendre profond avec plus de sécurité..... [http://www. chasse-sous-marine.com/forums/topic/51338recherche-chasseur-ou-apneiste-pour-allezprofond] (30.1.2015)

REmarques : Profond est un adjectif-adverbe de degré qui caractérise, au sens figuré, l'intensification de pensées ou de sentiments. Aller profond (I) se dit de quelqu'un ou quelque chose (ici : les yeux) qui perce, ou rentre profondément dans quelque chose/quelqu'un. Au sens figuré (II), il se dit de pensées, paroles, sentiments qui, pour ne pas rester superficiels, s'approfondissent, s'intensifient, vont plus en détail, afin d'élargir un champ de vision ou arriver à un résultat attendu. Profond reste invariable et est modifié par assez, bien, plus, seulement, si, très. En poésie, l'accord de profond renforce l'implication du sujet dans un mouvement qui va en profondeur, mais sans lui enlever sa valeur de modifieur du verbe. Dans ce cas-là, profond peut s'accorder avec le sujet (1839). Notons l'emploi de descendre profond.

\section{Aller raide}

I. Aller impétueusement, de façon résolue Intransitif

1543 Les fiers chevaulx piquer donne toy garde, Ains par la resne à force les retarde. De leur gré vont, voyre si roide et fort, Qu'à les tenir fault merveilleux effort (Clément Marot, Livre second de la métamorphose)

1610 Il y avoit le baron de Sault avec ses fesses, dont le proverbe en est venu, qui tendoit beau cul, sans y penser. La fin du coup va roide à son cul, d'autant qu'il estoit ainsi tourné parlant à d'autres ; et partant il eut le cul coupé. «Ha ! ce dit-il, monsieur, qu'avez-vous fait ? Vous avez gasté mon haut-de-chausse » (Béroalde de Verville, Le Moyen de parvenir) 
1833 Mais telle est la nature des révolutions qu'elles ne savent pas s'arrêter ; les hommes qui leur appartiennent sont sans ménagements; ils vont raide et droit devant eux, sans s'inquiéter s'ils ne creusent pas un tombeau aux idées libérales par leur inconcevable obstination (Baptiste Capefigue, Histoire de la Restauration)

1880 Mais, comme elle prenait le bouquet, il lui sauta sur les mains, avec la gloutonnerie de son bel âge. Elle dut le battre pour qu'il lâchât prise. En voilà un morveux qui allait raide ! Tout en le grondant, elle était devenue rose, elle souriait. Et elle le renvoya, en lui permettant de revenir. Il chancelait, il ne trouvait plus les portes (Émile Zola, Nana)

II. S'en aller en adoptant une posture verticale, tendue ; avancer raide comme un piquet

Pronominal

1840 Ainsi affûtés, apprêtés, bichonnés, ces gens d'un âge indicible, d'un sexe même problématique, tant ils se sont épilés dès leur première gelée blanche, s'en vont raides comme bâtons, poupées à ressorts, momies galvanisées, colportant çà et là un éternel sourire stéréotypé sur un double râtelier de Pernet (Francis Wey, L’Ami des artistes)

1870 VICTOIRE DE SARREBRUCK

gravure belge brillamment coloriée, se vend à Charleroi, 35 centimes

$\mathrm{Au}$ milieu, l'empereur, dans une apothéose

Bleue et jaune, s'en va, raide, sur son dada Flamboyant ; très heureux, - car il voit tout en rose,

Féroce comme Zeus et doux comme un papa (Arthur Rimbaud, Poésies)

1894 Et je dis à Dieu : « Puisque, dans votre colère, vous lui avez donné la richesse et la beauté, regardez-la, seigneur, avec mansuétude, et traitez-la selon votre grande miséricorde. » Et il s'en alla, raide et trâ̂nant la jambe, par l'avenue populeuse (Anatole France, Le Lys rouge)
Intransitif

1963 La glycine s'étire et le mur en éveil

Rougit. Une journée s'accroche aux lourdes branches ;

Les paysannes vont raides sous leur palanche ;

Les maires de parade ouvrent le grand conseil (Jean-François Hocedez, La Soif)

III. Aller rapidement, avec détermination et

force

Intransitif

1853 Le tout terminé par quelques considérations sur ce que peut être la littérature de l'avenir. La Bovary ne $v a$ pas raide : en une semaine deux pages !!! Il y a de quoi, quelquefois, se casser la gueule de découragement! (Gustave Flaubert, Correspondance)

1929 Une main d'usurier, ça chasse tout seul. Où ce qu'y a de l'or et de l'argent, ça y va raide tout droit. Ça irait vous chercher la bourse dans la poche. S'y a queq'chose au fond de la mer, la main à Lévy vous le trouvera pour sûr (Paul Claudel, Le Soulier de satin)

IV. ne pas aller raide : se porter mal

Intransitif

1880 La vertu seule m’a ramené vers l'article cerveau du Dictionnaire des sciences médicales. J'imagine que la Peinture ne $v a$ pas roide en ce moment, et que mon Loulou a un moment de découragement? Est-ce vrai ? Ma lettre est bien bête, et bien décousue, tâche de m'en écrire une longue (Gustave Flaubert, Correspondance. Supplément)

CORPUS WEB :

Et ils font reculer leurs deux barques de vingt pieds

Ils sont en place et puis ils s'observent de nouveau,

Et leurs barques vont raides comme des oiseaux,

Les lances se croisent et se touchent toutes deux,

La lance se brise dans la main de Thonnérieux! [http://www.histoire-genealogie.com/spip. php?article836] (14.11.2013) 
ciao tout le monde, comme le titre peut laisser deviner, je trouve mes cheveux (je suis asiatique) beaucoup trop

raides. Ils veulent pas suivre la courbe du crâne et s'en vont raides comme des curedents !!! [http://forum.doctissimo.fr/forme-beaute/peaucheveux/cheveux-raides-help-sujet_158667_1. $\mathrm{htm}]$ (14.11.2013)

Ils reçoivent moins de 400 millions/année et ils demandent 225 millions de plus. Ils y vont raide! [http://www.radio-canada.ca/regions/que bec/2013/10/24/008-maniestation-organisationscommunautaires.shtml] (14.11.2013)

REMARQUES : Raide est un adjectif-adverbe de manière qui réfère à la vitesse ou la brutalité d'un procédé effectué résolument et sans détour. Les exemples de 1543 et 1833 indiquent un emploi invariable. Raide est modifié par si. Notons la collocation avec les adjectifs-adverbes fort et droit. Utilisé à la forme négative (IV), raide se dit de quelque chose qui se porte mal, qui n'a pas de succès. Dans ces emplois, le mot est vieilli. Raide est également employé comme prédicat second orienté vers le sujet indiquant que celui-ci se déplace tenant le dos droit et rigide (II). Dans ce sens, il s'accorde avec le sujet, du moins dans un langage soigné (ex. de 1840, 1963 et CW). Dans les exemples provenant d'Internet et représentant une écriture spontanée (dernier et avant-dernier exemple du CW), la prédication seconde se situe dans un continuum sémantique avec l'emploi adverbial au sens de 'directement, résolument'. L'emploi invariable ou fléchi de raide reflète cette situation. Le dernier exemple pourrait documenter la continuité au Canada de l'usage ancien. Mentionnons l'emploi de ça chasse tout seul (à comparer avec ça va tout seul sous aller seul).

\section{Aller rapide}

I. s'en aller rapide : partir, mourir, disparaître rapidement

Pronominal

1845 Tout en irritant sa sensibilité par son imagination, il tâchait que son esprit en annulât les effets, et que le sérieux de la sensation s'en allât rapide comme elle. Dès que quelque chose était entré en lui, il l'en chassait sans pitié, maître inhospitalier qui veut que son palais soit vide pour y marcher plus à l'aise (Gustave Flaubert, La Première Éducation sentimentale)

1893 À travers la mer des Indes, la Circé s'en allait rapide et doucement balancée, toute blanche de toiles sous une incandescente lumière, entre deux infinis très bleus, laissant derrière elle, comme une longue queue, son éternelle traînée bruissante, qui étincelait de soleil (Pierre Loti, Matelot)

1922 Tandis qu'ils se glissaient à travers l'ombre des longs corridors, la jeune femme, en guise d'adieu à leurs plaisirs qu'elle sacrifiait à l'amour, lui récita les vers du poète : « La tulipe fleurit promptement et s'en va légère et rapide, mais le rubis qui se forme avec lenteur ne craint rien du vent ni de la pluie et traverse toutes les saisons " (Maurice Barrès, Un jardin sur l'Oronte)

II. Aller rapidement, vivement

Intransitif

1862 Alors, repassèrent en foule dans ses souvenirs les aimées d'autrefois, avec leurs attitudes préférées, leurs regards doux ou fiers : blondes, brunes, elles allaient lentes ou rapides, dignes ou cyniques. Mais pas une n'obtint un sourire. Elles ne parlaient plus ni à son imagination ni à son cœur. Anna était devenue tout son horizon (Paul Reider, Mademoiselle Vallantin)

1960 pensant à la peau, à la saveur des prunes des reines-claudes mûres bleuâtres se fendant et leur jus sucré, je la lâchai retombai sur le lit tâtant ma pommette pouvant l'entendre de nouveau aller et venir rapide avec ces mouvements rapides précis qu'ont les femmes pour ranger, se baissant ramassant quelque chose je me demandai comment elle pouvait faire (Claude Simon, La Route des Flandres)

CoRpus Web :

hier, je t'ai dit:

je t'appelle dans le vide !

je t’appelle au milieu de ma nuit !

mes mots s'en vont rapide 
mais iront-ils jusqu'a toi aujourdh'ui ? [http://forum.mejliss.com/ya-moulete-fi-galbianasi-passe] (14.9.2013)

en occident les presidents viennent et s'en vont rapide (Sarko aussi n'echappera pas à la regle) contrairement aux notres, tellement ils restent trop longtemps au poste on fini par oublier le nom du pays [http://blog.lefigaro.fr/ algerie/2011/03/libye-la-doctrine-algerienneface-aux-frappes-militaires.html] (14.9.2013)

Tenten se leva et entra dans les bras de Neji, je ne sais pas pourquoi mais je la trouve entreprenante ! Elle chuchota un truc dans l'oreil a Neji et celui-la souria. Vraiment ! Les gens vont rapide ! [Regarde Sasuke] Et moi, je suis plus lente qu'une limace [http://shippuden-fanfic-x.skyrock. com/2555983559-Chapitre-08.html] (14.9.2013)

REMARQUES : Rapide est un adjectif-adverbe de manière qui caractérise la vitesse de l'exécution d'une action ou du déroulement d'un événement. S'en aller rapide réfère à une disparition rapide (I). Aller rapide (II) désigne le fait de se déplacer, de marcher rapidement. La collocation aller et venir rapide laisse sous-entendre des allées et venues du sujet. L'accord des adjectifs avec lesquels rapide se combine indique un emploi appartenant à un registre soutenu qui préfère rapide à vite. Le premier exemple du CW est une prédication seconde, même si la sémantique de rapide tend à inclure le verbe. Par contre, les exemples suivants provenant de l'écriture spontanée du français actuel confirment que rapide peut fonctionner comme modifieur du verbe aller (ou s'en aller) tout en restant invariable. Historiquement, rapide est d'abord emprunté comme adjectif et, par la suite, de l'adverbe canonique rapidement. L'emploi adverbial de rapide apparait plus tard, au gré de son passage de la langue soignée à l'usage familier. Les exemples littéraires cités ici reflètent l'essor tardif de la fonction adverbiale, ainsi que l'emploi préférentiel comme prédicat second accordé. Les exemples du CW mettent en évidence que l'emploi adverbial invariable est entré dans l'usage familier.

\section{Aller serré}

y aller serré : entreprendre résolument, intensément quelque chose, sans lâcher prise Intransitif

1942 Même la bête a manqué de cœur. Penses-y, mon vieux, ça en vaut la peine. Ne crains pas d'installer un peu. Beau comme tu es, avec ces yeux-là, cet air royal que tu peux avoir... Pense au public, pense au boss. Vas-y serré, du drame dans la prunelle... Compris ? (Maurice Genevoix, Le Nid du condor)

\section{Aller seul}

I. aller (tout) seul : évoluer, fonctionner sans intervention externe

Intransitif

1592 Il prise comme il doit la volupté corporelle, mais il prefere celle de l'esprit, comme ayant plus de force, de constance, de facilité, de varieté, de dignité. Cette cy $v a$ nullement seule selon luy (il n'est pas si fantastique), mais seulement premiere. Pour luy, la temperance est moderatrice, non adversaire des voluptez (Michel de Montaigne, Essais)

1681 Que les hommes ne pensent plus que le monde va tout seul, et que ce qui a esté sera toûjours comme de luy-mesme. Dieu qui a tout fait, et par qui tout subsiste, va noyer tous les animaux avec tous les hommes, c'est à dire qu'il va détruire la plus belle partie de son ouvrage (Jacques-Bénigne Bossuet, Discours sur l'histoire universelle)

1710 Personne ne sauroit croire avec quelle admiration tout le monde nous regardoit. On ne pouvoit comprendre comment il étoit possible que cette machine allât seule, et sonnât toutes les heures du jour (Simon Tyssot de Patot, Voyages et avantures de Jaques Massé)

1800 La France révolutionnaire n’a pas été exempte de ces atroces et ridicules inconséquences, et elles nous ramènent involontairement aux usages de ces républiques anciennes où l'homme respectant son égal, et opprimant son semblable, autorisoit par ses lois le meurtre de l'enfant, 
du gladiateur, de l'esclave, punissoit d'un supplice affreux la foiblesse d'une vestale, lors même que pour de grands crimes, il n'infligeoit qu'à regret, une légère peine au citoyen. Le pouvoir fixé ou constitué, $v a$ tout seul, dit M. Bossuet, et avec la nature (Louis de Bonald, Essai analytique sur les lois naturelles de l'ordre social)

1883 Ce n'est pas comme à Saint-Nicolas, par exemple, où on ne laissait jamais la machine aller seule ; le mécanicien était toujours là, volant à droite, à gauche, mettant partout le doigt, essoufflé, empressé, parce qu'on ne songeait pas que la machine la mieux montée est celle qui exige le moins d'action de la part du moteur (Ernest Renan, Souvenirs d'enfance et de jeunesse)

1904 Il y a des voitures que des chevaux traînent par les rues. Elles sont terribles. Il y a des voitures qui vont toutes seules en soufflant très fort. Celles-là aussi sont pleines d'inimitié (Anatole France, Crainquebille, Putois, Riquet)

1911 Pour ne pas aimer son prochain, mon enfant, il faudrait se boucher les yeux et les oreilles. À tant de cris de détresse. Mais l'espérance ne va pas de soi. L'espérance ne va pas toute seule. Pour espérer, mon enfant, il faut être bien heureux, il faut avoir obtenu, reçu une grande grâce (Charles Péguy, Le Porche du mystère de la deuxième vertu)

Pronominal

1844 - Mais tu ne réponds pas à ce que nous te demandons ? reprit Marie en essayant de la retenir.

- Voyez, voyez, Mam'selle ? dit Jeanne ; mes vaches s'en vont toutes seules. Elles sauteraient dans le jardin ! Ne me détemsez pas, ma mignonne!

Et Jeanne, se dégageant, s'enfuit à travers la prairie (George Sand, Jeanne)

II. aller tout seul : aller de soi, être clair Intransitif

1723 SILVIA. Je ne l'en empêche pas, il est le maître : mais faut-il que je l'aime, moi ?
Non, et il ne le faut pas, parce que je ne le puis pas, cela va tout seul : un enfant le verrait, et vous ne le voyez pas.

TRIVELIN. Songez que c'est sur vous qu'il fait tomber le choix qu'il doit faire d'une épouse entre ses sujettes (Pierre de Marivaux, La Double inconstance)

III. aller tout seul : évoluer, fonctionner, se faire sans difficulté, sans problème, sans effort Intransitif

1736 Après cela, on dîne sans se parler, on se couche sans mot dire, et l'on se reléve en grondant; au lieu que quand un mari est toûjours gai avec sa femme, et quand il badine avec elle, dame, cela fait qu'elle a toûjours de l'amitié pour lui de reste, le ménage va tout seul : mon poulet, que veux-tu manger, vous viendra-t-elle dire? Ma poule, ce qu'il vous plaira, repondrez-vous (Pierre de Marivaux, Le Télémaque travesti)

1854 Par bonheur, mon inclination se trouve tout à fait du même côté que la sagesse. Les choses iront donc tout seul. J'ai du reste trouvé M. de Tallenay fort accueillant et très aimable. M. Cintrat lui avait écrit une lettre fort bienveillante pour moi (Arthur de Gobineau, Correspondance avec Alexis de Tocqueville)

1856 EDGARD. (à Bassecourt) Vous aimez donc bien Anatole?

BAsseCourt. Parbleu ! Un si charmant garçon!

(à Anatole) Soyez tranquille, je reparlerai encore à Péponet, et votre mariage ira tout seul

(Théodore Barrière et Ernest Capendu, Les Faux Bonshommes)

1924 L'affaire n'allait pas toute seule. Hugues trouva heureusement un allié. Adalbéron, arche-vêque de Reims, avait eu de graves difficultés avec Lothaire qui l'avait accusé de trahison (Jacques Bainville, Histoire de France)

1962 Quand elle lui tendit un petit couteau pointu, il avança pour le prendre une main qui tremblait. 
- Vous verrez, dit-elle, c'est facile. Quand on a pris le coup, ça va tout seul.

Elle commença, penchée sur la table et Julien regardait ses mains fortes aux doigts ronds et lisses, un peu rouges. Elle portait une blouse à manches courtes (Bernard Clavel, La Maison des autres)

IV. aller seul : en solitaire

Intransitif

1844 « mais on dit qu'il y joue tous les soirs aux dominos avec son ami M. Gobseck. Je ne veux pas aller là toute seule, mon oncle me conduit et me ramène » (Honoré de Balzac, Les Employés)

\section{CORPUS WEB :}

Les gens qui vont seul au cinéma, c'est quoi votre délire ? [https://twitter.com/abdouwahab/ status/319921567394058240] (14.11.2013)

Eh bien figurez-vous qu'ils y allèrent, dignes, fiers, et... seuls [https://www.justfocus.fr/ musique/critique-musique/pierre-et-georges-auconcert-des-chk-chk-chk.html] (22.5.2016)

REMARques : Seul est un adjectif-adverbe de manière qui réfère à une action exécutée de façon interne, sans intervention extérieure. La référence au mode d'exécution produit donc un rapport métonymique avec les circonstances du déroulement. Dans les deux cas de figure, le sémantisme est plutôt adverbial-circonstanciel, ce qui n'empêche pas que l'attribut soit fréquemment accordé, suivant ainsi la même tendance que d'autres langues romanes (ex. espagnol Las puertas se abren solas 'Les portes s'ouvrent seules'). Aller seul s'utilise dans les contextes suivants : (I) se dit d'une chose (machine, monde) qui fonctionne sans cause extérieure. Sous la forme négative (exemples de 1592 et 1911), se dit d'une chose abstraite qui, pour le locuteur, va accompagnée ou suivie d'une autre. (II) se dit d'une chose qui est claire, qui n'a pas besoin d'explication. (III), expression figée dont le sujet est inanimé et souvent imprécis (ça), renvoie à quelque chose qui fonctionne sans demander d'efforts ou l'intervention d'une tierce personne. Sous (IV) nous avons ajouté deux emplois comme prédicat second. Seul est modifié par donc, là, nullement, tout. Notons que tout est également fléchi, dans la plupart des cas, même si sa fonc- tion est considérée adverbiale (ex. toute seule). L'emploi invarié est exceptionnel (exemple de 1854 et premier exemple du CW, ce dernier pouvant relever d'une simple faute d'orthographe). Mentionnons l'emploi de ça va tout seul et de souffler fort.

\section{Aller soef}

I. s'en aller soef: aller, couler doucement, lentement

Pronominal

+1100 Amunt un duit s'en vunt süef, [variante : mult suef]

E od cordes traient lur nef.

$\mathrm{Al}$ chef del duit out une arbre

Itant blanche cume marbre,

$E$ les fuiles mult sunt ledes,

De ruge blanc taceledes (Benedeit, Voyage de saint Brendan [ $1^{\mathrm{er}}$ quart XII $]$, 489)

1370 Si te convendra ouvrer par sens en telle maniere que, tantost que tu seraz entrez en la chambre, tu te mettes serré du mur, et t'en va tout soef [variante : souavet] jusques au lit du roy et te quatis tous coiement dessoubz le lit, car moult bien t'i pourras repondre, et la te tien tous cois jusques a tant que tu aies oÿ comment ti adversaires conteront leur raison (Roman de Berinus, I, p. 70)

II. Aller doucement, tranquillement Intransitif

1170 Qui mellor quiert, ne set qu'il viaut.

Qui le chevauche, ne se diaut,

Ainz va plus eise et plus soef

Que s'il estoit an une nef

(Chrestien de Troyes, Erec et Enide, 1401)

+1225a Andoi sunt a pié descendu

Et vont avant tout souavet (Le Chevalier as deus espees [ $2^{\mathrm{e}}$ quart $\left.\left.\mathrm{XIII}{ }^{\mathrm{e}}\right], 10603\right)$

+1225b Et Gaus tint l'esrer a deduit, Cair il ne se doloit de rien. Se li plot mout et li fist bien, Et li autre souef aloient Por lui. Et devisé avoient Que Gaus a la cort en iroit (Le Chevalier as deus espees [2 $2^{\mathrm{e}}$ quart $\left.\left.\mathrm{XIII}{ }^{\mathrm{e}}\right], 10885\right)$ 
+1266 Compaignète, ne vous anuit, Quar en tel lieu serons anuit Où li vilains n'aura poissance. Alons souef, n’aiez doutance, Je chanterai, s'il vous agrée (La Chastelaine de Saint Gille [3 $3^{\mathrm{e}}$ tiers XIII $\left.{ }^{\mathrm{e}}\right]$ )

REMARQUES : En ancien français, soef est un adjectif-adverbe de manière modifié surtout par l'adverbe d'intensité tout, mais aussi : avant, plus. Aller soef se dit de quelqu'un qui se déplace comme s'il glissait sur l'eau, d'une manière douce et lente voire prudente. Notons la collocation aise et soef. VoIR AUSSI : ambler soef

\section{Aller sûr}

I. s'en aller sûr : partir en sécurité Pronominal

1176 Et d'autre part li dus enrage, Qui jure et afiche et propose Que seul a seul, se Cligés ose, Iert antr'aus .ii. bataille prise, Si la fera par tel devise Que se Cligés vaint la bataille L'empereres seürs s'an aille Et la pucele quite an maint (Chrestien de Troyes, Cligés, 3930)

II. Aller sans souci, sans inquiétude, avec un sentiment de sécurité, de confiance Intransitif

+1200 « Et se vos lor mandez sorfet, La honte, se l'en la me fet, En sera vostre et li maus miens. » «Va toz seürs, ne dote riens! Por quoi je puisse chevauchier, Se tu trueves le chevalier, Retorne a moi tot erraument » (Raoul de Houdenc, Meraugis de Portlesguez [début XIII'], 2022)

1209 Tant larrons avoit essorbez, Tant robeors fet essillier, Si seür com par un moustier Aloit chascuns par mi son regne (Jean Renart, Roman de Guillaume de Dole, 617)

1275 Meauz pourrait uns ribauz de Grieve Seürs e seus par tout aller, E devant les larrons baler, Senz douter aus ne leur affaire (Jehan de Meun, Roman de la rose [1269-1278], 5281)
1905 La route était déserte, la campagne vide d'êtres, ils ne voyaient point à dix pas devant eux ; ils allaient sereins et sûrs, dans la nuit bien-aimée. Jamais ils ne butaient contre les cailloux du chemin. Comme ils étaient en retard, ils prirent un raccourci (Romain Rolland, JeanChristophe. L'Adolescent)

REMARQues : Sûr est un adjectif-adverbe de manière caractérisant les circonstances d'un déplacement effectué en se sentant rassuré, confiant soit de par le fait de porter des armes, d'être sous la protection de quelqu'un ou de marcher dans un lieu sûr, complété par la notion d'éloignement du sujet (II). (I) renvoie à un départ en sécurité. Notons l'accord au cas sujet dans les exemples de l'ancien français. Dans l'exemple de 1905, l'interprétation penche du côté d'un prédicat second : les personnes se sentent sûres et se déplacent sans trébucher. Sûr est modifié par toz (tout), partout.

\section{Aller tortu}

Aller en zigzag

Intransitif

1670 Quand cette image doit estre portée par les ruës, on la met sur un cheval de bois, qui se tient en posture comme un cheval qui regarde ou s'esleve vers l'air : ce cheval-cy est sur un theatre de planches, et est porté sur les espaules ; et quand ils marchent ils ne vont pas le droit chemin, mais ils vont tortu, comme un cheval, qui se cabre (Thomas la Grue, La Porte ouverte [trad.])

1693 Mère Écrevisse un jour à sa Fille disait :

Comme tu vas, bon Dieu ! ne peux-tu marcher droit?

Et comme vous allez vous-même ! dit la Fille.

Puis-je autrement marcher que ne fait ma famille?

Veut-on que j'aille droit quand on y $v a$ tortu? (Jean de La Fontaine, L'Écrevisse et sa fille / Fables)

1764 Mère écrevisse qui reproche à sa fille de ne pas aller droit, et la fille lui répond que sa mère va tortu, n'a point paru une fable 
agréable (Voltaire, Dictionnaire philosophique)

1906 LE BERGER. (seul) (Il rentre)

Ceux-ci ne cachent pas leur jeu ! C'est la vertu

Des jeunes d'aller droit où les vieux vont tortu ;

Ils s'aiment comme la faunesse et le satyre, Gaîment, et c'est autant de pris sur le martyre !

(Émile Bergerat, La Fontaine de Jouvence)

REMARQues : Tortu est un adjectif-adverbe de manière qui caractérise la ligne parcourue lors d'un déplacement, par opposition à aller droit. Il reste invarié. Notons l'emploi des antonymes marcher droit et aller droit.

\section{Allier ferme}

Lier, unir d'une manière forte, solide, stable Transitif

1584 Afin que ta vertu d'un tel Prince appuyée, Et au sang des Lorrains d'un nœud ferme alliée,

Luise un nouveau Soleil, privant de sa clarté

Ceux qui seront jaloux de ta felicité

(Pierre de Ronsard, Élégies, p. 213)

REMARQUES : Ferme est un adjectif-adverbe de manière 'fortement' modifiant le participe passé alliée qui s'accorde avec le sujet.

\section{Allonger droit}

S'étendre de façon rectiligne, sans dévier, selon une ligne droite

Pronominal

1848 La ville est ceinte de murailles dont à marée haute la vague vient battre la base, les mâchicoulis sont encore intacts comme au temps de la reine Anne, et la ligne des pierres dentelées s'allonge sur les remparts droite et basse, en se découpant dans la brume (Gustave Flaubert, Par les champs et par les grèves)

1860 Ils allaient, et le fleuve changeait, et la rive. Ils côtoyaient de petites falaises, de petites rampes à pic, veinées de beau sable jaune, qui s'allongeaient toutes droites, et d'où pendaient, mortes, blanchies et desséchées, des herbes chevelues qui faisaient penser à la barbe limoneuse des vieux fleuves (Edmond et Jules de Goncourt, Charles Demailly)

1872 A ce moment, la calèche sortit du bois. L'avenue de l'impératrice s'allongeait toute droite dans le crépuscule, avec les deux lignes vertes de ses barrières de bois peint, qui allaient se toucher à l'horizon (Émile Zola, La Curée)

1884 La route s'allongeait droit devant elle (Hector Malot, Marichette)

1891 L'escarpement à pic montre en bandes étroites

Ses couches s'allongeant fermes, égales, droites,

Rides profondes, plis de ce front de la nuit. Contre ce mur se heurte et flotte et roule, et fuit

Ce que chaque saison pêle-mêle charrie (Victor Hugo, Dieu)

1934 Brusquement, il mit sa bête au pas. Le sable était profond. La grande avenue aux feuilles neuves s'allongeait, très droite, devant nous, jusqu'au pied de la montagne émeraude (Roger Vercel, Capitaine Conan)

1950 Nous entrons dans les bois, tournons à gauche, vers le nord, sur une route large qui s'allonge, toute droite entre les futaies. Beaucoup l'ont déjà reconnue :

- Dis, c'est-i' pas la Calonne?

- Ça m'en a l'air.

- Mais c'est pas les Boches, là où qu'on va c'soir ? (Maurice Genevoix, Ceux de 14)

1978 Maintenant qu'on savait que Marko était mort, on s'était tous tournés vers l'entrée, pour voir le vieux qui s'en allait. Dehors, la route, comme tu sais, s'allonge tout droit entre deux collines, tantôt montant, puis descendant, puis montant encore. Il était déjà loin (Marguerite Yourcenar, Nouvelles orientales)

2011 Au sortir de la dernière forêt, au bout de la piste qui s'allongeait droit devant nous, 
nous vîmes apparaître un cavalier qui s'avançait vers nous bride abattue et qui s'arrêta à notre hauteur (Adrien Caraguel, Les Noyaux d'abricots)

Transitif

1894 Dehors, dans la nuit moite et taciturne, Une lune d'octobre allongeait droit, Comme pour défendre et protéger le toit, L'ombre grande des peupliers nocturnes (Émile Verhaeren, Poèmes)

\section{CORPUS WEB :}

Elle allongea droit devant elle le bras recouvrant sa poitrine et fit tourner son indice en cercle vers le sol lui indiquant d'en faire autant, le tirant de sa rêverie. Puis elle rétracta rapidement le membre à son emplacement d'origine : l'avantcœur [http://orquesetelfes.asiafreeforum.com/ t167p25-eamane-enialis-valkhyria] (15.11.2013)

Il suffit de s'allonger droit sur le sol, les mains le long du corps et lever les deux jambes en même temps. Jambes légèrement pliées pour les débutants et allongées pour plus de difficulté [http://www.sportregimepourmaigrir. com/2016/02/exercices-pour-perdre-des-cuisseset-du.html\#] (22.6.2016)

On m'a dit de m'allonger droite sur mon lit, les yeux ouverts, et de chanter des prières et des versets de textes saints hindous pendant l'éclipse », explique Sonya Chadha, comptable à New Delhi, enceinte de sept mois, qui a prévu de prendre aujour-d'hui un jour de congé [http:// www.lavoixdunord.fr/France_Monde/actualite/ Secteur_France_Monde/2009/07/21/article_laplus-longue-eclipse-solaire-du-siecle.shtml] (22.06.2016)

REMARQUes : Dans la plupart des cas, droit se comporte comme un prédicat second qui reflète les marques du genre et du nombre du sujet. Il ne réfère pourtant pas à une posture droite, debout, mais à une avenue, muraille, rampe, route ou rue s'étendant de façon rectiligne. L'emploi invariable apparaît dans l'emploi directionnel des exemples de 1884, 1894, 1978, 2011. Dans l'exemple de 2011, l'invariabilité pourrait être la conséquence d'une réanalyse comme modifieur de devant (droit devant ; à comparer : droit à, vers, sur, etc.). Le premier exemple du CW confirme la tendance à utiliser droit comme modifieur de la préposition devant. Dans l'exemple de 1894, où le verbe est employé transitivement, la rime impose l'emploi non-fléchi. Droit est modifié par l'adverbe d'intensité tout. Notons l'emploi en tant que prédicat second orienté vers le sujet 'sans se tordre' dans le troisième exemple du CW.

\section{Allonger net}

Faire tomber quelqu'un brutalement, tout d'un coup

Transitif

1912 Un traître croc-en-jambe de Migue la Lune l'allongea net, le nez dans une taupière, les bras en avant, la gueule ouverte (Louis Pergaud, La Guerre des boutons)

2007 Le frère aîné de Foussèni est sorti à son tour et s'est dirigé vers Tièba pour le frapper, mais ce dernier lui a flanqué un grand coup de poing dans la tête qui l'a allongé net par terre (Gérard Dumestre et Seydou Touré, Maléfices et manigances)

\section{CORPUS WEB :}

Cet apres midi je suis allé promener mon chien Chow-Chow de 2 ans en foret et au bout de $3 \mathrm{~km}$ il s'est allongé net [http://www.jeuxvideo. com/forums/1-50-134484413-1-0-1-0-meurtre-j-aitue-mon-chien-peur.htm] (18.11.2013)

Mais l'animation est vraiment bien faite et les personnages réagissent en véritables corps humain. Il ne faut pas 50 balles pour coucher un mec et au fusil à pompe en 1 coup le type s'allonge net [http://chezkjel.over-blog.net/article-test-dela-beta-multi-medal-of-honor-2010-58970091. html] (18.11.2013)

Le combat n'avait pas commencé que Rocky m’a allongé net [http://beckskulte21.skyrock.com/ 1875778261-Disney-27-au-29-juin-2008.html] (18.11.2013)

Une villageoise qui ne comprenait pas s'est allongée net, une balle au milieu du front. Tout le monde pleurait [http://groomjazzlucifer. wordpress.com/2012/04/08/la-fete-de-la-fumee] (18.11.2013)

REMARQUES : Allonger net réfère au fait de faire tomber quelqu'un, de façon brutale, sans la moindre résistance. Même si les exemples de 1912 et de 2007 ne le démontrent pas directement, on peut supposer que net tend à l'emploi 
invariable. En effet, tout comme fort ou droit, l'adjectif-adverbe net se combine productivement avec bon nombre de verbes. Si lexicalisation il y a, elle touche directement l'adjectif-adverbe, et moins le groupe qui l'unit à un verbe particulier. La fréquence élevée de net dans l'écriture spontanée du CW, surtout dans l'emploi pronominal, souligne son usage dans la langue quotidienne. Le dernier exemple met en évidence son invariabilité.

\section{Allumer haut}

Brûler en faisant de hautes flammes; produire un grand éclairage

Intransitif

-1209 Et une nuit a mie nuit mistrent le feu es nés, et laissent les voilles aler al vent, et li feu allumer mult halt, si que il sembloit que tote la terre arsist. Et ensi s'en vienent vers la navie des pelerins ; et li criz lieve en l'ost ; et saillent as armes de totes parz (Geoffroi de Villehardouin, Conquête de Constantinople, § 217)

\section{CORPus Web :}

J'allume haut les cierges

Et les yeux dans l'effroi

Les doigts transis de froid

Le souffle à bout de berge

Je coule

[http://www.univers-rr.com/RPar tage $/$ index.php? page $=$ rp\&id $=5495 \&$ start $=1]$ (18.11.2013)

Tu saisis ainsi la main, chose douce solitaire,

Et cela comme le poison - tout en haut sur ta peau,

ça allume haut mon jour - et ça aussi c'est vrai,

Ensemble on est un - séparé on est deux [http://www.pardon-my-french.fr/songs/ Glafouk\%20-\%20Fille\%20tu\%20sais $\% 20$ c'est $\% 20$ vrai $\% 20$ (Tres\%20Petit\%20Vanille]).txt (18.11.2013)

Porte de la poésie qui s'allume haut dans le ciel

Oser

Etoile filante

Sort de magie

Illuminer
Enchanter les étoiles [http://jeunes.poetes. free.fr/ecrits_stmarcel_cecm07.htm] (18.11.2013)

Pour ton voyant si tu pouvais prendre une photo du voyant !!!

Car je pense bien au shift light (qui s'allume haut dans les tours pour te dire de passer un rapport !!!) [http://www.cbr-world.com/t14464probleme-electrique-je-pense-600-cbr-fs-2001] (18.11.2013)

REMARQUES : Haut est un adjectif-adverbe de lieu qui a un sens spatial et désigne un point élevé d'un point de vue statique ou résultatif. Avec une interprétation de manière, il caractérise la démarche de brûler en parlant d'un feu. Il reste invariable et est modifié par moult. Les exemples plus récents du CW mettent en évidence que le tour est apprécié en poésie, mais on le trouve aussi dans la communication quotidienne (dernier exemple). Notons également l'emploi pronominal ou transitif du verbe dans le CW.

\section{Allumer subit}

Allumer rapidement, brusquement

Transitif

1538 A Vulcan donc son dueil elle declaire, Qui tout subit (pour à Venus complaire) De son chault feu (bien autre qu'amoureux)

Vint allumer, par un soir malheureux D’Anne le lict chaste et immaculé, Et en dormant son beau corps a bruslé, Duquel adonc l'ame noble s'osta, Et toute gaye au ciel luysant saulta, Sans se sentir du feu de Vulcanus, Encores moins de celluy de Venus (Clément Marot, Élégies)

CORPuS WeB :

Comme on peut r'allumer subit une chandelle,

Quand la mesche ard encor d'un petit souffle : ainsi

De l'Amour presque estaint on voit le doux souci

Desrechef s'embrasser de la moindre estincelle [http://emblems.let.uu.nl/catsretorica/ html/va1618039.html] (18.11.2013) 
REMARQUES : Subit est un adjectif-adverbe de temps à base adjectivale. Il reste invariable et est modifié par tout. L'exemple du CW (réallumer subit) souligne l'appartenance de subit à un style recherché et plutôt archaïque.

\section{Amarrer long}

Attacher (un bateau) avec une longue amarre, en laissant une plus grande marge entre lui et le quai

Transitif

1964 J'ai amarré le bateau aussi long que cela m'a paru possible sans risquer de contact fâcheux avec le bateau voisin. Personnellement j'aimerais mieux donner un peu plus de champ au bateau, c'est-à-dire un amarrage plus long, car je crains toujours pour les taquets et galoches quand les vagues des péniches soulèvent les bateaux (Correspondance privée de Grundt, 31 juillet 1964 / Grundt : 321)

CoRpus Web :

Si j'amarre long, je ne sais pas comment tiknot va se comporter avec les vagues [http:// www.bateaubois.com/fora/viewtopic.php?f= 25\&t=1075] (18.11.2013)

La nous amarrons au quai celui-ci est assez élevé à marée basse, alors il faut s'amarrer long et ensuite attraper l'échelle pour monter sur le quai [http://adrick.baup.fr/voguer/vacances-2008/delile-doleron-a-lile-de-re] (18.11.2013)

$\mathrm{Au}$ ponton de Port Tudy, j’amarre long mon bateau pour laisser de la place aux autres et je laisse mon moteur baissé car mon hélice peut percer les pneumatiques [http://ploemeur-touri sme.fr/wa_files/carnet_20finalise_CC_81_20ver sion_20alle_CC_81ge_CC_81e.pdf] (18.11.2013)

REMARQUES : Amarrer long caractérise la distance par laquelle le cordage sépare le bateau du quai ou d'un autre bateau. L'emploi absolu dans le premier exemple et l'emploi pronominal dans le second attestent sa lexicalisation dans le vocabulaire des marins. Il est modifié par aussi.

\section{Ambler soef}

Aller doucement, paisiblement

Intransitif

1170 Ja ne cuide veoir cele ore Enide, qu'il soient monté.
Un palefroi de grant bonté,

Soef anblant, jant et bien fet,

$\mathrm{Li}$ a l'an fors au perron tret

(Chrestien de Troyes, Erec et Enide, 5317)

+1200 Et quant fu nuis les dras vestit :

Il chanja trestout son abit ;

Desus le palefroi monta

Au moine, qui souef ambla

(Le Chevalier qui fist sa fame confesse, 82)

REMARQues : Ambler se dit généralement d'un cheval qui se déplace entre le trot et le pas, en levant alternativement les deux jambes du même côté, produisant un effet esthétique chez le spectateur. En ancien français, ambler soef désigne pour un cheval le fait d'ambler doucement, d'une manière agréable pour le cavalier. Il est antéposé au verbe.

\section{Amener droit}

Amener directement

Transitif

$\sim 1225$ Et au cinquieme [= iors], aprés hore de vespres, li avint que sa voie l'amena [variante : droit] $a$ une blanche abeie (Queste del saint Graal, § 37, 34)

1460 Et incontinent ce fait, vindrent tuer plusieurs princes et autres grans seigneurs de son sang qui estoient autour de lui. Et ces choses faictes, ledit conte de Warwyk print ledit Henry et l'amena tout droit en la ville de Londres, et portoit l'espée nue devant ledit Henry comme son connestable (Jean de Roye, Chronique scandaleuse)

1667 Cette insolence que je commis, fit eslever un grand murmure ; trois ou quatre officiers me saisirent pour me retenir prisonnier, mais un lieutenant du regiment qui me connoissoit, me retira d'entre leurs mains, disant qu'il me tiendroit en sa garde, et que je n'estois pas un gentilhomme à mal traiter : et m'amena droit en son logis (Tristan l'Hermite, Le Page disgracié)

1751 Cependant son impatience est extrême d'embrasser sa nièce. Il veut emporter cette consolation en mourant ; et je lui en ai donné l'espérance, parce que si cette chère personne consent à mon bonheur, 
mon dessein est de l'amener droit ici en sortant de l'église (abbé Prévost, Lettres angloises [trad.])

1893 Mais elle était trop bas, elle sentit que la pointe s'enfonçait ensuite dans la planche. Une seconde percée l'amena droit sur le fer du crochet. Cette fois, c'était trop direct (Émile Zola, Le Docteur Pascal)

1913 Cantique du Rhône :

LÆTA. Qu'il est beau, le navire noir que le vent et cette brise même sur mon visage

Amène tout droit en quelques instants $d u$ fond de la mer,

Quand il laisse tomber son antenne, et tourne, et se couche sur le côté !

(Paul Claudel, La Cantate à trois voix)

1939 La transition l'amenait droit au récit de sa course au Matterhorn avec Rudi, mais vue par elle, cette fois. Un garçon dangereux, ce Rudi, et dont Kate aurait à se méfier (Joseph Peyré, Matterhorn)

1985 C'est une fille qui m’a aperçu et montré du doigt... Et aussitôt, la meute fait un arc de cercle et prend une bretelle qui va l'amener droit sur moi ! Rassemblant mes dernières forces, je pique un sprint vers... vers... Vers le Néant Total (Philippe Manœuvre, L'Enfant du rock)

CORPUS WEB :

Alors qu'Emma est plutôt introvertie, Hélène est du genre dévergondée et très vite entre les deux jeunes filles naît une relation ambiguë qui effraie Emma et la rend malade. Quant à Hélène, son comportement excessif va l'amener droit vers la clinique psychiatrique [http:// www.babelio.com/livres/Tasma-Desolation-etdestruction/391713] (22.6.2016)

Belle composition d'un paysage d'hiver, j'aime bien les traces dans la neige qui nous amène droits vers les maisons ou chalets [http:// www.treklens.com/gallery/photo497403.htm] (19.11.2013)

J'ai un tournevis magnétique mais trop court, de plus la vis n'adhère pas bien, je n'arrive pas à l'amener droite sur le trou qui est étroit et me demande de forcer $=>$ la vis tombe sans arrêt [http://forum.hardware.fr/hfr/Hardware/2D-3D/ unique-nvidia-maxwell-sujet_962857_336.htm] (22.6.2016)

REMARQues : Droit est un adjectif-adverbe de manière qui caractérise le trajet parcouru par un objet ou une personne. Amener droit se dit de quelqu'un ou quelque chose qui amène, entraîne quelqu'un/quelque chose directement vers un lieu ou une personne. Droit reste invariable (ex. de 1751) et est modifié par tout. Amener droit est généralement suivi d'un adverbe de lieu (ici, là) ou d'une préposition de lieu indiquant la direction (à, vers, sur, de). Droit a tendance à s'associer avec ces prépositions au point de faire partie $\mathrm{du}$ groupe prépositionnel comme modifieur de la préposition. À la différence de l'écriture contrôlée, l'écriture spontanée du CW présente l'accord adverbial. Droite au dernier exemple du CW permet également une analyse en tant que prédicat second orienté vers le sujet : on essaie d'introduire la vis dans une position droite. VoIR AUSSI : acheminer droit

\section{Amuser ferme}

S'amuser beaucoup, à fond

Pronominal

1896 - Delestang, ce militaire épris de batailles?

Madeleine répondit, rieuse :

- Il place des engrais.

- Servet?

- À Paris encore, ne faisant rien, s'amusant ferme...

(Édouard Estaunié, L’Empreinte)

1956 Juju et L'Artisse s'amusaient ferme. Les flics les dévisageaient de leurs yeux de brochet (René Fallet, La Grande Ceinture)

CORPUS WEB :

Malgré la chaleur, les gens s'amusaient fermes au tournoi international de volleyball de plage de Québec samedi [https://www. journaldequebec.com/2011/07/23/ambiance-deplage-au-quebec-open-jeep] (23.7.2011)

\section{Amuser plein}

Amuser beaucoup, autant qu'il est possible Transitif

1883 Voilà qui m'amuse tout plein (Victorien Sardou et Émile de Najac, Divorçons) 
CoRpus Web :

Mais c'est ça qui rend les choses plus amusantes! (surtout pour moi, vu que je m'amuse plein en écrivant ça) [https://www.fanfiction. net/s/1173474/9/When-it-s-time-to-cry] (19.11.2013)

Ça les amuse plein, les Blancs, de savoîr qu'on vit à dix dans des shotgun houses, qu'on a pas de chars pour voyager, que ce monde ça pus de manger dans le frige à la fin du mois [http:// www.lilimaxime.com/documents/blues_du_ bayou_extrait.pdf] (19.11.2013)

Remarques : Plein est un adjectif-adverbe de quantité. Amuser plein se dit de quelqu'un/ quelque chose qui divertit, égaie beaucoup et occupe très agréablement, complètement. Plein est modifié par l'adverbe d'intensité tout. Les exemples montrent son appartenance au langage informel. Le second exemple du CW est canadien.

\section{Annoncer clair}

Annoncer clairement

$\lambda$ annoncer haut

\section{Annoncer haut}

Annoncer, affirmer, dire à voix haute, d'une voix forte, ouvertement, publiquement

Transitif

1450 JHESUS. Une question vueil avoir, Puisqu'a demandant procedez, Et se bien vous me repondez A celle que je vous feray, A la vostre responderay Sans differer, soyés en sceurs. Je vous demande, messeigneurs, Se le baptesme que prescha Saint Jehan et si hault asnonça, Estoit don de Dieu supernel, C'est a dire venant du ciel Ou d'umainne institucion (Arnoul Gréban, Le Mystère de la Passion, 16907)

1604 ANDROMACHE. Aussi n'est-il pas seul, d'autres mauvais augures

Annoncent haut et clair nos tristes aventures

(Antoine de Montchrestien, Hector)

1782 On le voit aux trois spectacles. S'il paroît dans une promenade, tout le monde le salue ; il parle à l'un, sourit à l'autre, aborde un troisieme, annonce tout haut la distribution de sa journée, et parle de son oisiveté avec le sérieux que pourroit prendre l'homme sensé qui annonceroit une occupation utile (Louis-Sébastien Mercier, Tableau de Paris)

1830 Voilà cet instinct qui l'annonce Plus haut que l'aurore et la nuit. Voilà l'éternelle réponse Au doute qui se reproduit !

(Alphonse de Lamartine, Harmonies poétiques et religieuses)

1889 Rattier me racontait que le chirurgien Trélat avait fait une opération à son frère, en annonçant presque tout haut que cette opération devait être nécessairement suivie d'une embolie, qui emporterait l'opéré, mais l'opération était de 6000 francs (Edmond et Jules de Goncourt, Journal)

1932 Quand le nègre domestique entra pour servir le thé nous fîmes silence.

L'une de ces visiteuses devait posséder cependant plus de discernement que les autres car elle annonça très haut que je tremblais de fièvre et que je devais souffrir aussi d'une soif pas ordinaire. Ce qu'on servit en fait de collation me plut tout à fait malgré ma tremblote (Louis-Ferdinand Céline, Voyage au bout de la nuit)

1978 Bien que privés du droit de séjourner dans les hôtels, les Tatars sont de plus en plus nombreux à Moscou : 400 à l'été 1967, qui annoncent bien haut qu'ils vont tenir une réunion sur la Place Rouge pour être enfin entendus. Le moment est choisi. Moscou s'est ouvert au tourisme et la saison bat son plein (Hélène Carrère d'Encausse, L'Empire éclaté)

\section{Corpus Web :}

Cette carte de visite allait annoncer haut et fort sa présence, se vendant à plus de 100000 exemplaires [http://www.domaineforget.com/41/ calendrier/patrick-watson] (22.6.2016)

Ce sont donc de bonnes nouvelles d'Afrique que nous devons annoncer haut et fort [http://fr. 
bab.la/dictionnaire/francais-allemand/anno ncer] (22.6.2016)

Une pièce in progress dans laquelle les indications scéniques s'annoncent haut et fort, les scènes se succèdent à un rythme effréné et où l'on ne craint pas les dérapages [http:// theatrenational.be/fr/program/266] (19.11.2013)

Avec le Khimki Moscou comme ultime adversaire, la marche vers la phase de poules de l'Euroligue s'annonçait haute pour Le Mans [http:// www.lefigaro.fr/autres-sports/2010/10/04/0202120101004ARTSPO00519-le-mans-defie-lekhimki.php] (19.11.2013)

Déjà, la crétinerie de l'épisode s'annonçait haute vu que Rayman poursuivait des lapins habillés en disco-man sur le dos d'une araignée géante [http://www.nintendomaine.com/ site-apercu-wii-rayman_raving_rabbids.html] (19.11.2013)

ReMARQUeS : Haut est un adjectif-adverbe de lieu que s'emploie ici au sens figuré de 'à haute voix', ou, au sens abstrait de 'ouvertement'. Il reste invariable et est modifié par bien, presque tout (haut), tout, très, plus. Le schéma " annoncer (+ quantifieur) + haut " semble figé. Dans les exemples du CW, sans quantifieur, l'emploi pronominal 'se présenter par anticipation' prédomine. L'accord adverbial semble possible, du moins à en juger par les derniers exemples ; dans l'avant-dernier exemple du CW, l'emploi métaphorique renvoie au sens concret de haut. Notons les collocations clair et fort et haut et fort dans le CW. Le tour renonce alors à l'insertion de quantifieurs selon le schéma mentionné ci-dessus ; autrement dit, elles les remplacent dans la fonction d'intensification.

\section{Apercevoir clair}

Constater, se rendre compte clairement, avec certitude

Transitif

1450 SAINT BERTHELEMY. Ce n'est pas icy fantasie

N'esperit qui nous puist decevoir ;

Tout cler pouons apparcevoir

Qu'il est vray homme naturel

(Arnoul Gréban, Le Mystère de la Passion, 31265)
1857 Il aperçut clairs et distincts les feux, puis les bandits, qui entouraient les feux du côté de la savane au-dessus du vent pour éviter la fumée (Émile Carrey, L’Amazone)

Pronominal

+1450 Par vieil venin et envie moderne, En quoy chascun qui entend et discerne Et du sentier du vrai droit ne desvoie, S'aperçoit clair de vostre oblique voie (Georges Chastellain, Euvres [3 $3^{\mathrm{e}}$ quart $\mathrm{XV}^{\mathrm{e}}$ ], VI, p. 223)

1870 Il est cependant facile d'éviter ces inconvénients : il suffit, une fois le grain séparé, de tenir la cuite légère, de rester exclusivement à la preuve au filet, et d'achever la séparation du grain et du sirop par des entrées fréquentes ; de la sorte le grain s'aperçoit clair et net dans la preuve (É[douard] Mérijot, Traité complet de fabrication et raffinage du sucre de betteraves [trad.])

1951 J'ai vu les gens, les rues, les maisons. Et j'ai reçu un choc. C'était comme quelqu'un qu'on revoit au bout de quelques années et dont on s'aperçoit, aussi clair qu'il fait jour, qu'il a la mort sur le visage. Les gens autour rient, s'affairent, vont et viennent comme si de rien n'était. Mais on voit, et on sait. Tout seul (Julien Gracq, Le Rivage des Syrtes)

REMARques : Clair est un adjectif-adverbe de manière employé au sens figuré de 'clairement'. Dans son emploi transitif ou pronominal, se dit $\mathrm{du}$ fait de prendre conscience de quelque chose avec certitude, après un effort d'attention ou de recherche. Clair peut être antéposé (exemple de 1450) ou postposé (exemple de 1951) au verbe. Il est modifié par aussi, tout. L'exemple de 1857 semble relever de la prédication seconde, mais du point de vue logique, l'interprétation adverbiale est plus probable, malgré la coordination avec distinct, qui, accordé, joue en faveur de la prédication seconde. Notons la collocation clair et net. 


\section{Appareiller bel}

Parer d'une façon élégante, raffinée, belle

Transitif

+1200 En chelui jour que je vous di peussiés veoir ou palais le roi maint boin chevalier viestu et apparilliet biel et richement et mainte biele damoisiele et mainte biele dame prisie de biauté ; mais sor toutes celes qui le jour i furent emporta le pris et l'ounour de biauté Morgue la fille Igerne (Merlin [ $1^{\text {er }}$ quart XIII] , p. 166)

Remarques : Beau est un adjectif-adverbe de manière qui adopte ici la forme neutre bel. Employé ici au passif, appareiller bel se dit du fait d'apprêter, de parer d'une belle façon, le sujet arborant des bijoux, parures ou habits de bon goût et précieux. Bel modifie ici deux verbes coordonnés, vêtir et appareiller. Notons la coordination avec l'adverbe richement. VoIR AUSSI : vêtir beau

\section{Appeler}

[Nous avons exclu du dictionnaire les collocations du verbe appeler au sens de 'nommer' du type II l'appelle belle]

\section{Appeler bas}

Appeler à voix basse

$\lambda$ appeler haut

\section{Appeler bel}

Appeler aimablement, agréablement, accueillir aimablement, souhaiter la bienvenue

Transitif

+1150 Teris le regarda, si tient le cief enclin, Bel et cortoisement a apeler l'en prist (Aiol et Mirabel [2 moitié XII $]$, 10364)

1176 Bien est Alixandres venuz, Car a rien qu'il vuelle ne faut, N'an la cort n'a baron si haut Qui bel [variante : bien] ne l'apialt et acuelle (Chrestien de Troyes, Cligés, 391)

+1200a Entre en le paleis li curteis forester, par le poine tint Gui le dancel, le pessoner l'altre, Miles li ignel ; $\mathrm{Bov}[\mathrm{es}]$ les vist si les apele bel (Bueve de Hanstone [début XIII'] ${ }^{\mathrm{e}}$, 3017) +1200b Et, quant le prior le choisi,

En contre lui mout biau sailli ;

Bel l'apela, sel fist descendre.

Puis si a fet son cheval prendre

(Le Chevalier qui fist sa fame confesse, 54)

1250 Puis les enprist mout bel a apeler :

Seignor, fet il, .i. don vos veil rouver,

Et par amor le vos veil demender,

Que tuit soiez avec moi au souper

(Aymeri de Narbonne [milieu XIII] ], 2084)

Remarques : Beau est un adjectif-adverbe de manière qui adopte ici la forme neutre bel. Appeler bel se disait en ancien français du fait de s'adresser à quelqu'un d'une manière douce, agréable, de façon à obtenir de lui une information relative à sa présence, ou pour lui faire comprendre gentiment qu'on lui demande de venir près de soi, le sujet comme l'objet étant toujours animés. La coordination de bel avec cortoisement (ex. de +1150) et son remplacement par la variante bien (ex. de 1176) confirment sa fonction adverbiale. Bel est modifié par moult. Notons l'emploi de accueillir bel et saillir beau 'sauter, s'élancer'.

\section{Appeler fort}

Appeler intensément

$\lambda$ appeler juste

\section{Appeler haut}

I. Appeler à voix haute, d'une voix forte Transitif

1177 Deus, com or ai le cuer riant Et lié et sain ! fet la pucele. Lors saut avant et si l'apele, [variante : haut escrie]

Si haut que toz li pueples l'ot, A mout haute voiz : Lancelot ! Trestorne toi et si esgarde Qui est qui de toi se prant garde ! (Chrestien de Troyes, Lancelot ou Le Chevalier de la charrete, 3681)

1250 A tant es dant Picons venu A sa porte, qui fermee iere ; Puis apela sa chamberiere Si haut que tuit l'ont entendu (Le Prestre teint, 339) 
1365 Il ait lou ciel delassus hault appelleit et huchieit. et la terre pour discerneir et iugieir sou pueple (Psautier lorrain, p. 52)

1572 Haut appelloit les ames, qui venoient, Et sur l'obsèque espaisses se tenoient, Faisant tel bruit que font en la nichée Les arondeaux attendans la bechée (Pierre de Ronsard, La Franciade, p. 109)

1559a Ce temps pendant, frappoit le mary à la porte, appellant le plus hault qu'il pouvoit sa femme. Mais elle faignoit de ne le congnoistre poinct, et disoit tout hault aux varletz de leans : "Que ne vous levez vous et allez faire taire ceulx qui font ce bruict à la porte ? » (Marguerite d'Angoulême, Heptaméron, p. 47, 24)

1559b La contesse, qui en partye le croyoit et en partye doubtoit, s'en alla à sa fille et luy dist : « Pourquoy m'avez vous appellée si hault ? "(Marguerite d'Angoulême, Heptaméron, p. 99, 1028)

1594 Aprés que l'Assemblée fut entrée bien avant dedans la Grande Sale, approchant des degrez où le daiz estoit eslevé et les chaires preparées, la place fut assignée à chacun par un heraut d'armes intitulé Courte-joye sainct-Denys, qui les appella tout haut, par trois fois, ainsi : «Monsieur le Lieutenant ! monsieur le Lieutenant ! monsieur le Lieutenant de l'Estat de Couronne de France ! » (Satyre Ménippée)

1612 Car il eut peur que ces nymphes fouillant ses habits ne l'eussent treuvé. En ce doute il appella fort haut le petit Meril, car pour le servir il estoit couché à une garderobe fort proche (Honoré d'Urfé, L'Astrée)

1713a Il acceptoit leurs offres, et ne délibéroit plus que du choix d'une des places qui lui étoient offertes, lorsque l'un de ces messieurs, vêtu d'une robe de Palais, l'appella plus haut que les autres (Robert Challe, Les Illustres Françoises)

1713b Je vais dans notre chambre, je vous y attendrai. Elle vint où nous nous promenions, et prit le tems que nous marchions devant elle. Elle m'appella tout haut, je me tournai et la vis : voilà monsieur, me dit-elle d'un air enjoüé, un billet qui vient de tomber de votre basque (Robert Challe, Les Illustres Françoises)

1848 Hélas! La génération qui rendit l'indépendance aux Teutons est évanouie ; il n'est demeuré en Germanie que de vieux cabinets usés. Ils appellent le plus haut qu'ils peuvent Napoléon un grand homme, pour faire servir leur présente admiration d'excuse à leur bassesse passée (François de Chateaubriand, Mémoires d'outre-tombe)

1876 Je serais bien aise d'avoir de vos nouvelles, princesse, ou plutôt chère princesse (car pourquoi ne pas vous appeler tout haut comme je vous nomme tout bas). Il doit faire beau à Saint-Gratien et je vous suppose sinon heureuse du moins tranquille (Gustave Flaubert, Correspondance)

1913 Nous devinâmes que c'était Ganache, le bohémien, qui n’osait pas ou ne savait comment traverser la cour. D'une voix pressante, anxieuse, il appelait tantôt très haut, tantôt presque bas :

- Hou-ou ! Hou-ou !

- Dites ! Dites vite ! cria Meaulnes au jeune bohémien qui avait tressailli et qui rajustait ses habits pour partir (Alain-Fournier, Le Grand Meaulnes)

1921 Point de participes à accorder, mais l'orthographe des mots les plus communs me devenait bizarre. Je voulus les appeler tout haut : mais jamais pavillon rouvert après des siècles ne rendit des portraits et des meubles plus vermoulus que ne le fit ma mémoire après deux ans de silence (Jean Giraudoux, Suzanne et le Pacifique)

1950 Alors, j'ai délibérément posé ma tête au bord de la table. Enfin, m'man Tine me secoue l'épaule en m'appelant tout haut pour chasser mon sommeil. Tenant la lumière d'une main, elle m'entraîne dans la chambre. Je suis imprégné de sommeil, et plus rien ne frappe mes sens (Joseph Zobel, La Rue Cases-Nègres) 
II. Inviter à une destinée privilégiée, supérieure dans l'ordre spirituel

Transitif

1704 L'entreprise est grande ; mais le secours est égal au travail : Dieu qui vous appelle si haut, vous tend la main ; son fils, qui lui est égal, descend à vous pour vous porter. Dites donc avec saint Paul : courage, mon ame : je puis tout avec celui qui me fortifie (Jacques-Bénigne Bossuet, Méditations sur l'Évangile)

1786 Vainement, à genoux devant la déesse, j'ai osé lui parler de mes craintes, et rappeller le vœu de ta mere. Je n'ai point accepté ce vœu, m’a répondu la fille de Jupiter ; Numa ne sera point mon prêtre, ses destins l'appellent plus haut. Numa me servira mieux sur un trône, qu'à l'ombre de mes autels : qu'il marche à Rome, et que ta tendresse pour lui ne s'oppose plus aux décrets du ciel (Jean-Pierre Florian, Numa Pompilius)

\section{CORPUS WEB :}

Pour gagner, il appartient à l'Intersyndicale d'appeler haut et clair à la grève générale jusqu'au retrait. Cet appel serait un signe fort ! [http:// www.gsiqi.org/wp-content/uploads/2016/06/ LC_GSI_23-06-2016-OK.pdf] (22.6.2016)

Pour exprimer notre horreur et notre condamnation sans faille du racisme, de l'antisémitisme, de l'islamophobie et du terrorisme sous toutes ses formes, y compris celui qui assassine et brûle des enfants avec des bombes au phosphore blanc,

Pour appeler haut et fort à la vie, à la liberté et à la fraternité [http://www.uoif-online.com/ communiques/appel-participer-aux-manifesta tions-ce-week-end] (22.6.2016)

REMARQUES : Haut est un adjectif-adverbe de lieu qui a un sens spatial et désigne un point élevé, au sens concret, et au sens figuré. Avec appeler, il caractérise le niveau supérieur de la voix. (I) se dit du fait d'appeler quelqu'un/quelque chose en haussant fortement la voix, afin d'en être entendu ou pour attirer son attention. (II) se dit du fait d'appeler, d'inviter quelqu'un à suivre une destinée particulière, privilégiée afin de s'élever dans un ordre spirituel, voire divin. Il reste invariable et est modifié par fort, le plus, plus, si, tantôt, tout, très. L'exemple de 1913 contient également l'adjectif-adverbe bas qui est en opposition sémantique (appeler à voix basse) avec haut, constituant une collocation avec lui : appeler tantôt très haut, tantôt presque bas. Notons les collocations haut et clair et haut et fort dans le CW, en emploi absolu. Mentionnons également l'emploi de dire haut, écrier haut, nommer bas.

\section{Appeler juste}

Appeler quelqu'un de manière correcte, comme il convient

Emploi absolu

1893 Il faut attendre affreusement longtemps les réponses ; et c'est pourquoi je comprends bien ceux qui préfèrent appeler fort qu'appeler juste. On ne sort de sa solitude qu'à l'aide d'une illusion ; mais il faut consentir ; il y en a dont l'orgueil répugne à consentir à être la dupe (André Gide et Paul Valéry, Correspondance)

REMARQUES : Appeler juste se dit du fait de s'adresser à quelqu'un sur un ton adéquat en utilisant des mots justes, pesés et adaptés à la situation. Notons l'opposition contextuelle à appeler fort.

\section{Appeler soef}

Appeler à voix basse, avec douceur Transitif

-1100 Li boens serganz kil serveit volentiers, il le nunçat sum pedre Eufemïen, suëf l'apelet, si li ad conseilét : "Sire, dist il, morz est tes provenders, e ço sai dire qu'il fut bons cristïens » (Vie de saint Alexis [fin $\mathrm{XI}^{\mathrm{e}}$ ], BFM, 338)

$\sim 1160$ El cors li ert li feus, qui l'art ; El se tornot de l'autre part, Relevot soi, puis s'aseoit, Et donc se recolchot a droit Et apelot celui de Troie Tot soavet, que l'en ne l'oie. Antre ses danz dit belement : Amors me moine malement, e jor ai mal et la nuit pis (Eneas, 8424)

1176 Et cele mainne grant dangier Et se desfant come pucele : Et cil la prie et si l'apele Molt dolcemant [variantes : soavet, 
bonement] sa dolce amie

(Chrestien de Troyes, Cligés, 3335)

-1200 Quant Godefrois l'entent, s’a de pitiet ploré, Les maroniers apele belement et soef : Signor, dist Godefrois, .i. petit m'entendés (Elie de Saint Gille [fin $\mathrm{XII}$ ], 2478)

REMARQUES : Usuel en ancien français, soef est un adjectif-adverbe de manière qui peut être antéposé (ex. de -1100) ou postposé (ex. de 1160) au verbe. Appeler soef se dit du fait de s'adresser à quelqu'un en baissant légèrement la voix, afin d'émettre un son agréable à l'oreille de l'interlocuteur. Il reste invariable et est modifié par moult, tout. Son usage relève d'un registre soutenu, littéraire. Notons la coordination avec l'adverbe belement (ex. de -1200) et son remplacement par les variantes dolcemant et bonement dans l'exemple de $\sim 1176$, ce qui confirme sa fonction adverbiale.

\section{Applaudir bas}

I. Se vanter, se glorifier en secret

Pronominal

1745 Vous m'objecterez que c'est encore là une saillie de l'amour-propre, qu'on s'applaudit tout bas, et qu'on ne manque point de se mettre au-dessus des autres, lorsqu'on s'imagine avoir plus la faculté de penser : j’y consens, je veux bien que vous me supposiez de l'orgueil, pourvu que vous m'invitiez vous-même à l'entretenir (François de Baculard d'Arnaud, Les Époux malheureux)

II. Applaudir quelqu'un en secret, sans le lui faire savoir

Transitif

1830 Il offre en souriant sa vie en sacrifice, Il se confie au dieu que son œil ne voit pas ; Coupable, a le remords qui venge la justice, Vertueux, une voix qui l'applaudit tout bas ! (Alphonse de Lamartine, Harmonies poétiques et religieuses)

1867 Elle parle argot, elle nage dans la Seine (en costume de bain) avec un prétendant qu'elle voit pour la première fois, elle le met en fuite à coups d'inconvenances, elle fait le rapin et le gamin, elle tire les pétards les plus saugrenus au milieu des conversations graves, se lâche et se livre, et son père, qui la gronde tout haut, l'applaudit tout bas (Hippolyte Taine, Notes sur Paris)

REMARQUES : Bas est un adjectif-adverbe de lieu qui désigne un niveau inférieur. En tant qu'attribut d'applaudir, il se prête à une interprétation de manière au sens figuré qui réfère au caractère discret de l'action (ici un applaudissement). Il reste invariable (ex. de 1867) et est généralement modifié par l'adverbe d'intensité tout. Notons gronder tout haut, applaudir tout bas. VoIR AUSSI : gronder haut

\section{Applaudir jaune}

Applaudir de façon contrainte en dissimulant sa gêne, son dépit

Emploi absolu

1884 M. Ferry s'est mis à faire du zèle, à la grande joie de la gauche, au grand scandale du centre qui, par nécessité de situation, applaudissait, mais qui applaudissait... jaune, si l'expression est permise (L'Illustration)

1957 Après qu'ils eurent applaudi jaune [= l'envoi du spoutnik], les savants américains rentrèrent dans leurs laboratoires (Paris Match, 19 août 1957 / Grundt : 249)

\section{CORPUS WEB :}

À la fin, on a applaudi. Je ne peux pas parler pour les autres, mais je suis pas mal certain que nous étions plusieurs à applaudir jaune [http:// sharedsite.com/hlm-de-renaud/journaux/index. php5/articles/ledevoir_25-01-01.htm] (25.11.2013)

Les Sarkozystes qui ont applaudi jaune à Périgueux, aussi, çà les ronge quelque part, d'entendre dans les commentaires que Sarko a fait du gaullisme-gauchisme, tout comme la fée Ségo est plus à droite que Chirac... [http://www. les4verites.com/politique/segolene-royal-latentation-du-gauchisme] (25.11.2013)

REMARQUES : Calqué sur le modèle de rire jaune, applaudir jaune se dit du fait d'applaudir de manière forcée, avec gêne, à contrecœur, sans approuver complètement les actes du sujet ap- 
plaudi. Les attestations dans l'écriture spontanée du CW traduisent l'emploi familier. Jaune reste invariable. VoIR AUSSI : rire jaune

\section{Apporter droit}

Apporter directement

Transitif

1285 Lors y a tantost envoiié.

Et cil furent apareillié

Qui le cheval de fust garderent ;

Droit en la chambre l'aporterent

La ou Meniadus estoit

(Adenet le Roi, Cleomadés, 13112)

\section{CORPUS WEB :}

Les publications religieuses peuvent apporter droit instruction religieuse dans la maison avec une vente en douceur qui convient le confort du lecteur et de commodité [http://www.expertstourisme.fr/christianisme-incitation-b974143. htm] (25.11.2013)

Malheureusement, le portail les a apportés droits devant Sidorak, roi des hordes de visorak, équi ont projeté les employer comme amorce en rassemblant Zivon, afin d'essayer d'apporter une extrémité au Toa Hordika [http://www.gamekult com/blog/igni-tion/54049/combo-visorak.html] (25.11.2013)

Explorer le pays avec un guide ou faire cavalier seul en utilisant une carte et une boussole. Si vous utilisez un guide, il va connaître l'emplacement du buffle et vous apporter droite pour le troupeau. Si non, vous aurez à suivre le troupeau de loin [http://www.cardplayerr.com/ VKNQRKEP] (22.6.2016)

REMARQUES : Apporter droit caractérise le fait de conduire quelqu'un, de porter quelque chose directement en un lieu ou vers quelqu'un. Droit est normalement suivi d'une préposition de lieu indiquant la direction (en) qui traduit la précision de l'action et renforce l'idée de finalité. Il est également possible d'analyser droit comme modifieur de la préposition. Les deux derniers exemples du CW montrent la possibilité de fléchir l'adjectif-adverbe dans des registres non contrôlés par la norme.

\section{Apprécier moyen}

Approuver sans enthousiasme, ne pas trop apprécier

Emploi absolu

1989 L'Élysée apprécie moyen

(Libération, 7.7.1989 / Noailly 2010)

VOIR AUSSI : aimer moyen

\section{Apprendre dur}

Recevoir une éducation dure, sévère, sans indulgence

Transitif

+1365 En jonece me vint cils flueves ;

Car s'en viellece m'euïst pris, J'euïsse esté trop dur apris (Jean Froissart, Poésies [3 tiers XIVe])

\section{CORPUS WEB :}

Si vous avez un esprit créatif, vous trouverez d'autres méthodes qui peuvent être meilleurs que ceux. Mais peu importe la façon dont vous pouvez choisir, vous devez apprendre dur avec vos objectifs [http://www.edukeo.net/apprendreetrangere-a05309257.htm] (25.11.2013)

en tant que débutant ça me choque pas d'apprendre dur une électronique, ce que je sais faire actuellement $\mathrm{c}$ en l'apprenant seul sur ma Roland TD9... [http://www.ladrummerie.com/ viewtopic.php?p=412529] (25.11.2013)

La phrase correct est " Horses are animals ». On peut mettre " The horses are animals " si on parle des chevaux du dernier film qu'on a vu, par exemple. Or la phrase « Les chevaux sont des animaux » est une vérité général donc « the » à bannir

Anna4493 6 : J'ai du mal avec « some »

augustine.legay1 7 : moi aussi tes comme moi ???

sibydou 10 : Moi aussi are some c'est trop complex mais bon faut apprendre dure dure l'anglais !!!!! [https://de.duolingo.com/ comment/2840940] (21.6.2016)

REMARQUeS : Dans l'exemple du XIV siècle, $a p$ prendre dur désigne le fait d'éduquer, d'instruire quelqu'un (généralement une jeune personne) de manière dure, sévère, inflexible. Dans la langue moderne du CW, apprendre dur est un synonyme d'apprendre durement, donc en faisant un effort. 
Notons l'accord dans le dernier exemple du CW, avec la réduplication usuelle dur dur.

\section{Apprendre long}

en apprendre long : apprendre beaucoup, bien

(s')instruire sur quelque chose/quelqu'un Intransitif

1782 Il lui fit chanter souvent les couplets qu'elle savoit, regrettant qu'elle n'en eût pas appris plus long (Robert-Martin Lesuire, L’Aventurier françois ou Mémoires de Grégoire Merveil)

1855 J'ai souvent entendu ma mère soulever devant moi ce problème : « Mon enfant sera-t-elle plus heureuse ici qu'avec moi ? Je ne sais rien, c'est vrai, et je n'aurai pas le moyen de lui en faire apprendre bien long. L'héritage de son père peut être amoindri si sa grand'mère se désaffectionne en ne la voyant pas sans cesse, mais l'argent et les talents font-ils le bonheur? " (George Sand, Histoire de ma vie)

1876 Enfin, tout cela devait mal tourner... dès mon arrivée à Coulonges, au Lion d'Or, où nous avons pris une chambre, j’ai questionné les gens, j'en ai appris encore plus long (Émile Zola, Son Excellence Eugène Rougon)

1928 - Mais si je réussis, c'est pour moi la direction des ateliers d'ameublement moderne aux quatre quartiers...

- Tu ne m'en as jamais appris aussi long là-dessus (Colette, La Naissance du jour)

1959 - C'est ta nièce... ta putain de nièce...

- Ah ! attention, s'écrie Gabriel en retirant sa main pour la lever au ciel, ma nièce c'est ma nièce. Modère ton langage ou tu vas en apprendre long sur ta grand-mère (Raymond Queneau, Zazie dans le métro)

1978 Pourquoi n’ai-je jamais exigé que tu te livres un peu à l'écrivain, à supposer que la décence eût interdit au fils d'en $a p$ prendre trop long sur tes premiers émois? (Alain Bosquet, Une mère russe)

1981 J'en apprenais long sur les goûts, les dégoûts, les manies et les espoirs de chacun (Françoise Chandernagor, L’Allée du roi)

\section{CORPuS WEB :}

Regardez les vêtements et les cheveux de la personne. En plus du langage corporel, des expressions faciales et autres indicateurs physiques, vous pourrez en apprendre long sur quelqu'un en regardant simplement la façon dont quelqu'un se présente au monde. Les vêtements, les accessoires, la coiffure et le maquillage de quelqu'un peuvent être très révélateurs [http:// fr.wikihow.com/observer-les-gens] (21.6.2016)

Certains ont bien sûr rédigé des lettres qui ont survécu ; d'autres ont laissé derrière eux leur journal personnel ; le témoignage de leur existence figure dans les recensements et les actes de naissances, de mariages et de décès. Ils survivent aussi dans leurs chansons et les récits qu'ils nous ont légués. Tout cet héritage peut nous en apprendre long sur nos ancêtres. Mais les témoignages les plus importants que ces êtres ordinaires nous ont légués sont les objets qu'ils ont fabriqués et utilisés au quotidien [http:// allaboutshoes.ca/fr/chronicles/activity02 teaching_yourself.php] (21.6.2016)

REMARQUeS : Long est un adjectif-adverbe de dimension. Dans la collocation en apprendre long, il est employé au sens figuré comme quantifieur et signifie 'beaucoup, en profondeur'. En apprendre long est régulièrement modifié par aussi, bien, encore plus. À partir du $\mathrm{xx}^{\mathrm{e}}$ siècle, la locution prend un complément indirect introduit par la préposition sur (exemples de 1928, 1959, 1978, 1981 et CW).

\section{Approcher fort}

(S')approcher beaucoup, venir très près

$\lambda$ chevaucher fort

\section{Approcher petit}

S'approcher un peu

Pronominal

1364 Moult coiettement la huchai

Et petit de li m'approchai,

En sa grant biauté regardant,

S'onneur et son estat gardant,

Qu'autrement faire ne l'osoie

Pour son courrous que je doubtoie 
(Guillaume de Machaut, Le Livre du voir dit, 3911)

CORPuS WeB :

L'Approche. On va commencer par apprendre aux oiseaux à ne plus paniquer à notre approche. Pour cela il suffit de passer beaucoup de temps autour de la cage, à siffler, les observer de temps à autre mais faire comme s'ils n'étaient pas là. Faire ses activités les plus diverses autour d'eux, comme lire un livre, boire un verre d'eau, tout en fait ! Au début, il vont paniquer, il faut alors être un peu plus éloigner et s'approcher petit à petit. Ne pas les fixer mais leur parler, les appeler par leur nom ect... [http://infosperroquet.e-monsite. com/pages/apprivoiser-son-oiseau.html] (21.6.2016)

REMARQUeS : L'ancien français employait petit comme quantifieur équivalent à peu en français moderne. Notons l'expression figée petit à petit 'lentement, prudemment', usuelle dans l'usage moderne, dans le CW.

\section{Ardre bel}

ardre au plus bel : brûler de la manière la plus satisfaisante, avec intensité

Transitif

1300 Si trairont mi arcier environ de tous lés De mes dars en ardrai au plus bel les costés. [a cel bel, Fierabras (L), 2051]

- Sire, ce dist Brulans, ce n'est mie bontés: Ja est ja li solaus ens ou ciel esconsés ; S'or commenciés justice, vous en seriés blamés (Fierabras (K), 1948)

Intransitif

1386 Ces vaisseaux ardoient bel et clair, et le faisoient les Anglois à cette entente (intention) que ils se prensissent (attachassent) aux grands et gros vaisseaux qui là étoient d'Espagne et d'autres pays, ils n'avoient cure de qui (Jean Froissart, Chroniques (B), X, p. 329)

REMARQUES : Le neutre bel fait partie du groupe adverbial au plus bel qui réfère à la perfection dans l'action ou au sentiment de vouloir mener à bien son projet, se rapprochant d'un rôle d'intensifieur signifiant 'fort'. Notons la collocation avec l'adjectif-adverbe clair.

\section{Ardre clair}

Brûler en éclairant beaucoup, vivement Intransitif

$\sim 1000$ Il liuol faire mult amet. beuure liroua a porter. garda si uid grand claritet. decel uindre fud depardeu et sicum roors in cel esgranz et sicum flammes clar ardaz (Vie de saint Léger, 204)

$\sim 1170$ Li feus mout cler devant aus art. $\mathrm{Li}$ vavasors serjant n'avoit, Fors un tot seul qui le servoit, Ne chanberiere ne meschine (Chrestien de Troyes, Erec et Enide, 484)

$\sim 1180$ Et sachiez que de grant maniere Li sist au flanc et miex el poing, Et sambla bien que al besoing S'en deüst aidier comme ber. Derriers lui vit vallés ester Entor le fu qui cler ardoit (Chrestien de Troyes, Perceval ou Le Conte du Graal, 3181)

+1225 Si vi un image desus

De ma dame sainte Marie ;

S'avoit devant par seignourie Une lampe ki cler ardoit ; Hons ne feme ne le gardoit (Le Chevalier as deus espees [ $2^{\mathrm{e}}$ quart $\left.\mathrm{XIII}^{\mathrm{e}}\right]$, 475)

+1250 Ce dist Poncez « molt volonters ». Atant se metent es senters : En sa mein porte une candoille Qui si art cler con une estoille (Le Roman de Renart [2 moitié XIII'], Ib, 2946)

+1300 Adont li bailla par le main : Li chevaliers joians le prent. $\mathrm{Au}$ fu, qui cler art et esprent, Li escuiers tantost retourne, Si le recouvre, n’i sejourne, Puis entra errant en son lit (Le Prestre et le chevalier [ $1^{\mathrm{re}}$ moitié XIII'] $]$, 645)

REMARQUES : Clair est un adjectif-adverbe qualificatif qui forme une collocation usuelle avec le verbe ardre. Il reste invariable et est modifié par moult. L'antéposition de cler au verbe prédomine en ancien français. VoIR AUSSI : brûler clair 
Areer bel

Parer joliment

$\lambda$ arroyer bel

\section{Arer profond}

Labourer

Intransitif

1275 Asprement les esperonez

E les plus granz cos leur donez

Que vous onques doner pourreiz,

Quant plus parfont arer [variante : aler] vourreiz (Jehan de Meun, Roman de la rose [1269-1278], 19720)

REMARQues : Profond est un adjectif-adverbe de dimension. Il est modifié par plus.

\section{Armer beau (bel)}

Munir de belles armes imposantes, bien armer

Transitif

1170 La nueme bataille fu grant

E defensable e redotee :

Onc gent ne fu si bel armee [variante : bien] (Benoit de Sainte Maure, Le Roman de Troie, 7984)

$\sim 1177$ Deus an i ot, qui li estoient Ne sai ou cosin ou neveu, Por voir bien anseignié et preu : Cil l'arment si bel et si bien Qu'il n'i a soz le monde rien Don nus hon reprandre les puisse Por mesprison nule qu'il truisse An chofe qu'il i aient fet (Chrestien de Troyes, Lancelot ou Le Chevalier de la charrete, 6793)

1190a Garim, quer me di ore, garde ne soit chelés,

Por coi n’i est venus Rollant li alosés, Ou li quens Olivier qui tant est biax armés, Berart de Montdidier et Ogier l'alosés (Fierabras (L), 468)

1190b Un chevalier de Franche ai piecha aamé : Gui a nom, de Borgoigne, mout i a bel armé ;

Parens est Karlemaine et Rollant l'aduré (Fierabras (L), 2340)

1230 Sarasins et Persans le keurent esgarder, Et dist li uns à l'autre : "Véés com bel armé!»
De ci que en la place ne se sont aresté

(Gui de Bourgogne, p. 69)

+1265 Diex ! donnés que li puisse rendre

Sa courtoisie et sa vaillanche ;

Et se li doinst Dieus tel poissanche

Que ses cors n'i soit entamé,

C’ainques ne vi si biel armé

(Richars li Biaus [3e tiers XIII $]$, 1428)

-1334 Li Beaus Chevaliers chevaucha,

Qui sa route bien ordena,

Bien estoit parmi apparant ;

Car haus estoit et si iert blanc,

Escu ot noir de blanc lermé,

Molt par estoit tres bel ermé (Le Romans de la dame a la lycorne [1 ${ }^{\mathrm{er}}$ tiers XIV] $\mathrm{X}^{\mathrm{e}}$, 2677)

+1350 Quant Brun de la Montaigne fu en la court entré,

Onques nus hons ne vit de lui plus bel armé.

Doy chevalier si l'ont maintenant desarmé, Si tost que du cheval le virent desmonté (Brun de la Montaigne [ $2^{\mathrm{e}}$ moitié XIV $]$, 3576)

Pronominal

+1175 Del chastel issent maint et comunalment ; Li cuens Guillaumes s'en ist premierement,

Et fu armez bel et cortoisement

Sor un destrier arrabi et corrant

(Garin le Loherain [ $4^{e}$ quart XII $]$, 4674)

+1225 Et on si fait, et il se lieve

Et s'atorne, ke ne li grieve.

Et viest une cote a armer

En son dos d'un drap d'outre mer.

Puis s'arme, si biel comme il pot,

De quan c'a chevalier estot

Por assalir et por deffendre (Le Chevalier as deus espees [ $2^{\mathrm{e}}$ quart $\left.\mathrm{XIII} \mathrm{e}^{\mathrm{e}}\right]$, 1589)

1393 Atant vindrent au pié de la montaigne. Et descend Gieffroy et s'arma bien et bel, et remonte a cheval, et met l'escu au col et la lance ou poing (Jean d'Arras, Mélusine, p. 710 [manuscrit Arsenal])

1515 Ne demeura guiere aprés cela fait que celluy verlet vint pour soy armer et se arma bien et beau; puis mect la sallade en sa teste et monte à cheval et s'en va avec son 
maistre et avec les aultres gens d'armes, mais quant il vint avec eulx aux champs, il puoit comme le deable (Philippe de Vigneulles, Les Cent Nouvelles nouvelles, p. 125, 25)

REMARQUES : Le neutre bel s'emploie ici comme adverbe de manière, l'emploi de la forme adjectivale étant occasionnel, impliquant davantage le sujet. Armer bel se disait du fait de munir quelqu'un de belles armes imposantes et donnant de l'allure. Dans son emploi intransitif, désigne le fait d'être paré, d'arborer de belles armes puissantes. L'emploi pronominal accentue le sens de se parer soi-même de ces armes, impliquant davantage le sujet dans l'action. L'emploi du neutre bel est une caractéristique de l'ancien français. L'exemple de 1515 reprend la collocation ancienne, tout en remplaçant le neutre par le masculin beau. Notons que le verbe apparaît souvent dans sa forme de participe passé armé qui s'accorde avec le sujet. Bel / beau est modifié par plus, si, très. Notons la coordination de bel/ beau avec les adverbes bien et courtoisement.

\section{Armer dru}

Se munir d'une grande quantité d'armes, connotant la force

Emploi absolu

-1300 Par tote l'ost des Saisnes furent levé li hu ; Lors se corent armer espessement et dru (Jehan Bodel, La Chanson des Saisnes [fin XIII'], 6348)

REMARQUES : Armer dru réfère à un armement puissant, dans lequel on met tous les moyens. L'adverbe espessement, précédant l'adjectifadverbe, renforce l'idée de quantité et de force.

\section{Arraisonner bel}

Adresser à quelqu'un des paroles

convaincantes, raisonnables

Transitif

1230 Dus Sanses de Borgoigne fist forment à prisier,

Et sachiés tot sans faille qu'il ot Guion molt chier,

Qu'il l'avoit engendré de sa france moillier.

Bel et cortoisement le prist à araisnier

(Gui de Bourgogne, p. 94)
1275 De Malatrie fu Gerars bel araisniés:

Amis, dist la pucele, envers moi vous traiés,

Bien sai que a moi estes en message envoiiés (Adenet le Roi, Buevon de Conmarchis, 3670)

-1334 Au Beau Chevalier tout remue Li coers, quant ou manoir entra. Privés Dangiers tost l'avisa, Molt bel le va araisonner Et molt tres bel samblant moustrer (Le Romans de la dame a la lycorne $\left[1^{\mathrm{er}}\right.$ tiers XIV $\left.\left.{ }^{\mathrm{e}}\right], 7298\right)$

REMARQUES : En ancien français, arraisonner bel désigne le fait d'interpeller, d'adresser la parole à quelqu'un en cherchant à le persuader, à justifier son propos par des preuves ou des raisons. Le neutre bel est modifié par l'adverbe d'intensité moult. Notons que dans l'exemple de 1275, le verbe apparaît dans sa forme de participe passé qui s'accorde avec le sujet. Mentionnons aussi la coordination de bel avec l'adverbe cortoisement dans l'exemple de $\sim 1230$.

\section{Arrêter coi}

S'arrêter ou faire arrêter de façon à ne plus faire de bruit (hommes), voire à ne plus bouger (animaux) ; interrompre brusquement Intransitif

+1313 Tout cil qui la nouuielle sorent S'esmierueillent de la prouecce De celui qui tant ot perece D'ariester quoi en son ostel, Or a cel iour conquis los tel Que iamais ne sera blasmes Ne plus n'iert sauuages clames (Jean de Condé, Poèmes [1313-1337], 793)

1346 LE PAPE. Ho! seigneurs, coiz nous arrestons,

Puis que nous sommes en l'eglise

La dame plaine de franchise, Et me laissiez m'offrande faire, [Ave], royne debonnaire, Du treshault Dieu souverain temple Et aussi de tout bien exemple, Souverain mont de forteresse, Souveraine humble et en hautesse, Souveraine beneurté 
Des sains après la trinité !

(Miracle de un Pape qui vendi le basme, 1213)

1373 THIBERT. Seigneurs, arrestons ycy coy Touz ensemble, ce vous conmans. En la forest sommes du Mans (Miracle de notre dame Berthe, 700)

Pronominal

+1365 Je pri dou papier et de l'encre Et tous quois m'arestai à l'ancre Jusques à tant que j'ai escript Ensi com vous vés en escript (Jean Froissart, Poésies [3e tiers XIV $\left.{ }^{\mathrm{e}}\right]$ )

1370 Et quant il furent assez pres approuchié li uns de l'autre, li chevaliers qui gardoit le pas s'en vint vers Aigre, esperonnant sanz mot dire ; et li bers s'arresta tous cois et attendi tant que cilz fu prez de lui (Roman de Berinus, I, p. 280)

1558 Et à fin que l'Empereur fust plus esclaircy au vray de la verité de cela, il pensa à part soy : «Maintenant j'ay ouy dire souventesfois qu'il avoit une grosse verrue sur la nuque du col "; et s'approcha pour $\mathrm{y}$ voir si elle estoit ainsi en cete figure et s'il l'y trouveroit ; et il y trouva ainsi la verrue, - car il s'arresta coy comme un baston picqué et incontinent apres il se disparut, apres que l'Empereur en eut accomply son desir (Pierre-Victor Cayet, L'Histoire prodigieuse du Docteur Fauste)

1563 Les argentées suivent de mesme : et plus n'estoit qu'une ligne, qu'une d'elles ne fust royne nouvelle créée : mais en cestuy endroit le custode auré la guettoit : pourtant elle s'arresta coy (François Rabelais, Cinquième Livre)

1596 Car le fleuve d'oubly contre Amour n’a puissance.

L'esprit à cette fois tout coy s'est arresté, Adorant le saint lieu, tombeau de loyauté (Philippe Desportes, Euvres)

1838 On apprend aux chiens courants à décrire ces cercles en avant et en arrière, pour que plus tard cette manœuvre leur serve à lever un défaut. L'animal que l'on chasse a marché ou s'est arrêté coi dans un lieu que vous ignorez (Elzéar Blaze, Le Chasseur au chien courant)

2006 - M'ma Songo que désirez-vous ? questionna Wendkonta interloquée.

La jeune fille s'arrêta coite et attendit imprudemment l'arrivée de la dame (Adama Salle, Un mariage oblique)

Transitif

+1370 Adont les fist-on arester tout quoy pour avoir aultre consseil et fist-on aucuns compaignons monter sour courssiers pour escarmuchier as Escos et pour aviser le passage del rivière et pour veoir leur convenant de plus priès (Jean Froissart, Chroniques (A))

1550 Que Pallas, la sage guerriere, Luy happant les cheveux derriere, Tout gromelant l'arresta coy? (Pierre de Ronsard, Les Odes, p. 279)

1666a Un villageois, ayant perdu son veau, L'alla chercher dans la forêt prochaine. Il se plaça sur l'arbre le plus beau, Pour mieux entendre, et pour voir dans la plaine.

Vient une dame avec un jouvenceau.

Le lieu leur plaît, l'eau leur vient à la bouche,

Et le galant, qui sur l'herbe la couche, Crie, en voyant je ne sais quels appas :

« $\mathrm{O}$ dieux ! que vois-je ! et que ne vois-je pas!»

Sans dire quoi : car c'étaient lettres closes. Lors le manant les arrêtant tout coi :

«Homme de bien, qui voyez tant de choses, Voyez-vous point mon veau ? dites-le moi » (Jean de La Fontaine, Le Villageois qui cherche son veau)

1666b Sur ce propos l'autre l'arresta coy. Je vous entends, dit-elle, c'estoit moy (Jean de La Fontaine, La Servante justifiée)

1868 Quand je vois un archéologue se lancer dans cette voie, j'ai toujours envie de l'arrêter coi, et de lui dire, comme le bon fabuliste : 
Homme de bien qui voyez tant de choses Voyez-vous pas mon veau! Dites-le moi ? (F. Parenteau, La Découverte du Jardin des Plantes de Nantes)

REMARQUES : ( $S$ ')arrêter coi 's'arrêter et ne plus bouger' est vieux. Notons la dynamique résultative dans l'emploi transitif. Au figuré, il peut renvoyer à une pensée qui reste en suspens, ou à l'esprit qui cesse de cogiter. Le verbe prend alors le sens de 'demeurer', traduisant l'idée de se taire, de ne pas bouger, de ne pas intervenir. Le groupe s'est maintenu dans le vocabulaire archaïsant de la chasse. Il est modifié par tout. On trouve même un exemple fléchi (ex. de 2006). La flexion y est informelle ou 'modernisée' par rapport au féminin coie. Notons l'emploie de nouvelle créée (créer nouveau).

\section{Arrêter court}

I. Arrêter instantanément, brusquement Transitif

1544 O doncques, Roy, son cousin, frere et pere, Arreste court l'entreprise impropere ; Et toy, sa sœur, en qui tant elle espere, Mets y la main (Clément Marot, Chants divers)

1577 Mais ainsi que les deux armees n'attendoient sinon que le signe du combat, il arresta tout court ses gens à un ject d'arc des autres, et du haut d'une petite motte de terre, qui de fortune se rencontra là tout à propos, leur escria à haute voix en cette sorte (Blaise de Vigenère, L'Histoire de la décadence de l'Empire grec [trad.])

1610 Je voy bien qu'ils me respondent que si ceste beauté a esté produite pour estre aimée, c'est pour sa propre gloire et pour le dommage de ceux qui l'aimeront comme moy. Ceste pensée l'arresta si court, qu'en cessant de marcher, apres l'avoir long temps roulée dans son esprit, il profera telles paroles (Honoré d’Urfé, L’Astrée)

1638 SOSIE. La lune, pour me voir, arrêta court ses pas :

De vrai, cette première était plus longue encore,

Et je désespérais du retour de l'aurore (Jean de Rotrou, Les Sosies)
1702 Si vous avez de la broderie, bientôt les valets de chambre en porteront. Le seul moyen d'arrêter tout court le luxe est de donner vous-même l'exemple que Saint Louis donnait d'une grande simplicité. L'avez-vous donné en tout, cet exemple si nécessaire? (Francois de Fénelon, Examen de conscience)

1735 sans le consentement que j’avois donné à la rupture de mon mariage, qui avoit occasionné une lettre de la Cour, par laquelle on lui faisoit entendre que s'il poussoit les choses plus loin, il ne me reverroit jamais ; menace qui l'avoit arrêté tout court, par la tendresse qu'il avoit pour moi (Charles de Mouhy, La Paysanne parvenue)

1822 Si l'un des deux amants est trop supérieur dans les avantages qu'ils estiment tous les deux, il faut que l'amour de l'autre meure, car la crainte du mépris viendra tôt ou tard arrêter tout court la cristallisation. Rien n'est odieux aux gens médiocres comme la supériorité de l'esprit : c'est là, dans le monde de nos jours, la source de la haine (Stendhal, De l'amour)

1916 Il était grand et massif, moustachu de gris, et sa figure épaisse avait toujours une expression un peu gênée de bonne humeur arrêtée court par l'annonce d'un chagrin d'autrui, auquel il devait faire semblant de compatir (Louis Hémon, Maria Chapdelaine)

1925 Au pied d'un chêne isolé dans une lande, la petite chienne huma le vent ; un geste de son maître l'arrêta court, comme déjà elle s'élançait. Raboliot lui cingla le museau, tandis qu'un gros oiseau filait bas sur leurs têtes (Maurice Genevoix, Raboliot)

Pronominal

1579 Il y eut un homme en nostre forest qui avoit en son logis un gros chien mastin de poil noir, et laid comme un beau diable, lequel faisoit peur aux petits enfants. Il advint un jour, ainsi qu'il suivoit son maistre allant à ses affaires, vint rencontrer dedans les bois en un estroit chemin un grand regnard, lequel voyant le chien s'arresta 
sur le cul, tremblant comme la fueille. Le chien mesme s'arresta tout court. Or estant ainsi tous deux aculez l'un devant l'autre, commencerent à eux entreregarder sans rire si tres-ententivement et sans ciller ne parler (Philippe d'Alcripe, La Nouvelle Fabrique des excellents traicts de vérité)

1596 Je feray desormais ta puissance plus grande,

Et rendray par mes traits ton bras victorieux.

La mort s'arresta court, oyant cette promesse :

Et le cruel Amour du depuis n'a eu cesse, Faisant mourir tous ceux qui regardent vos yeux (Philippe Desportes, Euvres)

1624 Moy qui voyois que son regard estoit tout égaré, et qu'il sembloit à son geste qu'elle fust transportée de quelque fureur, et comme animée d'un esprit plus fort que le sien ; ne pouvant assez m'estonner de ceste nouveauté ; je m'arrestay tout court, sans me mettre en devoir, ny de m'advancer vers elle, ny de luy respondre (Jean de Gombauld, L'Endimion)

1835 Nous avançâmes sur les Arabes, ils s'arrêtèrent court; je me détachai de la caravane, en lui ordonnant de rester sous les armes ; je m’avançai avec mes deux compagnons et mon drogman ; nous parlementâmes ; et le scheik avec ses principaux cavaliers nous escortèrent eux-mêmes jusqu'à la brèche, en donnant ordre aux Arabes de l'intérieur de nous respecter, et de nous laisser examiner les monuments

(Alphonse de Lamartine, Souvenirs, impressions, pensées et paysages pendant un voyage en Orient)

1846 Quelque rapide que fût son élan, quelque glissant que fût un bloc de granit, elle $s^{\prime} y$ arrêtait tout court, au mot de «Mignonne » (Honoré de Balzac, Une passion dans le désert)

1902 Je travaille depuis une heure, quand un très léger frôlement derrière moi, du côté des petits couloirs d'entrée, me donne le sentiment de quelque discrète et gentille présence, et je me retourne : un chat, qui s'arrête court, une patte en l'air, hésitant, et me regarde bien dans les yeux, avec un air de dire : « Qui es-tu toi ? » (Pierre Loti, Les Derniers Jours de Pékin)

1940 - Oui, je vous demande si votre mari vous écrit quelquefois?

Ma question fit grand effet sur Rosita, qui traversait la chambre. Elle s'arrêta court, comme attendant la réponse de sa sœur.

- Non, dit enfin Délia. Il ne m'écrit pas, et il fait aussi bien. Nous n’avons rien à nous dire (Colette, La Lune de pluie)

1950 Je le précède, élevant la bougie. Et soudain, tous les deux ensemble, nous nous arrêtons court :

- Bigre!

- Ça, alors!

Sans transition, le parquet brut de la salle devient brillant et uni comme une glace ; la flamme du lumignon y plonge son reflet vacillant (Maurice Genevoix, Ceux de 14)

1972 Sous les halliers sortaient les premiers perce-neige. Il se mettait presque à courir, mais arrivé au gros foyard il s'arrêtait court puis retournait à la Rouéchotte en disant: - Lundi de Pâques! Pas avant ! Et il se remettait à l'établi (Henri Vincenot, Le Pape des escargots)

Intransitif

1679 Enfin l'on s'amusa tant que la petite pointe du jour (c'étoit dans les plus grands jours de l'été) commençoit à paroître quand l'on fut au bas de la descente des bonshommes. Justement au pied, le carrosse arrêta tout court (Jean-François de Gondi (Cardinal de Retz), Mémoires)

II. S'interrompre ou interrompre quelqu'un dans son discours, couper la parole Transitif

1630 Pour ton argument, s'il estoit ainsi, Judas, les Juifs et les bourreaux seroient les precurseurs de nos Prestres : mais je l'arrestai tout court, par un sophisme bien mieux troussé. Croyez-vous, lui dis-je, que le Pape est l'Antechrist ? Oüy, dict il, il n'est pas Chrestien qui ne le croit 
(Théodore Agrippa d'Aubigné, Confession catholique du sieur de Sancy)

1834 Il me semblait lâche et cruel d'avoir pris cette noble colère au dépourvu, de l'avoir fait rentrer en elle sans pitié, et de n'avoir pas respecté un fonds d'inviolable douleur jusque dans cette divagation violente. $\mathrm{M}$. de Couaën m'arrêta court avant que j'eusse fini : «Amaury, me dit-il, combattez-moi, réfutez-moi à extinction, pourvu que vous nous aimiez ! » (Charles Sainte-Beuve, Volupté)

1914 GABRIELLE. (même jeu) Ah ! Général... ! LE GÉNÉRAL. (l'arrêtant court) Mais ceci, bien entendu, à la condition que votre mari confirme vos excuses en y ajoutant les siennes ! Il passe numéro 1 devant Gabrielle.

GABRIELLE. Oh ! Si ce n'est que ça, il vous les fera.

LE GÉNÉRAL. Vous comprenez, moi... j’ai giflé votre mari !

(Georges Feydeau, La Dame de chez Maxim)

Pronominal

1744 En arrivant à la maison de Madame de Marignan, nous entrâmes d'abord chez D. Clara ; elle parloit avec agitation à un jeune homme qui embrassoit ses genoux, et dont le discours paroissoit aussi trèsanimé : mon ami s'arrêta tout court de surprise ; mais D. Clara n'eût pas sitôt apperçu son amant qu'elle vola vers lui pour l'embrasser ; ah ! lui dit-elle, en se jettant à son col, cher S. Julien, ne me condamnez pas au moins sans savoir si je suis coupable (Jean-Baptiste Jourdan, Le Guerrier philosophe)

1748 - On n'est point toujours une bête pour l'avoir été quelquefois ; et Votre Hautesse.. Mirzoza craignant d'offenser le sultan, s'arrêta là tout court.

- Achevez, madame, lui dit Mangogul, je vous entends ; et Ma Hautesse n'a-telle jamais fait la bête, voulez-vous dire, n'est-ce pas ? (Denis Diderot, Les Bijoux indiscrets)
1825 En cherchant la gloire, nous trouvons la mort. Je m'arrête tout court sur cette phrase, car je sens qu'un pareil style m'emporterait haut et loin (Paul-Louis Courier, Lettres écrites de France et d'Italie)

1886 Il lui arrivait d'entonner les Fillettes de Paimpol ; ou bien, en balançant la tête et battant la mesure avec son pied, elle prenait :

Pour la pêche d'Islande, mon mari vient de partir,

Il m’a laissée sans le sou,

Mais... trala, trala la lou..

J'en gagne!

J'en gagne !...

Chaque fois, cela s'arrêtait tout court, en même temps que ses yeux s'ouvraient bien grands dans le vague en perdant toute expression de vie, - comme ces flammes déjà mourantes qui s'agrandissent subitement pour s'éteindre (Pierre Loti, Pêcheur d'Islande)

III. Limiter quelqu'un dans son champ d'action, avoir une influence sur quelque chose Transitif

1830 Il avait osé lui faire des questions sur une foule de petites choses, dont l'ignorance arrête tout court l'intelligence d'un jeune homme né hors de la société (Stendhal, $L e$ Rouge et le noir)

1922 Je n’en étais pas arrivé à ce point pour Albertine. Ses mensonges, ses aveux, me laissaient à achever la tâche d'éclaircir la vérité : ses mensonges si nombreux, parce qu'elle ne se contentait pas de mentir comme tout être qui se croit aimé, mais parce que par nature elle était, en dehors de cela, menteuse (et si changeante d'ailleurs que, même en me disant chaque fois la vérité sur ce que, par exemple, elle pensait des gens, elle eût dit chaque fois des choses différentes ; ses aveux, parce que si rares, arrêtés si court, ils laissaient entre eux, en tant qu'ils concernaient le passé, de grands intervalles tout en blanc et sur toute la longueur desquels il me fallait retracer, et pour cela d'abord apprendre, sa vie (Marcel Proust, La Prisonnière) 
1929 Qu'on ne s'y laisse pas tromper ; c'est ici le nœud gordien de l'œuvre, celui que les débutants doivent s'évertuer à dénouer s'ils ne veulent être arrêtés court au commencement de la pratique (Fulcanelli, Les Demeures philosophales et le symbolisme hermétique)

1937 Ils avaient mis leurs bras au service de haines implacables, inexpiables, impuissantes, des haines de vieux. Si la France de 1918, arrêtée court en plein essor de production industrielle de guerre, s'est trouvée encombrée d'un matériel désormais inutilisable, elle disposait de plus vastes réserves de haine

(Georges Bernanos, Les Grands Cimetières sous la lune)

1938 Il a emmené captive la captivité, cela veut dire que, comme Samson, chargeant sur ses épaules les portes de Gaza et laissant là-bas ces autres portes démantibulées qui n’ont pas prévalu contre lui, il emporte avec lui jusqu'au ciel ces obstacles mêmes de la matière et de la chair qui nous tenaient prisonniers et qui arrêtaient court notre vue et notre mouvement et notre action (Paul Claudel, Un poète regarde la croix)

\section{CORPuS Web :}

Ainsi, arriver avec une assiette positive et ne rien changer jusqu'à l'impact avec le sol peut au moins faire toucher des roues plus tôt. Ensuite il ne s'agit plus que d'une question d'efficacité du freinage pour s'arrêter court. Toutefois, le pilote doit faire attention afin de ne pas toucher trois points sous prétexte de ne pas arrondir. L'assiette doit impérativement être positive pour que ce soit le train principal d'atterrissage qui percute en premier le sol. Si ce n'est pas le cas, il doit faire un arrondi, quoiqu'il arrive [http://home.nordnet.fr/ dmorieux/perfect0009.htm] (21.6.2016)

« Continue, mon frère, et achève ce que j’ai commencé. » Et celui qui se moquait reprit l'histoire, mais comme il n'avait ni le ton ni la manière il finit par s'arrêter court, et les pèlerins qui étaient là à souper l'abreuvèrent d'injures et de coups la moitié de la nuit [http://kiplinginfrench. free.fr/LH00.html] (21.6.2016)
Thomas Lélu, page 45. Je manque de m'endormir, fatigue passagère. Les flammes ont crépité tout ce temps. La danse s'est arrêtée courte, empêchement soudain. J'ai essayé d'être crédible à ses yeux, essayé d'être sérieuse et moimême [http://autourdejulien.canalblog.com/ archives/2007/11/01/6737797.html] (5.12.2013)

L'accouplement sert à interrompre la transmission de l'entraînement du moteur à la transmission, sur le demi-tour ou d'arrêter courte [http://www.beevar.com/renault-lagunacouplage-vous-detectez-des-defauts-de-sorte] (21.6.2016)

REMARques : Court est un adjectif-adverbe de manière qui reste invariable. Il est modifié par là, si, tout. (S')arrêter court forme un verbe complexe lexicalisé avec les significations de 'stopper', 'interrompre la parole' et 'empêcher quelqu'un de faire quelque chose'. Dans le langage actuel du CW, on trouve l'accord de l'adverbe dans les deux derniers exemples. Notons l'emploi de filer bas ; emporter haut et loin.

\section{Arrêter droit}

I. s'arrêter (tout) droit : s'arrêter brusquement, soudainement, brutalement

Pronominal

-1200 Et quant les voit Elies, s'en a gete .i. ris ; De che fist il que faus, quant ne daigna fuir.

A estal s'aresta droit en mi le chemin (Elie de Saint Gille [fin XII $]$, 1210)

1276 De Gloriande fu Ogiers adestrés, Devant le roi s'est tout droit arrestés (Adenet le Roi, Les Enfances Ogier, 3327)

-1334 Tost erranment, sans plus y atarder, Vient li secons, bel fet a regarder, Au bout du pré tout droit il s'aresta, A haut vois a celui s'escria : « Or cha! vas la! encor vus faut jouster! » Celui l'atent tout prest a retourner, Sans plus atendre viennent lance levee (Le Romans de la dame a la lycorne [1 ${ }^{\mathrm{er}}$ tiers $\left.\left.\mathrm{XIV}^{\mathrm{e}}\right], 320\right)$ 
II. s'arrêter (tout) droit devant quelqu'un/ quelque chose : s'arrêter juste, précisément devant quelqu'un ou devant un lieu Pronominal

1629 Il me suffira de vous dire, qu'apres que sous l'estendart d'Araxe, j'eus bien fait mon devoir avec Piroxene au premier combat des Zagayes, qu'ils firent à la façon des Mores, et des Perses, et où je m'estois desja fort exercé dans la Cour du Roy mon pere, je fus tout estonné, le Bal s'estant recommencé comme le soir precedent, que la Princesse Orixe suivie de six belles Dames, et accompagnee des Juges et des Herauts, se vint arrester tout droit devant la place de l'eschaffaut où j'estois assis, et le Roy d'armes qui la devançoit prenant aussi tost la parole me fit ce compliment à haute voix devant tous (François Le Métel de Boisrobert, Histoire indienne d'Alexandre et d'Orazie)

1832 Un soir, assis sur le pont qui est au bas de la terrasse de Richmond, je lisais les mémoires de Mme Hutchinson ; c'est l'une de mes passions.

- Mister Bell ! Dit un homme en s'arrêtant droit devant moi.

C'était M B - que j'avais vu en Italie, chez Milady Jersey à Milan (Stendhal, Souvenirs d'égotisme)

1942 Il se tailla une nouvelle tranche dans son quignon. Soudain Pompelune s'élança... Il trotta, comme d'une petite course entravée de gugusse, et, s'arrêtant droit devant Tonin Bagot, il fit, avec sa canne, un superbe moulinet, qui rasa la casquette de Tonin (Louis Guilloux, Le Pain des rêves)

III. arrêter droit : stopper quelque chose exactement, en un lieu ou sur quelqu'un de précis

Transitif

1837 Le regard de ses yeux vairons doublés d'une feuille d'argent était fuyant, mais terrible quand il l'arrêtait droit sur sa victime. Sa voix semblait éteinte comme celle d'un homme qui a longtemps parlé. Ses lèvres minces ne manquaient pas de grâce (Honoré de Balzac, Histoire de la grandeur et de la décadence de César Birotteau)
1931 Se sentant fatiguée elle avait seulement voulu s'étendre.

- Que tu m'as fait peur!

Pauline s’inquiétait de la voir si pâle, avec cette figure tendue, ces yeux arrêtés droit devant elle. Elle voulut aller chercher de l'eau d'arquebuse à la maison. Anne-Marie la retint par la jupe (Henri Pourrat, $L a$ Tour du Levant ou Quand Gaspard mit fin à l'histoire)

Pronominal

1849 ANTOINE. Les lèvres frémissent, les narines semblent s'ouvrir au mouvement du sein gonflé.

(Un coup de vent subit arrache l'image et la fait voltiger aux yeux d'Antoine)

LA VOIX. (mielleusement susurrante)

La voilà, elle te suit, elle saute.

(L’image s'arrête droit en l'air) (Gustave

Flaubert, La Tentation de saint Antoine)

\section{CORPUS WEB :}

Bonjour, j’ai un problème assez énervant pour ma discipline, mon cheval refuse catégoriquement de s'arrêter droit. Je l'ai longé, fait marché en main etc.... Il refuse de s'arrêter droit [http://equideo.actifforum.com/t4016-chevalrefusant-de-sarreter-droit] (20.6.2016)

Les freins ne se distinguent pas d'un autre scooter. Performant et précis, ils ne vous déstabiliseront pas. Pour vous arrêter droit, le frein arrière vous sera très utile pour atteindre la vitesse qui autorise le blocage [http://acidscooter. ch/cms/content/essai/2010/05/17/piaggio-mp3hybride-125] (20.6.2016)

REMARQues : Droit est un adjectif-adverbe de position spatiale. Il reste invariable (ex. de 1849 et 1931) et il est modifié par tout. Droit a tendance à s'associer avec des prépositions qu'il précède (devant, en, sur) au point de faire partie du groupe prépositionnel comme modifieur de la préposition.

\section{Arrêter ferme}

I. (s')arrêter d'une manière résolue, déterminée, inébranlable

Emploi absolu

-1469 Et pour ce, Monseigneur, quant on va en guerre, on doit chevaucher deliberé d'arrester et tenir ferme, quelque chose qu'il 
adviengne, sinon on ressemble à aucuns larrons de guerre, qui vont pour embler ung homme en sa maison, ou pour guetter ung chemin, ou pour prendre ung cheval à l'abrevoir, ou pour courre et racourre (Jean de Bueil, Le Jouvencel [1461]-1468, I, p. 201)

Pronominal

1816 On le [= le chamois] voit souvent sauter, en descendant, de vingt à trente pieds, et s'arrêter ferme pour peu qu'il trouve une pointe de roc pour le recevoir ; aussi sa chasse est-elle très-pénible et souvent dangereuse, lorsque, ne trouvant plus de moyen d'échapper, il se jette sur les chasseurs et les fait tomber dans les précipices sur les bords desquels ils sont obligés de le suivre (Frédéric Cuvier, Dictionnaire des sciences naturelles, s.v. Le Chamois)

II. arrêter ferme en quelque chose : au concret : fixer, être fortement ancré ; au figuré : s'en tenir à quelque chose d'une manière résolue, déterminée, inébranlable

Transitif

1566 Que plusieurs s'asseurans de leur Sauveur promis,

Me sont en ceste foy obstinez ennemis.

Le mesme premier homme, arresté ferme en elle,

A tenu le chemin de la vie eternelle

(Louis Des Masures, David fugitif)

1688 Posez dedans ce trou le gros bout de l'arbre coupé, élevez-le et l'arrêtez tout droit aiant lié auparavant à deux ou trois pieds proche du bout $\mathrm{F}$ [= renvoi au dessin]. Plusieurs liens de bois attachez bout à bout les uns des autres, comme vous le voiez par les lettres a, b, c, d, e, f, g, h, i, k, afin de les arrêter fermes avec des crochets de bois fichez en terre tout autour (Francois Fortin, Les Ruses innocentes)

III. s'arrêter ferme à quelque chose : s'attarder, fixer son attention sur quelque chose

Pronominal

1596 Qui veut au ciel d'amour voir ses ailes haussées,

Et de tous vieux ennuis la mémoire bannir,
Vienne au jour de vos yeux s'il les peut soustenir,

Beaux yeux, les doux meurtriers de mes paines passées.

Quiconque ainsi que moy s'y peut ferme arrester,

D’autres biens ne sçauroit son esprit contenter (Philippe Desportes, Euvres)

1683 Les vérités métaphysiques sont sublimes et délicates, et il est difficile à des hommes pétris de chair et de sang de s'arrêter fermes à la contemplation de ces vérités (Nicolas Malebranche, Méditations chrétiennes)

\section{CORPUS WEB :}

Les premiers soins d'Anne me permirent d'affermir mon intention d'arrêter et cela sans que j'eusse à faire un effort insurmontable, comme si le terrain avait été préparé à l'avance. Et rapidement j'arrêtais du jour au lendemain sans éprouver, à ma grande surprise, un manque énorme comme lors des précédents arrêts. Et surtout je sentais mon intention d'arrêter ferme et sans appel, ce qui pour moi était une première [http:// www.votreguerison.com/T\%E9moignages $\% 20$ de\%20clients.html] (20.6.2016)

Les vérités métaphysiques sont sublimes et délicates, et il est difficile à des hommes pétris de chair et de sang de s'arrêter ferme à la contemplation de ces vérités : leur imagination les séduit, et, prenant pour des principes incontestables des sentiments qui flattent quelqu'une de leurs passions, imprudents, téméraires, impies, ils se font des systèmes qui renversent les fondements de la foi [http://www.biblisem.net/meditat/malebpri. $\mathrm{htm}](20.6 .2016)$

REMARQUES : (S')arrêter ferme réfère à un arrêt brusque et décidé. L'accord peut renforcer l'implication du sujet dans l'action de s'arrêter (ex. de 1683). Notons l'emploi de arrêter droit et de tenir ferme.

\section{Arrêter net}

\section{I. s'arrêter net : cesser d'agir}

Pronominal

1823 Quelle audace! A la vue des grenadiers de la garde, les Russes s'arrêtèrent net. " Il était plus que temps disait Bertrand ; 
l'Empereur n’avait pas bougé ; tout ce qui l'entourait avait frémi » (Emmanuel de Las Cases, Le Mémorial de Sainte-Hélène)

1866 Jamais je ne lutte contre la mauvaise volonté, et je préfère extirper en moi le désir. Inépuisable de patience avec les enfants, avec les êtres faibles et humbles, je m’arrête tout net avec mes égaux, dès que j'entrevois l'ombre du mauvais vouloir pour ma personne (Henri-Frédéric Amiel, Journal intime de l'année 1866)

1875 LU MUSARDIÈRE. Oui, Mariette, et je cours...

(il fait un mouvement pour sortir)

MARIETTE. Edouard !

(La Musardière s'arrête net)

MADAME PICHARD. (à part) Hein !... comme c'est dressé !...

(Henri Meilhac et Ludovic Halévy, La Boule)

1913 soudain, la jument ralentit son allure, comme si son pied avait buté dans l'ombre ; Meaulnes vit sa tête plonger et se relever par deux fois ; puis elle s'arrêta net, les naseaux bas, semblant humer quelque chose. Autour des pieds de la bête, on entendait comme un clapotis d'eau. Un ruisseau coupait le chemin (Alain-Fournier, $L e$ Grand Meaulnes)

1915 L'effet était admirable, et Gaspard s'abandonna à l'idée que l'ennemi s'en arrêterait net. Il riait, riait, tapant la table, avec des glouglous dans la gorge.

- Non, non... mais l'est pilant c'mec-là !... dis donc, vieux?

(René Benjamin, Gaspard)

1925 Une branche craqua, un peu plus fort. Il s'arrêta tout net, se retourna, se frotta les yeux : décidément il avait la berlue ! Rien ni personne ne remuait plus à la place où il avait cru voir... mais qu'est-ce qu'il avait cru voir ? (Maurice Genevoix, Raboliot)

1932 La délivrance devient possible dans un sens tout nouveau ; la poussée mystique, si elle s'exerce quelque part avec assez de force, ne s'arrêtera plus net devant des impossibilités d'agir ; elle ne sera plus refoulée sur des doctrines de renoncement ou des pratiques d'extase ; au lieu de s'absorber en elle-même, l'âme s'ouvrira toute grande à un universel amour (Henri Bergson, Les Deux Sources de la morale et de la religion)

1948 Elle s'arrêta net et pâlit.

- Je ne peux pas plaisanter là-dessus, ditelle simplement.

- Je ne plaisante pas ; si j'ai l'air de tourner en rond, c'est parce que l'histoire est comme ça

(Boris Vian, Le Grand Sommeil [trad.])

1950 - C'est un phonographe, dit Suzanne. Joseph s'arrêta net de manger. Sous ses paupières à demi levées, ses yeux apparurent, éclatants. Chacun le regardait, même M. Jo.

- On en a déjà un, dit Joseph, de phono (Marguerite Duras, Un barrage contre le Pacifique)

1962 Le mercredi, ne voulant pas être en reste, Peinture apporta une fléchette qu'on empoisonna soigneusement en l'enduisant d'une décoction de cloportes pilés dans l'adhésine. Quand la flèche l'atteignit en plein dos, le retraité s'arrêta tout net et se redressa presque. On s'attendait à le voir faire face comme un vieux sanglier, mais il ne dit rien et au bout d'un instant il se courba plus bas (Boris Vian, Les Lurettes fourrées)

1988 Chapeau, j’ai pensé. Je n'avais plus du tout envie de pleurer. Tout s'était arrêté net. Chapeau. Je n'ai même plus le réflexe de dire képi. Ce képi que j’avais toujours sur la tête, vissé à jamais (Jean-Bernard Pouy, La Clef des mensonges)

II. Arrêter quelque chose/quelqu'un de façon brusque, soudaine

Transitif

1837 Constance, vêtue en matin, sortit de la chambre à coucher de Césarine où elle s'était habillée ; son premier coup d'œil arrêta net la verve de son mari, qui cherchait à formuler une phrase normale pour 
apprendre avec modestie ses grandeurs au prochain (Honoré de Balzac, Histoire de la grandeur et de la décadence de César Birotteau)

1854 Jadis, ceux qui avaient goûté aux fruits $\mathrm{du}$ Lotos oubliaient leur patrie et ne pouvaient plus quitter le pays des lotophages ; ceux qui ont trempé leurs lèvres dans l'eau du Nil l'aimeront, le regretteront et y penseront toujours. Depuis trois jours à peine j’avais quitté le Kaire, lorsque s'éleva un vent violent de khamsin qui nous arrêta net ; nous cherchâmes un abri à la pointe d'un îlot et nous attendîmes que la bourrasque fût passée (Maxime Du Camp, Le Nil. Égypte et Nubie)

1864 C'est bien parler pour un mathématicien et même pour un physicien ; mais il n'en est pas moins vrai que la nature réintégrée en son tout et divisée en ses parties concrètes, non plus dépouillée de certains attributs essentiels qui embarrasseraient sans profit la science, ou plutôt qui l'arrêteraient net, la nature exige qu'on lui rende les causes finales (Charles Renouvier, Essais de critique générale)

1876 Londres, sous l'oligarchie, existe, et Paris, sous la démocratie, n'existerait pas ! La cité de Londres a de tels droits qu'elle arrête tout net devant sa porte le roi d'Angleterre. À Temple-Bar le roi finit et le peuple commence. La porte se ferme, et le roi n'entre qu'en payant l'amende (Victor Hugo, Actes et paroles)

1881 Cela paralyse un homme dans la politique, les affaires ou sous l'Odéon! Il y a eu un moment même où j’ai été incapable de rien apprendre, mais rien ! Mon éducation moderne arrêtée net ! - les bords de mon chapeau avaient fait leur temps... ils se coupaient près du tuyau, et c'eût été folie de continuer à le porter par là (Jules Vallès, Jacques Vingtras : Le Bachelier)

1886 ... et $d z i n n$ encore, et $d z i n n !$ il en pleut maintenant, des balles. Tout près des marins, arrêtés net, elles s'enfoncent dans le sol inondé de la rizière, chacune avec un petit flac de grêle, sec et rapide, et un léger éclaboussement d'eau (Pierre Loti, Pêcheur d'Islande)

1899 Souvent, tandis qu'il parle, Guitry flûte. On ne l'interrompt pas aisément. Il a un « permettez! » qui vous arrête, net et sec. - Nous autres, dit-il, les quinze ou vingt connaisseurs de Paris... Il ne peut pas manger un fruit sans en dire l'espèce et sans la comparer aux autres (Jules Renard, Journal)

1928 Je pris mon parti rapidement : relevant mon col de pardessus, je me disposais à quitter ce couple décidé, à les laisser à leurs petites affaires. Un roulement de tambour et la curiosité m'arrêtèrent net. C'était un roulement sourd, presque étouffé, comme si le musicien avait eu peur de faire trop de bruit (Philippe Soupault, Les Dernières Nuits de Paris)

1939 Devant les flammes menaçantes, les malheureux furent bien obligés de sortir en foule dans les rues; ils y trouvèrent Bohémond qui, l'épée au poing, les poussait vers les créneaux. Plusieurs quartiers étaient incendiés, mais l'assaut des turcs fut arrêté net. Néanmoins, pour relever le moral de l'armée, il fallait un miracle. Le miracle se produisit. Ce fut la découverte de la Sainte lance (René Grousset, L'Épopée des croisades)

1975 Un camion freina devant « Le Roi du survêtement ». Le livreur descendit en courant chercher Charlie pour qu'il l'aide à décharger, mais en voyant L'Équipe il arrêta net de se presser, alluma fébrilement une gitane et se plongea dans la lecture (Florence Delay, Le Aïe aïe de la corne de brume)

1981 Monsieur Racine se jeta dans un buisson en déchirant son habit et disparut. Je regagnai l'allée. Le Roi, qui conduisait luimême sa calèche, l'arrêta tout net à ma vue et me tendit la main pour que je prisse place à son côté pour la suite de la promenade (Françoise Chandernagor, L'Allée $d u$ roi) 
Emploi absolu

1945 Sam s'était levé et marchait de long en large dans la partie la plus éclairée de la boutique.

- Oui, mais oublie pas qu'ils vont arrêter ça. Il y en aura plus de secours. Ça va arrêter net.

Il noua solidement ses grosses mains derrière son dos (Gabrielle Roy, Bonheur d'occasion)

III. s'arrêter tout net à quelque chose : fixer son attention sur quelque chose

Pronominal

1936 Je constate que le cinématographe plaît au peuple. Ce sont des suppositions. Un homme me parle ; je ne connais pas sa pensée, je la suppose. Si l'on s'arrêtait tout net à l'apparence, en s'appliquant à bien fixer le son, comme font les musiciens, quand ils s'accordent, on serait mieux placé ensuite pour deviner (Alain, Propos)

CORpus Web :

Un site pour arrêter net la fumette [http:// next.liberation.fr/vous/2008/05/22/un-site-pourarreter-net-la-fumette_72303] (20.6.2016)

Je voudrais vous donner un truc extrêmement simple pour arrêter net le hoquet. Je ne l'ai jamais vu mentionné nulle part. Vous remplissez à ras bord un verre d'eau et vous buvez une ou deux gorgées en posant vos lèvres sur le bord opposé à celui sur lequel vous buvez normalement [http://www.rebelle-sante.com/ rebelle-sant $\% \mathrm{C} 3 \% \mathrm{~A} 9-\mathrm{n} \% \mathrm{C} 2 \% \mathrm{~B} 0-178 /$ trucs/pourarr\%C3\%AAter-net-le-hoquet] (20.6.2016)

Je crois que je cherchais à lui faire comprendre qu'il ne devait pas me prendre pour une idiote qui était accrochée à lui... Sauf que j’ai perdu l'effet du SR je pense, ça a du le renvoyer à son angoisse que je ne croyais pas en notre couple... Il a arrêté de me répondre net... Je m'en veux car il n'est même plus question de sortie cette semaine alors qu'on en parlait la semaine dernière... [http://www.jerecuperemonex.com/ forum/reconquete/mon-recontactee-que-fairemaintenant-t39811.html] (23.11.2015)

Je passerai les détails sur les critiques virulentes et destructives que vous allez vous adresser, à la suite de cette apparition, les flagellations que vous allez vous infliger, les auto-censures que vous vous prescrivez ; c'est la descente aux enfers avec un impact cuisant sur votre progression, qui va s'arrêter nette [http://egeria.overblog. com/faites-taire-votre-gremlin] (6.12.2013)

Je suis sur le point d'arrêter nette ma conso de cannabis, dans l'attente de vos réflexion, vos interrogation, vos exeperiences, attention ce qui ne tue pas ne t'épargne pas pour autant alors bannissons le mot douce après drogue c'est ma conviction il n'y a que des drogues nuisible pour notre santé moral et physique [http:// sante-medecine.commentcamarche.net/forum/ affich-1259701-drogue-douce-et-dur-dependance] (6.12.2013)

Remarques : $\left(S^{\prime}\right)$ arrêter net désigne un arrêt brusque, sans freiner. Le groupe est lexicalisé au point de permettre l'emploi absolu. Il reste invariable, soit pour le sujet (ex. de 1823, 1913, 1932, 1948 et les trois premiers exemples du CW), soit pour le complément d'objet (ex. de 1854, 1864, 1881, 1886, 1981) et est modifié par tout. Ceci étant, l'écriture spontanée du CW admet l'accord de net avec le complément d'objet ou le sujet d'un verbe pronominal (deux derniers exemples $\mathrm{du} \mathrm{CW}$ ). Notons qu'à l'oral le - $t$ final est toujours prononcé, même au masculin. Dans le troisième exemple du CW, on perçoit à première vue le groupe répondre net, qui est attesté dans ce dictionnaire, mais il s'agit en réalité de la combinaison arrêter net (Il a arrêté net de me répondre) où net se voit déplacé après le second verbe, ce qui est assez exceptionnel pour un adjectif-adverbe. Mentionnons également la collocation net et sec.

\section{Arrêter petit}

s'arrêter petit : s'arrêter brièvement

Pronominal

1276 De Gloriande estoit moult honnorés, Au partir fu de ses bras acolés. Quant l'ot conduite Carahués en ses tres, Moult petitet s'est illuec arrestés ; A Ogier est erranment retoornés, Par son commant fu ses lis aportés Iluec, et est la nuit la demorés (Adenet le Roi, Les Enfances Ogier, 3717)

1370 Quant les mariniers seurent et entendirent la volenté de leur seigneur, si prindrent 
port et getterent leur ancre, et moult petit orent arresté quant les autres nefz vindrent au port, et ot chascun grant joye quant ilz se virent prez de terre, car moult orent eü a souffrir (Roman de Berinus, I, p. 38)

+1370 Le roy, qui avoit encoires l'annoy ou cœur, les receut en passant, petit s'arresta, ne fist contenance sus eulx, et passa oultre, et le plus, sus le chemin, à qui il parla, ce fut à l'evesque de Londres (Jean Froissart, Chroniques $(\mathrm{A})$ )

Intransitif

1364 Car petit au lire arresta

Pour ce qu'en un feu les getta (Guillaume de Machaut, Le Livre du voir dit, 5798)

\section{CORpus WeB :}

Sinon, pour répondre sur la mise à l'envol, je ne m'inquiéterai pas et essaerai de lui montrer le plus de gibier possible. S'il a arrêté petit, même pas longtemps, il arrêtera de nveau mais faut lui laisser le temps et SURTOUT le mettre le + possible en présence [http://www.epagneul-breton. org/viewtopic.php?t=2038] (6.12.2013)

Bref, ça me faisait plaisir et ça faisait plaisir à mon fils, alors tant que nous en éprouvions le besoin tous les 2, j'ai continué. Pourquoi veux-tu arrêter ? Est-ce que cela te pèse à toi ? Parce que là, ce serait différent - tu dois alors lui expliquer (mais si il comprendra !) et puis arrêter petit à petit - un soir tu lui dis que maintenant il est grand et que tu ne vas + l'allaiter que qques jours [http:// forum.infobebes.com/Mon-bebe/Allaitementbiberon-nutrition/arreter-allaitement-impossiblesujet_27462_1.htm] (20.6.2016)

REMARQUES : En ancien français, arrêter petit signifiait 'arrêter peu'. Le sujet désignait une personne qui interrompt son mouvement, cesse d'avancer ou fait halte en un lieu, le processus étant de courte durée. Petit est modifié par moult, illuec. Le groupe antonymique s'arrêter long n'est pas attesté. Rappelons tout de même l'emploi de long temps. Le premier exemple du CW pourrait être une prédication seconde qui a la même structure mais interprétée au concret comme 'arrêter quand il était petit', mais le contexte suggère plutôt une lecture temporelle. Le dernier exemple du CW met en lumière la continuité de petit comme adjectif-adverbe de temps dans la collocation petit à petit.

\section{Arrêter sec}

Arrêter brutalement, rudement, brusquement

Transitif

1899 Souvent, tandis qu'il parle, Guitry flûte. On ne l'interrompt pas aisément. Il a un « permettez! » qui vous arrête, net et sec. - Nous autres, dit-il, les quinze ou vingt connaisseurs de Paris... Il ne peut pas manger un fruit sans en dire l'espèce et sans la comparer aux autres (Jules Renard, Journal)

Pronominal

1920 Gédéon qui tapait avec sa serpe sur un aubépin, s'arrêta sec :

- Ça, c'est une menterie

(Ernest Perochon, Nêne)

1985 - Voyez-vous, monsieur Malaussène, j'en ai par-dessus la tête de me faire engueuler à ma place !

Suit un long rire suraigu qui semble une fuite de quelque chose, incontrôlable. Et ça s'arrête aussi sec (Daniel Pennac, $A u$ bonheur des ogres)

2002 Hypnotisées par nos haut-parleurs ! Le sol tremblait sous les sabots. La frousse qu'on a eue ! On a coupé le son, elles se sont arrêtées aussi sec : comme si on les avait débranchées. D’un seul coup, toutes à brouter, peinardes, l'air de rien. Apparemment il y avait quelque chose dans nos braillements, une longueur d'onde, ou une fréquence, qui les attirait prodigieusement (Olivier Rolin, Tigre en papier)

2006 c'est le beep-beep beep des engins de road construction (puisque là-bas on construit non seulement les bâtiments, mais aussi les routes et les rues, et souvent du même béton) sur Mercer, qui commençait aux petites heures du matin (petites du moins selon mon horloge interne) pour s'arrêter aussi sec, assez tôt dans l'après-midi : l'ouvrier américain regagne sa banlieue à temps pour la douche à l'étage, le dîner en famille et le feuilleton d'access primetime (Gérard Genette, Bardadrac) 
Intransitif

1989 Le Tigré, Qu'une-Oreille, la Blanche sourde, la Grincheuse-même-en-dormant, tous, ils ont arrêté aussi sec de me miauler, de me barrer la route, de me donner des coups de cul et de patte (Remo Forlani, Gouttière)

CoRpus Web :

j'ai fumer toute ma vie quasiment , j'ai commencer a 14 ans et j'ai arrêter sec a 26ans, je peut te dire que je recouvres la vrai vie, je dort mieux , je rêve en full HD, j'ai la pêche le matin :ok: par contre il faut bannir le bedo de ta bouche, l'es petite lattes occasionnelles te fon vote retomber :ok: [http://www.jeuxvideo.com/forums/1-5165509998-1-0-1-0-quel-effet-ca-fait-d-arreter-lebedo.htm] (20.6.2016)

Merci à toi qui à arrêter sec en auto tantôt quand je suis passé devant toi sans t’avoir vu. Tu m'as sauvé la vie. Merci encore [https://www. facebook.com/permalink.php?id=5786056621 60539\&story_fbid=1017595488261552] (20.6.2016)

J'étais encore une fille de rue et de méthadone... J'étais pas encore prête à arrêter sec comme ça [http://www.amecq.ca/dossier_du mois/2013/11/26] (6.12.2013)

Ta bagnole dérape en un crissement terrifiant, se marque au sol par deux larges traits sombres. La blonde pousse un hurlement de terreur et ta caisse finit par s'arrêter, sèche et brusque [http://xwritetolive.skyrock. com/3107256061-First-one-shot.html] (6.12.2013)

REMARQUES : Arrêter sec et arrêter net expriment le même concept de stopper brusquement, avec parfois une connotation de brutalité, froideur et immédiateté qui est plus forte dans le premier cas. La collocation net et sec renforce ce concept. Sec reste invariable (ex. de 2002). Dans le dernier exemple du CW, sec est employé au féminin et détaché syntaxiquement, mais sans abandonner la fonction adverbiale. Le style écrit de l'exemple l'identifie comme variante recherchée et non pas comme phénomène d'écriture spontanée.

\section{Arriver doux}

I. Arriver (concret) sans brusquer, sans à-coups, doucement

Intransitif

1908 Alors ils mouraient avec une résignation de chameaux mahométans ; on demandait de l'argent pour en acheter d'autres, et les nouveaux chameaux arrivaient tout doux, tout doux, trotti-trotta, cahin-caha, balançant la tête, bavant, rognant, et flairant sur le sable les squelettes de leurs frères et amis, morts à la peine (Pierre Mille, Barnavaux et quelques femmes)

II. Survenir sans se faire remarquer, doucement Intransitif

1963 Travaillerais. Travaillerais. Voilà quelque chose de nouveau, qui arrive, comme ça, tout doux, au conditionnel (Christiane Rochefort, Les Stances à Sophie)

\section{CORPUS WEB :}

Vous pouvez partager l'expérience de manger du pain fait maison et montrer à vos amis et proches que vous aimez en leur envoyant une miche. Bien que le pain d'envoi peut sembler compliqué, avec la bonne planification et à l'emballage, vous pouvez être sûr que votre pain va arriver, doux et frais [http://www.inspectian. com/jz6axeBGR] (20.6.2016)

REMARques : Doux est un adjectif-adverbe de manière équivalent à doucement (I, II). Il est modifié par tout. Notons que tout intensifie l'idée de calme, de modération dans le déplacement. L'emploi de doux comme modifieur du verbe penche facilement du côté de la prédication seconde : le pain est doux et frais au moment d'arriver (CW). Mentionnons la réduplication tout doux, tout doux.

\section{Arriver droit}

I. arriver droit (à, chez, devers, en, là, sur) : (sujet animé) parvenir directement, sans détours, en un lieu, à destination Intransitif

-1100a Danz Alexis entrat en une nef, ourent lur vent, laisent curre par mer, andreit Tarson espeiret ariver, mais ne puet estra, ailurs l'estot aler, 
andreit a Rome les portet li orez

(Vie de saint Alexis [fin $\mathrm{XI}^{\mathrm{e}}$ ], BFM, 193)

+1150 Vienent a Tornebrie, la sont droit ariue (Aiol et Mirabel [2 $2^{\mathrm{e}}$ moitié XII ${ }^{\mathrm{e}}$, 9815)

$\sim 1160$ Uit jors tos plains par mer erra Que nule terre ne trova. Au nueme jor sont arivé Tot droit a Baudas la cité Qui sist sor une roce bise, Desor le port en haut assise (Flore et Blancheflor, 1391)

$\sim 1235$ En la mer ne fu c'une nuit. L'endemain matin a deduit Sans avoir tormente n'ahan Est tout droit arrivés au Dam. Ses cevax des nes ou rivage Fist mettre, qu'il n'i eut damage (Philippe de Remi, sire de Beaumanoir, $L a$ Manekine, 2618)

1275 Atant se regardent, si voient Une galie qui venoit Par mi la mer a grant esploit. $A u$ port est tot droit arrivee, Fors en issent sanz demoree Jusqu'à .iiij.c. chevalier, Fors et hardi, preus et legier (Floriant et Florete, 8015)

1398 Nous partismes de Corfo le mardy ensuivant, .vije. jour de septembre et vigille de Nostre Dame ; et errasmes par mer, tant a voille comme a rames, jusques au sabmedy ensuivant que nous arrivasmes en une isle qu'on appelle Chifornia. Et arrivasmes droit $a$ une belle fonteine d'eaue doulce ou il ot jadis une ville que l'en appeloit Alexandria (Le Saint Voyage de Jherusalem, p. 7)

1680 J'ai été à Versailles ; je ne sais si je ne vous l'ai point mandé. J'allai avec d'Hacqueville tête à tête. Nous partîmes à trois heures. Nous arrivâmes droit chez M. de Louvois, que nous trouvâmes; ce bonheur me parut comme de donner droit dans le treize d'un trou-madame (Mme de Sévigné, Correspondance)
1755 Le nombre pair étant formé de quatre on vit bientôt les deux fléches abattre le pont mobile ; et les quatre coursiers font en marchant gémir les madriers. Le gros Bonneau tout essouflé chemine en arrivant droit devers la cuisine, songe au souper. Le moine au même lieu, dévotement en rendit grace à Dieu (Voltaire, La Pucelle d'Orléans)

1857 Comme j'ai été attendri, chère Madame, de votre bonne lettre! Les questions que vous m'y faites sur l'auteur et sur le livre sont arrivées droit à leur adresse, n'en doutez pas : voici donc toute l'histoire (Gustave Flaubert, Correspondance)

1859 Le marquis va dans le monde ; cent personnes de vos connaissances pourront vous présenter à lui. « Avec une lettre du marquis Gontran, vous arriverez tout droit en Bretagne chez le chevalier. Pourvu que vous aimiez passionnément la chasse, rien ne vous empêchera de passer un an au manoir » (Pierre-Alexis Ponson du Terrail, Rocambole)

1966 Des corps le frôlaient continuellement, touchant ses vêtements et déplaçant des souffles d'air. Des figures pâles, aux yeux enfoncés, arrivaient droit sur lui, et, au dernier moment, faisaient un détour. Il y avait des hommes debout devant les magasins, qui regardaient avec insistance (Jean-Marie Gustave Le Clézio, Le Déluge)

II. arriver droit (à quelqu'un) : (sujet inanimé) arriver à destination, qui va à son destinataire sans détour

Intransitif

-1100b Dreit a Lalice, ço fut citét mult bele, Iloec arivet sainement la nacele, Dunc an eisit danz Alexis acertes, Ço ne sai jo cum longes i converset, Ou que il seit de Deu servir ne cesset (Vie de saint Alexis [fin $\mathrm{XI}^{\mathrm{e}}$ ], BFM, 81)

1840 Heureuses et bénies ces vocations modestes et fermes, obéissantes et sûres, ces natures auxquelles il est donné d'arriver tout droit, en reconnaissant un guide illustre, en le suivant à côté et dans l'ombre, 
en se souvenant jusqu'au bout de lui ! Littérairement parlant, Lancelot est pour M. de Saint-Cyran, dans des teintes plus sombres, ce que Racine fils en ses mémoires est pour son père

(Charles Sainte-Beuve, Port-Royal)

1893 Et il ne pouvait pas plus le lui demander qu'elle-même n'avait pu montrer la lettre infâme à cette mère qui disait souvent : « J'élève ma fille d'après les principes anglais, dans la plus complète indépendance... » Elle avait d'heureux résultats, cette indépendance qui permettait à un billet de cet ordre d'arriver droit à la pauvre petite! (Paul Bourget, Cosmopolis)

III. Accoster

Pronominal

1371 LE PREVOST. Hyer, chier sire, m'estoie mis,

Avec de mes gens trois ou quatre, Jusques sur le port pour esbatre ;

Ainsi que je fu la, avint

Q'une nasselle par mer vint

Sanz gouvernement par mer nul, Sanz trait de cheval ne de mul, Sanz mast, sanz aviron, sanz voille, Quel qu'il fust, de soie ou de toille ;

Et si s'arriva droit au port.

Et je, qui estoie en desport,

M'en alay la sanz attendue,

Quant a rive la vy venue

(Miracle de la fille du roy de Hongrie, 635)

IV. Se diriger directement vers quelqu'un/ quelque chose (abstrait)

Intransitif

1833 Ses yeux, dépourvus de cils, n’avaient plus cette lenteur voilée qui sied si bien à la jeunesse. Son regard vous arrivait droit au visage, brusque, fixe et presque arrogant (George Sand, Lélia)

1932 Sa rousse et perverse chevelure (la peau allant avec) était parcourue pendant ce temps-là d'ondes étonnantes qui m'arrivaient droit par vibrations jusqu'au périnée. Comme elle m’interrogeait cette divine sur mes actions de guerre, je lui donnai tant de détails et des si excités et des si poignants, qu'elle ne me quitta désormais plus des yeux (Louis-Ferdinand Céline, Voyage au bout de la nuit)

V. arriver droit (sur, dessus) : arriver vers

quelqu'un à grande vitesse

Intransitif

1839 Voilà mes deux poltrons qui se mettent à vociférer, le guide qui jure, la demoiselle qui crie au secours. Je les envoie à tous les diables, et, n'apercevant ni père, ni chiens, je me lance dans l'avalanche, j'arrive droit sur leur demoiselle, et, aidé du guide, je la ramène saine et sauve sur la chaussée (Rodolphe Toepffer, Nouvelles genevoises)

1926 alors, voyant Romain être tranquillement assis devant une chopine et un verre, la joie l'a faite changer de couleur ; parce que la joie a tiré d'abord tout son sang au cœur, puis l'a refoulé, lui faisant les oreilles devenir toutes chaudes, lui gonflant les veines du cou. Elle arriva droit sur Romain :

- Mon dieu ! Romain qu'est-ce qui se passe?

(Charles-Ferdinand Ramuz, La Grande Peur dans la montagne)

1948 on voit des voiles fantomatiques à bâbord et à tribord, les feux d'un cargo qui vous arrive droit dessus, un paquebot tout illuminé qui passe à contrebord, à vous frôler (Blaise Cendrars, Bourlinguer)

VI. Arriver directement (un son) à quelque chose

Intransitif

1857 Mais l'anéantissement de ma vigueur physique ne diminuait en rien la netteté de mes perceptions. J'aurais été incapable de soulever mes paupières, et cependant le plus léger bruit arrivait droit à mes oreilles. Je ne perdis pas un mot de ce qui se disait autour de moi (Edmond About, Le Roi des montagnes)

VII. arriver tout droit de : venir directement de quelque part

Intransitif

1886 C'était $d u$ couvent qu'elle arrivait tout droit, la supérieure ayant fini par lui trouver 
cette place de lectrice, chez sa vieille amie, Mme Vanzade, devenue presque aveugle (Émile Zola, L'Évure)

1939 On nous servit des cocktails étranges et des sandwichs qui tenaient du bibelot, et qui arrivaient tout droit de la rue de Rivoli. La dernière Parisienne, qui s'appelait, je crois, Sarah, circulait entre les pétales et les porcelaines de son petit musée d'hôtel (Léon-Paul Fargue, Le Piéton de Paris)

1985 «Il t’a vu tout nu dans la cave, avec une fille !... Et tu vas me dire qui c'est, ta femelle !... » Elle avait hurlé sur les derniers mots. Il n'y avait plus ni douceur ni sourire, il n'y avait plus qu'une voix gorgée de haine arrivant droit des entrailles (Yann Queffélec, Les Noces barbares)

\section{Corpus Web :}

J'avais vu la voiture arriver droit sur nous [http://www.leprogres.fr/actualite/2015/04/25/javais-vu-la-voiture-arriver-droit-sur-nous] (20.6.2016)

dans tous les cas il doit changer le ballon de main et vu que le mec ne se baisse pas il doit raffuter voire tenter un cadrage débordement meme si l'espace est super limité mais forcément quand les deux arrivent droits ben ils s'ouvrent comme un livre, c'est impressionnant mais ce sont des gestes que tu es censé maitriser en senior [http:// www.ultras-sapiac.com/forum/viewtopic. php?f=2\&t=13\&start=60] (7.12.2013)

À travers les immenses verrières, les rayons du soleil nous arrivent droits dans les yeux, on se croirait en plein été! [http://lebaiserdelamouche. wordpress.com/2011/12/13/mon-1er-salonma-mouche-et-le-petit-peuple-de-decembre] (7.12.2013)

Qui peux m'expliquer pourquoi les ogives de la munition F5 de chez IMI que nous (militaires) utilisons dans les FAMAS arrivent droites dans les cibles à $25 \mathrm{~m}$ (et bien sûr plus loin) [http://94.23.243.216/ tirmaill/mildot/viewtopic. php?t=35826\&view=next\&sid $=46811570 \mathrm{cc} 847311$ a0575175829074c5] (7.12.2013)

Sur la cible, y'en a pas une meilleure que l'autre je trouve. Il faut prendre en compte, pour la précision en cible, que le tireur n'est pas expérimenté. Pour ce qui est d'arriver droites ou de travers, les photos parlent d'elle-mêmes. J'en conclus que si je dois en racheter, je chercherais la meilleure offre car je ne vois pas de différence à l'usage [http://corsicarms.activebb.net/ t34294p390-club-fabarm] (20.6.2016)

Et la première épreuve fait déjà des dégâts. $2,5 \mathrm{~km}$ autour du lac, il y a plus facile pour commencer. Le record à battre est de 13 minutes, la première équipe féminine (il y en a quatre en tout) s'en rapproche avec cinq petites minutes supplémentaires. Et certaines ont quelques difficultés. «Si vous pouviez arriver droites... non, c'est pour plaisanter, leur lance l'homme au micro » [http:// www.ladepeche.fr/article/2001/10/15/301812-lesforcats-du-bonheur.html] (20.6.2016)

REMARQues : Droit est un adjectif-adverbe de manière-direction qui est modifié par tout. Droit est souvent suivi d'une préposition de lieu indiquant la direction finale (à, chez, devers, en, sur, dessus) ou la provenance (de). Dans cet emploi, droit a tendance à s'associer avec les prépositions qui le suivent, au point de faire partie du groupe prépositionnel comme modifieur de la préposition. L'accord adverbial es fréquent dans l'écriture spontanée du CW, notamment dans le cercle des tireurs. L'ensemble des citations du CW met en évidence la tendance à faire l'accord dans des fonctions plutôt adverbiales au sens de 'directement'. Seul le dernier exemple actualise une prédication seconde au sens concret de 'debout en position verticale', où l'accord est pleinement justifié.

\section{Arriver haut}

I. Réussir, avoir du succès, atteindre une haute position sociale

Intransitif

1647 DON BERNARD. Je sais que, par un heur qui ne se conçoit pas,

Pour arriver si haut je n'ai pas fait un pas, Et que tout mon crédit et toute ma puissance

Ne sont qu'un simple effet de mon obéissance, Que je méritais moins que vous ne méritez, Et qu'on m'a tout donné ce que vous achetez

(Jean de Rotrou, Don Bernard de Cabrère) 
1845 - J'approuve cette idée, dit le cardinal après un moment de réflexion ; avec son mérite, avec sa puissance d'action sur les hommes, l'abbé Gabriel peut arriver très haut... s'il est docile ; et s'il ne l'est pas... il vaut mieux pour le salut de l'Église qu'il soit à Rome qu'ici... (Eugène Sue, Le Juif errant)

1854 Ils se firent les interprètes, les secrétaires, les conseillers des sultans ; et, cachés modestement dans des positions secondaires, ils eurent le talent de mener leurs maîtres. Plus d'un s'éleva jusqu'au rang d'hospodar, c'est-à-dire de gouverneur de province ; ceux qui n'arrivèrent pas si haut s'en consolèrent en s'enrichissant (Edmond About, La Grèce contemporaine)

1939 Entouré de banques, de bureaux, de compagnies de navigation, de magasins parfaitement parisiens, le Scribe est avant tout l'hôtel d'un certain nombre d'hommes d'affaires pour qui l'économie du taxi, le sauvetage d'une épingle, l'arrivée à pied bien visible au rendez-vous décisif, sont des moyens d'arriver vite et haut, à l'américaine, et fournit l'occasion de sourire à ce que les provinciaux appelleront toujours le trottin (Léon-Paul Fargue, Le Piéton de Paris)

\section{Sens spatial concret \\ Intransitif}

1812 Nos marins suspendent leur course : ils attendent une vague qui puisse les porter au but ; elle arrive haute et fière, couronnée d'écume, nous saisit, nous entraîne, se déroule en grondant, et dans son retour subit nous laisse à trente pas sur le rivage (Jean-Florimond Boudon de Saint-Amans, Voyage agricole, botanique et pittoresque)

2007a Évolutions : bonifications si le point fait suite à une réception en passe haute ou à une réception qui arrive haute dans une zone déterminée (ex. : les 3 mètres) ou encore à une attaque à l'aile en seconde main ; bonification pour l'équipe au service si l'équipe en réception ne peut renvoyer le ballon en attaquant (Gilles Bortoli, Manuel de volley-ball) 2007b La passe doit arriver haute et précise sur le passeur. Le passeur renvoie la balle parallèle au filet en hauteur. L'attaquant smatche, le ballon doit tomber dans le terrain adverse (Gilles Bortoli, Manuel de volley-ball)

III. Atteindre une valeur élevée

Intransitif

1945 Les trois commissions ne se cumulent jamais, et très souvent elles ne font renchérir le coût du crédit que de $1 \%$ par an, ou d'un montant de cet ordre de grandeur. Il y a néanmoins des cas où l'on arrive sensiblement plus haut, surtout dans des périodes de désordre monétaire et de crises de crédit (Fernand Baudhuin, Crédit et banque)

\section{Corpus Web :}

Voici toutefois ce que défend l'école Républicaine : à force de travail et d'abnégation, tout le monde peut y arriver. Mais pour arriver haut, très haut, il faut faire preuve d'autre chose. Il faut avoir un don/talent. Et c'est cette chose qui fera la différence [http://leplus.nouvelobs.com/ contribution/1214602-du-bac-a-l-ena-le-meriten-existe-pas-c-est-une-invention-qui-sert-bienla-republique.html] (20.6.2016)

C'est une vraie star : 97\% des Français la reconnaîtraient au premier coup d'œil, selon une étude. Cette icône, drapée de rouge et sourire aux lèvres, est l'une des plus belles réussites de l'histoire des marques françaises. Il faut dire que La vache qui rit est partie de loin pour arriver haut, très haut même... [http://www.francesoir.fr/ lifestyle-gastronomie/la-vache-qui-rit-toujoursle-sourire] (20.6.2016)

REMARQUES : Haut est un adjectif-adverbe de lieu qui a un sens spatial concret ou figuré, désignant un point élevé dans une perspective résultative. Dans l'emploi spatial concret (II), la flexion optionnelle de haut pousse son interprétation du côté de la prédication seconde. L'adjectif-adverbe insiste alors sur la position d'un objet, sans dynamique résultative. L'accord de haut, bas et droit par rapport à la position d'un ballon, d'une balle, d'un projectile, etc. est courant dans le domaine du sport. Employé au figuré (I, III), haut reste invariable et est modifié par si, plus, très. Notons la collocation 
avec vite qui suggère une ascension sociale ou professionnelle fulgurante. Notons l'emploi de renvoyer parallèle (le ballon); arriver précis.

\section{Arriver juste}

Arriver au bon moment, quand il faut, de manière opportune

Intransitif

1679 Le courrier dépêché à la cour, pour savoir les intentions de la reine, arriva juste, et il sembloit que le ciel étoit sur le point de bénir ce grand ouvrage, quand toutes les espérances s'évanouirent (Jean-François de Gondi (Cardinal de Retz), Mémoires)

+1847 Manicamp arrivait souvent trop tard par paresse. Cette fois, ils arrivèrent juste. Cinq chevaux étaient préparés (Alexandre Dumas père, Le Vicomte de Bragelonne [1847-1850])

1877 On lui donnait vingt minutes pour aller de la Rue de la Goutte-d'Or à la Rue du Caire, ce qui était suffisant, car ces tortillons de filles ont des jambes de cerf. Des fois, elle arrivait juste, mais si rouge, si essoufflée, qu'elle venait bien sûr de dégringoler de la barrière en dix minutes, après avoir musé en chemin (Émile Zola, L’Assommoir)

1934 Après avoir embrassé son fils, elle reprend sa besogne, sans cesser de parler :

- Comme ça, t'arrives d'à présent ?

- D’à présent, de la gare, j’arrive.

- T'arrives juste ! Je dis juste, à propos qu'on voulait t'écrire. On a bien fait de pas s'y décider, puisque voilà que t'arrives. C'est à propos qu'on y avait pensé, que je dis : t'arrives juste.

- À propos de quoi, vous vouliez m'écrire? - Des choses, des histoires qui traînent dans le bourg... T’as causé à personne, en venant ? (Gabriel Chevallier, Clochemerle)

1963 J'entrave tout d'un seul coup ! Si je me propulse vers la sortie! Malsain au possible de rester en contemplation. J'arrive aux marches juste quand le maton donne l'ordre de couper la flotte. « Tout le monde dehors! Pressons ! Pressons ! » Pas besoin de me le dire... le feu au derche littéralement (Alphonse Boudard, La Cerise)
CORPUS Web :

Cela nous assure que tout point libre sera nécessairement accroché à la grille du plan cartésien. Autrement dit, les coordonnées « arrivent justes » [http://www.gilles-jobin.org/ maths/monpremierscenario/etape2details.htm] (9.12.2013)

REMARQUES : Employé avec le verbe arriver, juste adopte la signification de 'exact' appliqué à un contexte temporel, 'au moment juste', les connotations 'presque trop tard' ou 'risquer d'arriver tard' étant possibles (Fais attention, tu vas arriver juste). Juste reste invariable (ex. de +1847). L'adjectif-adverbe juste peut également modifier une conjonction temporelle qui le suit. Ainsi, dans l'exemple de 1963, cité au hasard, il appartient à la subordonnée introduite par quand. Notons l'emploi accordé dans le CW, mis entre guillemets, et signifiant 'au moment juste, à propos'.

\section{Arriver précis}

Arriver à l'heure exacte

$\lambda$ arriver haut

\section{Arroyer (areer) bel}

Arranger, équiper, parer joliment, avec éclat et élégance

Pronominal

1275 Congié prent, si s'en torne que plus n’i arresta.

Venus est à son tre, moult bel s'apareilla, D'armes et de cheval bien et bel s'arrea (Adenet le Roi, Buevon de Conmarchis)

Transitif

1276 Lors prent congié Carahués com senés. Ou cheval monte ; quant fu issus des tres, A grant merveille fu de tous esgardés, Car richement et bel ert arreés (Adenet le Roi, Les Enfances Ogier, 2345)

1285 Et cil le firent sans dangier Noblement et bel arreer (Adenet le Roi, Cleomadés, 10261)

+1365 Trois jours dura la feste; mès Il y eut danses et carolles, Pour quoi j'ai empris les parolles, Car bien .VI ${ }^{\mathrm{xx}}$. jones et belles, Toutes dames et damoiselles, Filles de chevaliers ou fames, 
Dou pays les plus frices dames, Moult ricement et bel arrées, Très noblement et bien parées En draps de canjans et de soie (Jean Froissart, Poésies [3 $3^{\mathrm{e}}$ tiers XIV $]$ ])

REMARQUES : En ancien français, arroyer bel caractérise l'éclat, le faste dans l'équipage (vêtements, armes, cheval), qui contribue à la bonne apparence, au prestige de quelqu'un. La collocation du neutre bel avec les adverbes bien, richement et noblement accentue l'idée de magnificence et de faste. Notons l'emploi de s'appareiller bel. VOIR AUSSI : acesmer beau / bel

\section{Articuler mou}

Articuler mollement, sans énergie, indistinctement

Intransitif

1959 Mlle Arlette a tort d'articuler mou (Le Monde, 13 septembre 1959 / Grundt : 227)

Remarques : Articuler mou désigne ici le fait de prononcer les syllabes, un son, un mot, une phrase, de façon peu claire et peu distincte, l'adjectif-adverbe mou soulignant un manque d'exactitude, une sonorité faible, difficilement perceptible. Il reste invarié.

\section{Aspirer haut}

I. Avoir de grandes, nobles aspirations, ambitions ; viser haut

Intransitif

1589 LE DUC DE GUISE. Puis que Christ ne planta sa foy par la pistole, Qu'il dissimule bien le sac, l'impieté, Qu'il deteste la guerre, et toute hostilité, Que nourri en l'erreur qu'on luy a fait apprendre,

Si fausse on la cognoit, est contraint de se rendre,

N'est-ce un signe assez seur qu'il aspire plus haut,

Et qu'il veut reculer pour faire un plus grand saut?

(Pierre Matthieu, La Guisiade)

1596a Tourne, mon cœur, ailleurs ton esperance,

Laissant le bien vainement desiré ;

Pour un mortel c'est trop haut aspiré,
Il faut couper l'aile à notre arrogance

(Philippe Desportes, Euvres)

1596b Angelique beauté, je sacre à la memoire Ces vers, avantureux courriers de vostre gloire,

Qui n'atteindront pourtant au ciel de vostre honneur :

Pour aspirer si haut ma force est trop petite,

Je sçay mon impuissance et vostre heureux merite,

Et sçay qu'il vous faudroit un plus divin sonneur (Philippe Desportes, Euvres)

1628 Qui de vous posseder ne s'estimast heureuse?

Réveillez vostre force : une ame genereuse Jamais sur ses desseins ne demeure en deffaut ;

Le Ciel ayde au mortel aspirant tousjours haut (Jean de Schélandre, Tyr et Sidon)

1651 Il a son but à part, Grimoald, prends-y garde :

Quelque dessein qu'il ait, c'est toi seul qu'il regarde.

Examine ce cœur, juges-en comme il faut. Qui m'aime et me trahit aspire encor plus haut (Pierre Corneille, Pertharite)

1656 J'aspire un peu trop haut, il faut que je l'avouë,

Mais un grand cœur prétend qu'on l'aime, et qu'on le louë, Autant qu'on doit traitter de haine, et de mépris,

Les timides esprits

(Guillaume Colletet, Poésies diverses)

1833 J'ai aspiré trop haut, je t'ai revêtu d'une gloire qui ne fut sans doute jamais la tienne et que j'ai voulu égaler (George Sand, Lélia)

1838 Le peuple, qui a l'avenir et qui n'a pas le présent ; le peuple, orphelin, pauvre, intelligent et fort ; placé très bas, et aspirant très haut ; ayant sur le dos les marques de la servitude et dans le cœur les préméditations du génie ; le peuple, valet des grands seigneurs, et amoureux, dans sa misère et 
dans son abjection, de la seule figure qui, au milieu de cette société écroulée, représente pour lui, dans un divin rayonnement, l'autorité, la charité et la fécondité (Victor Hugo, Ruy Blas)

1839 Du désespoir si haut élevé au-delà de l'espérance, il aspire encore plus haut : insatiable de poursuivre une vaine guerre contre les cieux, et non instruit par son succès, il déploya de la sorte ses imaginations orgueilleuses (François de Chateaubriand, Le Paradis perdu)

II. aspirer tout haut : souhaiter ouvertement, afficher clairement ses ambitions

Intransitif

1799 Au milieu de ces excitateurs qu'il vient de signaler, qui, encore une fois, sont en petit nombre, mais semblent se multiplier par le bruit, il ne perd pas de vue ces autres royalistes d'une incurable frénésie, qui aspirent tout haut après un maître, qui le rappellent de tous leurs vœux, de toutes leurs actions (Emmanuel Sieyès, Euvres)

\section{CoRpus Web :}

Il faut faire exactement tout le contraire, pense-t-il, le théâtre est un lieu d'enchantement où chacun doit être transporté au-dessus de la vie courante. Et il n'est pas seul à penser ça. En 1927 Jouvet, Baty, Dullin et Pitoëff se regroupent pour former le fameux Cartel des Quatre, une manière pour eux d'aspirer haut et fort à un renouveau [http://www.lebandeau.net/t2552-giraudoux-oul-ironie-souriante] (20.6.2016)

Pour voir grand, il faut aspirer haut, et donc transcender l'horizon du présent. Ce qui ne suggère pas, que l'on doive faire fi du passé. Mais si le passé décrit une trajectoire d'expérience donnée, rien n'indique qu'il doive automatiquement se prolonger dans l'avenir suivant une courbe d'évolution fixe [https://www.linkedin. $\mathrm{com} /$ pulse/voir-grand-marcel-jb-tardif-mba] (20.6.2016)

Quelques fois par année, vous pouvez également battre les tapis de sortir la poussière profondément réglé. Vous pouvez accrocher ces puis utiliser un aspirateur vertical au réglage élevé. Ce va secouer toute la saleté et la crasse lâche, et puis vous pouvez aspirer haut en bas, puis côté à l'autre [http://www.davistile.com/lainecarpettes-do-it-yourself_5169926] (20.6.2016)

REMARQUES : Haut (I) est un adjectif-adverbe qui indique le lieu d'arrivée, partant d'un niveau inférieur vers un niveau supérieur, aussi au sens figuré de 'viser haut, d'avoir des visées ambitieuses' Haut (II) peut également signifier 'ouvertement, publiquement, à haute voix' (premier exemple du CW). Haut reste invariable et est modifié par plus, si, haut, tout, trop, encore plus qui soulignent le caractère ambitieux, voire irréalisable, du projet. Le sens concret directionnel 'passer l'aspirateur de haut en bas' est illustré par le dernier exemple du CW qui appartient au langage quotidien. Notons la collocation haut et fort ainsi que l'emploi de placer bas ; élever haut ; voir grand.

\section{Assaillir bel}

Assaillir, attaquer avec bravoure, avec courage

Emploi absolu

1176 Qant remese fu la parole,

Li rois Alixandre aparole,

Si l'apele son ami chier.

Amis, dist il, molt vos vi hier

Bel assaillir et bel desfandre [variantes :

bien ... bien ; biel ... bien]

(Chrestien de Troyes, Cligés, 1447)

REMARQUES : L'adjectif-adverbe de manière adopte ici la forme neutre bel qui indique la fonction adverbiale. Les variantes le remplacent donc par bien. Dans un combat, mené avec courage, il souligne la qualité d'attaque ou, plus généralement, les exploits ou prouesses du chevalier ou du combattant face à son adversaire. Notons l'emploi de défendre bel.

\section{Assaillir dur}

Assaillir, attaquer avec force, avec violence Transitif

1276 Avoec lui erent Açopart et Luti, Moult le tenoient a preu et a hardi. De no gent fist le jor maint malbailli, Car souvent orent esté dur assailli De lui ce jour, et entour et enmi (Adenet le Roi, Les Enfances Ogier, 5897) 


\section{CORPUS WEB :}

Il a cessé ; et Satan est resté pour ne pas répondre, mais, heureux que maintenant sa mer devrait trouver un rivage, avec l'alacrité fraîche et la force remplacée jaillit ascendant, comme une pyramide du feu, dans l'étendue sauvage, et par le choc des éléments de combat, sur tout l'entouré rond de côtés, gagne sa manière ; plus dur assailli et plus mis en danger que quand Argo a traversé Bosporus intermédiaire les roches justling, ou quand Ulysse sur le bâbord a évité Charybdis, et par le Th l"autre tourbillon a orienté [http:// bryantmcgill.com/wiki/poetry/john_milton/para dise_lost_book_02\#.UqXqFPPkSUk] (9.12.2013)

Remarques : Dur est un adjectif-adverbe de manière qui réfère ici à la façon dont le sujet attaque, dans une lutte ou un combat, son adversaire avec violence, force et sans ménagement. VOIR AUSSI : défendre dur

\section{Assaillir raide}

Attaquer quelqu'un avec vigueur, avec violence Emploi absolu

1365 Si alons assalir et si fort et si roit Qu'à terre l'abatons ; et s'abatus estoit, Sé li .i. de vous .iiii. li lanchoit d'un espoit, Je vous ai en couvent mes corpz li pardonroit (Li Romans de Bauduin de Sebourc, Chant III, 825)

REMARQUeS : Raide est un adjectif-adverbe de manière qui désigne la façon dont, dans une lutte ou un combat, le sujet, qui désigne une personne, attaque brusquement, vivement son adversaire. La collocation avec fort suggère l'idée de force et de rapidité dans l'action. VoIR AUSSI : défendre raide

\section{Assener droit}

I. Frapper, assener, donner (un coup) directement, exactement, avec précision Transitif

1176 Or la fera Amors dolante, Et molt se cuide bien vangier Del grant orguel et del dangier Qu'ele li a toz jorz mené.

Bien a Amors droit assené, [variante : droit a Amors]

Qu'el cuer l'a de son dart ferue.
Sovant palist, sovant tressue, Et maugré suen amer l'estuet (Chrestien de Troyes, Cligés, 460)

1177 Et cil an la gorge l'assanne Trestot droit par desoz la panne De l'escu, si le giete anvers Dessus les pierres an travers (Chrestien de Troyes, Lancelot ou Le Chevalier de la charrete, 2238)

+1225 Cil, tant con chevaus puet aller, De force haut et droit l'assene, Et le fiert en mont en la pene De l'escu, et si fort l'empaint Que li chevaus pas ne remaint En piés. La ciele a cil vuidie, Si ke par poi il n'a brisie L'espaule. Il est outre passés De son poindre, et s'est apensés K'a lui ne se combatra plus (Le Chevalier as deus espees [ $2^{\mathrm{e}}$ quart $\mathrm{XIII}{ }^{\mathrm{e}}$ ], 8765)

1250 U hauberc sous le bras l'a si droit assené Que l'espée trenchant l'a derout et faussé; U bras l'a .i. petit en la moure navré Que le cheval en a devant ensanglenté (Doon de Mayence, p. 133)

1276 Puis que dou Toivre passa les rades gués Quant combatirent dedenz l'isle ens es prés,

Il et Charlos ainsi com vous savés. $\mathrm{Au}$ tre Charlon est tout droit assenés Rois Carahués et Ogiers li senés (Adenet le Roi, Les Enfances Ogier, 4473)

Intransitif

+1313 Des lances si droit assenerent

K'en .iij. troncons les tronconnerent, Mais li artisiens tel cop ot K'ou ceual tenir ne se pot (Jean de Condé, Poèmes [1313-1337], 681)

II. Diriger, mener, conduire directement quelqu'un

Transitif

1200 Tant ont cerchié contreval la cité, Si com Deu plot, le Roi de majesté, Qu'a cel ostel sont tout droit assené, $\mathrm{Ou}$ ja estoient pluisor gent assamblé (Jourdain de Blaye, 3431) 
III. Donner, attribuer directement quelque chose à quelqu'un

Transitif

1325 Car à lui tout droit assena

La couronne et en couronna

Son chief ou plus haut, tout enson ;

Sans noise faire et sanz tençon

(Watriquet de Couvin, Dits, p. 89, 197)

CoRpus Web :

Que veut dire par là Luc Carvounas? Que le fait d'avoir fait arrêter le bus sur un parking durant la sortie scolaire, d'avoir fait amener la jeune fille dans une salle plutôt que d'avoir pris d'assaut le bus avec une escouade pour braquer des enfants est un bienfait dont il faudrait se targuer ? Partant de là oui, le solférinien Carvounas peut assener droit dans les yeux : « En cela, cette gauche qui est au pouvoir est vraiment une gauche humaniste " [https://cocq.wordpress. com/2013/10/17/carvounas-procureur-anti-romavocat-du-diable] (17.6.2016)

REMARQues : Droit est un adjectif-adverbe de manière-direction invariable qui est modifié par $s i$, tout. Assener droit appartient à l'ancien français, mais le CW atteste aussi l'emploi actuel où assener réfère au fait d'imposer avec force par la parole. Droit est modifié par si, tout, trestot. Notons la collocation haut et droit. Mentionnons également l'emploi de empeindre fort 'pousser fort'.

\section{Assener haut}

Atteindre, frapper fortement, gravement Transitif

+1365 Or est ainsi que bon Amour A mon cuer si hault assené En bien, en paix et en honneur Qu'il n'est homme de mere né Qui puist ymaginer comment Amours le m'a mis fermement Et assis en si hault endroit Que mon petit cuer vraiement Ameroit mieulx grace que droit (Jean Froissart, Poésies [3e tiers XIV]]

\section{CORPUS WEB :}

Cet homme, au cuir épais (des années de triathlon...ça fortifie !) reconnait et regrette, il est vrai, son entrée tardive dans la bataille. Mais comme il aime l'assener haut et fort, « mon combat et mon investissement pour la ville d'Anglet ne date pas d'hier » [https://fr-fr. facebook.com/permalink.php?story_fbid $=6092$ 91142449324\&id=543269369051502] (12.12.2013)

Alors moi, je soupçonne sérieusement les mamies un peu ginder de faire exprès d'asséner haut et fort à mes garçons « oh, les jolies petites filles... ». Rien que parce que ça la gène les cheveux long sur des garçons... [http://www. jumeaux-et-plus.fr/component/option,com_smf/ Itemid,88/topic,8029.255/wap2,wap2] (12.12.2013)

Jaime Ortega, tout sourire, a dit tout ce qu'il avait à dire : que l'absence de moyens de diffusion n'empêche pas les églises de se remplir, que la santeria (religion africaniste, pratiquée par $85 \%$ de la population) n'est qu'une « superstition », et qu’au fond Cuba n’a jamais été réellement évangélisée, que les Cubains doivent « abandonner le mensonge et l'hypocrisie qui les caractérisent aujourd'hui ». Autant de vérités que seul son habit de cardinal lui permet d'asséner haut et fort [http://www.liberation.fr/monde/1995/02/20/ jaime-ortega-l-eglise-cubaine-consacree_122595] (12.12.2013)

Encore une fois, des gros mensonges assénés hauts et forts pour faire vrai !! Sans nucléaire, plus de radiothérapie et autre radiographie, renseignez vous [http://www.francebleu.fr/ infos/centrale-nucleaire/evacuation-la-centralede-cruas-914926] (12.12.2013)

REMARques : Haut est un adjectif-adverbe de lieu employé au sens figuré désignant l'impact très fort que peut avoir quelque chose, un sentiment tel l'amour, sur l'être ou sur le corps. Le CW montre que la collocation assener haut et fort s'est lexicalisée, même sous sa forme fléchie (v. dernier exemple du CW), toujours employé par rapport au fait de frapper, d'imposer avec force par la parole.

\section{Asseoir bas}

I. Être placé / placer quelqu'un dans une position inférieure

Transitif

$\sim 1209$ Ne se contint pas come sires, Car ses granz senz et sa proece, Sa bonté et sa grant largece L'assist mout plus bas que ne die (Jean Renart, Roman de Guillaume de Dole, 352) 
1617 je diray que j'en donnay à prendre à deux gentils-hommes, l'un desquels estant un jour à mon logis, tomba en foiblesse, il fallut l'asseoir bas, luy donner du vin, luy frotter les temples de vin-aigre, je le fus voir quand il fust revenu à soy (Louise Bourgeois, Observations diverses sur la sterilite)

1883 Cet aviron étant plus facile à manier, le thalamite n'a pas besoin d'être dans des conditions aussi favorables et on peut l'asseoir bas, ce qui le forcera à lever plus haut les bras pour nager, mais le mettra hors d'atteinte de l'aviron zygite (Raoul Lemaître, De la disposition des rameurs sur la trière antique)

Intransitif

1403 Et aucuns princes de l'accort Se voulsissent bien entremettre, Mais, a peine y pourra on fin mettre, Se Dieu, de grace, n'y pourvoit, Car le plus sage a peine y voit ! De leurs gens, assis hault et bas En plusieurs degrez, ne sçay pas Qu'oncques veisse plus faulses gens Qu'aulcuns y a ; de tieulx sergens Fait on pastours, qui sont droit loups Et de char devourer jaloux (Christine de Pisan, Le Livre de la mutacion de fortune, II, 4353)

II. S'asseoir en-dessous de quelqu'un

Pronominal

1235 Lors le fait asseoir delés ly a destre et monseigneur Gauvain a senestre. Et le chevalier se vouloit asseoir plus bas que la damoiselle n'estoit, maiz elle ne le seuffre mie, ains li dit : " Ne vous remués, beau sire. Aussi hault vous devriés vous seoir ou plus que je ne devroye, car vostre dignité l'aporte : c'est la haultesse de chevalerie qui le commande » (La Suite du Roman de Merlin, § 467, 33)

Intransitif

1398 et pour luy faire grant honte lui firent porter plus que pour aidier a Nostre Seigneur ; et illec ou Nostre Seigneur reprint la croix a une pierre quarrée d'environ pié et demy de tous lez, assise plus bas que les autres pierres d'entour, sur laquelle estoit le pié de la croix quant Nostre Seigneur la reprint pour porter sur le monlt du Calvaire (Le Saint Voyage de Jherusalem, p. 14)

REMARques : Pris au sens propre (local) ou au sens figuré, asseoir bas réfère à l'idée d'une position inférieure ou de mouvement vers une telle position ou un état inférieur. Notons le contraste avec l'adjectif haut dans la collocation hault et bas. Il reste invariable et est modifié parfois par plus et moult plus. Notons l'emploi de seoir haut ; lever haut.

\section{Asseoir dur}

Poser sur un siège dur

$\pi$ coucher dur

\section{Asseoir haut}

I. Donner une place importante, une place d'honneur ; estimer beaucoup

Transitif

+1400 Humilité en riche homme bien siet : Plus se tient bas et plus hault on l'assiet (Christine de Pisan, Proverbes moraulx / Euvres poétiques [début Xve], III, p. 52)

+1415 S'il est ainsi mort par vostre peresse, Je vous requier, au moins, tant que je puis, Chascun de vous donnez lui une messe, Et j'ai espoir que brief ou paradis Des amoureux sera moult hault assis, Comme martir et treshonnoré saint, Qui a tenu de Loyauté le cours : Grant tourment a, puis que si fort se plaint ; Je l'oy crier piteusement secours (Charles d'Orléans, Poésies [ 1415-1440], I, Ballade XXVI, p. 45)

1450 JASPAR. Si fault dire qu'elle demonstre Quelque signifficacion. Ne quant a situacion Aux autres point ne s'appareille, Car ceste est moult bas a merveille Et les autres sont hault assises. Par quoy, aprés toutes devises, Il fault dire qu'elle nous signe Quelque hault et mirable signe Qui est de nouvel avenu (Arnoul Gréban, Le Mystère de la Passion, 5242) 
II. Asseoir, mettre dans une position supérieure Intransitif

1826 Son amour-propre et un reste de respect pour les choses de l'Église le faisaient souffrir à l'idée de voir le misérable agent couvert du même chapeau qui était une couronne pour lui, et assis aussi haut que lui-même, à cela près de l'emploi passager de ministre (Alfred de Vigny, Cinq-Mars)

1858 La mer montait rapidement, mais nous avions près de nous un escalier naturel. Elle mit la main devant ses yeux pour se garder de l'éblouissement des flots soleillés. Elle était assise très haut, sur un rocher, moi très bas, à ses pieds (Jules Michelet, Journal)

1866 Vous m'en direz des nouvelles dans huit jours, si vous avez des étouffements nerveux, d'après ce que m'a dit Lefébure. Pas trop d'exercice, au contraire, d'abord ! Laissez pendre vos pieds, en vous asseyant haut, quand le sang se porte à la poitrine, 5 minutes ! Et ne travaillez pas de suite après vos repas, mais une heure et demie après (Auguste de Villiers de L'Isle-Adam, Correspondance générale)

REMARQUES : Asseoir haut s'emploie ici au sens concret ou figuré : établir quelqu'un dans une position supérieure, dans une situation digne et propre à lui faire honneur. Il souligne également l'idée d'estimer quelque chose ou quelqu'un, de le considérer comme étant supérieur. Haut reste invariable et est modifié par aussi, moult, plus, très. Notons l'emploi de tenir bas. VoIR AUSSI : seoir haut

\section{Asseoir mou}

Poser sur un siège souple

入 coucher dur

\section{Assommer net}

Porter un coup violent

Transitif

1859 Nous avons vu un soir une jeune fille assommer net d'un coup de sa cruche de terre, un renard enragé qui se glissait autour d'une maison (Frédéric de Tschudi, Les Alpes: description pittoresque de la nature et de la faune alpestres [trad.])
1976 Le Colt .45 automatique pèse près de trois livres. J'ai assommé net ce mec. Il est tombé dans l'allée (Jean-Patrick Manchette, Que d'os!)

\section{Atourner bel}

Orner, parer, arranger d'une belle manière, de façon élégante

Transitif

1170a As osteus vienent, si s'aeisent, Si se deshuesent et atornent ; De lor beles robes s'aornent. Quant bien et bel atorné furent, Por aler a la cort s'esmurent (Chrestien de Troyes, Erec et Enide, 6457)

+1225a Puis li a sa grieve drecie,

Et li met un chief .i. capel.

Et quant fu atornés si bel,

Si fu si biaus comme il disoient

K'il onques mais veü n'avoient

Si bel, ains mais onques ne le vit (Le Chevalier as deus espees [ $2^{\mathrm{e}}$ quart $\left.\mathrm{XIII}{ }^{\mathrm{e}}\right], 4816$ )

+1225b Quant li dui

Chevalier ont le pastourel

Veü, si tres bien et si bel

Et si noblement atorné,

Tantost sunt cele part torné

Tout contreval le praërie.

Et li pastourials les escrie

K'il voisent fors de sa pasture (Le Chevalier as deus espees [2 $2^{\mathrm{e}}$ quart $\left.\left.\mathrm{XIII}^{\mathrm{e}}\right], 10514\right)$

1250a Il atourna son vis es sa plaie al plus biel k'il pot, et vint à la fieste, ki fu toute jour molt grans de boire et de mangier et de baus et de karolles (Le Roi Flore et la belle Jehanne [milieu XIII'], p.108)

1250b «Feites les vos aussi, et les barbes fremer ; Grant mestier nous ara, je cuit, ains retourner. »

Lors a fet Valebron, son bon mestre, mander.

Chil les atourna bel, que bien s'en sot aidier (Doon de Mayence, p. 247)

-1300 Tel mireoir covient au cors, Por bel atorner ce defors (La Vie de sainte Paule [fin $\left.\mathrm{XIII}^{\mathrm{e}}\right], 1221$ ) 
Pronominal

1170b Tant s'est la dame demantee Que bien et bel s'est atornee De la mellor robe qu'ele ot (Chrestien de Troyes, Erec et Enide, 2612)

1372 Atant la parole laissieren, Si dormirent et reposerent. Au matinet qu'il ajourna, Li roy bien et bel s'atourna Et trestuit li autre ensement (Guillaume de Machaut, La Prise d'Alexandrie [(1370-)1372], 2084)

1403 Si ont, en la fin, roy esleu Alixandre, si com j'ay leu, Car preux le virent et vaillant. Ainssy acrut ja son vaillant Alixandres, qui s'en retourne Vers son pere, et moult bel s'atourne, Mais, quant approcha du palays, D’assez loings il a oÿ les Instrumens sonner et la feste, Que li roys Phelippes appreste, Pour nouvelle femme espouser ; La mere Alixandre poser Vouloit jus, et une aultre prendre (Christine de Pisan, Le Livre de la mutacion de fortune, IV, 22196)

REMARQUES : En ancien français, atourner bel réfère à la façon de se vêtir, avec élégance et soin. Si le sujet désigne une personne, il souligne le fait de se préparer, de s'arranger de manière soignée, souvent dans le but de plaire à autrui. Notons la coordination fréquente du neutre bel avec l'adverbe bien, et aussi avec noblement. Dans le premier exemple pronominal ( 1170b), le sujet désigne une femme, sans que bel soit accordé. Il est modifié par al plus, moult, si. VoIR AUSSI : arroyer bel, atourner gent

\section{Atourner droit}

Aller, se diriger directement à

入 tourner droit

\section{Atourner gent}

Préparer, présenter, arranger avec goût Transitif

1250 Do de Maience aval u grant palès deschent ;
En la cuisine vint, si trouva largement

Char et fresche et salée atournée moult gent,

Venesons et oisiaux quanque au jour apent (Doon de Mayence, p. 109)

REMARQUES : Usuel en ancien français, gent est un adjectif-adverbe de manière qui, employé avec le verbe atourner, désigne le fait d'accommoder, de préparer, d'arranger des mets avec goût, d'une belle façon. Il est modifié par moult. VOIR AUSSI : arroyer bel

\section{Attacher court}

I. Attacher quelqu'un ou un animal avec un lien court, petit

Transitif

1496 BOURREAU. Il montent tous de[ux] au hault de l'eschelle, puis le bourreau lui mect a point son cas en disant ce qui s'ensuit : Mon amy, au temps advenir Ne pencez plus, mais du passé Veillez vous present souvenir, S’en bien vous l'avez compassé. Tantost vous serez trespassé Et ataché cy hault et court. Si de parler n'estes lassé, Despeschez vous, faictes le court (Andrieu de la Vigne, Le Mystère de saint Martin, 4276)

-1500 LE GENDARME. Je demande avoir du conseil

Et metz ad octo probandum.

LA FILLE. Mais une corde ou ung landon Pour vous attacher hault et court

(Le procès d'un jeune moyne et d'un viel gendarme devant Cupido, 404)

1891 Deux pauvres bœufs étiolés, amaigris, pitoyables, la peau déjà usée sur les saillies des os par les frottements du roulis. Depuis bien des jours ils naviguaient ainsi misérablement, tournant le dos à leur pâturage de là-bas où personne ne les ramènerait plus jamais, attachés court, par les cornes, à côté l'un de l'autre et baissant la tête avec résignation chaque fois qu'une lame venait inonder leur corps d'une nouvelle douche si froide (Pierre Loti, Le Livre de la pitié et de la mort) 
1914 une grosse Italienne noire et flasque, puis beaucoup d'enfants bouchaient les portes étroites des voitures - et, attaché court sous la première, un vieil ours pelé faisait trois petits pas, puis levait une patte de derrière, puis revenait et refaisait trois petits pas et ainsi de suite, indéfiniment, à donner le vertige (Alain-Fournier, Correspondance avec Jacques Rivière)

1928 Cachons sous la dernière lettre l'image que je ne veux pas voir : une tête à demi vaincue qui tournait de côté et d'autre, sur l'oreiller, son col sec et son impatience de pauvre chèvre attachée court... La dernière lettre, ma mère en l'écrivant voulut sans doute m'assurer qu'elle avait déjà quitté l'obligation d'employer notre langage (Colette, La Naissance du jour)

1934 Déjà, déroulant les cordes, le bonhomme Herbelot improvisait un attelage.

- Ne l'attachez pas trop court, dit mon père, qu'il ait du jeu.

Les cordes nouées, Herbelot prit le cheval par la bride et commença de lui parler (Georges Duhamel, Vue de la terre promise)

II. Attacher, maintenir quelque chose

(à / sur quelque chose)

Transitif

1798 Le plus sûr est de leur donner leur avoine dans un sac, et de les attacher court et haut à un anneau de chaque côté (J.-F. Bastien, La Nouvelle Maison rustique)

1851 Peut-être n’avait-il que vingt-huit ans ; on pouvait, sans l'offenser, lui en donner hardiment trente-cinq, grâce sans doute aux nobles ennuis qui avaient pâli son front. Il était mis avec recherche. Le ruban d'un ordre étranger brillait à sa boutonnière. Attaché court au gilet, un bouquet de breloques pendait sur sa poitrine (Jules Sandeau, Sacs et parchemins)

1902 Chose bizarre, une perche pointue, liée au bras de l'homme, oscillait avec ses mouvements. Plus près, il laissa voir son mufle barbu et tout encadré de longs cheveux gras. A cause des étriers, attachés court par des cordes, ses genoux relevaient la longue crinière du cheval (Paul Adam, L'Enfant d'Austerlitz)

2011 Elle était banale et revêche, toute vêtue de gris, avec des cheveux noirs attachés courts sur la nuque (Anthony Horowitz, $\mathrm{La}$ Maison de soie [trad.])

REMARQUeS : Attacher court désigne le fait de fixer, maintenir ou retenir une personne ou un animal à l'aide d'un objet, d'une attache (une chaîne, un crochet, une corde, un lien quelconque) qui lie et qui a peu de longueur. Court est invariable dans la plupart des cas, mais l'exemple de 2011 montre que la flexion n'est pas exclue. Notons le groupe figé haut et court (à comparer : pendre haut et court) qui a un sens spatial et désigne un point élevé. Court est modifié par trop. Attacher court est surtout employé dans le langage rural par rapport aux animaux domestiqués.

\section{Attacher serré}

I. Attacher quelqu'un ou quelque chose en serrant, avec un lien étroit, serré

Transitif

1691 Je lui dis qu'elle était la maîtresse de me bander les yeux, et même de me les crever, si elle y trouvait quelque plaisir. Elle m'attacha un mouchoir autour de la tête, si serré, qu'elle me fit d'abord une douleur effroyable (Marie-Catherine d'Aulnoy, $R e$ lation du voyage d'Espagne)

1946 Je me suis lavé avec un peu de whisky ; mon bras ne saignait plus ; j'ai réussi à le retirer de ma manche et à l'attacher serré autour de mon torse avec mon foulard et de la corde. J'ai failli chialer, tellement j'avais mal, car il fallait que je le replie (Boris Vian, J'irai cracher sur vos tombes)

1964 En me servant de sa laisse je l'ai attachée [= la chienne] à la poignée de la porte arrière droite - la plus éloignée de moi. Pas trop serré pour qu'elle pût s'étendre si l'envie lui en prenait. Assez serré pour qu'il lui fût impossible de m'atteindre (Colette Audry, La Chienne et nous)

1977 En attendant, je passe le commandement au chef du premier groupe. Je vais livrer 
personnellement mes prisonniers. En tas, derrière. Quelques grognements. Ils sont attachés serrés. Je peux y aller tout seul. Trois kilomètres de route, un peu plus de chemin... (Jean-Pierre Chabrol, La Folie des miens)

1992 Les archers avaient eu du mal à mater les filles déchaînées dont la force était décuplée. Elles les mordirent, il fallut les attacher serré, les embarquer ainsi dans une charrette jusqu'à l'hôpital des fous, à Saujon (Hortense Dufour, La Fille du saulnier)

2008a La marchandise dans du papier de soie, rangée bien à l'abri de boîtes en carton, emballées elles-mêmes par deux ou trois épaisseurs de papier kraft, maintenues à leur tour par une ficelle attachée serrée en croix. Rien de visible, il faut demander. Trente ans plus tard rien n'a changé dans la boutique quand, au dernier jour de mes longues vacances, on achète là ma blouse pour la rentrée (Martine Sonnet, Atelier 62)

2011 Eurydice vint changer son pansement, elle apporta sur un plateau métallique des bandages, du désinfectant, du coton et des épingles de sûreté toutes neuves, toute une boîte écrite en anglais. Elle attachait ses cheveux très serré et boutonnait sa blouse jusqu'en haut, mais il suffisait à Victorien un battement de ses cils, un frémissement de ses lèvres pour la deviner tout entière, son corps nu et toutes ses courbes, sa peau vivante (Alexis Jenni, L’Art français de la guerre)

Pronominal

1890 Et toute notre ville se démonte de la même manière, se plie, s'attache serré dans des quantités de ficelles; puis se charge sur des mules qui ruent, sur des chameaux qui grognent ; en route, notre camp est levé ! (Pierre Loti, Au Maroc)
II. s'attacher à quelque chose : être très lié à quelqu'un ou quelque chose, tenir beaucoup, fermement à quelqu'un ou quelque chose Pronominal

1901 Souviens-toi de ce que je t’ai enseigné : l'homme, faisant de lui-même sa fin, moins il se peut satisfaire, plus serré il s'attachera à ses causes, à la cause par laquelle il existe en tant qu'homme, et celui-ci entre les autres (Paul Claudel, Le Repos du septième jour)

Transitif

2008bEn juin 1962, c’était grâce aux nommés Sauvet, Lebail et Schwartz, qu'avec 15 points ceux des forges avaient gardé la coupe. Le rempart contre l'ennui à la ville, et ce qui m'y attache serrée, c'est la Bibliothèque juste derrière chez nous. D'abord un drôle de chantier sous nos fenêtres, côté cuisine, salle de bains, chambre des parents (Martine Sonnet, Atelier 62)

\section{CORPUS WEB :}

J'ai enfin trouvé quelques réponses au pourquoi je n'arrive jamais à avoir les cheveux longs. En voici les causes...

J'ai appris qu'il ne fallait pas les attacher serré, car ça casse les cheveux. Ensuite, il ne faut pas les déméler en tirant de dessus. Il faut arrêter le sèche cheveux. Il faut faire attention à bien les placer quand on dort [http://journaldepousse. canalblog.com] (17.6.2016)

si tu veux un carré plongeant, cheveux longs devant et courts derrière, il faudra les attacher serrés dans la nuque et couper : si tu visualises, les cheveux au niveau de la nuque seront coupés à ras, tandis que ceux de devant garderont de la longueur [http://forum.doctissimo.fr/forme-beaute/ Coiffure-et-coloration/possible-degradescheveux-sujet_11653_1.htm] (13.12.2013)

L'autre chose à noter est que certains des modèles plus anciens laisser un espace entre le matelas et le bedrail afin que votre bébé pourrait tomber entre le rail et le matelas. Regardez donc pour les modèles plus récents ou ceux qui s'attachent serrés pour le matelas et vous évitera cette issue [http://www.experts-tourisme.fr/ securite-ferroviaire-s365878.htm] (13.12.2013) 
REMARQues : Serré est un adjectif-adverbe de manière, issu du verbe serrer. Dans cet emploi, serré est invariable (ex. de 1890, de 1964, de 1992 et de 2011), mais dans les exemples de 1977, de 2008a/b, et dans le deuxième exemple du CW, il s'accorde en genre et en nombre avec l'objet, ce qui peut relever d'une interprétation de prédicat second orienté vers l'objet. Dans l'emploi pronominal du verbe, il peut s'accorder avec le sujet (v. le troisième exemple du CW). Dans l'exemple de 1977, la flexion pourrait référer au fait de former un groupe serré, compact, mais le contexte induit la même interprétation que dans les autres exemples : celui qui livre les prisonniers peut le faire tout seul parce que ceux-ci sont bien attachés, sans marges de manœuvre. Serré est modifié par assez, pas trop, plus, très.

\section{Attacher solide}

Attacher sans risque de se détacher

Transitif

1937 Mais ta jument tu as dû l'attacher solide. Le cul du tilbury flotte mais elle est toujours attachée en bas au fond (Jean Giono, Batailles dans la montagne)

1979 Loret le mataf qui pique sa crise [...], faut qu'on le maîtrise, qu'on l'attache solide (François Cavanna, Les Russkoffs)

REMARQUes : Attacher solide se dit du fait de fixer fermement un être animé ou un objet qui risquent de se détacher.

\section{Atteindre haut}

I. Parvenir à un niveau élevé, supérieur, ou obtenir de bons résultats, accomplir un travail considérable qui est le résultat, l'aboutissement d'un effort

Emploi absolu

$\sim 1275$ E pour ce que nule richece A valeur d'ami ne s'adrece, Qu'el ne pourrait si haut ataindre Que valeur d'ami ne seit graindre, Qu'adès vaut meauz amis en veie Que ne font denier en courreie (Jehan de Meun, Roman de la rose [1269-1278], 4945)

1538 Au temps passé Apelles, painctre sage, Feit seulement de Venus le visage, Par fiction ; mais pour plus hault attaindre,
Ton pere a faict de Venus, sans rien faindre,

Entierement la face et le corsage

(Clément Marot, Rondeaux)

1592 Nostre ame ne sçauroit de son siege atteindre si haut. Il faut qu'elle le quitte et s'esleve, et, prenant le frein aux dents, qu'elle emporte et ravisse son homme si loing qu'apres il s'estonne luy-mesme de son faict (Michel de Montaigne, Essais)

1625 En cela outre la gloire qui vous demeurera d'avoir avancé vostre Cadet, je croy que vous suivrez le dessein du Ciel et de la Terre : Le party est de telle sorte, qu'estant trop peu pour vous, qui pouvez atteindre plus haut et esperer davantage, il est trop riche pour moy, qui comme Cadet n'ay que la cappe et l'espee : car les loix de la Catalogne nous rangent tout à fait à la mercy et discretion de nos aisnez (Jean-Pierre Camus, Palombe ou La Femme honnorable)

1637 Je lui serai bon père, et puisque ce parti À sa condition se rencontre assorti, Bien qu'elle pût encore un peu plus haut atteindre,

Je la veux enhardir à ne se plus contraindre (Pierre Corneille, La Suivante)

1715 Je suis charmé d'un auteur qui s'efforce de vaincre les anciens [...]. Le public doit louer ses efforts, l'encourager, espérer qu'il pourra atteindre encore plus haut dans la suite et admirer ce qu'il a déjà d'approchant des anciens modèles :... etc. Je voudrois que tout le Parnasse le comblât d'éloges :... etc. (François de Fénelon, Lettre à l'Académie)

1783 MAURICE. Il ne faudrait aussi plus de bœufs pour labourer la terre : on tirerait la charrue soi-même ; et en dix pas on serait au bout du champ. Tenez, encore, je vis l'autre jour plus de cinquante hommes qui enfonçaient des pilotis pour faire une chaussée. Comme ils travaillaient! Eh bien! Avec un grand marteau, comme on pourrait alors en porter, un homme seul aurait fait toute leur besogne en un jour. N'est-il pas vrai, mon papa? 
M. DE LEYRIS. Voilà qui est fort bon à dire ; mais avec tous ces beaux souhaits, vous n'êtes que des fous?

MAURICE. Comment des fous ?

M. DE LEYRIS. Oui, de croire que vous seriez alors plus heureux que vous ne l'êtes.

MAURICE. Mais si nous devenions capables de faire plus de choses que nous n'en faisons à présent ?

FRÉDÉRIC. Par exemple, ne serait-ce pas fort commode de pouvoir atteindre bien haut, et de faire d'un seul pas bien du chemin ? (Arnaud Berquin, L'Ami des enfans)

1890 L'école philosophique a sa patrie sous le ciel de la Grèce et de l'Inde ; le temple et la science sacerdotale, s'expliquant en énigmes et en symboles, voilant la vérité sous le mystère, atteignant souvent plus haut, parce qu'elle est moins inquiète de regarder en arrière et de s'assurer de sa marche, tel est le caractère de la race religieuse et théocratique des Sémites (Ernest Renan, L’Avenir de la science)

1923 Poésie anglaise, plus riche, plus abondante que la française ; mais celle-ci, me semble-t-il, atteint parfois plus haut. Je ne puis aimer toutes les facilités que le poète anglais s'accorde, et cette absence de rigueur ; les cordes de sa lyre, presque toujours, me paraissent insuffisamment tendues (André Gide, Journal)

1956 afin de couper court aux effusions et leur garder ainsi une juste résonance, baiser la main d'une pauvre femme et briser là, croyez-moi cher monsieur, c'est atteindre plus haut que l'ambitieux vulgaire et se hisser à ce point culminant où la vertu ne se nourrit plus que d'elle-même. Arrêtons-nous sur ces cimes (Albert Camus, $\mathrm{La}$ Chute)

II. Concerner, toucher quelqu'un fortement Transitif

1823 Dans la situation extraordinaire où le sort m’avait élevé, mes trésors étaient les siens ; je m'étais identifié sans réserve avec ses destinées. Quel autre calcul eût pu m'atteindre si haut? M'a-t-on jamais vu m'occuper de moi ? Je ne me suis jamais connu d'autres jouissances, d'autres richesses que celles du public

(Emmanuel de Las Cases, Le Mémorial de Sainte-Hélène)

\section{CORPUS WEB :}

Mettez la cocotte sur le poêle à feu moyenélevé et attendre la jauge d'atteindre haute. Selon la taille de l'autocuiseur, cela peut prendre entre 2 et 5 minutes [http://nourriture.fooddrink.info/ cooking-baking/cooking-techniques/1007009021 .html] (16.6.2016)

REMARQUES : Atteindre haut confère une interprétation directionnelle à l'adjectif haut qui désigne un point élevé. Il s'emploie également au sens figuré. Haut reste invariable dans la majorité des cas, mais dans l'exemples du CW il est mis au féminin. Il est modifié de façon très varié par bien, plus, encore plus, encore un peu plus, parfois plus, si, souvent plus.

\section{Atterrir court}

Atterrir sur une courte distance

Intransitif

1961 Les Boeing 707320 B atterrissent et décolleront plus court (Le Monde, 6 octobre 1961 / Grundt : 317)

2011 Il calcule ses chances : atterrir trop court reviendra à se fracasser sur les rochers, et atterrir trop long à dépasser la zone de pose pour dégringoler de six mille mètres le long de la montagne (Patrick de Gmeline, Baron rouge et cigogne blanche)

\section{CORPUS WeB :}

Le problème, avec le DA40, c'est qu'il est un peu difficile sur ces vitesses d'atterrissage : si on est trop rapide, il ne se pose pas. Personnellement, j'ai un peu de mal à l'atterrir court [http:// petite.pilote.legere.over-blog.com/categorie439375.html] (13.12.2013)

Les spécifications techniques étaient sévères, car cet avion doit atterrir court, sur tout type de terrain, lancé, à pleine charge, à plus de 270 km/h [http://www.linguee.fr/francais-anglais/ traduction/atterrir+court.html] (13.12.2013) 
La vitesse de croisière est voisine de 150 $\mathrm{km} / \mathrm{h}$ et la vitesse d'atterrissage est de $45 \mathrm{~km} / \mathrm{h}$ ( $58 \%$ de la demande). Il est capable de poser et d'atterrir court (STOL), sur des pistes de fortune (tout-terrain) [http://www.ulmag.fr/mag/ dossiers/sondage_131101_8.php] (13.12.2013)

Remarques : Dans le domaine de l'aviation, atterrir court désigne le fait de prendre contact avec le sol pour arrêter le vol, court se rapportant à la distance réduite dont l'avion a besoin pour atterrir. Notons l'emploi transitif dans le premier exemple du CW. Court reste invariable et est modifié par plus, trop. Il s'oppose à atterrir long (ex. de 2011). Notons l'emploi de décoller court.

\section{Atterrir long}

Atterrir sur une longue distance

$\lambda$ atterrir court

\section{Avaler bas}

Descendre beaucoup, fortement

$\pi$ aller haut, exemple de 1119

\section{Avaler doux}

I. avaler doux comme lait : avaler un liquide facilement, sans peine

Transitif

+1480 LE SOT. Pour Dieu, qu'elle me soit aprise. Ventre bieu, la me celés vous ?

MAISTRE PIERRE. Recipe pour gens qui sont coux :

Quelque bon bruvaige doulcet,

C'est a dire ung bruvaige doux

Et l'avaler doux comme lait

(Sottie de Maître Pierre Doribus, 91)

II. avaler doux comme lait, confiture, eau, miel, sirop, vin : accepter quelque chose sans critique, sans rancune, ou avec plaisir ; être crédule, croire facilement

Transitif

1579 Je me doubte bien que ce belistre de Ruffin me l'aura desbauchée ; toutesfois, il faut que j'avalle cela doux comme laict, ne luy en osant parler, crainte que, mouvant trop ceste ordure, l'odeur ne se respande d'avantage parmy le peuple, et que ce qui n'est sçeu que d'un ou de deux devienne la fable du commun (Pierre de Larivey, Les Esprits)
1646 Son valet mesme a sceu nous en-seigner, En l'estrillant au lieu de le peigner, Qu'aucun ne doit le souffrir à sa table ; Dés qu'il paroist, on le chasse à l'estable, On siffle, on hue, en le poussant abas $\mathrm{Au}$ son des pots, des chaudrons, et des plats ;

Sans s'estonner, aussi-tost il remonte ;

Doux comme vin il avale la honte ;

Et le premier nous le voyons placé, Dés que son nez luy dit qu'on a dressé (François de Boisrobert, Épistres en vers)

1713 Il n'y a point de chat qui craigne tant l'eau. Comment ! Jamais ne se laver pour soimême, et ne décrasser que ce qu'il faut nécessairement que l'on montre, c'està-dire la gorge et les mains ! La Temple avalait cela plus doux que les confitures ; et l'officieuse Hobart, pour ne pas perdre de temps, la déshabillait en attendant sa femme de chambre (Antoine Hamilton, Mémoires de la vie du comte de Gramont)

1732 C'est une dame nouvellement mariée, et si belle, que... mais, ajouta-t-elle en s'interrompant elle-même, je ne vous en dirai pas davantage ; il faut vous laisser le plaisir de la surprise que sa vue doit vous causer. J'avalai tout cela doux comme lait, et je ne me possédais pas, tant j'étais enivré de mon mérite (Alain-René Lesage, Histoire de Guzman d'Alfarache)

1807 - Grace, voisin. - Non, point de grace ;

Pan ! pan! à la fin, je me lasse

D'avaler doux comme sirop

Tous les affronts qu'elle me brasse !

- On se met bien à votre place

Mais... Mais on ne s'y met que trop ! (Philippe-Laurent Pons de Verdun, Le Pourquoi)

1843 - Et qu'elle boira avec la petite blonde.

- C'est crânement arrangé, bourgeois.

- Et surtout que la vieille ne se doute de rien!

- Calmez-vous, bourgeois, elle avalera ça doux comme miel.

- Allons, bonne chance, mon garçon! Si je suis content, peut-être je vous emploierai encore (Eugène Sue, Les Mystères de Paris) 
1931 Anne-Marie ne paraissait pas. Du tournant, cela le surprit singulièrement d'entendre sa voix, qui s'élevait comme pour une semonce. À qui en avait-elle?

- Hé ! Madame Anne-Marie, vous voulez rire ! C'était au bossu. Il avalait doux comme l'eau ce qu'elle lui disait, se contentant de répéter : "Hé ! Vous voulez rire, Madame Anne-Marie ! »

(Henri Pourrat, La Tour du Levant ou Quand Gaspard mit fin à l'histoire)

REMARQUES : Au sens propre, avaler doux désigne le fait de boire un liquide, soit en raison de son goût agréable au palais, soit en raison de sa composition, de sa matière, le liquide descendant facilement. Au sens figuré, il souligne la façon plutôt positive dont une personne prend les choses. L'exemple de 1480 inclut la douceur du liquide (prédicat second), mais l'ensemble des citations montre bien que l'interprétation adverbiale est primordiale, l'inclusion de la douceur de quelque chose ayant un statut inférentiel. Avaler doux a développé un schéma phraséologique dans lequel le liquide apparaît comme variable : avaler doux comme + LIQUIDE.

\section{Avaler droit}

s'en avaler droit : descendre rapidement et directement, dévaler

Pronominal

+1200 Que puet chaloir ? Sains et hetiez Issi chascuns de la nef fors.

Li cuens Gladoains qui fu lors

A Handitou s'en avala

Droit a la mer (Raoul de Houdenc,

Meraugis de Portlesguez [début XIII'], 3432)

CORPus WeB :

C'est pas de la faute à Hollande si les truffes coutent si cher, la droite lump critique encore la gauche caviar, pour un article de fond, il y est bien! Ca reste quand même bien moins cher que le morceau de rillette à 600 mille euros que sarko vient se fourrer dans le museau devant 2 ou 3 cents journalistes avec 2 ou 3 mille policiers pour veiller à ce qu'on ne l'empeche pas d'avaler droit [http://www.agoravox.fr/commentaire3207056] (6.16.2016) j'ai voulu mixer une petite carotte préalablement coupée en petits dés pour la cuisson, et le résultat me laisse perplexe : cela ne ressemble pas du tout à une purée ! le mixage est grossier, la petite n'a pas réussi à avaler « droit » et du coup elle s'est ruée sur le sein embarrassé (oops) [http:// www.forums.supertoinette.com/recettes_53443. mixage_baby_c_k.html] (6.16.2016)

REMARQUES : En ancien français, avaler droit désigne un mouvement de descente vers le bas, en aval. En français moderne (CW), avaler droit réfère surtout au fait d'ingérer directement, correctement, sans complications.

\section{Avaler ferme}

Manger beaucoup

Emploi absolu

1877 - Ah ! Si vous croyez que c'est toujours amusant? On voit bien que vous n'avez pas été en ménage... non, Monsieur Coupeau, il faut que je pense aux choses sérieuses. La rigolade, ça ne mène à rien, entendez-vous ! J'ai deux bouches à la maison, et qui avalent ferme, allez ! Comment voulez-vous que j'arrive à élever mon petit monde, si je m'amuse à la bagatelle ?... et puis, écoutez, mon malheur a été une fameuse leçon (Émile Zola, L’Assommoir)

REMARQUES : Avaler ferme désigne le fait de se nourrir abondamment, d'avaler de la nourriture en grande quantité. L'emploi absolu invarié souligne l'usage comme tour figé dans le langage quotidien.

\section{Avaler gros}

avaler gros comme ça (de quelque chose):

avaler, manger en abondance

Transitif

1878 - Ne te tourmente pas, ce ne sera rien, bien vrai... maintenant que tu as fini, tu vas me recoucher... je voulais te voir à table, parce que je te connais, tu n'aurais pas avalé gros comme ça de pain (Émile Zola, Une page d'amour)

1884 Ce n'est pas parce que votre mari est parti, que vous devez vous crever de désespoir. Bien sûr, quand j'ai perdu Gabin, j'étais pareille à vous, je suis restée trois jours sans 
pouvoir avaler gros comme ça de nourriture (Émile Zola, La Mort d’Olivier Bécaille)

\section{CORPus WEB :}

L'un de mes mâles combattant passait sa journée à chasser à l'affut les alevins de gouramis. Dès qu'un combattant aura compris qu'une crevette, ça se mange, quelque soit les cachettes, il les aura à terme. Et ça a une bien grande bouche, ça peut avaler gros (ou déchiqueter comme l'écrivait Pecky) [http://www.aquariophilie.org/ forum/viewtopic.php?f=15\&t=78087\&start=40] (14.12.2013)

REMARQues : Avaler gros désigne le fait d'ingurgiter, de faire descendre de la nourriture dans le gosier en grande quantité ou en gros morceaux, le sujet désignant une personne. Émile Zola documente ainsi cet emploi dans le registre populaire, que l'on reconnaît aussi à l'emploi du sujet générique ça en emploi absolu (CW).

\section{Avaler lourd}

Manger autant que son propre poids

Emploi absolu

1866 À l'âge de votre papa, il en tombe [= du poids] juste autant qu'il en arrive, et voilà pourquoi sa taille demeure toujours la même, bien qu'il avale dans son année trois fois plus lourd que lui (Jean Macé, Histoire d'une bouchée de pain)

\section{CORPUS WEB :}

Et puis, « réformateur » est bien une lettre du PRL ; c'est là une menue consolation pour les libéraux qui avalent lourd et mal le sacrifice du L de « libéral » [https://www.lalibre.be/belgique/ 24-mars-2002-51b8da9fe4b0de6db9c341e9] (24.9.2011)

REMARQUES : La citation du CW met en évidence l'emploi au figuré 'accepter avec difficulté'.

\section{Avaler net}

avaler (tout) net : avaler d'un seul coup Transitif

1532 Voyant Pantagruel qu'il s'amusoit à tirer sa dite masse, qui tenoit en terre entre le roc, luy courut sus, et luy vouloit avaller la teste tout net ; mais son mast, de male fortune, toucha un peu au fust de la masse de
Loupgarou, qui estoit pheée, comme avons dit devant (François Rabelais, Pantagruel)

\section{CORPUS WEB :}

Portant au col un anneau qui l'empêche D'avaler net le produit de sa péthe [= pêche]. Tout cormoran bien dressé doit savoir Plonger, happer truite, carpe ou lamproie, Puis, au signal donné, rendre sa proie, Comme un Tantale'du devoir [http://gallica.bnf.fr/ark:/12148/bpt6k2739559/ f3.textePage] (14.12.2013)

Sachez que votre personnage aura sans doute une durée de vie très courte, dans un monde où un tyrannosaure peut l'avaler net ou un géant peut l'écraser sans même s'en rendre compte [http://hotel.muxxu.com/tid/forum\#! view/11|thread/25301329] (14.12.2013)

Il fallait dire que cette tarte là était de la largeur du creux de la main. On pouvait donc l'avaler net [http://dream-nightmare.forumactif. com/t146-petit-creux-pv-reechart] (14.12.2013)

C'est à cet instant que Dino Cavallone pénétra dans l'immense salle à manger de la Varia, son instinct de survie s'étant fait la malle. Ledit Cavallone claqua violemment les portes de la pièce, en interrompant de même le petit déjeuner mouvementé. Bel lâcha la mâchoire de Tsuna, geste qui avait pour but de lui faire avaler nette sa petite cuillère [https://www.fanfiction. net/s/5863949/7/Boss-Amn\%C3\%A9siqueEmmerde] (16.6.2016)

Harry s'assit au comptoir et commanda un verre de whisky un petit remontant ne lui ferait pas de mal après les évènements passés. Il l'avala cul-sec et en commanda un autre. Il repensa à sa portion sensée lui guérir sa blessure au dos et la déboucha avant de l'avaler nette elle aussi [https://www.fanfiction.net/s/4199261/6/Il-y-ades-choses-qu-on-oublie-pas] (16.6.2016)

REMARQUES : Avaler net désigne le fait d'ingurgiter, de manger quelque chose entier, en un seul morceau et d'un seul coup. Net est modifié par l'adverbe d'intensité tout. Dans l'écriture spontanée du CW, l'adjectif-adverbe peut s'accorder avec l'objet féminin (v. les deux derniers exemples du CW), tout en conservant son interprétation de manière. Notons que le masculin net et le féminin nette sont prononcés de la même façon, ce qui peut favoriser la graphie nette. 


\section{Avancer ferme}

Progresser dans une démarche ou une action avec volonté et de manière décidée

Intransitif

1839 Elles avancent fermes sans se rompre : ni haute colline, ni vallée rétrécie, ni bois, ni ruisseau, ne divisent leurs rangs parfaits, car elles marchent élevées au-dessus du sol et l'air obéissant soutient leur pas agile : comme l'espèce entière des oiseaux rangés en ordre sur leur aile, furent appelés dans Éden pour recevoir leur nom de toi, ô ADAM (François de Chateaubriand, Le Paradis perdu)

1891 Ma cantate continue à avancer ferme. Elle sera bien, très bien orchestrée, mais un point c'est tout (Guillaume Lekeu, Corres pondance)

Transitif

1853 Il en va être ainsi pendant trois semaines. Je suis curieux de voir la mine que je vais faire. J'éprouverai si l'homme décidément est un animal sociable. J'espère d'ici à ton arrivée avancer ferme la Bovary. Si ma scène d'amour n'est pas faite, elle le sera aux trois quarts (Gustave Flaubert, Correspondance)

Pronominal

1879 Mais, quand on les [= les martyrs] sommait de renier Jésus-Christ, ils s'avançaient fermes et invincibles (François Moigno, Les Splendeurs de la foi)

1882 Le maître de forges, pris à partie, s’avança ferme et presque menaçant. Claire pâlit. Les deux hommes allaient-ils se trouver lancés l'un contre l'autre par l'implacable haine de la duchesse ? (Georges Ohnet, Le Maître de forges)

CORPUS WEB :

Touba, le Magal et les fidèles. La foule, la poussière aux abords de la mosquée est partout dans la ville. La visibilité n'est pas des meilleures, la lumière du jour mêlée à la poussière rend fou. Comme hypnotisés par ces minarets si proches et si loin à la fois, ils avancent les pèlerins massifs. Ils respirent l'air crasseux, toussent, mais avancent fermes [http://www.enqueteplus. com/content/magal-touba-2013-bamba-draineencore-sa-foule] (16.6.2016)

Mais les enfants de Dieu tiennent à prévoir, pour rester purs. Ils se souviennent du chant très suave qui est celui de la Cité chaste : «Bienheureux ceux qui sont immaculés dans leurs voies, et qui s'avancent fermes dans les sentiers de la loi divine »[http://gallica.bnf.fr/ark:/12148/ bpt6k65607207/texteBrut] (16.6.2016)

REMARQUES : Avancer ferme désigne la résolution ferme du sujet, sa ténacité, se situant parfois aux confins de la prédication seconde, mais pouvant également se rapprocher de la fonction adverbiale 'fermement, sans ralentir' (ex. de 1853, 1891). L'accord de ferme est particulièrement apprécié dans les textes religieux pour inclure davantage l'attitude du sujet (ex. de 1879 et CW).

\section{Avoir cher}

I. Aimer, avoir de l'affection pour quelqu'un, chérir ; tenir beaucoup à quelque chose Transitif

1100a Ço dist Rollant : « Mis cumpainz est irez ! Encuntre mei fait asez a preiser. Pur itels colps nos ad Charles plus cher. » A voiz escriet : «Ferez i, chevale ! » (Chanson de Roland, 1560)

1100b Ja devers els bataille n'ert lessee. Suz cel n'ad gent que Carles ait plus chere, Fors cels de France, ki les regnes cunquerent (Chanson de Roland, 3031)

1100c U est Otes e li quens Berengers? Ive e Ivorie, que jo aveie tant chers? Qu'est devenuz li Guascuinz Engeler? Sansun li dux e Anseïs li bers?

(Chanson de Roland, 2406)

+1125 Noé, ses treiz fiz, Quant vint li periz, Volt deus retenir, Lor quatre moilliers ; Cez out deus si ciers, Nes laissat perir (Un sermon en vers [ [2 $2^{\mathrm{e}}$ quart $\mathrm{XII}{ }^{\mathrm{e}}$ ], 24)

+1150a Bien pert as beles armes et al destrier, As riches garnimens que il a chier, Qu'il n'a en nule tere tel cheualier (Aiol et Mirabel [2 $2^{\mathrm{e}}$ moitié XII ${ }^{\mathrm{e}}$, 1971) 
+1150b Vous ne cremies nient le pooir l'auersier ; Vos amis en getastes, que tant auies chier (Aiol et Mirabel [2 moitié XII $\left.{ }^{\mathrm{e}}\right], 6211$ )

1165 Ensemble od sa femme premiere Mist sa femme que tant ot chiere. El la receut cum sa serur E mult li porta grant honur ; De deu servir l'amonesta E sun ordre li enseigna (Marie de France, Lais, 1166)

1176 Li cuens Angrés est molt marriz, Por i tant que traïner voit Ces devant lui que chiers avoit (Chrestien de Troyes, Cligés, 1500)

$\sim 1177$ a Car a lor plaies ressener Ont mestier de mire et d'antret. Devant lui mener les an fet Li rois, qui mout chiers les avoit. Un cirurgiien, qui savoit De cirurgie plus que nus, Lor fet mander li rois Artus (Chrestien de Troyes, Yvain ou Le Chevalier au lion, 6503)

$\sim 1177$ b Li vavasors avoit a fame Une bien afeitiee dame Et cinc fiz qu'il avoit mout chiers, Trois vaslez et deus chevaliers, Et deus filles jantes et beles, Qui ancore estoient puceles (Chrestien de Troyes, Lancelot ou Le Chevalier de la charrete, 2059)

1177c Et quant il vindrent del recet Pres a sis liues ou a set, Ou li rois Bademaguz iere, Novele que il ot mout chiere Li fu de Lancelot contee, Si l'a volantiers escoutee, Qu'il vit et vient sains et heitiez (Chrestien de Troyes, Lancelot ou Le Chevalier de la charrete, 4428)

$\sim 1200$ Procas fu rois prouz et vailanz, De sa mulier out dous enfanz, Communement les out mult chiers ; Amulius fu li premiers, Numitor out l'altres a nom (Brut, 3819)
+1200 Ensi vint la dame a court o tout ses enfans qu'elle avoit moult chiers. Et elle estoit de si grant biauté plainne que a paines peust on veir ne trouver sa pareille de biauté (Merlin [ $1^{\mathrm{er}}$ quart XIII ${ }^{\mathrm{e}}$, p. 146)

1209 Tote nuit i sont sorvenant Chevalier, baron d'autre terre, Qui lor conpegnons vienent querre Por raiembre ou por ostagier. Sachiez li prodoms a plus chier De ceuz qu'il a a sa main pris, Que s'onor i soit et son pris, Ce sachiez, qu'il les raensist (Jean Renart, Roman de Guillaume de Dole, 2922)

+1225 Je sui Sarrazine et renoie, car autrement ne peusse je jà durer, ains fusse piecha morte. Mais or vous pri jou et casti si chier comme vous avés vos vies, et honneurs à avoir gregneurs ke vos n'eustes onques, que por chose que vos aiiés oïe ne veue nul plus biel semblant n'en faites, mais simplement vos maintenés (La Comtesse de Ponthieu [2 $2^{\mathrm{e}}$ quart XIII'], p. 213)

-1234 Dit Otinel : Issi doit on changier Cop por colée, maille por denier. Ja Alfanie ne vos aura mestier, La vostre amie, que vous aviés tant chier (Otinel [ $1^{\mathrm{er}}$ tiers XIII $\left.\left.{ }^{\mathrm{e}}\right], 1494\right)$

1235 Mais, pour chou que ne sont pas beles, Le vous avons nous tant celé ; Mais or vous sera revelé. Mesires nous a fait savoir, Si chier que nous volons avoir Nos vies sans recevoir mort, Que nous, ou a droit ou a tort, Vous metons ardoir en un fu Et chou que de vous est issu (Philippe de Remi, sire de Beaumanoir, $\mathrm{La}$ Manekine, 3668)

1250 Vers Kallez le bon roi, qu'en sot tant henourer, Et comme il prist Flandrine la courtoise à moullier, La fille l'Aubigant que onques Dieu n'ot chier ; 
Sire estoit de Vauclere et tint tout l'eritier (Doon de Mayence, p. 182)

1275 Margiste nostre serve avoec vous laisserai Et Aliste sa fille, plus belle riens ne sai Pour ce que vous ressamble, assés plus chiere l'ai,

Et Tibert leur cousin avoec envoierai (Adenet le Roi, Berte aus grans piés, 187)

1280 Aprés cen, se tu me veuz crere, Tu doiz tant laborer et fere Que cognoisses la chamberiere Que ta dame a segree et chiere (Vivien de Nogent, La Clef d'amour, 588)

1325a Luxure, c'on avoit tant chier, Y est jetée en telle ordure Que nuls n'a jà mais de li cure, Et ont chacié à grant effort Hors de la court Mesdit le fort, Pour ce qu'en li a trop de vice (Watriquet de Couvin, Dits, p. 343, 64)

$\sim 1325$ b Lors fis en repentance i. saut, A Souffiance à lie chière Alai, car moult la dame oi chiere, Qui me reçut mont chierement Et me conta tout l'errement De la dame à la grant biauté, Que Haute Honneur et Loiauté Orent de par Nature en garde ; Moult en faisoient bonne garde (Watriquet de Couvin, Dits, p. 18, 542)

1364a Si vous pri si chier que vous m’avés que vous le veilliez savoir, se vous poés (Guillaume de Machaut, Le Livre du voir dit, p. 572)

1364b Hé las, je l'avoie si chier Et tant l'amoie sans trichier Qu'en verité je ne savoie Se je l'ooie ou vëoie (Guillaume de Machaut, Le Livre du voir dit, 8271)

+1365a Car je sçai bien combien l'ai chiere. Mès elle fait trop millour ciere A pluisours gens Qu'à moi, qui ai mis tout mon temps (Jean Froissart, Poésies [3 $3^{\mathrm{e}}$ tiers XIV $\mathrm{XV}^{\mathrm{e}}$ ) +1365b Car Aurora ne l'a pas chier, Ançois le tint en grant debat (Jean Froissart, Poésies [3 ${ }^{\mathrm{e}}$ tiers XIV $\left.{ }^{\mathrm{e}}\right]$ )

+1400a Telz chevaliers doit on avoir moult chiers ; Dieu et les sains et le monde les prise. Or suive donc toudis si fais sentiers, Qui maintenir veult l'ordre a droite guise (Christine de Pisan, Cent balades / Euvres poétiques [début $\mathrm{XV}$ ] , I, p. 66, 25)

+1400 b A vous, vaillant seigneur de haute emprise,

Et si vous viens donner d'amour esprise La riens qui soit que doy plus chier avoir Et soubzmettre du tout a vo franchise, Si le vueilliez, noble duc, recevoir (Christine de Pisan, Autres balades / Euvres poétiques [début $\mathrm{Xv}^{\mathrm{e}}$ ], I, p. 232, 8)

+1540 L'Homme. Or bien, Alyson, qu(e j)'ay tant chère,

Baise moy (un peu) au departement (Farce nouvelle d'un amoureux / Ancien Théâtre françois)

1544 Tant plus je veulx d'elle me souvenir, Plus à mon mal, maulgré moy, je consens. Que j'aurois cher (s'il debvoit advenir) Que la douleur m'osta plus tost le sens Que la memoire, ou reposer je sens Le nom de celle, Amour, ou tu regnois Lors qu'au besoing tu me circonvenois, Tant qu'à la perdre à present je souhaicte Car si en rien je ne m'en souvenois, Je ne pourrois sentir douleur parfaicte (Maurice Scève, Délie, object de plus haulte vertu)

1556 Au mien propos ha si bien respondu Celle que j'ay plus chere que mon ame, Et mon vouloir sagement entendu, Que je consens qu'il me soit donne blame Si je l'oublie : car elle m'a rendu Le sens, l'esprit, l'honneur, le cœur et l'ame

Estant navré

(Louise Labé, Double rondeau, à elle)

1558 Nature ne nous peut donner qu'un pere, et qu'une mere : mais le mariage en represente plusieurs en noz enfans, lesquels 
nous reverent et honorent, et ont plus chers que leurs propres entrailles (Pierre Boaistuau, Le Théâtre du monde)

1610 Il m’a sacrifiée, à ce qu'il dit, pour la santé de Calidon, monstrant en cela qu'il l'avoit plus cher que moy. Et bien, à la bonne heure! Mais ne se contente-t'il que son sacrifice ait esté receu, et que son cher Calidon ait esté rappellé du tombeau ? (Honoré d'Urfé, L’Astrée)

1636 HERCULE. Alcide a vaincu tout, et cede à ce poison ;

Ce feu ne cesse point, la toille qu'il allume, Attachée à ce corps, avec luy se consume ; En vain tout mon effort s'employe à l'arracher ;

Voila le sort du fils que vous eustes si cher (Jean de Rotrou, Hercule mourant)

Pronominal

+1150 Or sont li fil Aiol andoi si escuier,

Meruelles s'entramoient, durement s'orent chier (Aiol et Mirabel [ $2^{\mathrm{e}}$ moitié XII $], 10235$ )

II. Avoir, obtenir contre beaucoup d'argent Transitif

1945 «Pas étonnant, songeait Rose-Anna, qu'on l'a eue pas cher. Si près des tracks, c'est quasiment pas habitable. Ce bruit-là, je m’y habituerai jamais. » Et cependant, elle ne perdait pas pied (Gabrielle Roy, Bonheur d'occasion)

1965 - Faut savoir acheter, disait-il. C'est pas l'tout d'bien travailler, faut savoir acheter. - Et les fers, lui dis-je, vous pouvez pas les avoir moins cher à Paris ?

Il me regarda avec étonnement ; il n'y avait pas pensé. Mais comment s'y prendre ? Pour les clous, un représentant était passé chez lui, mais les fers? (Jacques Perry, Vie d'un païen)

\section{CORPus Web :}

j'ose mm pas imaginer le son de cette vieille boite de conserve... t'as pas du l'avoir chère [http:// www.latavernedesbatteurs.com/viewtopic. php?f=22\&t=988] (14.12.2013)

Si tu veux du bon son sans avoir cher un 2voies, vmais pas besoin d'amplifier le kit
Sauf si tu veux te péter les tympans, j'ai jamais écouter oxygène mais je crois que c'est une bonne marque à confirmer, les 13,5 sont un peu moin puissant (généralement fait pour les portières arrière) que des 16,5 [http://www.meganefrance.net/xoops/modules/newbb/viewtopic. php?viewmode=compact\&topic_id=] 15627\&fo rum $=7$ (15.12.2013)

dans un immeuble tout blanc où il ne devait pas y avoir cher d'économiquement faibles 1963 [http://www.languefrancaise.net/bob/detail. php?id=1300] (14.12.2013)

Encore bravo ! Revenez vite en Belgique les pélos, y'a cher de la gâche pour le hip hop ici ;-) [https://www.facebook.com/Lanimalerie] (15.12.2013)

Remarques : D'une part, cher est un adjectifadverbe qui peut référer à une qualité de cœur du participant désigné par le complément d'objet direct (I). Ceci explique l'accord morphologique qui s'observe dans la plupart des cas, surtout quand cher désigne une qualité humaine. Cet emploi est privilégié dans la langue ancienne. D'autre part, avoir cher se comporte aussi comme un verbe complexe qui a intégré la forme masculine neutre. Ceci vaut notamment pour l'emploi moderne au sens de 'acheter cher' (II et deux premiers exemples du CW). Il est modifié par assez plus, moins, moult, plus, si, tant. Les exemples du CW illustrent l'usage dans l'écriture spontanée. Dans les deux premiers exemples, l'adjectifadverbe réfère au prix de quelque chose, l'accord étant facultatif. Dans le restant des exemples $\mathrm{du}$ CW, (ne pas) avoir cher de quelque chose est employé dans l'acception '(ne pas) avoir beaucoup de quelque chose'.

\section{Avoir gras}

I. Avoir beaucoup de réserves, de provisions Intransitif

1333 Ne ne cuide pas orgueileus

Ne userier ne convoiteus,

Luxurieus ne bobencier,

Pour ce s'il ont gras leur pail[ier],

Assez a boire et a mengier

(Le « Bestiaire marial » tiré du « Rosarius ») 
II. il y a gras : il y a beaucoup de

Emploi absolu

1843 - Que ça d'honnêteté ?... merci !... dis donc, Malicorne, reprit l'homme en se retournant vers son camarade, il n'y a pas gras... ici... c'est pas comme chez le vicomte de Saint-Remy?

(Eugène Sue, Les Mystères de Paris)

III. il y a gras : il y a beaucoup à gagner

Emploi absolu

1844 Fougères regarda la pratique sans rire, car M. Vervelle présentait un diamant de mille écus à sa chemise. Fougères regarda Magus et dit : « Il y a gras ! » en employant un mot d'argot, alors à la mode dans les ateliers (Honoré de Balzac, Pierre Grassou)

1951 «Continua la commedia, se dit Angelo. Et personne ne songe à jouer des coudes ou la fille de l'air. Si je prends mon temps, il y aura gras » (Jean Giono, Le Hussard sur le toit)

REMARQUES : Gras est un quantifieur signifiant 'beaucoup' (II) ou, plus spécifiquement, 'beaucoup à gagner' (III) ; il a son origine dans le domaine de la nourriture (I). Comme dans le cas de gros, son emploi avec le verbe avoir peut motiver des emplois où gras se rapproche d'une fonction de manière (s.v. échapper gras).

\section{Avoir gros}

I. (en) avoir gros comme : avoir une quantité égale à

Intransitif

1532 Adonc que Galemelle fut descendue : il luy demanda quelle chausse elle avoit là. Adonc luy respond en eslargissant ses cuysses qu'elle avoit celle playe de nature : Grant Gosier regardant la playe large et rouge comme le feu Sainct Antoine : le membre lui dressa : lequel il avoit gros comme le ventre d'une cacque de hareng : et long à l'advenant : il dist à Galemelle que il estoit barbier, et que de son membre feroit esprouvette pour sçavoir si la playe estoit parfonde : à laquelle playe il ne trouva nul fons (Les Grandes et Inestimables Chroniques)
1852 Mon Dieu, qu'est-ce donc que ce chagrin? N'en avons-nous pas assez, en dehors de nous-mêmes ? Dites, et si j'y puis quelque chose, je suis entièrement à vous. Moi, j'en ai gros comme une montagne, aussi ! Ce ménage que vous savez est un enfer, et chacun vient à son tour me faire sa plainte et son récit (George Sand, Correspondance)

1862 Demoiselle Jeannette lui rit au nez et parla plus clairement ; il éclata de rire à son tour et dit avec la plus aimable confiance :

- Ch'est de l'argent qu'il faut pour cha? Vous auriez dû le dire tout de chuite. J'en ai gros comme moi, de l'argent! (Edmond About, Le Nez d'un notaire)

1942 Au partage, on commence par tirer l'eau du pot, et chacun fait oraison pour qu'on retrouve la viande : la joie éclate quand on la retrouve, et finalement, quand on l'a découpée, chacun en a gros comme un dé. La table demeure nette, on peut le croire : les chiens se plaignent de n'avoir pas un reste d'os à ronger. C'est là une pasquinade (Edmond Faral, La Vie quotidienne au temps de saint Louis)

II. il y a gros que, gros à parier que : il y a de bonnes raisons de penser que

Intransitif

1790 Ah, messieux, les bons apôtres, vous faisiez la patte de velours pour nous mieux écorcher, et monter vous-mêmes sur des échasses ; mais je savons aujourd'hui le fin mot de votre pensée, et les États généraux rabattront votre caquet de plus d'un cran. Vous en avez la foire, mes enfans, et $y$ a gros que vous en serez les dindons. Quand on ne pisse pas clair, le médecin fait peur

(Cahier des plaintes et doléances des Dames de la halle et des marchés de Paris / Les Femmes dans la Révolution française)

1938 Il y a, en quelque sorte, fort peu de chances pour l'appel de ce mot dans notre activité intérieure, et il y a gros à parier que l'on peut vivre et réfléchir, agir et méditer toute une année, sans que la nécessité de l'articuler ou de le penser soit une seule fois ressentie (Paul Valéry, Variété IV) 
III. (en / y) avoir gros : (y) avoir beaucoup (de)

Intransitif

1833 - Voyez, ma mère, le beau travail.

- Oh ! il y a gros d'or, dit Nanon en apportant le café.

- Qu'est-ce que c'est que cela, demanda Charles en riant

(Honoré de Balzac, Eugénie Grandet)

1884 Mais, enfin, il faut au moins avoir l'air de quelque chose... ah ! Voilà M. Lazare qui la soulève, pour qu'elle ne mouille pas ses bottines. Il n'en a pas gros dans les bras, allez ! C'est vrai qu'il y a des hommes qui aiment les os... Véronique s'interrompait net, en sentant près d'elle le tressaillement de Pauline (Émile Zola, La Joie de vivre)

1922 MME GRAYOTTE. Il sera dans les bras de qui qu'y voudra, nous le ferons-ben lever ! D'abord il nous attend. Ah ! c'est que j'en ai gros à lui raconter... Elle-le-dé-mo-li-ra son-mur, la Philomène !... Elle nous en a fait voir, allez ! (George Chepfer, Saynètes, paysanneries 1 )

IV. (en) avoir gros sur le cœur, sur la patate, sur la pomme : avoir beaucoup de chagrin, de dépit, de rancune Intransitif

1865 Brulette, qui avait eu gros sur le cœur le mauvais comportement envers elle des muletiers dans le bois de la Roche, fut si sensible à l'estime et aux compliments du Grand-Bûcheux, qu'elle en eut des larmes prêtes à couler, et que, se jetant à son cou, elle ne sut lui répondre qu'en le baisant comme si ce fût son propre père (George Sand, Les Maîtres sonneurs)

1890 Mais je sais à quel point tu es tenu, je n'osais pas te demander de venir. Enfin, te voilà, et j'en ai si gros, si gros sur le cœur ! Elle s'interrompit, pour jeter craintivement un regard par la fenêtre (Émile Zola, La Bête humaine)

1936 C'était pas un moment commode pour entreprendre des promenades !... Il faisait tout de même un peu frais! Je peux dire qu'elle était en rage... Elle en avait gros sur la pomme... Elle arrêtait plus de glapir.
- Il m’a fait ça le pourceau ! le satyre ! la finie canaille ! À moi, Ferdinand !... À moi !...

(Louis-Ferdinand Céline, Mort à crédit)

1944 - Je viens de passer six mois dans la forêt vierge à filmer des borgeiros, indiens particulièrement sauvages comme vous ne l'ignorez pas.

- Faut avoir tué père et mère pour faire des trucs comme ça.

- Exactement. Faut en avoir gros sur la patate.

- À cause d'une femme.

- Exactement

(Raymond Queneau, Loin de Rueil)

1969 Il écumait et sa voix, quoique faiblarde, portait loin, dans l'air calme de cet aprèsmidi printanier. Je n'ai pas perdu un mot de sa diatribe. Il en avait gros sur la patate, il se débondait. J'ai compris que Jeanne, en somme, était l'attraction de ce bistrot. Elle faisait fonction d'allumeuse (Léo Malet, Sueur aux tripes)

V. en avoir gros : en avoir assez

Intransitif

1932 Comme l'averse finissait on a trouvé un taxi. On se précipite et nous voilà casés les uns contre les autres. D'abord, on ne se dit rien. On en avait gros entre nous et puis j'avais comme ça assez gaffé pour ma part. Je pouvais attendre un petit peu avant de m'y remettre (Louis-Ferdinand Céline, Voyage au bout de la nuit)

\section{CORPuS WeB :}

Que faire lorsqu'on en a gros sur la conscience et que l'on a déjà tué sept hommes ? [http://calmann-levy.fr/livres/magdalenapecheresse] (15.12.2013)

Remarques : Gros est un adjectif-adverbe de quantité invariable qui a développé une série de locutions qui reflètent un usage oral informel plutôt populaire ou familier. En avoir gros comme (I) compare l'ampleur de quelque chose avec un objet dont les dimensions sont supposées connues. Il y a gros à parier (II) représente un effort rhétorique qui met en relief ce qui est affirmé par la suite. (III) est une expression fami- 
lière pour 'avoir beaucoup de'. (En) avoir gros sur le cœur, la patate, la pomme (IV) transpose métaphoriquement la pesanteur associée à gros sur le plan des préoccupations humaines. Finalement, (V) exprime le fait d'en avoir assez. Les locutions sont rarement modifiées, mais on trouve si pour l'acception (IV), ex. de 1890. Notons l'emploi de interrompre net. VOIR AUSSI : avoir cher de (CW)

\section{Avoir long}

I. avoir long comme le doigt de quelque chose : en avoir peu

Intransitif

1623 Vous voudriez avoir de l'authorité dessus nos autres aussi long que le bras, apres en avoir eu long comme le doigt : mais à qui vendez vous vos coquilles (Charles Sorel, Les Nouvelles françaises)

II. (en) avoir long: en avoir beaucoup, aussi au sens temporel

Intransitif

1771 On vous mandera les détails de ce qui s'est passé aujourd'hui : il y en a bien long et je ne saurais par où m'y prendre pour vous en informer (Julie de Lespinasse, Lettres à Condorcet)

$1813 \mathrm{Si}$ vous me demandez, après avoir lu l'intrigante, comment il se fait qu'une comédie en cinq actes, en vers, dont le caractère est bien aperçu et fortement tracé, dont les mœurs sont vraies, dont le style est de la meilleure école, n’ait pas fourni sur la scène une plus longue carrière, je vous répondrai... j'en aurais trop long à vous répondre (Étienne de Jouy, L'Hermite de la Chaussée-d'Antin)

1832 Par mercredi le paquet, tu en auras plus long : ceci est pour répondre seulement à ta lettre, adieu ma bonne mère, je t'embrasse de tout mon cœur (Honoré de Balzac, Correspondance)

1880 Je ne t'en ai pas parlé, de celle-là, lorsque tu pleurais par terre ; j'aurais trop long à en dire (Émile Zola, Nana)

1914 Ils s'bouffent des yeux tout leur temps, sans rien dire... Ils en auraient trop long, probable ! (Francis Carco, Jésus-la-Caille)
1925 C'est un carnet que j'ai trouvé par hasard ; un journal intime de papa ; je ne comprends pas comment il l'a laissé traîner. N'importe qui pouvait le lire. Je l'ai pris pour ne pas qu'Armand le voie. Ne lui en parlez pas. Il n'y en a pas très long. Vous pouvez le lire en dix minutes et me le rendre avant de partir (André Gide, Les Faux-Monnayeurs)

1943 Oh ! Il y en avait long dans sa tête ce soir (Simone de Beauvoir, L'Invitée)

1962 Elle doit en avoir long comme un peloton de ficelle à nous raconter. M'est avis qu'elle est dans les papelards du chef poulet, elle (San-Antonio, Ménage tes méninges)

2002 Pour que les apprenants acquièrent cette éducation, il faut que les enseignants l'aient eux-même acquise. On dit que " pour donner long comme la main, il faut avoir long comme le bras"

(Félicité Muhimpundu, Éducation et citoyenneté au Rwanda)

\section{CORPuS Web :}

si on lui en donne long comme le doigt, il veut en avoir long comme le bras [http://www. languefrancaise.net/bob/detail.php?id=49392] (15.12.2013)

C'est une satire qui croule littéralement sous le nombre de ses cibles (et sous un casting qui est l'équivalent franco-québécois de celui du peu mémorable Voyage des damnés) et s'enferre dans le piège du contenu : croire qu'en avoir long à dire revient à en avoir long à narrer, sans réel souci d'entraîner le spectateur à sa suite, un peu comme d'autres tombent dans le piège de la forme [http:// dvdtoile.com/Thread.php?94652] (15.12.2013)

REMARQUES : Long est un adjectif-adverbe de dimension ou de temps qui s'emploie ici également au sens figuré de 'beaucoup' et de 'beaucoup de temps'. Il reste toujours invariable. Le premier exemple de 1623 montre bien le rapport qui s'établit entre le sens dimensionnel (la longueur d'un bras, d'un doigt) et l'emploi comme quantifieur. La construction en avoir long $\grave{a}+$ verbe est un schéma lexicalisé. Le premier exemple du CW illustre la locution figée long comme le bras qui désigne les exigences exagérées de quelqu'un. 
Avouer haut

avouer tout haut : avouer à voix haute, franchement, ouvertement, publiquement Transitif

1667 CLITANDRE. Pour moi, je ne sais pas, mais j'avouerai tout haut

Que j’ai cru jusqu'ici Madame sans défaut. ACASTE. De grâces et d'attraits je vois qu'elle est pourvue ;

Mais les défauts qu'elle a ne frappent point ma vue (Molière, Le Misanthrope)

1833 Christine. (à Falkenskield)

Il vous trompe, il vous abuse.

ÉrIC. Non, mademoiselle ; ce que je dis, je dois le dire ; je suis trop heureux de l'avouer tout haut, (avec intention et la regardant) et de donner au parti que je sers ce dernier gage de dévouement (Eugène Scribe, Bertrand et Raton)

1848 il devina que le monarque prendrait cette route, et ne se mêlerait pas de la guerre de l'Occident. En n'avouant pas tout haut son projet d'invasion, Bonaparte ne pouvait néanmoins le cacher ; avec les diplomates il mettait en avant trois griefs (François de Chateaubriand, Mémoires d'outre-tombe)

1872 Elle avait aussi de grandes affaires, des affaires qu'elle pouvait avouer tout haut, et dont elle rebattait les oreilles des gens qui l'approchaient : un long procès qu'une famille noble ruinée l'avait chargée de suivre, et une dette contractée par l'Angleterre vis-à-vis de la France, du temps des Stuarts, et dont le chiffre, avec les intérêts composés, montait à près de trois milliards (Émile Zola, La Curée)

1884 De Falloux, plus hautain et plus cauteleux, appartenait à cette secte libérale dans laquelle étaient déjà réunis et de Montalembert et Cochin, et Lacordaire et de Broglie ; il appartenait, tout entier, aux idées du Correspondant, une revue qui s'efforçait de couvrir d'un vernis de tolérance les théories impérieuses de l'Église ; Veuillot, plus débraillé, plus franc, rejetait ces masques, attestait sans hésiter la tyrannie des volontés ultramontaines, avouait et ré- clamait tout haut l'impitoyable joug de ses dogmes (Joris-Karl Huysmans, À rebours)

1916 On en est incommodé. Nous nous regardons en hochant la tête et n'osant pas avouer tout haut que ça sent mauvais. On ne s'éloigne pourtant que lentement. Voici poindre dans la brume des dos courbés d'hommes qui sont joints par quelque chose qu'ils portent (Henri Barbusse, Le $\mathrm{Feu}$ )

1949 - Mais il se contente d'éliminer Arthur de notre vie, d'envelopper de silence cette affection malade. Abcès mal pansé : le pus coule en dedans. »

Brusquement, Roberte avoue, tout haut :

- Tu sais, papa, il y a une chose que je ne m'explique pas. J'écris toutes les semaines à Arthur : il ne m’a jamais répondu (Hervé Bazin, La Tête contre les murs)

Emploi absolu

1780 M. B. aura mardi toutes vos lettres, dont je veux tirer du moins les brouillons que je n'ai pas. Pour les miennes, faites-en ce qu'il vous plaira. J'écris toujours ce que j'ai dans l'ame ; j'avoue tout haut mes amis, et je me moque des caquets (Honoré de Mirabeau, Lettres originales écrites $d u$ donjon de Vincennes)

1846 - Et ce père, c'est...

- Eh bien! Caderousse, c'est le comte de Monte-Cristo.

- Bah!

- Oui ; tu comprends, alors tout s'explique. Il ne peut pas m'avouer tout haut, à ce qu'il paraît, mais il me fait reconnaître par M. Cavalcanti, à qui il donne cinquante mille francs pour ça (Alexandre Dumas père, Le Comte de Monte-Christo)

Pronominal

1948 Or, elle, elle était à la fois gênée et émue. Il lui aurait donné rendez-vous pour le lendemain qu'elle eût, avec la moindre résistance, accepté. Sans se l'avouer trop haut, elle désirait renouer (Maurice Druon, Les Grandes Familles) 


\section{CoRpus WeB :}

Aujourd'hui, on peut l'avouer haut et fort, que le gouvernement veut étouffer les populations réputées proches de l'opposition au su et au vu de la communauté internationale qui demeure silencieuse face à ces violences ethniques [http:// www.lejourguinee.com/index.php/fr/nouvelles/ societe/1473-violences-a-conakry-l-inquietanteattitude-du-gouvernement] (15.12.2013)

De toutes manières on le sait les déchets venus d'autres pays et non triés sont brulés chez nous, il n'y a vraiment plus besoin d'en faire un fromage surtout quand on sait qu'une personne âgée et son passé compte désormais pour beurre chez certains socialistes qui n'ont aucune crainte à l'avouer haut et clair [http://guinchard.blog.tdg. ch/archive/2013/03/31/dechets-plastiques-et-si-1exemple-venait-d-asie.html] (15.12.2013)

Je le savais, je connaissais mes sentiments à son égard, mais les avouer haut et fort ne ferait que rendre la chose plus réelle encore, pour ensuite quoi ? [http://www.berkeley-u.com/ t34348-quelques-explications-s-imposent-pvemy] (15.12.2013)

Ils semblent se rapprocher tous les deux, peut être pas s'avouer haut et fort qu'ils s'aiment [https://www.fanfiction.net/r/3556066/0/2] (15.07.2016)
Les signes de la crispation toute proche ont beau être tenus en respect, voire refoulés, ils ne s'accumulent pas moins avec une cruelle cohérence. Vient le moment où il faut s'avouer haut et net que «ça ne sera décidément pas possible ». Et passer son chemin sans crainte d'avoir péché par impatience : après tout, à chacun de fixer le point au-delà duquel une divine surprise paraît chimérique [http://www.juanasensio. com/archive/2013/10/12/alice-ferney-passesous-silence-olivier-rolin-tigre-papier.html] (15.07.2016)

Naoki. Ce connard. Comme s'il n'avait pas assez de problèmes. On lui rajoutait celui-là. Réellement, le jeune homme ne regrettait pas d'être venu aujourd'hui... Son collègue aurait fait ça derrière son dos, sans jamais lui avouer haute. Et, il ignorait ce qui l'énervait en réalité... [http:// inappropriate-city.forumactif.org/t489-heybrother-there-s-an-endless-road-to-rediscover-o] (15.07.2016)

REMARQUES : Haut est un adjectif-adverbe de lieu dimensionnel qui s'emploie ici au sens métaphorique de 'à haute voix' et 'publiquement' ou 'ouvertement'. Haut reste invariable dans la majorité des cas, mais dans le dernier exemple du CW, il est mis au féminin. Il est modifié par trop et, bien souvent, tout. Il apparaît en collocation avec les adjectifs-adverbes fort, clair et net. Notons l'emploi de réclamer haut. 